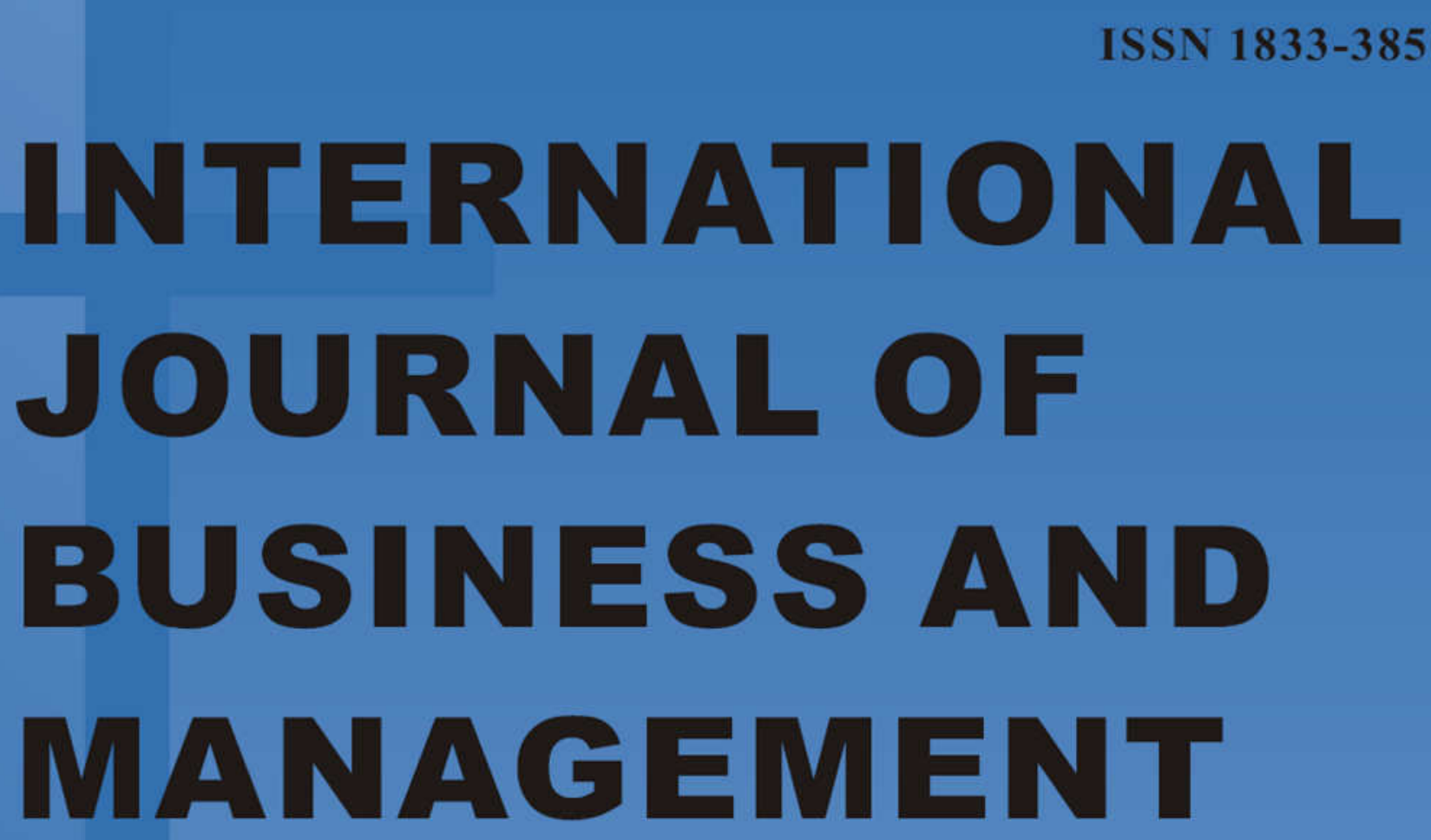

Vol. 3, No. 11

November 2008

Chief Editor

Robert Joe

Co-editors

Tony Smith

David Liu

CCSE

Canadian Center of Science and Education 


\section{Contents}

An Analysis of Lean Management Procedures within Irish Motor Dealerships

Clive Atkinson, Margaret Linehan

Monetary Policy Transmission Mechanism in Fiji: An Empirical Analysis of The Quarterly Model

T.K. Jayaraman, Chee-Keong Choong

Mechanism Demand and Optimizing Research of Entrepreneur Professionalism

Huiyuan Mao, Xinliang Zhao,Zeping Wang

The Research on the Independent College Teachers Configuration Model

Xiaobai Lv

Consumption Model of Financial Products among Minangkabau \& Chinese in Bank Nagari, Sumatra

Heryanto, Laily Paim, Ahmad Hariza Hashim,Sharifah Azizah Haron

The Business Strategy of Mcdonald's

Jing Han

Optimization of Security Investment Portfolio Based on Improved Simulated Annealing Algorithm

Lin Xiao, Zhongyuan Wu

Do Producer Prices Cause Consumer Prices? Some Empirical Evidence

Mohd Fahmi Ghazali, Ooi Ai Yee, Mohd Zulkifli Muhammad

The Rhetoric and Translation of English Advertisement

Xiang Xu

From American Westward Movement to Chinese Western Development------General Analysis of

Relationships between Institutions and Economic Development as Well as the Enlightenment for China

Xijing Sun, Lanhui Wang, Huancheng Du

Examining the Relationship between Work Life Conflict, Stress and Turnover Intentions among Marketing

Executives in Pakistan

Sarooj Noor, Nazia Maad

Analysis of Cultural Differences between West and East in International Business Negotiation

Peng Luo

Research Framework of Human Resource Development Based on Competency about Knowledge

Enterprise

Jianfeng Jia, Lili Fan

Managers Behaviors Trough Economic Crisis at Agro-Industries in Turkey: A Case Study in Sanliurfa

Province

Yusuf Çelik, Kenan Peker, Abdullah Karaman

Study on the Cross-Regional Urban Flexible Management Pattern: The Core Testing Zone of

Shen-Fu New Town as the Case

Feng Han, Yachen Liu

An Optimized Supply Chain Planning Model for Manufacture Company Based on JIT

Ruilin Guo, Qi Tang 


\section{Contents}

Audit Expectation Gap in Auditor Responsibilities: Comparison between India and Iran

G.H. Mahadevaswamy,Mahdi Salehi

Independent Innovation Ability and Industrial Chain Expanding_—Policies to Firms in Liaoning Province

Lin Lu, Yanying Chen, Binbin Jiang

On Securitization of International Syndicated Loans

Jing He

Power Congruence Approaches to Downward Influence in Malaysia Manufacturing Industry

May-Chiun Lo, Intan Osman

Analysis of the Market Prospect of Folk Cultural Heritage Exhibition Center in Longji

Jin Zhang

Research on the Financing of Small and Medium Enterprises

Juan Zhao

Cost-Effectiveness Analysis for Arsenic Water Supply Project in Bangladesh 


\title{
An Analysis of Lean Management \\ Procedures within Irish Motor Dealerships
}

\author{
Clive Atkinson (Corresponding author) \\ School of Engineering, Cork Institute of Technology, Rossa Ave, Bishopstown, Cork, Ireland \\ Tel: 353-85-2738388 E-mail: clive.atkinson@cit.ie \\ Dr Margaret Linehan \\ School of Business, Cork Institute of Technology, Rossa Ave, Bishopstown, Cork, Ireland
}

Tel: 353-21-4326100Ｅ-mail: margaret.linehan@cit.ie

\begin{abstract}
There is a large volume of extant literature relating to lean management within the automobile manufacturing industry, but, there is very limited research on lean management within dealerships. Furthermore, the relevance of lean management within the Irish motor industry is a relatively unexplored area. Due to a lack of information, many misconceptions and misunderstandings exist regarding lean management and its relevance to motor dealerships.

This paper explores the impact of lean management on Irish motor dealerships which have implemented lean procedures and explores the perceptions of dealerships which have not embarked on a lean management programme. The paper provides an analysis of lean management procedures from the perspective of senior managers working in franchised Audi and Volkswagen dealerships in Ireland. Overall, the results of the study indicate that lean management procedures have a positive influence on dealerships, but, the importance of training and commitment for lean procedures to be successful should be emphasised.
\end{abstract}

Keywords: Lean management, Irish motor dealerships

\section{Introduction}

\subsection{Background to Lean Management}

Lean management evolved from philosophies such as Just-In-Time (JIT), Total Quality Management (TQM) and World Class Manufacturing. From a business perspective the term 'lean' is used to describe a philosophy of management which involves a set of tools and techniques used to optimise time, assets, and productivity, while continually improving the quality of products and services for customers. Todd (1995) suggests that the term 'lean production' was coined to clarify what the concepts of JIT and TQM did and did not stand for, along with highlighting that lean uses less of everything in comparison to mass production.

Lean production is derived from the Toyota production system devised in the 1950s to eliminate waste within the organisation. Lean production developed over the years to provide a competitive advantage for Toyota having an ability to provide higher quality cars, in less worker hours and with fewer defects than competing car manufacturers. Jones and Mitchell (2006) suggest that the lean management provides four significant benefits for an organisation. First, increased productivity results within the organisation because the same workers can achieve more output from existing resource levels. Second, the delivery of work is improved through increased standards of work completed in less time. Third, quality increases due to a reduction in the number of mistakes. Finally, increased satisfaction levels ensure better staff morale and a stable workforce.

\subsection{Relevance of Lean Management within Irish Motor Dealerships}

O'Brien (2006), speaking at a Society of Irish Motor Industry (SIMI) annual dealer conference, outlined findings of a survey of more than 70 Irish motor dealerships, carried out by consultants Grant Thornton which indicates that the average return on investment in Irish motor dealerships was just four percent while dealer profit before tax comprised 0.8 percent of sales. Furthermore, O'Brien contends that the 'shrewd' investor seeks a return on investment in excess of eight percent per annum, thereby currently making motor dealerships unattractive for investment.

Some of the pressures which franchised motor dealerships in Ireland are subjected to include:

Lower profits despite increased new car sales 
Tougher sales targets in order to obtain rebates from manufacturers

Higher levels of used car stocks, exerting pressure on prices and margins

Lower margins on overall car sales leading to increased dependency on after-sales activities

Tighter manufacturers' standards for facilities within the dealership

Increased staff-training, administration and operating costs

Tighter cash flows

Competition Commissioner Kroes (2006), in a speech to the European Council for Motor Trades and Repairs (CECRA), suggests that since the introduction of the new Block Exemption rules in October 2002 dealer margins have fallen to such an extent that many franchised car dealerships within Ireland and throughout Europe are fortunate if they maintain margins of one percent on new car sales.

As a consequence of the pressures on the car sales business, future profitability within motor dealerships will rely heavily on after-sales activities. The level of after-sales activity within dealerships has declined due to increased reliability of motor vehicles along with significant extension in recommended service intervals. These factors are increasing the level of competition between motor dealerships for the declining quantity of work available. Furthermore, as the quality of all cars has improved, after-sales service is a less significant differentiator, thereby making customer service the most important differentiator between dealerships. A more proactive approach, therefore, is required by Irish motor dealerships to increase profitability. Advocates of lean management contend the implementation of lean techniques can provide opportunities for dealerships to address the outlined difficulties, to increase return on investment, and create a sustainable competitive advantage (Womack and Jones, 2005; Hines et al., 2002).

\section{Research Methodology}

Eleven in-depth face-to-face interviews were conducted for this research. Ten Audi and Volkswagen Irish motor dealerships within the group were selected for inclusion in this study. A further interview was held with the Irish Audi and Volkswagen distributor in order to get an overall view of the implementation of lean management within the dealerships. It was decided to concentrate on the Audi and Volkswagen group as there has been a coordinated effort by their distributor to encourage dealers to participate in a lean management programme. The dealers were located in the Leinster province, and primarily within Dublin. A further consideration was to select dealers representing a variety of organisation sizes.

A criterion of qualifying as a research interviewee was that the participant had to be a senior manager within the dealership and directly involved in implementation of lean management within the organisation. The reason for such criteria was to evaluate why the dealership had become involved with lean processes, and the effects of lean within the organisation from a managerial point of view. The belief that junior staff may not have been in a position to answer these questions influenced these criteria. The interviewees comprised eight dealer principals, two after-sales managers, and one representative for the Audi and Volkswagen distributor in Ireland. All the dealer principals and after-sales managers had direct responsibility for the implementation of lean management within their organisation, while the distributor representative had monitored the implementation of lean procedures within the dealers concerned.

After interviewing three dealers who had not implemented lean management, common findings were emerging so a decision was taken not to continue with further interviewing of dealers who had not implemented lean. This concurs with Seidman (1998) who suggests that saturation of information occurs where the interviewer begins to hear the same information and is no longer learning anything new. All interviews were recorded on tape and transcribed verbatim shortly after each interview. Analysis of data was based on the grounded theory approach.

\section{Research Findings}

\subsection{Reasons for Implementing Lean management procedures in Irish Audi and Volkswagen Dealerships}

The research findings indicated that there is no one reason why dealers became involved in implementing lean management techniques. The reasons for dealers becoming involved with the introduction of lean management depend on the individual circumstances of each dealer. The findings suggest, however, that some reasons are common to most of the dealers involved. For dealers with physical space constraints, one of the primary reasons for implementing lean was to improve the utilisation of limited resources. Other dealers embarked on lean management in an attempt to overcome problems with the running of certain departments within the organisation, most commonly the service and parts departments. The problems varied in nature from operational to personnel issues. While increasing performance levels and workshop utilisation were important considerations, the improvement of quality standards and customer satisfaction levels were outlined as the primary objectives for some dealers becoming involved in the introduction of lean management. An excerpt from the interview with one of the dealers reflects the concern of many of the interviewees: 
We have a problem with repeat repairs and customer satisfaction levels and I reckoned that better analysis and procedures would mean fewer repeat repairs which in turn would lead to increased satisfaction levels (Dealer 7).

\subsection{Attitudes Towards Lean Management Within Dealerships}

The findings highlight the importance of having staff and management who have a positive and committed attitude towards lean. In addition to showing a high level of commitment to implementing lean, a further advantage of having management involved as trainers is that they should gain a thorough understanding of how the concepts work. For the successful implementation of lean management within an organisation it is essential that a strong and dedicated leader is involved. One of the conditions under which the consultants undertook to work with each dealer was that the dealer principal had to be directly involved and participate in all the training courses. This was seen as essential so that the introduction of lean would not be delegated to someone else within the organisation having less authority than the dealer principal.

The research findings indicate that dealerships which have achieved most from the implementation of lean are those where senior management has remained closely involved in the process. On the other hand, those who found that they were too busy to remain directly involved have allowed the system to 'slip', as indicated by two excerpts from the interviews:

The reality of what happened here, and it shouldn't be an excuse, but we probably just got too busy and things were let slip (Dealer 4).

At different stages we have lost momentum and then you can get into a rut and it is hard to pick it up again (Dealer 2).

The culture within an organisation has a major influence on the success or otherwise of lean management. While advocates of lean insist that it is the processes rather than people that make the system work, the current study suggests having the right people for the job is essential for successful implementation of lean principles. Furthermore, where there is a less positive attitude towards lean, its implementation is more difficult:

The biggest problem to implementing lean management is what we call inertia or resistance to change (Dealer 1).

Most of the personnel have been doing things their own way for so long that it is very hard to change them (Dealer 5).

The majority of the dealers interviewed believed that when the objectives of lean were fully explained resistance was generally overcome. Once staff saw there was a benefit for themselves, as workers, in addition to the benefit for the company they cooperated:

A lot is to do with the way you sell it to staff. Many people, when they hear the term 'lean' think it is to do with layoffs and so on. It is very important that one communicates to them that this is not what lean is about (Dealer 1).

In some dealerships most resistance to the implementation of lean was from middle management whereas the workers on the floor were quite willing to become involved in improving their work practices but were almost discouraged by their managers. Dealers found that once staff embraced the true concept of lean management its effect increased feedback and contributions, from staff at all levels, for logical improvements to the workplace and work practices:

Mechanics would be forthcoming with ideas on how the tool room should be laid out, where tools should be located according to use, etc. (Dealer 1).

It is clear that many factors influence the culture change necessary for adopting lean processes. There is no 'one size fits all' solution due to the different backgrounds of all the dealers involved. The importance of having committed and skilled management in place to develop a culture where all staff willingly become involved and actively work to make improvements within the organisation is emphasised by the findings.

\subsection{Methodologies and Tools Used in the Implementation of Lean}

Many different tools are used for the implementation of lean. Some of the most relevant tools used for the motor retailer are briefly described in this section.

\subsubsection{Pre-diagnosis}

Pre-diagnosis involves the physical checking of each vehicle when left to the workshop, by the customer, to have service and repair work carried out to identify what exactly is required prior to the mechanic actually beginning work on the car. This, however, is really only the second stage in the pre-diagnosis process. The first stage involves having the ability to correctly ascertain from the customer at the time of booking, all relevant details in order to be able to make an informed estimate of the extent of work required. This means that the relevant parts required can be ordered and readily available when the car actually arrives for the service. It is acknowledged that the unavailability of parts at the required time is a major contributor to delays in completion of service and repair work within motor dealerships. Furthermore, adequate workshop time can be allocated at the booking-in stage to ensure each job can be completed with a single workshop visit. 
As part of this process 'green stream' work was identified. 'Green stream' is the term used for standard type operations which have the ability to flow smoothly. Due to the wide variety of work carried out in the after-sales department, from standard pre-delivery inspections, servicing and repairs to the unpredictable repair of sporadic faults and breakdowns, it makes the implementation of a green stream vital for the smooth operation of pre-diagnosis:

We took the jobs with the most straightforward work content and they were the ones that we 'green streamed' and we got them through the system as quickly as possible (Dealer 7).

This means that every job is initially examined to ascertain whether it is suited for the green stream or not and this will affect the planning involved prior to the car arriving at the workshop. In the case of green stream work the parts can be ordered in advance and relatively accurate labour time allocation is possible in most cases. On the other hand, with non-green stream jobs, the amount of preparatory work that can be done before the car actually arrives might be quite limited. Preparatory work for non-green stream jobs can involve researching manufacturers' technical data for any records of similar known problems and solutions. The overriding goal of the pre-diagnosis, either at the time of booking or when the car actually arrives, is to quantify the job:

The only real way to quantify a job is to carry out pre-diagnosis which means physically checking the car over. You can do so much on the telephone but you are still only seeing part of the picture and it is not until the car arrives that you can see that the drive boots are damaged or something else (Dealer 1).

The dealers involved have undertaken the physical element of pre-diagnosis to varying degrees. Some dealers physically pre-diagnose all jobs while others pre-diagnose only the 'green stream' type jobs as identified at the time of booking. One possible difficulty identified by some dealers in relation to pre-diagnosis is the effect of long lead times for workshops. It is essential to shorten lead times in order to improve flexibility and to allow prompt adapting to specific demands which arise. Furthermore, short lead times reduce the risk of obsolete stock becoming an issue. This is particularly relevant to the motor dealer where specific parts are required for specific vehicles and cannot be re-sold if the customer does not return to have the part fitted. Effective pre-diagnosis in tandem with short lead times helps reduce the risk of obsolete stock:

Pre-diagnosis has helped reduce the level of stock due to parts being ordered and the customer not returning (Dealer 1).

Another important consideration is the need for adequately trained and experienced staff working at service reception with good technical knowledge for the successful implementation of pre-diagnosis. The current research findings illustrate that when the dealer has pre-diagnosis working effectively the benefits are significant, as it reduces the number of cars having to return for completion of repairs which in turn reduces the administration and paperwork. Pre-diagnosis provides opportunities for up-selling, it increases workshop throughputs by making the service process more efficient, and it helps to reduce the stress levels for both staff and customers when repairs can be completed on time, first time.

\subsubsection{Spaghetti Maps}

Many of the dealers interviewed mentioned the use of spaghetti maps as one of the tools used which had a big influence on refining how certain jobs were being done. Spaghetti mapping involves tracing the movements of a worker while he or she is carrying out a particular task. This highlights the waste involved in each process and provides a focus whereby people begin to think more about what they are doing and ways of simplifying procedures. Most dealers viewed this as being a very simple and logical tool and yet very effective for highlighting waste within work practices. Spaghetti diagrams were viewed by many interviewees as a key 'selling point' of lean procedures to workers who can see a tangible benefit for them:

Through the use of a spaghetti map it was observed that one guy who was valeting a car actually walked $1.8 \mathrm{~km}$ while cleaning the car. Through analysis we were able to modify the way he did the job in a logical way so that he could clean the car while having to walk only $0.25 \mathrm{~km}$ (Dealer 1).

The spaghetti chart was probably the most effective tool to get everyone thinking about reducing waste. The idea of reducing waste by eliminating unnecessary journeys and doing a job in the least possible manoeuvres really brought the idea home (Dealer 7).

The use of spaghetti maps provided amazing findings which was very beneficial to the dealers. We mapped one particular service job and observed the mechanic from when he actually got the jobcard to when he began working on the car. Between walking around looking for keys, seat covers, floor mats and so on and then having to move other cars to get the one he was to work on into the workshop it took twenty-five minutes from receiving the job card to when he began working on the car (Distributor Representative).

The findings confirm that spaghetti mapping is one of the key lean tools that all dealers obtained significant benefits from. First, in terms of identifying wasteful elements of existing practices and second, through highlighting to all staff members how worthwhile and realistic lean management techniques can be. 


\subsubsection{Job Card Data Analysis}

The workshop job card is an invaluable source of information for analysing after-sales activities. In addition to providing a description of the work requested by the customer for the technician prior to commencement of work, the job card provides a record of feedback from the technician on exactly what work has been carried out during the service, along with any outstanding repairs which need further attention. Data analysis of workshop job cards was carried out by the lean management consultants and highlighted many inefficiencies within the after-sales department at all levels along with highlighting the potential for increased sales. This detailed procedure involved analysing up to three hundred job cards within the dealership and identifying where repairs were not completed fully or on time. The numbers of cars which required more than one visit to the dealership to have work completed were tracked and the reason why the revisit was necessary was identified in each case. Additionally, the loss of potential workshop sales identified during the service of a car was highlighted. The analysis highlighted the reasons why this work was not completed in the workshop and the value of the potential lost sales to the dealership:

We decided that instead of booking for fifty hours work a day in the workshop, we would pear it back and only book for twenty five hours, however we find now that we are up-selling to such an extent that we are actually selling fifty three labour hours a day (Dealer 6).

The analysis of job cards proved that, contrary to what dealers had believed, it was actually the lack of adequate preparation that was the weakest part of the service process. It also highlighted that some dealers were experiencing comebacks in the region of fifty to sixty percent, many of which were caused by straightforward procedures not being carried out in an efficient manner, such as specific parts not being ordered for cars before the car arrived for servicing:

I think that if the dealers did nothing else in relation to lean but carry out data analysis and then use the findings to make improvements it would be very worthwhile (Distributor Representative).

The current research indicates that jobcard data analysis has highlighted significant shortfalls when dealing with customers and difficulties with existing processes within the dealership. In most cases, the information forthcoming through data analysis had been overlooked by dealers before embarking on lean principles. Furthermore, data analysis highlights increased opportunities for 'up-selling' within the after sales department. The benefits obtained from up-selling are twofold. First, with increased parts and labour hours sold, and second, through reduced administration work per day which is viewed as non-value adding work.

\subsubsection{Pre-picking of Parts}

Many dealers had already embarked on the pre-picking of parts prior to implementing lean management procedures. It was, however, in a quite haphazard fashion as they did not fully analyse the requirements before the cars arrived for servicing. Pre-picking is based on the concept of JIT whereby the parts for a particular job are gathered together and available for the technician when he/she requires them. This eliminates waiting times and helps to evenly spread the workload of the parts personnel throughout the day.

Some of the dealers have gone so far as to close off the counter between the parts department and the workshop and employ a dedicated 'parts-to-workshop' person. This means that the mechanics do not have to come looking for parts. Instead, the parts are already picked and waiting for them. Some dealers provide mechanics with a 'pool stock' of common items used in servicing, such as light bulbs, fuses and other consumables which are replenished regularly by the parts-to-service person and this eliminates the need for mechanics to waste time looking for these consumables during the course of servicing a car:

We did something quite radical. We closed the parts counter to the workshop completely and employed a person specifically to become a parts-to-service person (Dealer 3).

The findings indicate that while some dealers had previously introduced some pre-picking of parts, the introduction of lean thinking made the system more effective due to more efficient booking-in processes and pre-diagnosis. This suggests that efficient pre-picking of parts can happen only in tandem with adequate pre-diagnosis.

\subsubsection{Location of Special Tools}

Prior to the introduction of lean management the general attitude was to keep special tools locked in a secure location, perhaps even in the parts department where a system of 'signing out' a tool was adopted to monitor the location of the tool. While this approach was good from a security perspective, it was not conducive to the lean philosophy because it caused delays while mechanics were searching for tools or waiting at the parts counter for a tool.

From an importers point of view we were advising that, because there are so many special tools, they should be locked away in the parts department. From a lean thinking view, ideally every mechanic should have their own set of special tools, but at the very least special tools should be located on a visible shadow board and no more than a twenty metre walk from all the mechanics (Distributor Representative). 
The findings suggest that the location of special tools which are purchased by the dealership and commonly available to all mechanics can relatively easily be adapted to lean processes. Where the tools belonging to individual mechanics are concerned however, there may be a certain resistance to being told how to organise their personal tool box unless mechanics can see the benefit for themselves.

\subsubsection{Customer Fulfilment Reporting}

Customer fulfilment reporting involves monitoring the progress of each job as it progresses through the workshop from start to finish. It requires detailed analysis of the different stages and examines if the time allocated for each job was adequate; what extra work was found during the service; and if the work could be finished in the time allocated or, if not, why not. Through this monitoring, trends arise which indicate where problems and 'bottlenecks' are occurring and, therefore, it highlights where changes need to be made to improve the process. Due to the significant time required for conducting the customer fulfilment report, the study indicates that only one dealership has fully adopted this aspect of lean management. Other dealers contend that it is not practical as it almost requires a dedicated person to carry out the reporting.

If you were to clock the time spent filling out the customer fulfilment report each day it would be about two hours. It can cause a degree of analysis paralysis at times, but it is a very effective tool (Dealer 1).

The research findings indicate that some dealerships have adopted a broader range of methodologies than others for implementing lean. This is primarily influenced by the duration which the dealership has been involved with the lean programme, but not definitively. In many cases the commitment of management proved a more influential factor. In the majority of cases, however, pre-diagnosis, spaghetti mapping, and job-card analysis were the basic methodologies applied.

\subsection{Analysing the Influence of Lean Management within Motor Dealerships}

Assessing the effectiveness of lean management takes on different forms depending on what a dealer expects from lean. Regardless of individual dealership needs, the overriding objective of all dealers was to make significant improvements to the running of their businesses. The findings suggest that every dealer has obtained at least some benefit from implementing lean management, including those who commenced implementing it relatively recently. Furthermore, the findings indicate that the degree to which all dealers achieve their expectations depends on the commitment to the programme. Some of the benefits the dealers experienced are summarised below.

\subsubsection{Lean Management and Performance Levels}

Performance levels, namely workshop throughputs, which include the sale of labour hours and vehicle parts, have generally improved in all dealers who have implemented lean management techniques within their after-sales departments. Performance, however, has been influenced to varying degrees and generally those who have put more time and effort into lean have seen greater returns. The interviewees who have been using lean practices for a considerable time estimate that turnover through the service and parts department has increased in the region of eighteen to twenty percent as a consequence of implementing lean management:

Our workshop efficiency soared and our profitability soared and the mechanics bonuses also went up, and from that moment everybody was convinced that lean was worthwhile. It was a win-win situation (Dealer 3).

Other dealers have observed that standard service times have been reduced significantly, which leads to increased throughput and with lower stress levels for all concerned:

We have always run at above ninety-five percent productivity but the stress levels in order to keep it at that level are quite high. So what I see from lean is a reduction in stress levels, and if you reduce the stress levels people stay with you longer. People are happier, people earn more money, and if they are well paid yet not so stressed they look after customers better which is beneficial for the long-term future of the company (Dealer 6).

A difficulty highlighted in the current research is that the dealers involved appear to have no definite method of determining the effectiveness of lean management with regard to increasing performance levels. This results in quite subjective views regarding the effectiveness or otherwise of lean management pertaining to performance levels.

\subsubsection{Lean Management and Quality Standards}

It is difficult for many of the dealers to accurately estimate the effect that lean management has had on the improvement or otherwise of quality standards within their businesses. Various factors affect the perceived quality levels and many of these factors are outside the direct control of the motor retailer. Some dealers commented that the product quality of the cars they are selling and servicing has improved greatly in recent years and that contributes to the overall perception of improved quality, even if this is not directly attributable to the implementation of lean in the motor dealership: 
Quality has definitely improved, however, in reality I believe it is a combination of improved product quality as highlighted by a reduction in warranty problems in 2006 when compared to 2005, which we can't really take credit for. We haven't been able to strip out and identify exactly how much of the improved customer satisfaction figures is attributable to lean (Dealer 2).

The research findings highlight a contradiction in relation to quality and lean management whereby the manufacturer stipulates that a definite number of quality checks must be carried out and recorded as part of the dealer monthly quality standards checklist. This is contrary to the widely held views of lean advocates that quality checks are a form of waste. An important finding from the current research it that there is no one technique used to monitor quality standards within the dealership and consequently how quality is affected by lean management.

\subsubsection{Customer Satisfaction and Lean Management}

The most common tool used to monitor quality is the customer-satisfaction survey, which involves an analysis by a marketing company on behalf of the distributor to record customer satisfaction levels and to rank each dealer accordingly. A difficulty arises, however, as there is a considerable time delay before the data is made available, so it limits the opportunity a dealer has to resolve a difficulty for the customer and to retrieve the situation.

While some dealers are attributing improved customer satisfaction directly to the implementation of lean, the distributor who monitors customer satisfaction on an ongoing basis, contradicts this:

Our own research into customer satisfaction has showed that it has not got any better. From our research there appears to be no direct link to show that customer satisfaction improved with lean thinking (Distributor Representative).

The current findings indicate that while customer satisfaction surveys are applicable to all dealers, there is no one effective method of assessing customer satisfaction being used by all dealers involved in lean management. This suggests that assessing customer satisfaction and the significance of lean to customer satisfaction is quite subjective. While dealers express their own views on what is important, more research into customer satisfaction levels is required to accurately determine and compare the levels of improvement involved.

\subsection{Difficulties in Implementing Lean Management}

From the research conducted, it is apparent that certain difficulties have hindered the development of lean management among the dealers interviewed. These problems can be attributed in some cases to the attitudes and activities of personnel within the dealership. Some of the difficulties, however, are outside the control of the individual dealers and result from limitations of distributors and suppliers.

\subsubsection{Cherry-Picking Elements of Lean Management}

Most of the dealers interviewed have to some extent cherry-picked elements of lean management which either appealed most to them or suited their individual circumstance. Cave (2003) contends that cherry-picking the more attractive elements while leaving out the more difficult elements ultimately results in failure of lean management within the organisation. This is due to processes not working effectively in isolation and therefore maximum benefit cannot be obtained.

\subsubsection{Need for a Dedicated Lean Manager within the Dealership}

The current research findings suggest that if a dedicated lean manager was appointed with the sole responsibility of implementing lean techniques, then it would have been possible to maintain momentum to a greater degree. It is clear that there are significant benefits from implementing lean management, both financial and otherwise, so a cost-benefit analysis should indicate that the cost of having a dedicated lean manager could pay many times over through increased productivity and stable workforce.

\subsubsection{Personnel Difficulties}

The attitudes and ability of personnel within the dealership has a significant impact on the success of lean management within the dealership. The ability to maintain staff levels and minimise staff turnover are essential if the organisation is to be successful with implementing lean management procedures. The need for effective management to create stability within the dealership with regard to staffing is also important.

\subsubsection{Time Span for Implementation of Lean Management}

The current research findings highlight the importance of adapting the timeframe for the implementation of lean management according to the requirements of individual dealerships. The nature of the business dictates that each dealer must be analysed individually and targets set accordingly. The approach of forming groups of dealers and allocating a common timeframe for the group to implement specific lean procedures appears to have had only limited success. 


\subsubsection{Suppliers}

To some extent, dealerships are constrained with implementing lean procedures due to external influences, which are outside of their control. The most significant theme that emerged from dealers in this regard was in relation to the supply of parts. The interviewees highlighted that the current system, whereby parts are delivered from the manufacturer to the dealer via the importer, was not in line with the concept of lean management and JIT.

\section{Conclusions}

Previous literature relating to lean management within the motor industry focused primarily on manufacturing processes and in particular the Toyota Production System. The relevance of this to Ireland is limited as there have been no automobile manufacturing plants operational in Ireland for some years.

Despite the improved variety and quality of products, Womack and Jones (2005) contend that customer satisfaction appears to be deteriorating. Furthermore, they suggest that 'lean consumption' should be more satisfying due to the availability of cheaper and more reliable products, however, this is not the reality. Instead, the consumption process very often involves significant effort for the consumer for which there is no remuneration or satisfaction. The essence of lean management in the motor retail trade is to improve the consumption process for the customer through increasing the efficiency of processes within the dealership.

The primary conclusions from the current study confirm that senior managers consider lean management to be a worthwhile project for motor dealerships. Within those dealerships which have not implemented lean, all interviewees commented that it was something that they would possibly undertake in the future:

We would not have the time available to dedicate to implementing lean management up until now but perhaps in the future we will consider it (Dealer 9).

The findings from the current study suggest that there is a generally positive attitude towards lean management; however, there is also some misunderstanding on what is actually involved. A factor that all interviewees agree on is that lean management requires much time and effort. The rate at which lean techniques are implemented varies, depending on the circumstance of individual dealerships. This suggests that the practice adopted by the consultants of grouping dealerships and attempting to coordinate the implementation of lean practices, whilst appearing more cost effective, may not be the most successful approach for individual dealerships. In all cases, for lean management to be successful, it is essential that senior management is committed to the lean programme and encourage all staff to be directly involved with the training and implementation of lean. In dealerships where lean management is embraced, significant improvements accrue, which makes the programme worthwhile both in financial terms and in developing a positive working environment. Finally, in agreement with many advocates of lean management the findings suggest that lean is a long-term process which involves many difficulties and requires commitment and resilience.

\section{References}

Cave, A. (2003). Lean for all. Metalworking Production, June, Vol. 6: 15.

Hines, P., Riccardo, S., and Bartolini, M. (2002). Demand chain management: An integrative approach in automotive retailing, Journal of Operations Management, November, Vol. 20, No. 6: 707-728.

Jones, D. and Mitchell, A. (2006). Lean thinking for the NHS. London: NHS Confederation.

Kroes, N. (2006). The regulation that is driving dealers to despair. Irish Motor Management, November/December: 43.

O'Brien, T. (2006). Under the bonnet - the options for Irish dealers. Irish Motor Management, November/December: 42.

Todd, J. (1995). World-class manufacturing. Berkshire: McGraw-Hill.

Womack, J. P. and Jones, D. T. (2005). Lean solutions: How companies and customers can create value and wealth together. London: Simon \& Schuster. 


\title{
Monetary Policy Transmission
}

\section{Mechanism in Fiji: An Empirical Analysis of}

\section{The Quarterly Model}

\author{
T.K. Jayaraman \\ School of Economics, Faculty of Business and Economics \\ the University of the South Pacific, Laucala Bay Road, Suva, Fiji Islands. \\ Tel: +679-323-2178 E-mail: jayaraman_tk@usp.ac.fj \\ Chee-Keong Choong (Corresponding author) \\ Department of Economics, Faculty of Accountancy and Management \\ Universiti Tunku Abdul Rahman, Lot PT 21144 \\ Jalan Sungai Long, Bandar Sungai Long, Cheras, 43000 Kajang, Selangor D.E., Malaysia. \\ Tel: +603-9019-4772Ｅ-mail: choongck@mail.utar.edu.my
}

\begin{abstract}
Fiji's central bank, the Reserve Bank of Fiji (RBF) since its inception in 1983, has been pursuing monetary policy with the mandated objectives of economic growth with price stability and an adequate level of exchange reserves. In 1988, as part of financial sector reforms, RBF discontinued the use of direct instruments and switched on to employment of indirect instruments for influencing interest rates. For the past two decades, RBF has been conducting regular open market type operations in its own paper, known as RBF Notes for liquidity management. The yield to maturity of its 91-day RBF Notes determined through tender system, known as policy indicator rate (PIR) signals the monetary policy stance of RBF. This paper undertakes an empirical study of transmission mechanism of monetary policy over a 17-year period (1990Q1-2006Q4). Using variance decomposition and impulse response analysis, we find that money channel is the most important one amongst the four channels of transmission mechanism investigated.
\end{abstract}

Keywords: Monetary Policy, Transmission Mechanism, Structural VAR, Monetary Aggregates, Bank Credit, Fiji

\section{Introduction}

Among the 14 independent Pacific island countries (PICs), eight have been using the currencies of their former rulers, as legal tender ever since their political independence: Cook Islands and Niue (the New Zealand dollar); Kiribati, Nauru and Tuvalu (the Australian dollar); and Federated States of Micronesia, Palau and Republic of Marshall islands (the US dollar). The other six PICs namely, Fiji, Papua New Guinea (PNG), Samoa, Solomon Islands, Tonga and Vanuatu introduced their own currencies after their independence in the 1970s. While PNG shifted to a floating exchange rate regime in 1994, the other five countries continued to adopt some forms of fixed exchange rate regimes. The currencies of Fiji, Samoa and Vanuatu are pegged to a basket of currencies of their major trading partners, while the exchange rate regime of Solomon Islands is a crawling peg and the currency of Tonga has a peg within horizontal bands (Browne 2006). The tasks of exchange rate management together with maintenance of price stability through the formulation and implementation of monetary policies and their implementation are performed by their respective monetary authorities.

However, there is a paucity of studies on transmission mechanism of monetary policy in the Pacific island countries. Although Fiji's monetary policy received considerable attention from various authors (Rao and Singh 2006, Waqabaca 2000, Katafono 2000, Waqabaca and Morling 1991), their studies did not specifically focus on channels of transmission mechanism, as part of continuous investigation of what is inside the "black box" (Mishkin 2001). Accordingly, this paper has been motivated to undertake a more detailed analysis of monetary policy transmission mechanism in the island countries under fixed exchange rate regime by examining the case of Fiji.

The choice of Fiji is dictated by various factors. Aside from the availability of consistent time series of data, Fiji with private sector activities of some significance has, amongst PICs, relatively well-developed money and capital markets. Further, Fiji was the first among PICs to move away from quantitative controls on credit and interest rates, by switching 
to market based instruments of monetary policy as part of financial sector liberalisation and deregulation measures since 1988. Fiji's central bank's monetary policy framework now uses its own 91-day paper's yield to maturity rate, labeled as the policy indicator rate (PIR) as the main instrument to signal the stance of monetary policy. The changes in PIR are intended to influence the tightness or otherwise of money market conditions, and accordingly to determine the overnight inter-bank lending rate and the money market rates in general on all short term instruments.

The objective of the paper is to examine the links between PIR and the key outcomes including output growth and price level and investigate how fast and to what extent changes in the central bank's interest instrument impact output and inflation. The paper is organised on the following lines. The second section provides a brief literature survey; the third section reviews the monetary policy measures adopted in Fiji since the establishment of its monetary authority in 1983; the fourth section outlines the modeling procedure and methodology for the study; the fifth section presents the results and the sixth section provides a summary listing some conclusions with policy implications.

\section{Monetary Policy Transmission: A Brief Literature Survey}

Monetary policy is aimed at influencing interest rate and availability of loanable funds for investment through central bank's control of money supply. The process through which monetary policy decisions affect aggregate demand, gross domestic product (GDP) in real terms, and price level is described as monetary transmission (Meltzer 1995). The impact of monetary policy decision on the country's GDP domestic product is through its influences on consumption and investment decisions of households, business and financial intermediaries. Monetary transmission mechanism refers to the general conceptual framework, while the channel of monetary influences refers to "the route through which the monetary disturbances influence the goal variables" (Pierce and Tysome 1985: 22). Thus, by differentiating between a given transmission mechanism and a channel of monetary influence, the two authors indicated that it is possible for a number of channels of monetary influences to operate within the same transmission mechanism.

There are at least six channels through which monetary policy appears to be impacting economic activities (Mishkin 2006). These are: (i) interest rate channel; (ii) money supply channel; (iii) credit channel; (iv) balance-sheet channel; (v) asset price channel; (vi) exchange rate channel; and (vii) expectations channel. A stylized presentation (Figure 1) illustrates the channels of transmission mechanism (IMF 2004). One should however recognise these channels of transmission operate with varying lags depending on the levels of economic development in general.

\subsection{Interest Rate Channel}

The Keynesian view is that a fall in nominal interest rate, following a rise in nominal money stock, given the unchanged price level in the short run due to market rigidities, would cause rise in investment spending, thereby increasing aggregate demand and rise in output. The key point here is that it is the real rather than nominal rate that influences investment. Taylor (1995) in his survey on empirical research studies on interest rate channel concluded that there is strong empirical evidence for substantial effects on consumer spending on semi-durables and investment spending, making the interest rate monetary transmission mechanism a strong one.

\subsection{Money Supply Channel}

The money supply view takes the position that expansionary monetary policy increases bank reserves, thereby relaxing the constraints to banks' ability to create more loans. As a result, short-term interest rate falls. Thus, expansionary monetary policy, which lowers the short-term nominal interest rate, also lowers the short-term real interest rate, holding true in a world with rational expectations (Mishkin 1996). Here, money supply would mean either narrow money, M1 (comprising currency outside the banks and demand deposits) or broad money M2, (consisting of M1 and savings and time deposits).

\subsection{Credit Channel}

Even if investment is insensitive to interest rate, increase in money supply through rise in bank reserves steps up banks' ability to expand lending. Consequently, banks would make available loans to new borrowers as well, since most of the latter are dependent on bank loans. This would encourage further consumption spending in terms of purchases of semi-durable goods, which would lead to rise in GDP. The bank credit channel has assumed greater importance in recent years, not only in advanced but also in developing economies as documented by Bernanke (1986), Bernanke and Blinder (1988), Kashyap et al. (1993) and Kashyap and Stein (1994).

On the other hand, King (1986), Romer and Romer (1990), Ramsey (1993) and Guender (1998) questioned the strength of credit mechanism. Morris and Sellon (1995) who noted that money supply and interest rate channels are significant transmission channels, did not totally reject the role of bank credit. These apparent contradictions appear to have resulted from the difficulty in isolating the effect of monetary variables on output due to feedback effect from output to monetary variables.

\subsection{Balance Sheet Channel}

The balance sheet channel view lays emphasis on the role of collateral in reducing moral hazards. An expansionary monetary policy causes increases in financial and physical asset prices, thereby raising the market net worth of firms 
and the value of collateral, company cash flow and ultimately the firms' credit worthiness. Further, a rise in asset prices increases the ratio of liquid financial assets to household debt, thereby reducing the probability of financial distress and therefore increases consumption and housing investment (Mishkin 2006, 2001).

\subsection{Asset Price Channel}

Similar to the operating ways of balance sheet channel, expansionary monetary policy raises the value of equities. This particular transmission channel rests on Tobin's $q$ theory, which is applied to business investment. Expansionary monetary policy raises price level of stocks. Increase in its stock prices enables the firm to raise additional equity capital by issuing less number of stocks. Importance of asset price channel is further strengthened by Modigliani's life cycle model, according to which increase in financial wealth raises consumption by households (Mishkin 2006, 2001).

\subsection{Exchange Rate Channel}

Monetary policy influences exchange rate through interest rates. An expansionary monetary policy would increase money supply, leading to a fall in interest rate. Under conditions of perfect capital mobility and perfect substitutability of financial assets, capital would flow out and domestic currency would depreciate. Depreciation would make the country's exports more attractive to foreigners; an increase in net exports would result in greater aggregate demand leading to rise in output (Mishkin 2006, 2001).

\subsection{Expectations Channel}

Monetary policy measures have an impact on the economy through their influence on the expectations of economic agents about the future outlook of the economy. In particular, the expectation effects may improve monetary policy transmission channels by shortening reaction lags (Mayes 2004). The expectation channel is more effective, if the central bank has acquired a high degree of credibility established through its past performance.

\section{Fiji's Monetary Policy Measures and Implementation}

The financial sectors in PICs suffer from several weaknesses, which are not very different from those observed in other parts of the developing world (Pill and Pradhan 1995, 1997). These include the following: (i) the underdeveloped nature of banking systems and inefficient payments system; (ii) a limited range and number of securities traded as well as irregular trading; (iii) high transaction costs for banking services; (iv) poorly developed information systems; (v) lack of transparency including inadequacies in the provision of information disclosure requirements and accounting standards; (vi) restrictions on the nature of financial instruments, in regard to issuing and pricing of instruments and trading in these instruments; (vii) inadequate regulatory and prudential supervision of banks and financial markets; and (viii) inappropriate capital controls.

Although Fiji, whose selected key indicators are given in Table 1, is relatively better endowed with human resources than other PICs, with a vibrant private sector, its financial sector institutions are still at early stages of development. Fiji's financial sector comprises three major sectors, namely the banking system, insurance industry and non-bank financial institutions. The banking system had a major setback in 1995/96, when the state-owned National Bank of Fiji (NBF) failed. The failure of NBF, which once accounted for one third of total bank credit, was a wake-up call to the nation. Improvements in bank supervision and regulatory reforms were quickly undertaken (Chandra et al. 2004). Following the restructuring program, the failed bank's operations were taken over by an Australian owned commercial bank. As of 2007, all the five commercial banks (Note 1)are all foreign- owned and are well capitalised. Capital adequacy ratios were maintained above the minimum requirement of $8 \%$, at an average of $12 \%$. Management performance is rated satisfactory in view of strong performance in the components capital adequacy, asset quality, management, earnings and liquidity known as CAMEL [Reserve Bank of Fiji (RBF) 2007a].

Except one bank, which is supervised by a local board, all the foreign-owned commercial banks are supervised from their respective headquarters. However, the general impression has been that they have been conservative with relatively high lending rates. To meet the growing criticisms, banks have shown greater interest in recent years in extending their operations beyond urban areas by running mobile banks in rural areas as well. Sectors to which banks have been lending include private individuals for consumer credit, housing, wholesale, retail, hotels and restaurants and building and construction.

The insurance sector covers life insurance and general insurance. There are two life insurance companies, eight general insurance companies, and five insurance brokers with a large number of insurance agents. Most of the insurance companies have been reported to be well capitalised, meeting their solvency requirements. The bulk of total assets of insurance institutions are invested in government securities as well as in term deposits with commercial banks (RBF 2007a).

There are three non-bank licensed credit institutions (Note 2) (LCI), which cater to the credit needs of private sector in various areas. These include consumer credit, real estate, transport and storage, wholesale, retail, hotels and restaurants, and building and construction. Capital adequacy has remained strong in recent years. In 2007, the capital adequacy 
ratio was $23.7 \%$, compared to the minimum requirement of $10 \%$. In regard to other criteria of asset quality, earnings and liquidity, LCIs have recorded satisfactory position (RBF 2007a).

In addition to these institutions, there is a state-sponsored pension institution, known as Fiji National Provident Fund (FNPF), which collects a stipulated percentage of the salaries of employees in the formal sector matched by a similar contribution from the employers. By an amendment in the Act governing FNPF, domestic workers employed in the informal sector, such as house girls are also covered since 2005. These contributions become payable together with interest to returnable with interest to the members of FNPF upon on their retirement but members have their option to either withdraw lump sum or to take out a pension. The FNPF, as with other institutions, has been restricted to placing their funds overseas. Its investments are concentrated in fixed income securities, the bulk of which is in long-term government and government guaranteed bonds. In recent years FNPF has stepped up its holdings in domestic equities and loans and advances. Short-term funds are kept with commercial banks as deposits of varying duration or invested in government short-term treasury bills.

The government and its agencies, including Fiji Development Bank and Housing Authority are the only source of financial securities. Most of them are short-term treasury bills with limited issue of long-term bonds. Fiji's stock market is at its nascent stage, handling in limited number of privately issued equity stock. There is no secondary market in these securities. Therefore, most of the holders of debt securities hold them until their dates of maturity.

Three years after gaining independence in 1970, Fiji replaced its Currency Board by establishing a Central Monetary Authority (CMA). In 1974, the Fiji dollar was pegged to the US dollar, severing the fixed link with the British pound. In 1975, ending the short-lived link with the US dollar, Fiji pegged its currency to a trade weighted basket of currencies of the major trading partners, an arrangement still continuing till today. The CMA was replaced by Reserve Bank of Fiji (RBF) in 1984, which was set up by an Act of the country's parliament.

The monetary policy measures by RBF until 1988 were more of direct and quantitative in nature. In addition to employment of statutory reserve deposit (SRD) ratio, requiring the commercial banks to hold with monetary authority a stipulated proportion of their deposits mainly meant for prudential purpose, RBF relied on further direct interventions. These included measures under which all licensed financial institutions including commercial banks were required to maintain a minimum of not more than $35 \%$ of deposits and other liabilities in minimum holding of unimpaired liquid assets (ULA) in terms of treasury bills of the government and securities issued by government and by official agencies, which were guaranteed by the government. Aside from imposition of ULA requirement, RBF was fixing credit limits and controlling both deposit and lending rates, along with mandated priority sector lending targets. These quantitative restrictions were gradually relaxed beginning from 1989 and gradually discontinued, as part of financial sector liberalisation programme.

With view to improving its competitiveness, Fiji devalued its currency in 1988 twice by a total 33\%. There was another devaluation of the currency by $20 \%$ in 1998 , as a pre-emptive measure in the wake of Asian financial crisis of October 1997. The Fiji dollar continues to be pegged to a basket of the U.S, Australian and New Zealand dollars, the euro, and the Japanese yen. Weights are based on a three-year moving average of Fiji's direction of trade, which are reviewed annually but not published. The exchange rate is currently allowed to move within the existing band from $+/-0.07 \%$, which was once reportedly considered to be expanded to $+/-2 \%$.

The RBF began in 1989 an open-market type of operations in its own short-term debt paper of various maturities, known as RBF Notes, ranging from 91 to 180 days, primarily as a measure towards liquidity management. The RBF Notes are offered for sale through a tendering system, usually twice a week. The yield to maturity of the 91-day RBF Notes has now come to be officially recognised as the policy indicator rate (PIR), signaling the monetary policy stance of RBF. The rate is set in line with RBF's declared monetary policy objectives of low inflation of about $3 \%$ and adequate level of international reserves to cover about 4 months of imports of goods and services. When the actual 91-day rate is not aligned with the policy indicator rate, RBF would exert pressure on the market for short-term funds by selling or redeeming RBF Notes to influence the amounts of funds in their market. The open market operations are conducted to drain out the excess liquidity in the system until the 91-day yield to maturity rate of RBF Note is brought in alignment with the policy indicator interest rate. By maintaining a continuous pressure on the system, the RBF expects to influence the short-term interest rate. The discount rate, at which commercial banks can borrow from RBF known as minimum lending rate (MLR), is linked to PIR. The MLR is normally fixed 50 basis points above PIR. Thus, changes to the PIR are automatically reflected in the MLR.

The PIR is expected to affect other rates in a number of ways. Firstly, changes in PIR are expected to affect money market rate (MMR), which is the inter-bank lending rate and other short-term and capital market interest rates. The primary source of non-bank financial institutions is through issuance of securities in the market. A change in PIR affects the cost of funds, which are raised through the issue of securities and accordingly their lending rates. Change in non-bank lending rates also affect commercial bank rates as they compete in the same market. The RBF Notes provide an alternative investment avenue for investors, as the latter can park their funds in. Therefore, commercial banks would 
find it imperative to offer a competitive rate for attracting/retaining the depositors. Thus, changes in PIR are transmitted to changes in deposit rates. Lending rates are thereafter adjusted in order for banks to maintain the interest rate spread between lending and deposit rates.

The RBF view of on transmission mechanism is no different from the conventional view: transmission of monetary policy is envisaged to be chiefly through interest rate channel (RBF 2007b). There are three main stages identified in the transmission mechanism. : (i) the flow on of changes in short term money market interest rates to other interest rates in the economy, particularly commercial bank lending and deposit rates; (ii) the effects of changes in economic activity; and (iii) the effects of economic activity on inflation and foreign exchange reserves (RBF 2007b).

However, Fiji's success with monetary policy as a tool of economic growth during a 30-year period (1975-2005) is mixed (Dahalan and Jayaraman 2006). Deregulation of the economy and financial sector reforms, which led to adoption of market based PIR did not seem to have had any substantial impact on the economy until 2000, which was hit by political uncertainties. Excess liquidity in the system in the post 1987 coup years due to poor investment climate continued to linger on for the next ten years. The then prevailing environment of low interest rate and low inflation did not however inspire any investor confidence, since political uncertainties posed major stumbling blocks to revival of private investment. With the adoption of a new constitution in 1997, which was followed by the general elections and the installation of an elected government in 1999, the economy appeared to have recovered for while, until there was another coup in May 2000. Fresh elections after the return of democracy in 2001 led to relative stability during the next five years. Fiji witnessed the easing of official trade and aid sanctions by metropolitan powers in the region and a welcome rebound in tourism. In particular, Fiji's economic growth during 2001-2006 was facilitated by an expansionary fiscal policy (D'Hoore 2006).

The prevailing environment of relative political stability during 2001-20005 with favourable factors of low interest rate and low inflation revived consumer confidence as well. Steady rise in private domestic credit, which began with increase in borrowings for consumer durables, spilled over into real estate market as well. There was thus, a revival of private sector credit, which reflected a catching up from the past-depressed levels of investment climate due to political instability. These developments contributed to uninterrupted economic growth during the four years (2001-2006) at an average of 3\%, a remarkable phase in Fiji's recent economic history.

The stock of total domestic credit during the early 1970 s was around $22 \%$ of GDP. It rose gradually to $30 \%$ of GDP in the 1980s. During 1980-1984, it was about 32\% of GDP, with credit to private sector being around $25 \%$ of GDP. Consequent to the liberalization of the economy in 1988, as noted earlier, domestic credit comprising both public and private credit rose to new heights. As a proportion of GDP, domestic credit to private sector in 1989 was around $31 \%$ of GDP. However, growth in credit in subsequent years was no longer remarkable, reflecting the general uncertainties, mainly due to political instability, which was responsible for poor private investment climate. After the enactment of a new Constitution in 1997 and the General Elections in 1999, domestic credit recorded new increases. However, a civilian coup in 2000 plunged the nation into new crisis. As a result, domestic credit as a proportion of GDP fell in from $38 \%$ of GDP. With return to democratic government in 2001, normalcy was restored and domestic credit increased again during the next four years to reach a new high at around 47\% of GDP in 2005. Credit to public sector registered increases, as banks and non-bank institutions stepped up investment in government bonds. Credit to private sector also went up, as it recorded increases from 29\% of GDP in 2001 to 39\% of GDP in 2005.

However, "too much of a good thing" had its own problems (Jayaraman and Choong 2007a). Annual budget deficits due to expansionary fiscal policies combined with steady rise in private sector credit during 2001-2006 led to bulging annual current account deficits. As the twin deficits reached unprecedented proportions of GDP (Jayaraman and Choong 2007b), RBF decided to apply brakes by raising PIR from 1.75 \%in two stages in late 2005 to reach $2.25 \%$. Again in February 2006, PIR was further raised to 3.25\%; and in June 2006, another increase in PIR was resorted to. This time, it was raised by a full percentage point to $4.25 \%$, the highest in recent years. The MLR was fixed 100 basis points above PIR. Further, during 2006, the statutory deposit ratio (SDR) was also increased from 5\% to $7 \%$ and stringent exchange control measures were also imposed, all with a view to "lowering credit growth and slowing imports" (RBF 2007c).

The results of the restrictive monetary policy pursued since mid 2006 appear to have yielded the intended results. From the second quarter of 2007 onwards, there has been a steady decline in private sector credit growth and fall in imports. Further, as the government also resorted to fiscal adjustments in terms of reducing the number of ministries and departments and non-essential expenditures and freezing vacancies, the current account deficit also got reduced (RBF 2007d).

\section{Modeling and Methodology}

The modeling of monetary policy transmission mechanism in PICs has necessarily to take into consideration of the unique features, which characterize the Pacific island economies. The small sized and undeveloped money and capital markets limit the effectiveness of monetary policy transmission mechanism acting through various channels (Worrell 
2000). In particular, as noted earlier, Fiji's financial sector being shallow with only a few numbers of participants is not deep enough to absorb debt instruments and equities. Furthermore, there is no vibrant secondary market, in which these financial assets could be traded with ease and speed. Thus, there are obvious limitations to the efficient functioning of interest rate channel.

The balance sheet approach presupposes that financial assets are important constituents of firms/consumers portfolios and assumes the existence of convertibility between illiquid (consumer durables) and liquid (financial) assets. Empirical studies in the Caribbean island economies have shown that the markets have not attained such a degree of sophistication that would enable it to function as an efficient conduit for monetary policy (Baksh and Craigwell 1997). A more recent study on Armenia (Dabla-Norris and Floerkemeir 2006) notes that the inability of banks in developing countries to properly assess credit risk, due to both weak risk management expertise and opaque corporate accounting practices, increases banking spreads and reduces the effectiveness of balance sheet channel.

As regards asset price channel mechanism and its variants of Tobin's $q$ theory (valuation of equities) and Modigliani's wealth and consumption model, it has been noted that an important pre-condition, namely presence of financial assets constituting a key component of borrowers' and wealth holders' portfolios does not exist in developing countries. Fiji is no exception. Further, in small economies, as in Fiji, commercial banks dominate the financial sector, since the non-bank financial sector (stock market, debt securities market, mortgage market, insurance market) is still in its infancy. Thus, market financing does not matter, a situation which "largely precludes the asset price channel's working through wealth and income effects" (Dabla-Norris and Floerkemeir 2006: 8)

The exchange rate channel transmission mechanism for its full efficiency presupposes a floating system, which adjusts to capital flows. Since the South Pacific island countries including Fiji, which have independent currencies, follow a fixed exchange rate regime, this particular channel may not operate. The scope for exchange rate channel is further limited in those countries, which still have controls on capital movements and whose financial assets are not perfectly substitutable and desirable from the point of view of foreigners.

\subsection{Monetary Transmission Mechanism in Fiji}

For the purpose of modeling, in Fiji, we define the monetary transmission mechanism as the impact of a change in short term interest rate, on intermediate targets or variables which include money supply, bank credit to private sector, exchange rate and the final objectives, namely output and price level. As for the short-term interest rate, we choose RBF's PIR, the yield to maturity of 91-day RBF Notes, which as noted earlier, represents the monetary stance of the central bank. The second variable chosen is broad money (M2), since the latter is more highly correlated with output (RGDP) and prices, represented by consumer price index (P) than narrow money (M1) (Figure 2). The third variable is bank credit to private sector (CRE), which in recent years has substantially emerged to be of considerable importance. The fourth variable is the nominal exchange rate $(\mathrm{E})$, which is expressed as units of domestic currency per one unit of foreign currency (US dollar) with view to examining the effects of exchange rate changes on output and prices. As noted by Dabla-Norris and Floerkemeir (2006), using the nominal exchange rate as opposed to a real exchange rate makes it easier to distinguish the exchange rate channel from other channels, since we can isolate changes in the nominal exchange rate on real economic activity, separately from changes in prices. Further, since the real exchange rate is already adjusted for changes in prices, using it would make it difficult to isolate price changes (inflation) from exchange rate changes.

For exploring how the monetary shocks affect output and price level, we employ the VAR methodology based on Sims (1980), which has been increasingly employed in recent years in many studies (Dabla-Norris and Floerkemeir 2006, Ramlogan 2004, Morsink and Bayoumi 2001, Ahmed 2002). The chief advantage of using the standard VAR is that only minimal restrictions need to be imposed. Following Berananke and Blinder (1992) and Sims (1992), a VAR with $k$ endogenous variables and $n$ lags can be expressed as:

$\Pi y_{t}=\Pi y_{t-1}+\Pi y_{t-2}+\Pi y_{t-3}+\ldots+\Pi y_{t-n}+\varepsilon_{t}$

where, $y_{t}$ is a $k$ times 1 vector of endogenous variables, $\Pi$ is $k$ times $k$ matrix of standard parameters of the endogenous variables and $\varepsilon_{t}$ is $k$ time 1 vectors structural disturbances.

The model is identified using a recursive, contemporaneous system, whereby it is assumed that the structural shocks $\varepsilon_{t}$ is orthogonal and that $\prod$ is lower triangular. If there is no contemporaneous feedback from the non-policy variable to policy variable, it is theoretically sound to place the policy variable first in the recursively ordered system. If the contemporaneous correlation among the shocks in the reduced-form VAR is high (Ahmed 2006), ordering becomes a matter of concern.

\subsection{Data and Choice of Variables}

The model uses quarterly data covering a 17-year period (1990-2006). Data on all variables except real GDP (RGDP) are available on a quarterly time series basis. In the absence of quarterly data on RGDP as well as any data on industrial 
production or any alternative to RGDP, we are constrained to use cubic spline procedure for generating a quarterly RGDP series. The data sources used are Government of Fiji (2007) and RBF (2007a) for real GDP and PIR respectively; and IMF (2007) for M2, CRE, E and P. All six variables duly transformed into logarithmic form are entered into VAR equation in the following order, PIR, M2, CRE, E, RGDP and P.

\section{Empirical Results}

\subsection{Unit Root and Cointegration Tests}

The empirical study begins investigation into the time series properties of each variable employed in the study. A number of unit root tests are used to examine the order of integration of the series under study. The results are shown in Table 3. They include Augmented Dickey-Fuler (ADF) test and Ng-Perron MZ test, which based on the null hypothesis that a unit root exists in the autoregressive representation of the time series. As reported in the table, the variables in equation (1) are non-stationary at level. However, both Augmented Dickey-Fuller (ADF) and Ng and Perron unit root tests indicate that RGDP, M2, CRE, E, PIR and P are integrated of order one.

Using ordinary least squares (OLS) to estimate equation (1) might produce spurious regression or ignore important information about the underlying data-generating processes. However, a long-run relationship between the variables under study can be inferred if the variables are cointegrated; that is, if there exists a linear combination of them that is stationary. The results of the multivariate cointegration analysis following Johansen and Juselius (1990)) are shown in Table 4.

As can be seen from Table 4, both the trace and the maximum eigenvalue statistic point to the existence of long run relationship between real GDP, M2, private credit, exchange rate, interest rate (PIR) and price. Overall, the diagnostics of the VAR indicate Gaussian, uncorrelated and homoscedastic residuals. Only the VAR Jacque-Bera normality joint test is significant at the 5 per cent level. Gonzalo (1994), however, shows that non-fulfillment of the residual normality assumption in the vector autoregression still yield unbiased and consistent estimators.

\subsection{Variance Decomposition of Log Output (RGDP)}

All the variables are then entered in the VAR in log levels giving the system appearance of an unrestricted vector error correction mechanism (Dale and Haldane, 1995). We now proceed to examine the relative strengths of various channels through which monetary pulses are transmitted to output and prices. This is accomplished by carrying out a decomposition of $\log$ RGDP and $\log$ P, with a view to determining the size of the fluctuations in a given variable that are caused by different shocks. We calculate the variance decomposition at forecast horizons of four through 28 quarters. One quarter ahead is the short run and four, eight and 12 quarters represent the medium term, while 20 quarters ahead is the long run. VAR for each variable was estimated, which included 7 lags. The results are reported in Table 5 and Table 6 respectively for $\log$ RGDP and $\log$ P, indicating the percentages of variance of the variable forecast as attributable to each variable at a 28 -quarter horizon. The first column lists the quarters ahead, whereas the second column refers to standard error (SE), which is the forecast error of the variable at different quarters. Variables were ordered in the same way they appear in the Table. That is, the third column refers to PIR, the fourth M2, the fifth CRE, the sixth E, the seventh RGDP and the last P.

Table 5 shows that money channel is the most important channel one amongst all in explaining variation in output, in the short, as well as medium and long terms. In the first quarter, shocks in M2 were the most influential, as they account for 7 percent of the variance in output. Importance of M2 rapidly grows over the next three quarters. In the fourth quarter, shocks in M2 explain 46 percent of variability in output; 74 percent of variability in output in the $8^{\text {th }}$ quarter; and 68 percent of variability in output in the $12^{\text {th }}$ quarter. In the $20^{\text {th }}$ quarter ahead, shocks in $\mathrm{M} 2$ explained nearly three-fourth of variance in output.

Among the other three channels, interest rate channel is well ahead of both exchange rate and credit channels in influencing the variability in output. In the first quarter, shocks in PIR and E respectively account for 3 percent and 2 percent of variability in output, followed by CRE, accounting much less than half a percent of variability in output. However, by the end of short run ( $4^{\text {th }}$ quarter), we find CRE gaining importance over both PIR and E. Shocks in CRE account nearly 4 percent of variability in output, followed closely by E ( 3 percent), whereas shocks in PIR explain output variability only for about one percent. Over the medium term, shocks in PIR emerged to be more responsible for variability in output to a larger extent than CRE and E. In the $12^{\text {th }}$ quarter, shocks in PIR account for about 7 percent of variability in RGDP, while shocks in CRE and shocks in E respectively account for 2 percent and nearly 4 percent of variability. In the long run, shocks in PIR play a more dominant role than shocks in CRE and $\mathrm{E}$ in explaining the variability in output.

\subsection{Variance Decomposition of Log Price (P)}

Table 6 shows the variance decomposition of $\log$ P. The results indicate that in the first quarter, shocks in PIR in the first quarter are the most important influence in explaining the variability in price level. In comparison to M2, CRE and 
E, shocks in PIR in the first quarter ahead, account for 15 percent of variability in price level. In the fourth quarter ahead, shocks in M2 become more influential in explaining the variability in price level. However, beginning from the eighth quarter, influence of PIR declines and shocks in M2 assume a far bigger role. In the medium term., shocks in M2 account for 36 percent variability in price in $8^{\text {th }}$ quarter and 32 percent in $12^{\text {th }}$ quarter. In the long run, shocks in M2 explained nearly 40 percent of variability.

Shocks in PIR have a steady influence on price level, explaining about the 12 percent of variability in price level in the medium term. Thereafter in the long run, shocks in PIR accounted for 11 percent in variability in price level. Exchange rate played an increasingly larger role after its low influence on price level in the first quarter. At the end of the short term, shocks in exchange rate accounted for 5 percent of variability in price level. In the medium term, the influence of exchange rate on price level increased as shocks in E accounted for around 8 percent of variability in price level. In the long run, shocks in E explained the variability of price level for about 5 percent in $20^{\text {th }}$ quarter. Among all the variables, bank credit to private sector played the least important role. Shocks in CRE explained about 2 percent of variability in price level, and 4 percent in the medium and long run.

\subsection{Correlation Matrix of Reduced-form VAR Residuals}

With view to testing the robustness of the VAR results, which would vary based on different orderings of the variables, we resorted to testing the correlation of reduced-form VAR residuals. Table 7 shows the correlation matrix of the reduced-form VAR residuals based on the ordering of variables, which were entered into VAR. The elements of the correlation matrix between the policy variable, PIR and the rest of the system are very low, indicating that the contemporaneous feedback is not a problem. These correlations suggest that the ordering of the variables in a Choleski decomposition is not of any major concern.

\subsection{Impulse Response Function of Log Output (RGDP) and Log Price (P)}

The extent to which shock in different channels influence both output price can be assessed through impulse response function. The simulation horizon covers 40 quarters. The solid lines are impulse responses and the dotted lines are approximate $90 \%$ error bands that are derived from a bootstrap routine with 2000 replications.

Impulse response function is depicted for a horizon of 40 quarters in Figures 3 and 4, which enables us to trace out the response of output and price to a shock in policy variables. The shock is represented by one standard deviation of the error term in the underlying structural model for the variable. Since all variables are measured in logs, the impulse response functions depict the growth rate relative to the base period when the shock occurred. The first graph in Figure 3 shows the response of output to shock in PIR (tightening of monetary stance) represented by one standard deviation of monetary aggregate. A one-standard deviation shock to PIR dampens the growth in RGDP, literally reducing it to zero until the fifth quarter and thereafter has a negative impact on output in the medium term.

Shock in monetary aggregate (M2) has a positive impact on output right from the first quarter reaching the peak between the seventh and eighth quarter and thereafter gently declining in the tenth quarter. After that, the positive influence of shock of M2 on the growth of RGDP increases. Similarly, the shock to credit (CRE) has positive impact on real GDP. The peak is reached after the fourth quarter. Thereafter, the effect gently declines to reach zero after the seventh quarter and becomes negative. Overall, the impact of shock to credit on real output is not strong in the long-term. A shock to exchange rate (E) produces negative impact on real GDP throughout the period. It is thus clear from Figure 3 that shocks to money, amongst all the policy variables, have the largest impact on output followed by shocks to credit and exchange rate.

In regard to price (Figure 4), one-standard deviation shock to interest rate (PIR) has a negative impact on price until the third quarter, which gets stabilized to exercise a positive effect on price for a while until fifth quarter and thereafter gently rises. One-standard deviation shock to the money has a positive effect on the price. The effect gradually increases and reaches the peak in the twelfth quarter. Thereafter, it shows a decreasing trend but begins to stabilize after four quarters. However, the effect remains substantial throughout 24 quarters or six years. This indicates that shocks to monetary aggregate have greater impact on prices in the long run.

Over a period of first eight quarters, the impact shock to credit on prices remains negative. After some fluctuations in the next few quarters, the impact becomes positive, and stabilizes afterward in the long run. A shock to exchange rate has a much more dampening effect on price level throughout the period. Thus, inferences drawn from variance decomposition analysis are confirmed by impulse response analysis as well (Figures 3 and 4).

\section{Summary and Conclusions}

This paper undertook an empirical investigation of monetary policy transmission mechanism in Fiji. As part of financial sector reforms, in 1998 Fiji's central bank switched on to the use of indirect instruments by moving away from direct intervention measures, which in the past included ceilings on lending rates and fixing deposit rates as well as quantitative controls on credit to priority sectors. The RBF presently aims at influencing the short-term interest rate 
through open market type operations in its own paper, known as RBF Notes. The yield to maturity of 91-day RBF Note is now known as the policy indicator interest rate (PIR). Changes in PIR signify changes in monetary stance of RBF.

Since Fiji's financial sector is small with an underdeveloped primary market along with near absence of a significant secondary market for government securities and central bank papers, the money market is not efficient for transmitting monetary pulses emitted through changes in PIR. However, RBF's open market operations in its own paper result in changes in nonborrowable reserves, which in their turn alter banks' reserves, monetary base and finally money supply. Thus, money channel becomes an important conduit of monetary policy shocks. Changes in broad money supply impact bank's balance sheets and banks' liabilities are duly transformed into assets through bank credit to private sector.

Focusing on four channels of transmission, PIR, M2, bank credit to private sector, and nominal exchange rate, our empirical investigation covered a 17-year period (1990-2006). Using quarterly data and employing variance decomposition and impulse response analyses, our investigation shows that money channel has been the most important one amongst all the transmission mechanisms studied.

In the context of the current under-developed status of Fiji's money market, the results are not surprising: interest rate channel is not the principal conduit of monetary policy shocks. The study finding that money channel is the most dominant channel in Fiji is similar to the findings documented by studies on other developing countries. In the developing countries, including PICs, savers as investors have a limited portfolio choice and hence tend to depend on the banking system. Since Fiji's financial sector development is still at an evolving stage, it is only reasonable to expect that with the emergence of various financial instruments, monetary policy transmission mechanism would undergo changes in the future.

\section{References}

Ahmed, S. (2003). Sources of economic fluctuations in Latin America and implications for choice of exchange rate regimes. Journal of Development Economics, 72, 181-202.

Asian Development Bank (ADB) (2007). Key Indicators of Developing Asian and Pacific Countries, Manila: ADB.

Baksh, S. and Craigwell, R.C. (1997). The monetary transmission mechanism in small open economies: A case study of Barbados. Savings and Development, XXI, 179-193.

Bernanke, B.S. (1986). Alternative explanations of money-income correlation. Working Paper No. 184 Washington, D.C.: National Bureau of Economic Research.

Bernanke, B.S and Blinder, A.S. (1988). Is it money, or credit or both or neither? Credit, Money and Aggregate Demand. American Economic Review, 78, 435-439.

Bernanke, B.S and Blinder, A.S. (1992). The federal funds rate and the channels of monetary transmission. American Economic Review, 82, 901-921.

Chandra, A., Jayaraman, T.K. and Waqabaka, F. (2004). Reforms in banking supervision in Fiji: A review of progress. Pacific Economic Bulletin, 19, 102-114.

Dabla-Norris, E. and Floerkemeir, H. (2006). Transmission mechanism of monetary policy in Armenia. Working Paper WP/06/248, Washington, D. C.: International Monetary Fund.

Dahalan, J. and Jayaraman, T.K. (2006). Monetary and fiscal policies in Fiji: A test of effectiveness. Pacific Economic Bulletin, 21, 94-102.

Dale, S. and Haldane, A.G. (1995). Interest rates and the channels of monetary policy transmission: Some sectoral estimates. European Economic Review, 39, 1611-1626.

D’Hoore, A. (2006). Fiji. Chapter 8 in C. Brown (ed.) Pacific Island Economies. Washington, D.C.: IMF.

Engel, R.F. and Granger, C.W.J. (1987). Cointegration and error correction: Representation, estimation and testing. Econometrica, 55, 251-276.

Government of Fiji (2007). Key Statistics December 2006, Suva; Fiji Islands Bureau of Statistics.

Guender, A.V. (1998). Is there a bank lending channel of monetary policy in New Zealand? The Economic Record, 7 , 243-265

International Monetary Fund (IMF) (2004). Monetary Policy Implementation at Different Stages of Market Development: Country Cases and Appendices-Supplementary Information, Washington, D.C.: IMF

International Monetary Fund (IMF) (2007). International Financial Statistics, July 2007, CD-ROM, Washington, D.C: IMF.

Jayaraman, T.K. and Choong, C.K. (2007a). Financial sector development and private sector credit boom in Fiji: 
Implications of private credit. Asia Pacific Economic Journal, 5, 1-20.

Jayaraman, T. K. and Choong, C.K. (2007b). Is the Twin Deficit Hypothesis relevant to Fiji. Journal of Fijian Studies, $5,1-27$.

Johansen, S. (1988). Statistical analysis of cointegrating vectors. Journal of Economic Dynamics and Control, 12, 231-254.

Johansen, S and Juselius, K. (1990). Maximum likelihood estimation and inference on cointegration with applications to the demand for money. Oxford Bulletin of Economics and Statistics, 52, 169-210.

Kashyap, A.K. and Stein, J.C. (1994). The impact of monetary policy on bank balance sheets. NBER Working Paper 4821, Cambridge, Mass: National Bureau of Economic Research.

Kashyap, A.K., Stein, J.C. and Wilcox, D.W. (1993). Monetary policy and credit conditions: Evidence from the composition of external finance. American Economic Review, 83(1), 78-98.

Katafono, R. (2000). The relationship between monetary aggregates, inflation and output in Fiji. Working Paper No.00/02, Suva: Reserve Bank of Fiji

King (1986). Monetary transmission-through bank loans or bank liabilities. Journal of Money, Credit and Banking, 18, 290-333.

Mayes, D. (2004). The Monetary Transmission Mechanism in the Baltic States. Talinin: Bank of Estonia.

Meltzer, A.H. (1995). Monetary, credit and other transmission process. Journal of Economic Perspectives, 9, 3-10

Mishkin , F. (1996). "The Channels of Monetary Policy Transmission: Lessons for Monetary Policy”, NBER Working Paper 5464, Cambridge, Mass: National Bureau of Economic Research.

Mishkin. F. (2001). The Transmission Mechanism and the Role of Asset Prices", NBER Working Paper 8617, Cambridge, Mass: National Bureau of Economic Research.

Mishkin, F. (2006). The Economics of Money, Banking and Financial Markets. $8^{\text {th }}$ Edition, New York: Addison Wesley.

Morsink, J. and Bayoumi, T. (2001). A Peep in inside the Black Box: Monetary Transmission in Japan. IMF Staff Papers, 48(1), 22-57.

Morris, C.S. and Sellon, G.H. (1995). Bank lending and monetary policy: Evidence on a credit channel. Economic Review, Quarter II, 59-95

Pierce, D.G. and Tysome, P.J. (1985). Monetary Economics: Theories, Evidence and Policy, London: Butterworth.

Pill, H. and Pradhan, M. (1995). Financial indicators and fianacial change in Africa and Asia. IMF Working Paper, No.95/123, Washington, D.C.: IMF.

Pill, H. and Pradhan, M. (1997). Financial liberalisation in Africa. Finance and Development, June, 7-10

Ramey, V. (1993). How important is the credit channel in the transmission of monetary policy? Carnegie-Rochester Conference Series on Public Policy, 39, 1-46.

Ramlogan, C. (2004). The transmission mechanism of monetary policy: Evidence from the Caribbean. Journal of Economic Studies, 34, 435-447.

Reserve Bank of Fiji (RBF) (2007a). RBF Annual Report and Accounts 2006, Suva: RBF.

Reserve Bank of Fiji (RBF) (2007b). The Monetary Policy Transmission Mechanism. [Online] Available: www.rbf.gov.fj (August 19, 2007).

Reserve Bank of Fiji (RBF) (2007c). Monetary Policy Statement May 2007, Suva: RBF.

Reserve Bank of Fiji (RBF) (2007d). Quarterly Review June 2007, Suva: RBF.

Romer, C. and Romer, D. (1990). New evidence on the monetary transmission mechanism. Brookings Papers on Economic Activity, 1, 149-198.

Sims, C. (1980). Macroeconomics and reality. Econometrica, 48, 1-48.

Sims, C. (1992). Interpreting the macroeconomic time series fact: The facts of monetary policy. European Economic Review, 36, 975-101.

Taylor, J.B. (1995). The monetary transmission mechanism: an empirical framework. Journal of Economic Perspectives, 9(Fall), 11-26.

UNESCAP (2007). Social and Economic Survey of Asia and Pacific, 2004. Bangkok: UNESCAP. 
Waqabaca, C. (2000). Financial sector development and reform in Fiji. Working Paper No 00/05, Suva: Reserve Bank of Fiji

Waqabaca, C. and Morling, S. (1999). The conduct of monetary policy in Fiji. Working Paper No99/01, Suva: Reserve Bank of Fiji.

Worrell, D. (2000). Monetary and fiscal coordination in small open economies. Working Paper WP/00/56, Washington, D.C.: IMF.

Notes

Note 1. These are: Australian and New Zealand Banking Group Limited (ANZ), Westpac Banking Corporation (Westpac), Bank of Baroda (BOB), Colonial National Bank and Bank of South Pacific.

Note 2. LCIs include Merchant Finance Investment Company Limited, Credit Corporation (Fiji) Limited and Home Finance Company Limited.

Table 1. Fiji: General key indicators

\begin{tabular}{|l|r|}
\hline Surface Area (sq km) & 18,270 \\
\hline Population (2005) & 835,000 \\
\hline Total GDP at current prices (US \$ million) 2002 & 1,750 \\
\hline Per capita GDP in current price (US\$) & 2,360 \\
\hline Human Development Index (Rank) 2002 & 81 \\
\hline Aid per capita (US\$) 2002 & 41 \\
\hline Aid per capita (\% of GDP) 2002 & 1.8 \\
\hline Openness:(\% of Export \& Imports of GDP) 2005 & 88 \\
\hline
\end{tabular}

Source: ADB (2007), UNESCAP (2007)

Table 2. Growth rates and monetary statistics in Fiji

\begin{tabular}{|l|c|c|c|c|c|c|c|c|c|}
\hline & $\begin{array}{c}\text { Growth } \\
\text { Rate } \\
\text { (\%) }\end{array}$ & $\begin{array}{c}\text { M1 } \\
\text { (F\$ } \\
\text { Million) }\end{array}$ & $\begin{array}{c}\text { M2 } \\
\text { (F\$ }\end{array}$ & $\begin{array}{c}\text { M1 } \\
\text { Mo of } \\
\text { GDP) }\end{array}$ & $\begin{array}{c}\text { M2 } \\
\text { (\%o of } \\
\text { GDP) }\end{array}$ & $\begin{array}{c}\text { RBF } \\
\text { (Index) }\end{array}$ & $\begin{array}{c}\text { Money } \\
\text { Indicator } \\
\text { Rate } \\
\mathbf{( \% )}\end{array}$ & $\begin{array}{c}\text { Nominal } \\
\text { Market } \\
\text { Rate } \\
\text { (\%) }\end{array}$ & $\begin{array}{c}\text { Exchange } \\
\text { Rate } \\
\text { (Index) }\end{array}$ \\
\hline $\begin{array}{l}\mathbf{1 9 8 5 - 1 9 8 9} \\
\text { (Average) }\end{array}$ & 0.4 & 276.0 & 810.0 & 15.7 & 46.2 & 57.4 & NA & 5.2 & 139.6 \\
\hline $\begin{array}{l}\mathbf{1 9 9 0 - 1 9 9 4} \\
\text { (Average) }\end{array}$ & 2.9 & 331.4 & 1274.0 & 14.4 & 55.2 & 84.3 & NA & 3.4 & 117.3 \\
\hline $\begin{array}{l}\mathbf{1 9 9 5 - 1 9 9 9} \\
\text { (Average) }\end{array}$ & 2.8 & 500.4 & 1454.2 & 15.6 & 46.2 & 98.8 & 2.10 & 2.2 & 111.7 \\
\hline $\mathbf{2 0 0 0}$ & -1.7 & 593.7 & 1513.8 & 16.5 & 42.2 & 100.0 & 2.30 & 1.0 & 100.0 \\
\hline $\mathbf{2 0 0 1}$ & 2.0 & 620.9 & 1467.8 & 16.4 & 38.8 & 102.3 & 1.25 & 1.0 & 99.4 \\
\hline $\mathbf{2 0 0 2}$ & 3.2 & 712.0 & 1583.0 & 17.7 & 39.3 & 106.0 & 1.25 & 0.9 & 101.1 \\
\hline $\mathbf{2 0 0 3}$ & 1.1 & 900.6 & 1980.4 & 20.6 & 45.2 & 109.6 & 1.19 & 0.9 & 106.0 \\
\hline $\mathbf{2 0 0 4}$ & 5.3 & 1018.0 & 1926.0 & 21.5 & 40.7 & 113.2 & 1.75 & 0.9 & 107.8 \\
\hline $\mathbf{2 0 0 5}$ & 0.7 & 1197.0 & 2241.0 & 23.6 & 44.2 & 115.7 & 2.25 & 2.1 & 107.7 \\
\hline $\mathbf{2 0 0 6}$ & 2.0 & 1142.4 & 3012.8 & 21.3 & 44.2 & 118.8 & 4.25 & 5.3 & 105.9 \\
\hline
\end{tabular}

Sources: Government of Fiji (2006); ADB (2007); IMF (2007)

Authors' calculations. 
Table 3. Unit root tests

\begin{tabular}{|l|c|c|c|c|}
\hline \multirow{2}{*}{ Variable } & \multicolumn{2}{|c|}{ ADF Test } & \multicolumn{2}{c|}{ Ng and Perron MZ Test } \\
\cline { 2 - 5 } & $\begin{array}{c}\text { Level (Constant } \\
\text { with Trend) }\end{array}$ & $\begin{array}{c}\text { First Difference } \\
\text { (Constant } \\
\text { without Trend) }\end{array}$ & $\begin{array}{c}\text { Level (Constant } \\
\text { with Trend) }\end{array}$ & $\begin{array}{c}\text { First Difference } \\
\text { (Constant } \\
\text { without Trend) }\end{array}$ \\
\hline PIR & $-1.38(0)$ & $-5.83^{* *}(1)$ & $-7.28(0)$ & $-42.57 * *(1)$ \\
\hline CRE & $2.96(0)$ & $-4.58^{* *}(0)$ & $-2.22(1)$ & $-25.11^{* *}(1)$ \\
\hline M2 & $2.25(1)$ & $-4.66^{* *}(0)$ & $1.01(0)$ & $-46.34^{* *}(0)$ \\
\hline E & $-1.93(0)$ & $-8.22^{* *}(0)$ & $-7.11(0)$ & $-33.98^{* *}(0)$ \\
\hline RGDP & $-0.25(10)$ & $-2.97 * *(0)$ & $0.28(10)$ & $-36.32^{* *}(1)$ \\
\hline P & $-3.14(3)$ & $-7.49^{* *}(1)$ & $-15.18(0)$ & $-61.76^{* *}(1)$ \\
\hline
\end{tabular}

Notes: The ADF critical value at 5\% level is -2.9640 and -3.5629 for constant without trend and constant with trend regressions, respectively. These critical values are based on Mckinnon. The optimal lag is selected on the basis of Akaike Information Criterion (AIC). The Ng and Perron critical value is based on $\mathrm{Ng}$ and Perron (2001) critical value and the optimal lag is selected based on Spectral GLS-detrended AR based on SIC. The null hypothesis of the test is: a series has a unit root. The asterisk ** denotes the rejection of the null hypothesis at the 5\% level of significance. The figures in brackets denote number of lags.

Table 4. Results of Johansen and Juselius Multivariate Procedure (VAR with 2 lags)

\begin{tabular}{|c|c|c|c|c|}
\hline \multicolumn{5}{|c|}{$\begin{array}{l}\text { Variables: RGDP M2 CRE E PIR P } \\
\text { Sample Period: 1990Q1-2006Q4 (68 observations) }\end{array}$} \\
\hline \multirow[t]{2}{*}{ Hypothesis } & \multicolumn{2}{|c|}{ Maximum Eigenvalue } & \multicolumn{2}{|c|}{ Trace } \\
\hline & Test Statistic & $95 \%$ & Test Statistic & $95 \%$ \\
\hline $\mathrm{P}=0$ & $56.47 * *$ & 44.50 & $152.21 * *$ & 117.71 \\
\hline $\mathrm{P} \leq 1$ & 37.71 & 38.33 & $95.73 * *$ & 88.80 \\
\hline $\mathrm{P} \leq 2$ & 28.41 & 32.12 & 58.02 & 63.88 \\
\hline $\mathrm{P} \leq 3$ & 16.78 & 25.82 & 29.61 & 42.92 \\
\hline $\mathrm{P} \leq 4$ & 9.34 & 19.39 & 12.83 & 25.87 \\
\hline $\mathrm{P} \leq 5$ & 3.49 & 12.52 & 3.49 & 12.52 \\
\hline \multicolumn{5}{|c|}{ Diagnostic Checking } \\
\hline \multicolumn{5}{|c|}{ VAR Residual Serial Correlation LM Tests } \\
\hline Lags & \multicolumn{2}{|c|}{ LM-Stat } & & \\
\hline 3 & \multicolumn{2}{|c|}{$32.39[0.6408]$} & & \\
\hline 4 & \multicolumn{2}{|c|}{$46.32[0.1163]$} & & \\
\hline 5 & \multicolumn{2}{|c|}{$23.07[0.9530]$} & & \\
\hline
\end{tabular}

Notes: ** indicates significant at 5 per cent level.

VAR specification: lag-length 1.

Critical values of trace and maximum eigenvalue according to Osterwald-Lenum (1992).

Values in brackets are probability value of the test statistics.

Jarque-Bera test, null hypothesis: normal residuals, Breusch-Godfrey Serial Correlation LM Tests, null hypothesis: no autocorrelation. 
Table 5. Variance Decomposition of Log Output (RGDP)

\begin{tabular}{|c|c|c|c|c|c|c|c|}
\hline $\begin{array}{c}\text { Quarters } \\
\text { ahead }\end{array}$ & S.E. & PIR & M2 & CRE & E & P & RGDP \\
\hline 1 & 0.6723 & 2.6143 & 7.2991 & 0.0594 & 2.4554 & 0.0000 & 87.5718 \\
\hline 4 & 7.0035 & 1.3608 & 45.5884 & 3.7260 & 3.4078 & 11.3062 & 34.6107 \\
\hline 8 & 16.7886 & 4.7353 & 73.9038 & 2.1336 & 1.9747 & 8.1981 & 9.0545 \\
\hline 12 & 18.1584 & 6.5936 & 68.4588 & 2.4461 & 3.8545 & 7.1396 & 11.5075 \\
\hline 16 & 23.5872 & 7.2570 & 67.2580 & 2.2019 & 2.3275 & 11.4065 & 9.5492 \\
\hline 20 & 32.6488 & 5.0245 & 73.9577 & 2.1902 & 2.6506 & 9.7437 & 6.4334 \\
\hline 24 & 37.1978 & 7.7880 & 65.7485 & 3.3002 & 4.9341 & 12.7793 & 5.4499 \\
\hline 28 & 41.5988 & 7.8691 & 62.5871 & 2.8430 & 4.9051 & 16.5480 & 5.2477 \\
\hline
\end{tabular}

Cholesky Ordering: PIR CRE M2 E RGDP P

Table 6. Variance Decomposition of Price (P)

\begin{tabular}{|c|c|c|c|c|c|c|c|}
\hline $\begin{array}{c}\text { Quarters } \\
\text { ahead }\end{array}$ & S.E. & PIR & M2 & CRE & E & P & RGDP \\
\hline 1 & 0.8844 & 15.0286 & 12.7376 & 0.9480 & 0.1704 & 69.4644 & 1.6510 \\
\hline 4 & 1.3955 & 13.0018 & 31.1558 & 2.2386 & 5.2596 & 47.1677 & 1.1765 \\
\hline 8 & 1.7212 & 12.5798 & 36.3445 & 4.4307 & 7.5775 & 37.8232 & 1.2443 \\
\hline 12 & 1.9556 & 13.9073 & 31.6278 & 4.6123 & 7.7383 & 37.1247 & 4.9895 \\
\hline 16 & 2.4169 & 10.3144 & 38.2205 & 4.0009 & 5.1654 & 34.1175 & 8.1814 \\
\hline 20 & 2.5440 & 11.7999 & 38.9824 & 4.0222 & 5.1048 & 32.5929 & 7.4978 \\
\hline 24 & 2.7592 & 11.8518 & 41.5544 & 3.9850 & 7.1328 & 28.5335 & 6.9425 \\
\hline 28 & 3.0252 & 17.2349 & 35.7977 & 5.7352 & 9.5568 & 25.7190 & 5.9564 \\
\hline
\end{tabular}

Cholesky Ordering: PIR CRE M2 E RGDP P

Table 7. Correlation matrix of reduced-form residuals

\begin{tabular}{|l|llllll|}
\hline & RGDP & M2 & CRE & PIR & E & P \\
\hline RGDP & 1 & 0.0758 & -0.1263 & 0.0635 & -0.0333 & 0.1984 \\
M2 & & 1 & 0.0994 & -0.1540 & 0.0521 & -0.0811 \\
CRE & & & 1 & 0.2236 & -0.0717 & 0.0190 \\
PIR & & & & 1 & 0.0044 & -0.2676 \\
E & & & & & 1 & -0.3167 \\
P & & & & & & 1 \\
\hline
\end{tabular}




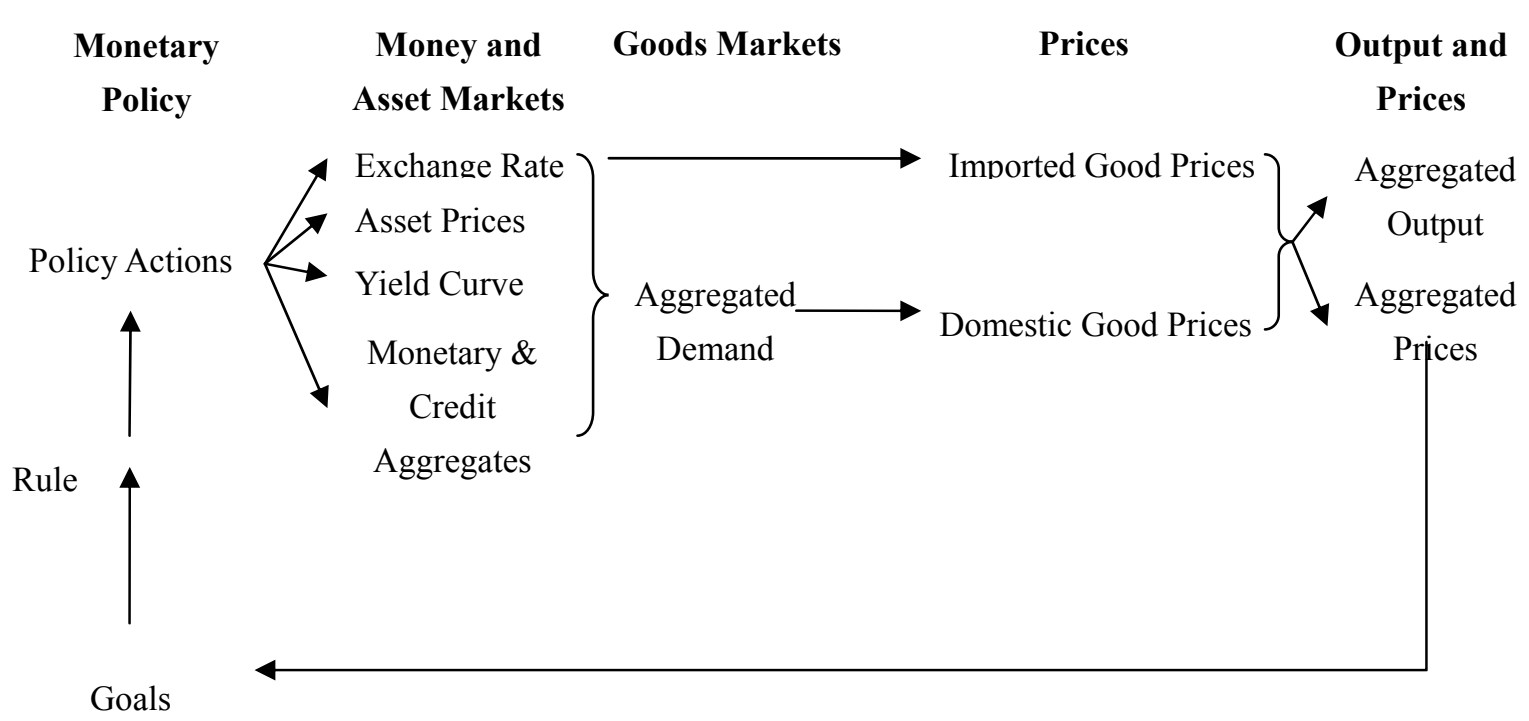

Source: IMF (2004)

Figure 1. Stylized representation of the channels of transmission

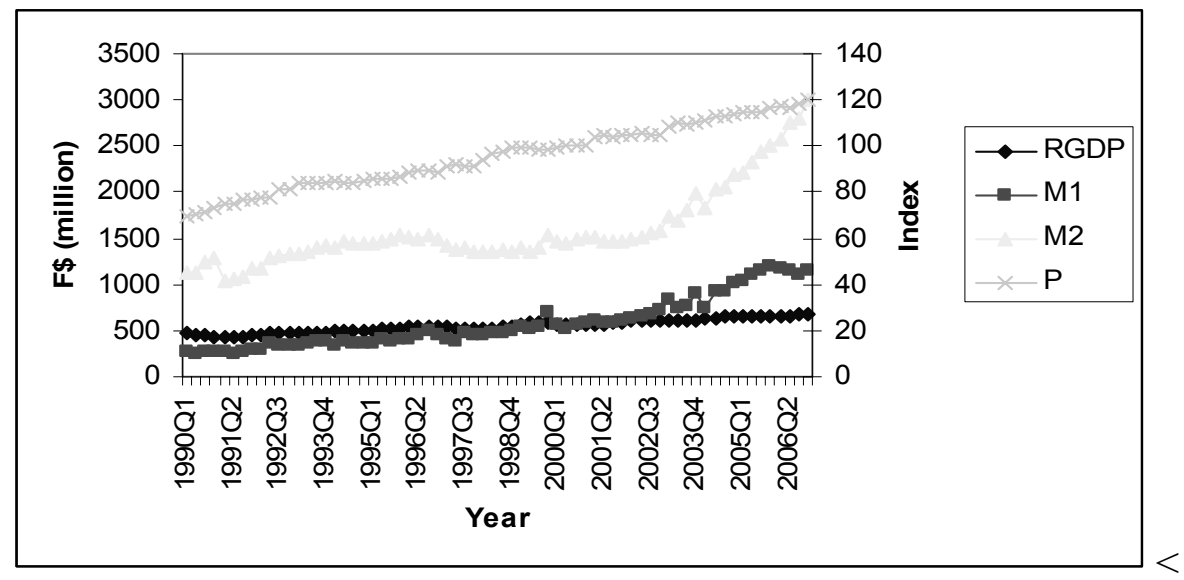

Figure 2. Graph of Movements in M1, M2, P and RGDP

Source: International Monetary Fund, International Financial Statistics, various issues. 
Response to Cholesky One S.D. Innovations \pm 2 S.E.
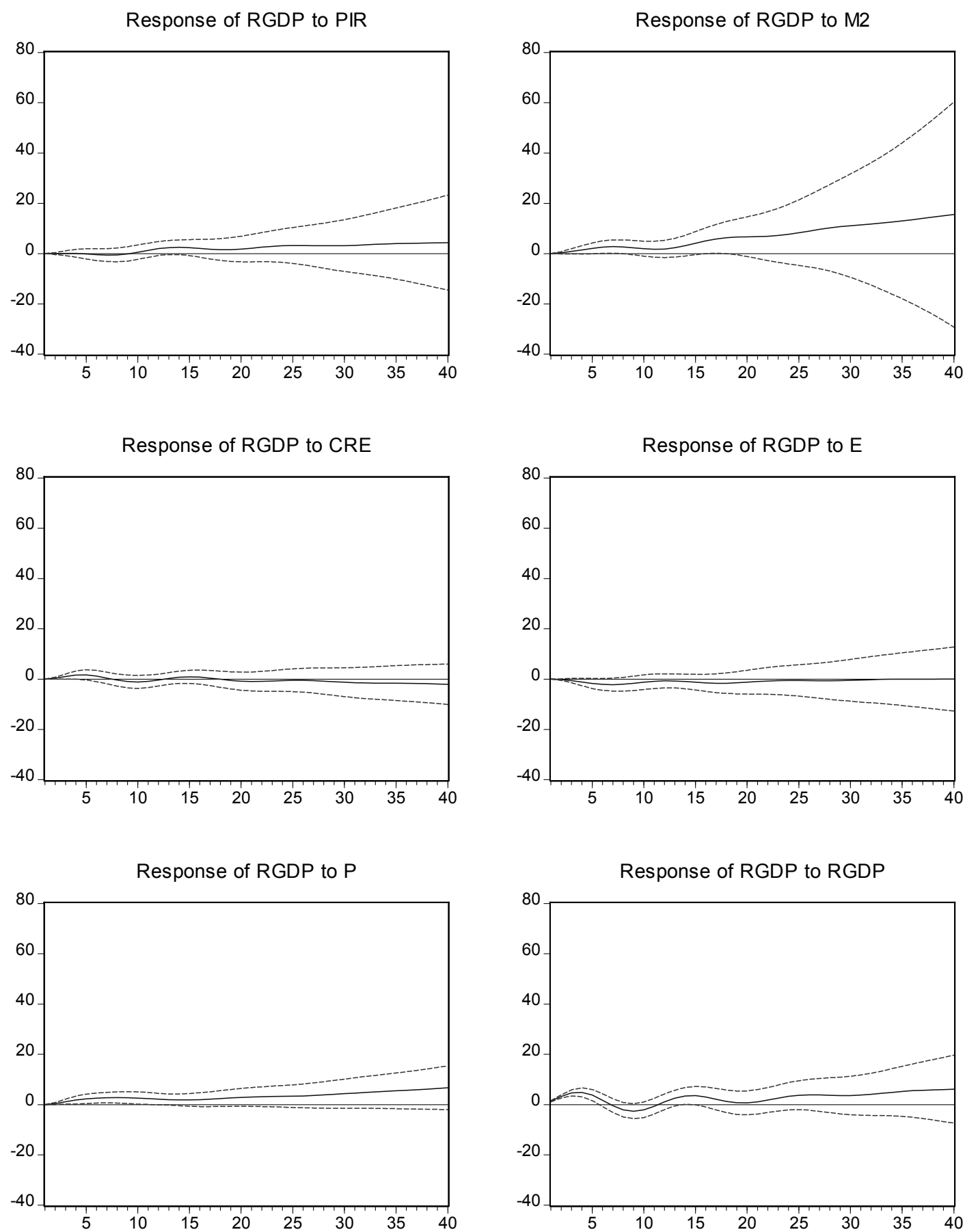

Figure 3. Response of log Output (RGDP) in Fiji 
Response to Cholesky One S.D. Innovations \pm 2 S.E.

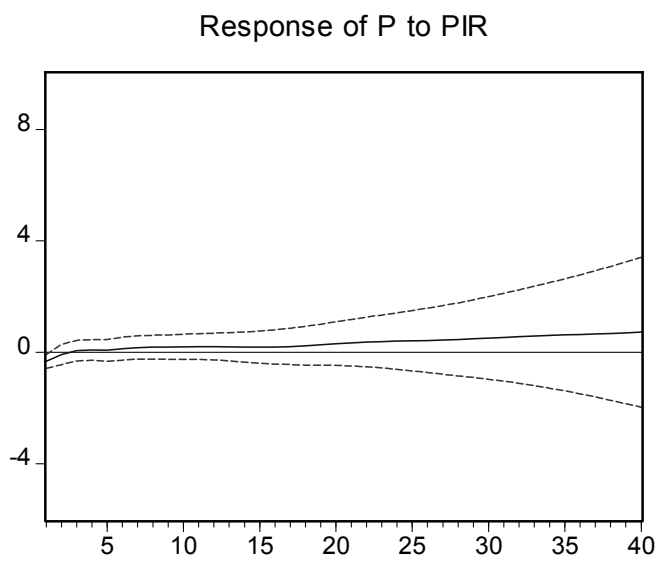

Response of $\mathrm{P}$ to $\mathrm{M} 2$

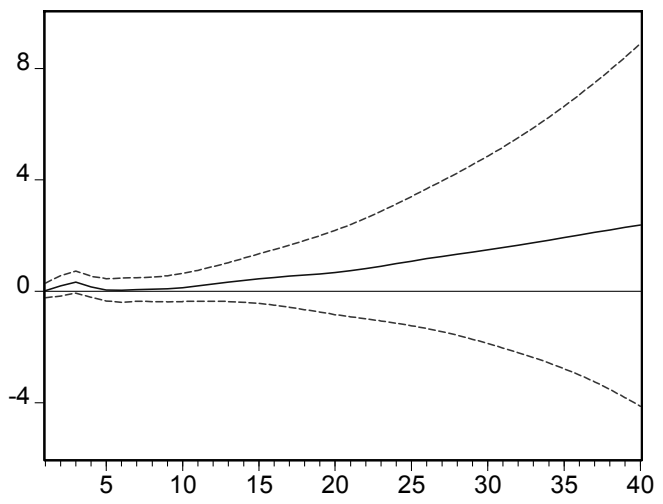

Response of $\mathrm{P}$ to $\mathrm{CRE}$

Response of $P$ to $E$
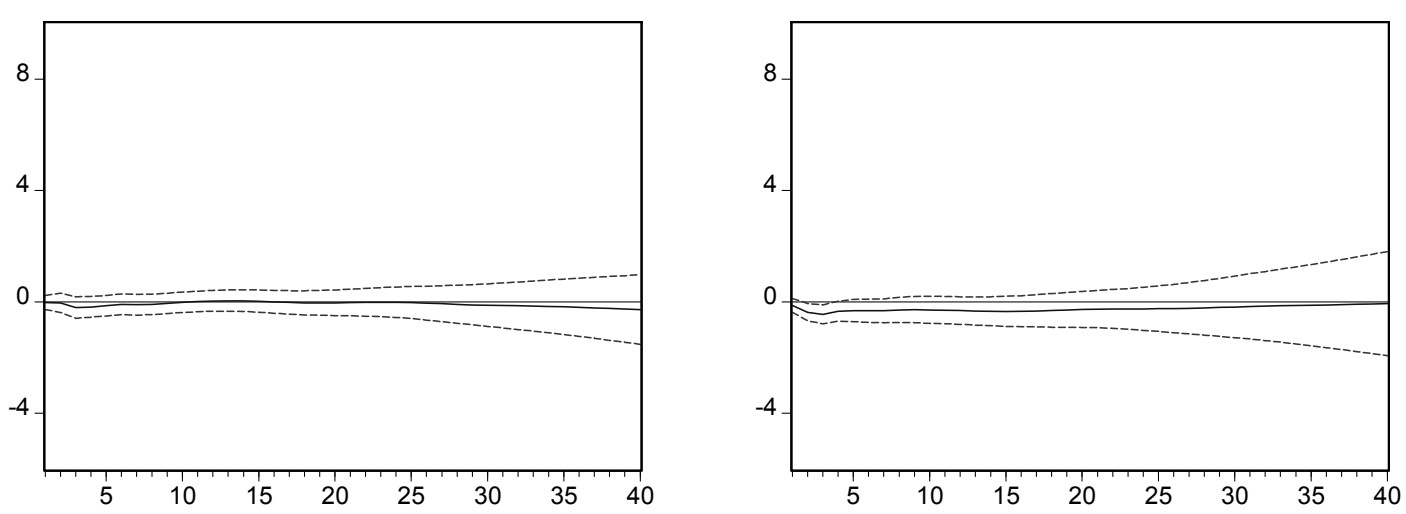

Response of $\mathrm{P}$ to $\mathrm{P}$

Response of $\mathrm{P}$ to RGDP
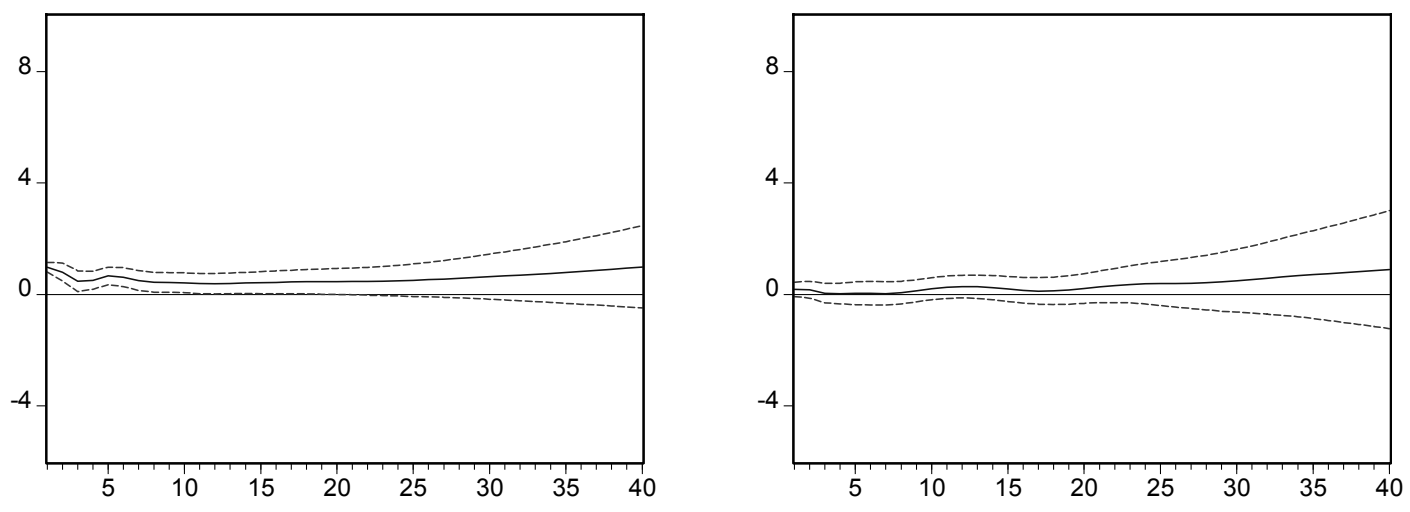

Figure 4. Response of Price (P) in Fiji 


\title{
Mechanism Demand and Optimizing Research \\ Of Entrepreneur Professionalism
}

\author{
Huiyuan Mao \\ School of Business and Administration, Northeastern University, Shenyang 110004, China \\ Shenyang University, Liaoning 110004, China
}

Tel: 86-24-2389-4862Ｅ-mail: maohuiyuan2004@126.com

Xinliang Zhao

School of Business and Administration, Northeastern University, Shenyang 110004, China

Zeping Wang

Neusoft Group Cor. Ltd., 110179, China

Fund Item: This paper is Liaoning Province Science department item: Result of Leader officer, Enterprise talent quality evaluation mechanism research and system develop research.(2005401012)

\begin{abstract}
With the advanced development of modern economy, more and more countries recognize economy progress is connected with human resource capital closely, especially the usage of entrepreneur human resource capital. How to increase entrepreneur quality; establish entrepreneur occupational operating mechanism is the most impendency task which our country's enterprise is encountering. This paper provides existent mechanism deficiency of entrepreneur professionalism, provides that we should be provided with two thoughts of "strategy" and "tactics" mechanism optimizing for promoting entrepreneur occupational grow-up.
\end{abstract}

Keywords: Entrepreneur, Occupation, Mechanism Demand, Optimizing

Entrepreneur is the soul of modern enterprise, is the scarce capital in the company. The most important way is the occupation of the entrepreneur in constructing modern enterprise institutes. However, although entrepreneur professionalism have been put forward for many years in our country, it gets along very slowly in the course of operation, moreover, it can't be put into practice. (Liu \& Ling, 2004, PP.90-91) With the advanced development of modern economy, more and more countries recognize economy progress is connected with human resource capital closely, especially the usage of entrepreneur human resource capital. How to increase entrepreneur quality; establish entrepreneur occupational operating mechanism is the most impendency task which our country's enterprise is encountering.

\section{Mechanism demand of Entrepreneur Professionalism}

Ownership entrepreneur "politicalize" attribute blocks the development of entrepreneur professionalism. The key is to determine the mechanism demand of entrepreneur professionalism grow-up to change the block state of entrepreneur professionalism course.

\subsection{Forming Mechanism of Entrepreneur}

The ultimately result of entrepreneur professionalism grow-up is emerge of entrepreneur stage. Inner or exterior mechanism which can promote this consequence to emerge will show the forming mechanism of entrepreneur. Commonly, the design of forming mechanism of entrepreneur in a social system should contain position mechanism of entrepreneur role, value orientation mechanism and superior or inferior mechanism etc.

Firstly, with regard to role position mechanism. In our country, entrepreneur role position appears at loose ends and self-paradox status, in the first place, ownership entrepreneur operating target multi-level, namely, political, economical, also social and cultural, this makes entrepreneur role position appear multi-fission, sometimes suffer pains of inner heart "spirit fission" as role play. In the other hand, Let entrepreneur liberate from the multi-role of "politician", "charitarian" and "culturalism", resume its original face and role status, make it can be deep in enterprise operating management 
work, play a good part in "entrepreneur" occupational role.

Secondly, with regard to value orientation mechanism. As ownership enterprise political economy compound quality, not less entrepreneur occupation orientation still is reluctant to leave the official career preferment, which makes some entrepreneur take operating management enterprise as springboard at the beginning, but the ultimate goal is to come true more higher stage official position so called "shock leap". Therefore, it must be reformed of entrepreneur identity connection with administration level, traditional way of officer interchange position with entrepreneur, implementing position classified management, promoting entrepreneur to walk up occupational and professionalism development way.

Thirdly, with regard to survival of the fittest. Entrepreneur professionalism need entrepreneur identification and hold for self-occupation, but can't understand this problem one side. If an entrepreneur oneself is lack of talent and potentiality, in another word, he can't become entrepreneur or excellent entrepreneur in any case, and want to hold his ground and to walk up occupational road, that just only so called no "sacrifice": in the first place, he wastes his life and the talent in other aspect, in the other hand, he also waste social wealth as configuring social resource costly, works social welfare loss. Inducting superior or inferior mechanism, makes superior person can gain position reward, and inferior person can gain ruthless elimination as well.

\subsection{Protecting mechanism of entrepreneur}

Protecting mechanism of entrepreneur occupational grow-up is a system arrangement given safeguard or relieve for entrepreneur right and status. Protecting mechanism is a cushion or release for entrepreneur occupational risk, which is good at ensuring common occupational living demand of entrepreneur. In our country, correspondent law and regulation are not sound or complete, especially in a certain extent, ignore right suit of entrepreneur occupational grow-up, can't play an strongly part in supporting entrepreneur occupational grow-up. This point is standing out in earlier ownership enterprise. A survey shows that, threatened or injured entrepreneur in position work is high up to 50.9\%, almost of them, threatened or injured entrepreneur over three times is $28.6 \%$, furthermore, ownership entrepreneur manager (factory director or manager) is $53.5 \%$ and $29.9 \%$ respectively. (Wu, 2003)

\subsection{Encouragement and restriction mechanism of entrepreneur}

Entrepreneur pursues profit by right of entrepreneur talent and distinct innovative spirit in market economy wind-door and wave-fine, and pays more courage and energy in enterprise operation and management that ordinary person can't imagine, undertakes enormous responsibility and venture. Therefore, correspondent with high investment and high venture, naturally entrepreneur may require a high return. This special request can't simply be looked as satisfaction of entrepreneur for creature comfort and wealth capture, in more extent, it becomes an urge to promote entrepreneur continual enterprising and be brave in innovation, becomes a tempt choice of entrepreneur professionalism. Therefore, in order to make ownership entrepreneur occupational grow-up, we should provide and hold might encourage headspring in the aspect of economic status and benefit.

In the same time of establishing encouragement mechanism, we must construct constrained mechanism for entrepreneur in-phase. Encouragement mechanism and restriction mechanism is to supplement each other, we can call encouragement-restriction mechanism. According to trust-agency theory, even if ownership entrepreneur is provided with pretty encouragement mechanism, entrepreneur behavior may still departure owner's benefit. Even as Sarmuerson's analysis: one is the power person may be determined by vote, give themselves or their relative rich and generous salaries, public expenditure, bonus and high pension. All of them will harm shareholder's benefit; the other one is all enterprise managers would like to make their enterprise increase and prolong, although it may be better method if this capital is invested into other company or shareholder's consuming." Therefore, entrepreneur must be get corresponding Conditioning, did not restrict between power will bring about corruption.

Therefore, forming mechanism, protecting mechanism, encouraging and restricting mechanism jointly constitute mechanism system of entrepreneur occupational grow-up, they are reciprocity and depending on one another, we must plan as a whole in designing mechanism mutually, can't divide up artificially.

\section{Existent mechanism deficiency of entrepreneur professionalism}

As reformation and development of ownership enterprise about 30 years, the work of entrepreneur professionalism has acquired some progress, but viewed as a whole, entrepreneur occupational grow-up mechanism hasn't been sounded, still exists obvious mechanism deficiency, there are several aspects mainly as below:

\subsection{Forming mechanism no marketing.}

Entrepreneur grow-up need a correspondent entrepreneur forming mechanism with market economical development, all reflect the request of market economy character in the aspect of role position, value orientation and superior or inferior. Coming by reformation openly practice near 30 years, our country has established socialism market economy system, but entrepreneur forming mechanism which entrepreneur occupational grow-up need hasn't transformed from the 
forming mechanism of by past administration dominating to forming mechanism of modern market dominating. In the first place, it intensively shows that society affinity for the role of entrepreneur is not high, even if social visualization is the worst in some aspects, value orientation is disadvantage for entrepreneur occupational grow-up. In another place, superior or inferior mechanism of entrepreneur hasn't founded yet recently, most entrepreneurs still acquire position by "organization appointment".

\subsection{Protection mechanism no legalization.}

Protection mechanism provides basic space for entrepreneur to do great things and maintain social surviving, which is very meaningful for entrepreneur occupational grow-up, but. at present entrepreneur otherwise is "shelter" which is not enjoying protection mechanism, or this protection mechanism mostly is provided specially by superior leader or correlation department, these protection mechanism is not legalized, not forming seriousness and authority of power and social status protection of entrepreneur. Furthermore, many places even if take much count of the assignment of entrepreneur protection mechanism, but sometimes is "short view", which emphasize the protection of current period or short period benefit, and that not correspond positively to the long period benefit suit of entrepreneur.

\subsection{Encouragement-restriction mechanism no standardization and scientific.}

At present, it is a great step to emphasize the problem of the construction of entrepreneur encouragement mechanism in reformation of ownership enterprise, which is comparable with past days, but, encouragement mechanism assignment hasn't presented the request of scientific and rationality, shows mainly: one is that there is asymmetry for encouragement-restriction of entrepreneur, otherwise emphasizes encouragement unilaterally, or emphasizes restriction unilaterally, not makes encouragement and restriction mechanism as a whole, brings out the best in each other; the another one is that content construction and period construction of encouragement is not rational; the third one is that the styles of restriction are multiplicity, but efficiency is not high, inner or outer mechanism of restriction can't harmonize each other, random of restriction measurement is greater, which is lack of law and regulation etc. Therefore, encouragement-restriction mechanism of entrepreneur is not regulation and institution, exists a large of leakage, which brings about the falling off horse of entrepreneur with "former fall forward and subsequence".

\section{Optimizing mechanism of entrepreneur occupation}

For promoting entrepreneur occupational grow-up, we must grasp mechanism optimizing work, in conducting optimizing for entrepreneur occupational grow-up mechanism, we should be provided with two thoughts of "strategy" and " tactics" mechanism optimizing.

\subsection{Mechanism optimizing of strategy level}

Mechanism optimizing of strategy level, is that a series of mighty things on entrepreneur occupational grow-up should be planned as a whole, recognizes and deals with different relationship exactly, forms the whole mechanism design of entrepreneur occupational grow-up and optimizing whole conception and thought. This is a mutual relationship problem on occupation, market and institution of entrepreneur. No clear position for this three relationship, only talking about occupation by occupation or promoting occupation wholly by occupation are not effect in fact, must establish "union operation mechanism" of occupation, market and institution in mechanism designing, grasp and optimize entrepreneur occupational grow-up mechanism as a whole. Establishing an excellent entrepreneur group, must conduct on the basis of market economy. This demands entrepreneur grow-up should be provided with the basis of market, in another word, only grow-up on the basis of market mechanism.

\subsection{Mechanism optimizing of tactics}

Mechanism optimizing of tactics, (Yang \& Ye,2005) refer to the micro-operation thought and change and innovation on entrepreneur occupational grow-up mechanism, mainly in relation to amending and forming mechanism, protection mechanism and encouragement-restriction mechanism of entrepreneur occupation.

Firstly, optimizing forming mechanism of entrepreneur occupation is with the breakthrough of the reformation of entrepreneur choice appointment mechanism. Great and middle ownership enterprise managers represent the direction of the reformation of human resource system of ownership enterprise in public inviting application for a job of inner or outer of our country, must hold the line. In operating details we must take notice of, although public choice pattern of entrepreneur comes about single organization appointment which shows more market and democracy, but in conducting of public choice mechanism, emerges "examination group", these talents have strong management theory ability, but may be lack of the practice experience of management enterprise. Especially the highest manager of entrepreneur in position namely "first hand" choice directly relates the future development orientation of the whole enterprise.

Secondly, constitution and implementation of speciality law and regulation as a measurement to optimize protection mechanism of entrepreneur occupation. Particularity and complexity of entrepreneur work haven't gain the extensive identification and understanding, some phenomenon of disrespective entrepreneur and violating legal right at will are still very severe in some region. By far, our country hasn't a national level special law and regulation to protect the right 
and interest of enterprise manager containing entrepreneur, this can't ever say a great pity. Suggesting that our country should come on quickly, implements right and interest protection law of entrepreneur, provide necessary protection mechanism for our country's entrepreneur occupational grow-up.

Finally, prior thing is optimizing principle and concrete thought in encouragement and restriction construction, taking encouragement-restriction mechanism construction as focus.

\section{References}

Liu, Change, Ling, Wenquan. (2004). Influence analysis of entrepreneur occupation.Enterprise Economy, (12):90-91.

Wu, Kaisheng. (2003). Establishing Chinese entrepreneur institution. Management Modernization, (3).

Yan, Yonghai, Huang, Yuanyou. (2004). Quicken the research of the course of enterprise manager occupation. Anhui Industrial University Transaction, (12),60-62.

Yang, Chaoren, Ye, Yuanxi. (2005). Enterprise institution innovation and entrepreneur occupation. Haitian Press. 


\title{
The Research on the Independent College
}

\section{Teachers Configuration Model}

\author{
Xiaobai Lv \\ Department of Management, Wuhan University of Science and Technology, Wuhan 430083, China
}

Tel: 86-27-8649-0789Ｅ-mail: lvxiaobai@126.com

\begin{abstract}
All along, the Ministry of Education in China requires colleges and universities allocating teachers and lecturers according to the number of students in the campus, and gives the unified standard, which is delivered after considering teaching and research universities-double functions and assumption of teachers have teaching and scientific research works. Independent Institute appears in the last few years, which is a brand new organization. Although it is an integral part of China's higher education, it is a single function of teaching and training with characters of training the students to the Multi-skill talents, and this character determine its teachers should be configured to meet the requirements of the principle of teaching. It is different from original features of Universities in China. This paper contents truths analysis of Universities in Hubei Province and gives new ideas on teacher allocation.
\end{abstract}

Keywords: Independent colleges, Teachers, Configuration model

China's independent Institute is a new type of institutions of higher learning founded by public institutions of higher learning and non-governmental organizations or individuals cooperation. It is unlike the State of direct investment in the construction and management of public institutions of higher learning (short as "Public Universities" as follow). According to the Ministry of Education announced early in April 2007 of the National Independent Colleges latest statistics, as of the date of publication, number of Independent National Institutes is 318 within 543,000 new students in 2006. Totally, this number in independent colleges in China at present has reached 1.467 million people. In a short period of years, the development of independent college extraordinary speeds.

Almost all the independent colleges at the beginning rely on original university- Independent College and the organizer of the public institutions of higher learning around the human resources to solve its staffing problems, as the independent Institute of Teaching in the short term security operation played a key role. Along with the popularization of China's higher education forward, the initial use of the original University human resources has become increasingly unable to meet the needs of the development. To consider the future development of independent colleges must create their own workforce particularly teachers. It has become increasingly important and urgent independent colleges' work.

Author leadership of the "Hubei Independent Colleges allocation of human resources" has been on the preliminary results. Accordingly, I would like to share and participate to explore China's independent college teachers configuration related issues after recent two years research.

\section{INDEPENDENT COLLEGE STUDENT STATUS AND TRAINING OBJECTIVES}

Independent College' student resource is from the third batch of entrance examination for admission. Through investigation, the independent student enrolment in China results in a lowest level. Interest in study of theory is low, lacking of learning dynamic phenomenon. Survey selected in a study in the Independent Institute found that $82.86 \%$ students are in good health condition. It formed a striking contrast to widespread psychological problems, and by a factor of eight on the psychological state of the research project, all factors considered under absolutely no question of the total number of students the highest proportion of only 76.45 percent, the lowest for 37.04 percent. The above data indicate that an independent college student's physical condition is not bad, and ability to adapt to new learning environment, but the psychological situation is worrying. In order to adapt to the characteristics of independent college students, almost without exception, established by the independent Institute of Applied talent is to nurture the direction of the school, students tried to strengthen the operational capacity of the training, to enhance the interest of students in learning at the same time avoiding the basic knowledge of which is not firm, and the lack of dynamic learning deficiencies, so as to achieve training to meet the needs of the community of the purpose of cultivating talents.

Application training personnel need to be clear three issues: first, what kind of application-type personnel the community needs; second, whether students have applied to become professionals; third, what kind of teachers. This paper is concerned 
about how effective allocation of teachers to meet the training of qualified personnel on the application of the requirements of teachers.

\section{INDEPENDENT COLLEGES AND THE STATE OF THE EXISTING CHARACTERISTICS OF A TEACHER}

Through the Group of Hubei Province (mainly in Wuhan City) for twelve representative surveys that independent colleges: Those surveyed were independent colleges have their own full-time teachers, full-time teachers are very similar age structure, following the 30-year-old young teachers of the total number of teachers in more than half of nearly 60 -year-old and 60 -year-old teacher about the above accounted for more than 20 per cent, independent colleges more than 30 percent, while 35 to 55 -year-old teacher less than 5\%. Teachers' imbalance in the ratio of men to women is also very prominent, especially in the youth under 30 years of female teachers in more than $60 \%$. Independent College teachers' age, sex structure of the apparent defects can't be ignored.

In the Group of Independent Colleges survey, young people under the age of 35 teachers in the master's degree in the proportion of over 50 per cent. In-depth analysis of the past few years graduation in the knowledge structure of postgraduate found that due to the guidance of graduate entrance exam subjects, almost all graduate students would like to read to enter college in the beginning stages of establishing a postgraduate examination subjects as the main objectives of the study and study direction Other courses of study merely to "just pass" to the level of professional knowledge structure in the "shortcomings" in the phenomenon are more popular among graduate students. Especially that graduation is just as professional teaching young teachers, more deadly practice is the lack of professional experience and ability, professional ability structure there are obvious flaws.

In order to achieve the independent Institute of the sponsoring the request of Chinese Ministry of Education assessment indicators a group of independent colleges to introduce more than 60-year-old retired public college professors, associate professors. Although teaching in independent colleges, many teachers still use in the past in public colleges and universities teaching ideas and methods. Then independent college students and teachers in the teaching process are feeling not comfortable. Although teachers in the independent colleges in the percentage of teachers in the $20 \%$ to $30 \%$, they bear a considerable number of tasks in particular professional teaching core curriculum teachings, the impact on student learning and teaching youth to the exemplary role of can not be ignored. There is a concept of education, teaching methods and expertise adjustment.

\section{INDEPENDENT COLLEGE TEACHER CONFIGURATION MODEL}

Independent College configuration teachers must consider two questions: where are those teachers? How to hire right teachers? The former is the direction of the allocation issue, while the latter is the level of configuration issues. Through research team found that, since the Independent College tuition is the only source of funds for schools, coupled with an independent institutes for training personnel of the direction of the school, the teachers of Independent Colleges with market direction and the allocation of costs at the two characteristics. Those refer to both market and expense aspects. The direction of cost has principles based on cost saving for teacher allocation. In fact, independent college's human resource allocation was concerned by two aspects: one is market aspects and another is cost saving. And the result is here as follow:

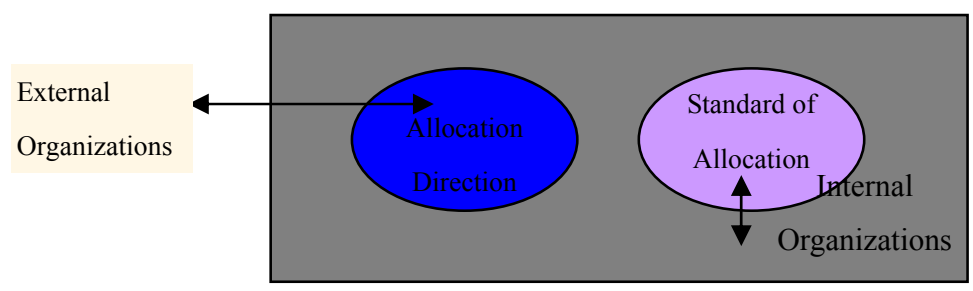

Figure 1. The Model of teacher allocation

\section{DiRECTION OF INDEPENDENT COLLEgE TEACHERS CONFIGURATION}

The direction of human resource market has the power that put someone has majored related experience and academic ability knowing "market" in the consideration range. And that will be the most important human resource for allocation further. Since independent college is established by both public university and social funds, some of the principles and behavior has similarity with public university ineluctably.

At the moment the "matrix" university does not put much attention on practice and high technology applications while independent colleges have the same situation. And there are several differences between independent colleges and public university on student resource, academic objective and methods. The public university do not have main human resource from companies and related organizations is because of the educational principles and objectives meanwhile independent colleges put much attentions on market needs is base on the same principles too. So it is the appropriate way to consider the development for independent colleges itself instead of simply copy the public university's allocation principles. 
The professional capacity of teachers and experience to a large extent determines the status of the professional capability of students, the two highly correlating. Teachers at the configuration of the market is rich practical experience and professional know that the market "prices" that the allocation of teachers as resources in the community to learn from the experience and practice of professional human resource capacity in the teacher-configuration, and are not confined to in the retired teachers in public colleges and universities and graduate students. Previous analysis, the independent existence of the College of professional practice the ability of teachers, teaching methods, such as shortage of ideas deficiencies in the further allocation in particular need to be filled.

\section{The Standard of Teachers Allocation}

Survey shows that independent colleges in the human resources costs of the 40 per cent to 50 per cent, which was the number of teachers of the total number of (2) $60 \%$ to $70 \%$, the average income of teachers and the general level higher than that of other officers Therefore, teachers of the total cost of human resources more than 70 percent of the cost, about 30 per cent of the total cost. In addition, the independent colleges need to organize (the mother college) Payment of the total fee income by $20 \% \sim 25 \%$ of the management fees. While the independent Institute of higher public college tuition income doubled, but the actual operating fund is not well-off, thus, the allocation of Independent College teachers must consider cost.

While the cost of the major concerns teacher-configuration standards and the total teacher-amount. And the Ministry of Education called for Independent Colleges and Universities in the school by the number of the total allocation of teachers, the ratio of teachers and students for 1:18. This configuration has not considered professional nature and quantity, the number of teaching classes, the number of hours of teaching programmer, and the organization of various kinds of teaching and so forth, so it is quite rough. And the allocation criteria in the light of the teaching and research universities have a double function, teachers need to shoulder the double task of teaching and scientific research on the premise of the. The Independent Institute is only a single application of the teaching function and nurture talent; obviously this configuration will directly increase their costs.

Through research, it shows that the total allocation decisions for teachers is a key element of the teaching workload of teachers rated the workload at the same time, professional nature, the number of classroom teaching classes, ratio of comparing teaching the theory to experimental teaching class is an important factor. The research team obtained the allocation formula is that as follow.

$$
\begin{array}{r}
\mathrm{S}_{\mathrm{k}}=(\mathrm{T} / \mathrm{t}) \cdot \mathrm{i} \bullet \mathrm{j} \\
\mathrm{S}=\Sigma \mathrm{S}_{\mathrm{k}}
\end{array}
$$

Table 1. Elements of allocation formula

\begin{tabular}{|c|c|c|}
\hline Parameters & Contents & Reference Values \\
\hline $\mathrm{S}_{\mathrm{k}}$ & Teachers from each unit & Integer number \\
\hline $\mathrm{S}$ & Total teachers & Integer number \\
\hline $\mathrm{T}$ & $\begin{array}{c}\text { Teaching hours per year of } \\
\text { unit }\end{array}$ & $\begin{array}{c}\text { Base on duties of major } \& \\
\text { non-professional }\end{array}$ \\
\hline $\mathrm{t}$ & Regular teaching hours & 400 500 hours/year semester \\
\hline $\mathrm{i}$ & Teaching coefficient & $1.1 \sim 1.5$ \\
\hline $\mathrm{j}$ & Teaching categories factor & $1.0 \sim 2.0$ \\
\hline $\mathrm{k}$ & Ordinal number & \\
\hline
\end{tabular}

$\mathrm{i}$ is used for amendment caused by variety of class hours. Such as combine classes i recommendation value is low, if a single-instruction classes i need to take the high value. Major factor for $\mathrm{i}$ is for changing according to difference between theory 
teaching and practice. In the absence of practical teaching, the $\mathrm{j}$ limits near bottom level. If the theory teaching comparing to practice of is more than one, it is recommended that $j$ values high. (Even above the peak value).

Formula (1) (2) shows that faculties from teaching units (program, ministry, teaching and research section), the coefficient of $i$ and $j$ are readily accessible, thus teachers can be configured more accurately calculated. School faculties' configuration can be obtained by adding all teachers from each academic unit.

According to Formula (1) (2) compare teachers: students are approximately 1:28 30, obviously this configuration can meet the teaching needs, and save money.

\section{INDEPENDENT COLLEGE TEACHER-ALLOCATION NEEDS TO BE CONSIDERED THE DYNAMIC REQUIREMENTS.}

Independent College is a fast-growing organization. In the rapidly growing number of teachers, it is mainly meet the requirements of quantity of teachers. However, after entering the stable development period, the allocation of teachers turns to base on teaching quality and the timing for decreasing competition among colleges in future.

This paper belongs to a project of Hubei Province's Education Department, focusing on the humanities and social sciences research called "Hubei Independent Colleges Distribution of Human Resources" Item Number: 2005 Z077, the author is the director-general of this project.

\section{REFERENCES}

Li, Hongsong and Lv, Xiaobai. (2007). Independent teacher-configuration and optimal allocation. Education Development Research. 3B.

Lv, Xiaobai and Li, Jun. (2008). Rsearch on administration positions and work profesions in independent colleges. Morden Education Research. Vol.3.

$\mathrm{Lv}$, Xiaobai and $\mathrm{Wu}$, Youjun. (2008) Specity and direction of teacher allocation for indepentent college. volume of peak forum of mainland. Taiwan and Hong Kong, Beijing University press.

Lv, Xiaobai. (2003). Obstacle and Countermeasures for non-structure in human resource allocation. Science development and countemeasures. Vol.5.

Ministry of Education in China. On the norms and strengthen the college with a new mechanism and modalities of the pilot views of Independent Colleges. 04-23. 


\title{
Consumption Model of Financial Products
}

\section{Among Minangkabau \& Chinese in Bank Nagari, Sumatra}

\author{
Heryanto (Corresponding author) \\ Regional Development Bank of West Sumatra \\ Jalan Pemuda No. 21 PO Box 111 Padang 25117 West Sumatra Indonesia \\ Tel: +62-8126771699Ｅ-mail: dr_heryanto@yahoo.com
}

Laily Paim

Dean of Human Ecology Faculty, Universiti Putra Malaysia, 43400 Serdang, Selangor, Malaysia

Tel: 603-8946-7051Ｅ-mail: laily@putra.upm.edu.my

\author{
Ahmad Hariza Hashim \\ Deputy Dean (Academic \& International Affair) of Human Ecology Faculty, Universiti Putra Malaysia \\ 43400 Serdang, Selangor, Malaysia \\ Tel: 603-8946-7052Ｅ-mail: ahariza@putra.upm.edu.my
}

\section{Sharifah Azizah Haron}

Lecturer of the Department of Management Resource \& Consumer Studies Faculty of Human Ecology, Universiti Putra Malaysia, 43400 Serdang, Selangor, Malaysia

Tel: 603-8946-7108Ｅ-mail: sh.azizah@putra.upm.edu.my

\begin{abstract}
The purpose of the present study are first to analyze the differences in customer product preferences between Minangkabau and Chinese customers of Bank Nagari. Second, to determine factors affecting the use of Bank Nagari products among Minangkabau and Chinese customers. Third, to determine the Minangkabau and Chinese consumption models. The sample size amount 216 customers consisted of Minangkabau would amount to 162 persons and Chinese would amount to 54 persons. Systematic sampling is applied in this study as it often yields sampling error which is smaller. Data analysis technique is use consisted of factor analysis and logistic regression.

The result of logistics regression test for credit and saving products show partial significance at probability level of .050 and result of Hosmer and Lemershow Goodnes-of-Fit test show total significance at .050. Test result of ANOVA indicates that there is ethnic difference in the consumption of financial products. Cultural factor, saving and credit perception very much determine the consumption of ethnic Minangkabau and Chinese.
\end{abstract}

Keywords: Minangkabau, Chinese, Consumption, Financial products, Saving, and credit

\section{Introduction}

Deregulation is part of government action in banking industry. Since banking sector deregulation was issued on 1 June 1983 and followed by policy packing on 27 October 1988, Indonesia's banking industry has been continuously growing. In September 1988, it was recorded that the number of banks operating in Indonesia was 111 and it increased to 240 banks in 1995 (Febrianto, 1998). The condition coused some problems for the banking industry in Indonesia such as limited asset, capital, human resources, technology, and network operation. Hence, the banks underwent difficulties in business.

According to Info Bank Research Bureau, there were five Regional Development Banks, which had shown the ability to produce profit before tax during the economic crisis (Idris, 1997) namely, The Regional Development Bank of West Java (Rp.17.529 million), Jakarta (Rp.15.311 million), Middle Java (Rp.11.528 million), West Sumatra (Rp.8.131 million) and North Sumatra (Rp.7.360 million). 
The West Sumatra banking development is in line with the national banking development. It began with the financial deregulation, until the central government implemented immediate deregulation in financial sectors; for example, deregulation in terminating the operation of the bank (bank beku operasi), and acquisition of the bank by the government (bank akuisisi) in 1997-1999. Thus, the banks that still exist in West Sumatra are public banks and People Credit Banks (Bank Perkreditan Rakyat (BPR)) (Note 1). Public banks consist of conventional and syariah public banks. Meanwhile the conventional and syariah public banks are divided into government and private banks. The government banks in Padang consist of Bank Nagari Bank Pembangunan Daerah Sumatera Barat (Bank Nagari BPD SB), Bank Negara Indonesia (BNI) 1946, Bank Negara Indonesia (BNI) 1946 Syariah, Bank Rakyat Indonesia (BRI), Bank Rakyat Indonesia (BRI) Syariah, Bank Tabungan Negara (BTN), Bank Pensiunan Tabungan Negara (BPTN), Bank Mandiri, and Bank Mandiri Syariah. The private banks consist of Bank Central Asia (BCA), Bank Bukopin, Bank Mega, Bank Permata, Bank Mestika, Bank Lippo, Bank Danamon, Bank Indonesia Internasional (BII) and Bank Muamalat.

The current situation in the banking business has increased in complexity in terms of customer, distribution and product (Kimbal \& Gregor, 1995). The industry can be characterized by the changes in customers' preferences and the rising competition among and between banks and non-bank services providers. Customer satisfaction with the service of banks is a moving target; banks must continually monitor the rapidly changing marketplace and strive to understand and become more responsive to their customers' needs and preferences (Chakravarty, \& Winddows, 1995; Glassman, 1995). Thus excellent service provides the bank with internal advantage retention of its customer. The needs and preferences are different for customers of Bank Nagari. The difference is caused by ethnic background, interest rates, perceived service, location, technology available, safety, networking, easiness, and prompt services.

As the banks grow and mature in West Sumatra, Bank Nagari moves stronger in retail than the business corporate. Bank Nagari always tries to balance between the fund collection and distribution. About $85 \%$ to $90 \%$ of the total fund collected in the form of saving, deposit, and giro are distributed to the community in the form of credits. Most notably the average growth of credit between 1995-1999 in West Sumatra was only 5.86\% and the Bank Nagari credit grew up to 23.5\% ("Untung Ada," 2000; "Bersama Membangun," 2001).

Almost all commercial banks including Bank Nagari that operate in this region are very aggressive in collecting fund from the community through saving, deposit, and giro (Note 2). Beside small and medium businesses, Bank Nagari also establishes micro banking. Micro banking activities concentrate on simple products ("Salah Satu,"2001), such as TAMI, KUMI, KUKI, SIMPEDA, KESRA (Note 3), personal and commercial credit.

Bank Nagari operates inside and outside of the West Sumatra, and has lower communication and information technologies compared to other government and private banks (Table 1).

In Table 1 it is seen that technological network was predominated by government and private banks i.e., BNI 1946 (26\%), Bank Mandiri (22\%) and BCA (17\%). Banks with technological network means below 2\% and lower were i.e., Bank Nagari, Bank BTN, Bank BTPN, Bank Mega, Bank Permata, Bank Mestika and Bank Muamalat. However, the simple products and good services provided by the Bank Nagari have contributed to its success ("Salah Satu," 2001; "Bersama Membangun," 2001).

Bank Nagari is different from other banks in sociological aspects success ("Salah Satu," 2001; "Bersama Membangun," 2001). It has a strategic position (location choice) and close relationship with Minangkabau. Hence, this condition is used by the bank management in collecting fund optimally from the Minangkabau community in Sumatra and Java. Moreover Anis Mucthar in "Hebat, BPD" (2000) explained that the reason Pekanbaru and Jakarta regions were chosen for establishing branches of regional development banks is that these regions are resided mostly by the Minangkabau. This idea is parallel with that of Kato Tsuyoshi in Junus (1990) that the migration areas of the Minangkabau outside West Sumatra is Jakarta and Pekanbaru.

Besides the Minangkabau, the Chinese is the second largest customers of Bank Nagari. They have bigger amount in credit facilities. Therefore the Chinese contribute higher revenue as compared to the Minangkabau. Hence, services received by the Chinese are better than those enjoyed by the Minangkabau. Pick up and delivery services are just for the Chinese and not for the Minangkabau. It means for the Chinese customers "welcoming services" as well as other services received are not limited within the bank's office, but also other convenient places for the client. These customers are deemed to be rational and more sensitive to price change, service, and economic condition. Moreover, the Chinese have very strong capital and get various amenities and facilities in doing business (Roziqin, 1997).

The purpose of the present study are first to analyze the differences in customer product preferences between Minangkabau and Chinese customers of Bank Nagari. Second, to determine factors affecting the use of Bank Nagari products among Minangkabau and Chinese customers. Third, to determine the Minangkabau and Chinese consumption models. This study is an extension of existing consumption theories namely classical and Duesenbery consumption theories. Both theories explain that the use of income is influenced only by culture, attitude, and habit. The present study combine both theories and add other factors that influence financial products consumption. This study enrich our knowledge and understanding on consumption behavior of different ethnic and factors affecting the choice made. 
Indonesia is divided into 26 provinces, each region has its own regional development bank which is different from one another. Bank Nagari is the Regional Development Bank of West Sumatra that has branches outside the West Sumatra province and follows their customers. It differs from the Regional Development Bank of West Java, Jakarta, Mid Java and North Sumatra. They differ in terms of ethnic market and diversity. The study will benefit regional development banks, Bankers and financial customers. It hopes to facilitate regional development banks, in attaining optimal profits. Whereas Bankers would be able to offer optimal service to its customer and give priority to customers first, this encourage customer to use banking products and services, and provide alternatives to customers in the use of banking services. Furthermore, it is as indicator in arranging the regional financial planning for regional governments. Besides facilitate banks in attaining optimal profit, the findings of the study also be used in identifying and developing relevant policies in helping the traders (especially small traders) managing credit and savings.

This study has several limitations including selection of population and respondents and products studied. The study is limited to micro and small banking products of Bank Nagari. Banks that have corporate banking products are not included in the study. The respondents studied were Minangkabau and Chinese customers of Bank Nagari. There are other ethnics in Indonesia which were not included in the study. Ethnic and culture are closely related, thus different ethnics would have different consumption behavior. Amongst all the products offered by the Bank Nagari, only two products were studied i.e., saving and credit products.

2. Theoretical framework: Classical and Post Keynes consumption theory, the list of value (LOV), Service Quality (SERVQUAL), implication for the Construction of a Conceptual Model for Consumption, Conceptual Moder for Consumption and hypothesis

\subsection{Classical and Post Keynes consumption theory}

In adopting this theory, considerable insight into the culture of other people, their general way of living, their point of view and their attitude need to be gathered before one can understand the significance of their experiences in using goods, or what their consumption means to them. What people get from their consumption depends partly on their point of view, as well as their general attitude toward life and living.

The common definition of culture is the mode of living that distinguishes one large group of mankind from another. Yet a culture is not a mere sum of beliefs, practices, and goods and services consumed (Hoyt, 1976); it is beliefs, practices, goods, service linked, and bound together, first by a mutual dependence on some common point of view, and second by a mutual interdependence on one another. A culture, in other words, is organic. A simple figure 1 will illustrate this influence of culture as follows (Hoyt, 1976).

In this diagram, the lines between nature and man represent the course that is taken by the various factors, which enter their experience. Only the very simplest things proceed directly, as by the heavy black vertical line. Almost everything is deflected by cultural attitude, some things more and some things less, and therefore reach man by an indirect route.

The illustration above presents that culture plays an important role in explaining consumption behaviour. In this case, culture is one of the factors that determine consumption. Kyrk (1976) tried to relate that culture is drawn by habit and consumption as human behavior in the fulfillment of the standard of living.

Keynes' (1936) said in the General Theory of Employment, Interest and Money:

"The fundamental psychological law, upon which we are entitled to depend with great confidence both apriori from our knowledge of human nature and from the detailed facts of experience, is that men are disposed, as a rule and on the average to increase their consumption as their income increase, but not by as much as the increase in their income “(p.96)

The theory also draws up a corresponding list of motives to consumption such as enjoyment, shortsightedness, generosity, miscalculation, orientation and extravagance (Keynes, 1936). An earlier analysis by Duesenbery (1949) emphasized an established habit patterns. According to this theory having become accustomed to a new living standard provided by growth of income, people also become reluctant to sacrifice that living standard in the face of income shrinkage. Thus, the relative income hypothesis expects the short-run consumption function to ratchet upward as the result of the establishment of higher standards of living.

\subsection{List of Values (LOV)}

Researchers have developed culture value inventories by studying particular cultures, identifying their values, and then determining whether these values are widely held (Assael, 1998). The best know inventory is the Rokeach Value Survey established in 1968 as cited in Schiffman and Kanuk (1991).

According to Assael (1998), the Rokeach Value Survey is based on a study of American culture. Then Kahle, Beatty, and Homer (1986) developed another widely used cultural inventory called the LOV. 
"LOV was developed from a theoretical base of Feather's in 1975, Maslow's in 1954 and Rokeach's in 1973 work on values in order to assess adaptation to various roles through value fulfillment. Beside that, LOV has been related to a number of important measures of mental health, well-being, and adaptation to society, roles, and self in Kahle, 1983, as well as geographic dispersement in Kahle, 1986" (Cited in Kahle et al., 1986, pp.406-407).

The LOV development was as an alternative to Rokeach's Value Inventory because the terminal values identified by Rokeach were too abstract and difficult to apply to marketing situations (Assael, 1998). Therefore, a study by Kahle et al. (1986) proposed that the LOV inventory measures nine values:

$\begin{array}{ll}\text { 1. } & \text { Self-fulfillment } \\ \text { 2. } & \text { Excitement } \\ \text { 3. } & \text { Sense of Accomplishment } \\ \text { 4. } & \text { Self-respect } \\ \text { 5. } & \text { Sense of Belonging } \\ \text { 6. } & \text { Being Well Respected } \\ \text { 7. } & \text { Security } \\ \text { 8. } & \text { Fun and Enjoyment in Life } \\ \text { 9. } & \text { Warm Relationships with Others }\end{array}$

Kahle et al. (1986) compared LOV and VALS (Value of LifeStyle) and concluded that LOV significantly predicts consumer behavior trends more often than does the VALS scoring system. In other words, LOV has greater predictive utility than does VALS in consumer behavior trends.

As global competition increases, understanding the cultural impacts of services becomes more critical for service firms (Riddle, 1992). Because culture provides the framework for social interactions, social rules and consumer expectations that are related to service encounters are likely to vary from culture to culture (Pucik \& Katz, 1986). Service influences consumption through consumer satisfaction, and consumer satisfaction can be known by the voice the consumer.

\subsection{Service Quality (SERVQUAL)}

SERVQUAL has been described as a form of attitude, related but not equivalent to satisfaction that results from the comparison of expectations with performance (Bolton \& Drew, 1991; Parasuraman, Zeitham, \& Berry, 1998). The most common explanation of the difference between the two is that perceived service quality is a form of attitude, a long-run overall evaluation, whereas satisfaction is a transaction-specific measure(Bitner, 1990; Bolton \& Drew, 1991; Parasurman et al., 1998); Parasuraman et al., 1988) further suggested that the difference lies in the way disconfirmation is operationalized. They stated that in measuring perceived service quality the level of comparison is according to what a consumer should expect, whereas in measures of satisfaction the appropriate comparison is based on what a consumer would expect. However, such a differentiation appears to be inconsistent with Woodruff, Codotte, and Jenkins' (1983) suggestion that expectations should be based on experience norms i.e., what consumers should expect from a given service provider given their experience with that specific type of service organization.

The SERVQUAL instrument has been productively used for measuring service quality in many proprietary studies. It has also served as the basis for measurement approaches used in published studies examining service quality in a variety of contexts such as physicians in private practice (Brown \& Swartz, 1989); a dental school patient clinic, a business school placement center, and a tyre store (Carman, 1990) ; discount and departmental stores (Teas, 1993) ; a gas and electric utility company (Babakus \& Boller, 1992); hospitals (Carman, 1990) ; banks, pest control providers, dry cleaners, and fast food chains (Cronin \& Taylor, 1992) and institutions of higher education (Boulding, Kalra, Staelin \& Zeithaml, 1993) .

While the SERVQUAL instrument has generated considerable interest in service quality measurement, it has also raised questions about the need to measure expectations (Cronin \& Taylor,1992; Cronin \& Taylor, 1994), the interpretation and operationalization of expectation (Teas, 1993; 1994), the reliability and validity of SERVQUAL's difference-score formulation (Babakus \& Boller, 1992; Brown, Churchil \& Peter, 1993), and SERVQUAL's dimensions (Carman, 1990).

As SERVQUAL instrument's expectation statement relate to the service level that consumers believe they should get from the service provider, its expectation components reflect the desired service construct. According to Parasuraman et al. (1994) that desired service is the level of service representing a blend of what consumers believe "can be" and "should be" provided and adequate service is the minimum level of service consumers are willing to accept. However, to incorporate the recently revised conceptualization of expectations they modified SERVQUAL's structure in order to capture not only the discrepancy between perceived service and desired service - labeled as measure of service superiority (or MSS) - but also the discrepancy between perceived service and adequate service or minimum service labeled as measure of service adequacy (or MSA). SERVQUAL's dimensions or as Parasuraman et al. (1994) called 
if the SERVQUAL Battery consist of five sub-dimensions namely reliability, responsiveness, assurance, empathy, and tangibility. Every SERVQUAL Battery has elements serving as indicators that measure the battery. The set of battery items are as in Table 2.

Based on the classical and post Keynes consumption theories discussed, some conclusions can therefore be derived. Classical consumption theory states that culture influences consumption through the relationship between nature and man, and post Keynes theory indicates that consumption is determined by income.

The current research defines consumption as how customers use financial products in business activities, or it is also known as business consumption. The current consumption is measured by culture, Service Quality (SERVQUAL) and income variable. It means Consumption is a dependent and a function of independent variables i.e., culture, SERVQUAL and income.

\subsection{Implications for the Construction of a Conceptual Model for Consumption}

Duesenbery (1949) asserted: "In every case the kinds of activities in which people engage are culturally determined; nearly all purchases of goods are made ... either to provide physical comfort or to implement the activities which make up the life of our culture" (p.25)

Moreover, purchase motivation may influence how people feel in service encounters. Consumers come into service consumption situations with different service-specific goals (Bitner, 1992; Lawson, 1997) that influence their pre-consumption expectations, including their affective expectations (Dube, 1990).

A study about culture-service relation to consumption has been considered by McCracken (1986), Riddle (1992), Pucik and Katz (1986), Mattila (1999), Bitner (1992), Lawson (1997), Dube (1990) and Tan and Farley (1987). Several studies have examined about ethnic consumption. Tan and Farley's (1987) study examined how cultural elements influence relationships between attitudes and intentions in a non-western culture i.e., Singapore. This study was concerned with product origins (local/foreign) of goods i.e., men's clothing, women's clothing and face cream, and it used two cultural variables i.e., family orientation (affection for family, interaction with family members, parental influence on thought and tendency to compromise subject needs with family needs) and conformity, defined as the sum of two scales: behavior according to what others expect and the sacrifice of personal desires to conform to social norms. Donthu and Cherian (1994), observed the Hispanic retail shopping behavior. Their study explored the differences in retail shopping behaviors of strongly and weakly identified Hispanics. The result showed that strongly identified Hispanics are more likely than weakly identified Hispanics to be loyal to product brands used by family and friends, to be influenced by the media, and to be less concerned about economic value.

Furthermore, the relationship between purchase intentions and consumer satisfaction has been addressed in several studies, including those by Bearden and Teel (1983), Oliver (1980), and Oliver and Swan (1989). LaBarbera and Mazursky (1983) investigated the relationship between actual purchase behavior and customer satisfaction. There have also been a number of recent empirical attempts to validate the specific nature of the relationship between service quality and consumer satisfaction in the formation of consumers' purchase intentions ( Bitner, 1990; Cronin \& Taylor, 1992).

Beside that Taylor and Baker (1994) stated that the results of empirical efforts to validate the specific nature of the relationship between service quality, consumer satisfaction, and purchase intentions have supported both possible relationships among the constructs (i.e., SERVQUAL, satisfaction, purchase intentions; satisfaction, SERVQUAL, purchase intentions).

\subsection{Conceptual Model for Consumption}

Based on a preceding study by Tan and Farley (1987), Donthu and Cherian (1994) affirmed that studies about ethnic consumption had been limited customer goods e.g., clothing, and food. Studies on the consumption of financial goods according to ethnic groups were rarely done before it.

The conceptual model of this study is based on strongly postulate relationships of culture-income and culture-service. Customers' indifferent cultures may have different levels of service expectation, because cultures differ in their patterns of behavior and attitudes (Donthu \& Yoo, 1998). Income is independently influenced by culture. Household consumption is always maintained even though its income decreases (Duesenberry, 1949), because household consumption is a habitual expenditure.

Culture, SERVQUAL, and income are independent variables. Culture, service and income variables are measured using LOV, SERVQUAL and consumer expenditure per month (Figure 2).

\subsection{Hypotheses}

A set of hypotheses is developed based on consumption factors for financial products among Minangkabau and Chinese customers. LOV, SERVQUAL, and consumer expenditure per month are endogenous variables that influence saving and credit consumption between Minangkabau and Chinese customers. 
$\mathrm{Ha}_{1}$. There is significant difference in preference between Minangkabau and Chinese customers in Bank Nagari. Minangkabau customers outnumbers the Chinese customers. The Minangkabau are constituted of micro, small and middle entrepreneurs. Conversely, Chinese customers are involved in medium enterprises. Customers attitude is seen through LOV, SERVQUAL and consumer expenditure per month variables in relation to saving and credit consumption in Bank Nagari. Beside that the Chinese ethnics are more sensitive to the changing market interest rate, resulting in the fluctuation of their behaviour.

Therefore, there are significant differences in cultural values, SERVQUAL and income between the Minangkabau and Chinese customers with relevance to consumption. Specifically, this hypothesis postulates that:

Ha $_{1.1}$ There is significant difference between Minangkabau and Chinese LOV to financial products consumption.

$\mathbf{H a}_{1.2}$ There is significant difference between Minangkabau and Chinese SERVQUAL to financial products consumption.

$\mathbf{H a}_{1.3}$ There is significant difference between Minangkabau and Chinese household expenditure to financial products consumption .

$\mathrm{Ha}_{2}$. There is a positive relationship between consumption and SERVQUAL. SERVQUAL has a positive relationship with saving and credit product consumption, meaning that an increase in SERVQUAL increases product consumption. Service has a two-way relationship with product consumption. In other words consumption changes due to changes in the SERVQUAL expected by customers.

$\mathrm{Ha}_{3}$. There is a positive relationship between consumption and expenditure per month. Income through expenditure per month influences saving and credit consumptions i.e., the extent to which consumption changes is determined by changes in expenditure per month. It has a positive and two-way relationship with product consumption.

\section{Methods}

\subsection{Sampling Procedure}

The population comprised of all Minangkabau and Chinese customers of Bank Nagari in Padang. To select the respondents, a list of saving-credit customers were obtained from the bank and names were selected randomly. This technique is called systematic random sampling. Systematic random sampling is a method of sample selection, whereby only initially the sample is selected at random, while the selection process hereafter is carried out systematically according to a certain pattern. In addition, systematic sampling often yields sampling error which is smaller. It caused by divergent sample member flattened in all population. According to Mantra and Kasto (1989) systematic sampling can be run at two situations. First, if there are names or identification in the elementary set of population list (sampling framework), that set can be given a series of numbers. Second, if that population have a regular pattern, then the sample size would be determined in accordance with the assumption of the desired precision level, the desired confidence level and a standard deviation.

Subsequently data were collected in one round by trained interviewers using questionnaire. Interview sessions were conducted most often in the afternoon. The one round personal interview was done with the consideration for the limited time the merchants could spare to be able to do interviews repeatedly. Data type is cross sectional data that provide information on a group of entities at a given time and differ from the time series data that provide information on one entity time. Data collection was carried out in May to August 2003.

Padang is the leading port on Sumatra's west coast and is now the main city of the Minangkabau of West Sumatra. The city's port, formerly Emmahaven, lies at the mouth of the Padang River at a point 5 miles $(8 \mathrm{~km})$ to the south of the city. Originally Padang is a bunker port for coal from the Umbilin coalfields, now it also ships coffee, rubber, cinnamon, tea, nutmeg, rattan, and plywood. Based on the 1990 census data, Padang had a population of 631.263 people, in 2000 the amount was 713.242 people. Based on SUSENAS 2001 'national economic social survey' data its population amounted to 720.783 people in terms of manpower. In 2001, the number was 240.192 people or 41.88 percent of the population aged more than 10 years old. Most of them (61.94 percent) worked in the trade and service sectors and the remaining were employed in other sectors. Furthermore, according to Twang (1998) Padang is one of the areas occupied by the Chinese ethnics outside Java Island. They occupy an area called 'Pondok', creating polarization within the island (Figure 3).

\subsection{Sample Size}

The purpose of sampling is to estimate population parameter value as accurately as possible. The only way to predict a parameter value from sample data is to come up with an estimate in the form of a confidence interval, usually $95 \%$ confidence interval is required for a social research.

The total population of this study was 514 customers, which was divided into two groups namely Minangkabau and Chinese. There were some assumptions in the sample size determination between Minangkabau and Chinese. This is in line with Parasuraman's (1986) idea: 
(1) The desired precision level is $10 \%$. The desired precision level, is the magnitude of the \pm term that the researcher (or decision maker) is willing to tolerate. It means the researcher wants to estimate the percentage of a population that owns Bank Nagari product accounts within a margin error of $10 \%$.

(2) The desired confidence level is $95 \%$. The desired confidence level is degree of confidence that the decision maker wants to have in the interval estimate.

(3) A standard deviation (the degree of variability in the population) is accounted by the minimum and maximum value of the variable in the population. If the variable value for the population unit can be assumed to be normally distributed, the standard deviation can be estimated as follows:

$\mathrm{s} \quad=\underline{\text { Maximum Value }- \text { Minimum Value }}$

6

This expression is derived in such a way that, given a group of numbers that are normally distributed, almost all the numbers will be included in the interval formed by the group mean \pm three standard deviation. In other words, the difference between the largest and smallest numbers in the group should be approximately equal to six standard deviations (Parasuraman, 1986). Because the minimum and maximum values of the variable in the population are unknow hence deviation standard was specified at arbitrarily $75 \%$.

Then, given a desired precision level (c), a desired confidence level (q), and an estimate of the standard deviation (s), the following equation can be established (Parasuraman, 1986):

$\mathrm{c} \quad \underline{\mathrm{Z}}_{\mathrm{q}} \underline{\mathrm{S}}$

$\sqrt{n}$

One can square both sides of equation 5 and rewrite it as follows:

$\mathrm{n}=\underline{\mathrm{Z}_{\mathrm{q}}{ }^{2} \mathrm{~s}^{2}}$

$\mathrm{c}^{2}$

where $\mathrm{n}=$ sample size, $\mathrm{Z}_{\mathrm{q}}=$ desired confidence level, $\mathrm{s}=$ standard deviation and $\mathrm{c}=\mathrm{a}$ desired precision. Equation 6 can be used to determine sample size, irrespective of whether the objective is to estimate a population mean.

In this study, the researcher wanted to estimate the number of sample size to be taken with assumption marginal of error $\pm 10 \%$, confidence level $95 \%$ and standard deviation arbitrarily $75 \%$. Thus, $\mathrm{c}=10 \%, \mathrm{~s}=75 \%$ and $\mathrm{Z}_{\mathrm{q}}=1.96$ (corresponding to a confidence level of 95\%) notice that $\mathrm{c}$ and $\mathrm{s}$ are expressed in the same unit. The value of $\mathrm{n}$ can be derived by using equation (6), where $n=(1.96)^{2}(0.75)^{2} /(0.10)^{2}=216$ customers, approximately. By virtue of the ethnic composition within the bank's saving-credit customers list 75\% Minangkabau would amount to162 persons and $25 \%$ Chinese would amount to 54 persons.

\subsection{Instrument}

Generally, there were two important steps in choosing indicators and variables that would best represent consumption (Paim, 1993). First, an inspection of face validity or logical validity of the variables, and inspection of unidimentionality of the indicators were carried out. The chosen variables are those which would logically indicate consumption, and from which a composite indicator could be developed. The composite indicator has values ranging from low to high. Second, the amount of variance provide by those variables and the bivariate relationships among them were examined. A variable would not be very useful in the creation of a measure if no one responds to that variable or everybody gives the same response.

Furthermore, the variables were trying to measure namely culture, SERVQUAL and income. Culture variable is measured by self-fulfillment, excitement, sense of accomplishment, self-respect, sense of belonging, being well respected, security, fun and enjoyment in life and warm relationships with other. SERVQUAL is measured by one of the three alternative service quality measurement formats (Parasuraman et al., 1994; Cronin \& Taylor, 1992). Meanwhile, income variable is measured by household expenditure per month.

The questionnaire was pre-tested prior to the actual interview. Based on the pretest, some adjustments and modifications would be made to improve the questionnaire. According to Hunt, Sparkman, and Wilcox (1982) the questionnaire pre-test can be done by face-to-face interview but this opinion was objected by Parasuraman (1986), because being face to face with respondents may suggest problem areas or points of confusion that may otherwise go unnoticed. Parasuraman (1986) generally suggested that the pre-test is first conducted by using personal interviews and a second pre-test should be conducted using the proposed questionnaire administration method. The purpose of this method of pre-test is to detect problems that may be unique to the way in which the questionnaire is to be administered.

To be more accurate in data analysis, a researcher ought to first test reliability and validity of the questionnaire. Nunnally (1978) proposed using alpha values or the Cronbach's coefficient alpha test between 0.5 and 0.6 for exploratory studies. However, Peter (1979) refuted his suggestion by saying that these measures should not be taken as 
the absolute standard for market research and as Guilford cited in Tay (1998), an alpha value of even 0.35 is applicable in some cases. To test reliability and validity, the present study used SPPS-11.5.

\subsection{Factor Analysis}

Factor analysis is used to reduce recommended variable as independent variables which influence ethnic consumption. The KMO test and Bartlett's and correlation anti-image were used to know the feasibility of these variables. A Variable is feasible if the KMO test and Bartlet's and anti-image correlation are above 0.50 (Santoso, 2001). If the anti-image correlation from a variable is below 0.50 , hence that variable has to be dismissed, and factor analysis have to be carried out again on the variable until the KMO and Bartlet's and anti-image correlation are above 0.50. After each $\mathrm{KMO}$ test and Bartlett's and anti-image correlation is feasible, this variable can be accepted in the form of variable which have been reduced. To enable every variable to be used in regression analysis, each factor would deputize the variables in the form of score (Santoso, 2001).

\subsection{The Consumption Equation}

The logit models are appropriate to solve the consumption models. Hence, the dependent variable takes a binary form here. Such model is known as linear probability or binary choice model. If it is estimated by regressing the dummy variable $\mathrm{P}$ against culture, SERVQUAL and income variables, the residual will be heteroscedastic. Hence, the application of ordinary least square (OLS) will yield inefficient estimates (Ramanathan, 1992) .

Thus, the logit model has the following functional form as follow:

$\operatorname{Ln}\{\mathrm{P} / 1-\mathrm{P} \quad\}=\beta_{1}+\beta_{2} \mathrm{X}_{1 \mathrm{t}}+\beta_{3} \mathrm{X}_{2 \mathrm{t}}+\beta_{4} \mathrm{X}_{3 \mathrm{t}}+\mathrm{e}_{\mathrm{t}}$

where $P$ is the value of the dependent variable between 0 and 1.1 is for Minangkabau consumption and 0 is for Chinese consumption, $t$ subscript $=1 \ldots \mathrm{n}$ indexes the cross-section observation, $\beta_{1}$ is intervening variable, $\beta_{2}, \beta_{3}, \beta_{4}$ are LOV, SERVQUAL and income parameter respectively, $\mathrm{X}_{1}, \mathrm{X}_{2}, \mathrm{X}_{3}$ subscript are LOV, SERVQUAL and income, and e is error. If an ordinary regression model is used in such case, there is assurance that the predicted value will lie between 0 and 1 (Ramanathan, 1992). Thus, the rationale for this form can be seen by solving the equation for P (by first exponentiation both sides). It then obtains the probability that the dependent variable takes the value $\mathrm{P}$, as follows:

$P=1 / 1+e^{-\left(\beta_{1}+\beta_{2} x_{1 t}+\beta_{3} x_{2 t}+\beta_{4} x_{3 t}+e_{t}\right)}$

It is easy to see that if $\left(\Sigma \beta_{\mathrm{i}} \mathrm{X}_{\mathrm{it}}\right)=+\infty$, P is 1 , and when $\quad\left(\Sigma \beta_{\mathrm{i}} \mathrm{X}_{\mathrm{it}}\right)=-\infty, \mathrm{P}$ takes the value 0 . Thus, P can never deviate from the range 0, 1 (Ramanathan, 1992; Lehmann, Gupta \& Steckel, 1998). The estimation procedure depends on whether the observed $\mathrm{P}$ is between 0 and 1 . Alternatively, whether it is binary and takes the value 0 or the value 1 . In the case in which $\mathrm{P}$ is strictly between 0 and 1 , the method is simply to transform $\mathrm{P}$ and obtain $\mathrm{C}=\mathrm{Ln}\{\mathrm{P} / 1-\mathrm{P}\}$. Then $\mathrm{C}$ is regressed against LOV, SERVQUAL and income variables. When $\mathrm{P}$ is binary the logarithm of $\mathrm{P} / 1-\mathrm{P}$ is undefined.

The marginal effect of $\mathrm{X}$ on $\mathrm{P}$ is calculated by taking the partial derivative of $\mathrm{P}$ with respect to an estimated marginal effect as given below:

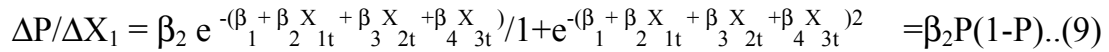

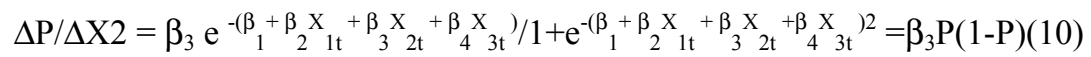

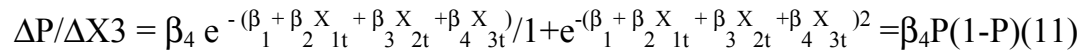

Then the ethnic consumption equation will be written according to the above model concept as follows:

\section{Saving}

$C_{\text {saving }}=\beta_{1}+\beta_{2} X_{1 \mathrm{t}}+\beta_{3} X_{2 \mathrm{t}}+\beta_{4} X_{3 \mathrm{t}}+\mathrm{e}_{\mathrm{t}}$

where $C_{\text {saving }}$ is binary variable i.e., Minangkabau saving is 1 and Chinese saving is $0 . X_{1}, X_{2}$, and $X_{3}$ are LOV, SERVQUAL and income variables respectively. $\beta_{1}$ is intervening variable, $\beta_{2}, \beta_{3}$, and $\beta_{4}$, are LOV, SERVQUAL and income coefficients and e is error.

\section{Credit}

$C_{\text {Credit }}=\beta_{1}+\beta_{2} X_{1 \mathrm{t}}+\beta_{3} X_{2 t}+\beta_{4} X_{3 t}+e_{t}$

where $C_{\text {credit }}$ is binary variable i.e., Minangkabau credit is 1 and Chinese credit is $0 . X_{1}, X_{2}$, and $X_{3}$ are LOV, SERVQUAL and income variables respectively. $\beta_{1}$ is intervening variable, $\beta_{2}, \beta_{3}$, and $\beta_{4}$ are LOV, SERVQUAL and income coefficients and e is error.

\section{Results and discussion}

\subsection{Respondents' profile}

Of the 200 respondents in the study, $75.0 \%$ were Minangkabau and $25.0 \%$ were Chinese. The majority of them were within the age of $<50$ years $(59.5 \%)$. Most respondents were male $(75.5 \%)$. Almost all respondents $98.5 \%$ were married and $1.5 \%$ were separated. More than half (68.5\%) of the respondents' education was at the high school level 
and $26.0 \%$ of respondents were university degree holders. Majority of the respondents $(94.5 \%)$ were traders, $1.5 \%$ were manufacturers, $2.5 \%$ were distributors, and $1.5 \%$ were of other professions such as lawyer and doctor (Table 3 ).

\subsection{The Variable Test}

\subsubsection{The questionnaire test of culture}

The reliability analysis indicate that self-fulfillment (c1), excitement (c2), sense of accomplishment (c3), self-respect (c4), sense of belonging (c5), being well respected (c6), security (c7), fun and enjoyment in life (c8), and warm relationships with others (c9) instruments are valid. This indicates that the validity analysis in corrected item-total correlation or $\mathrm{r}$-account is positive (Table 6), more than the t-table in degree of freedom $(\mathrm{df}=200-2) 198$ and significance level $5 \%$ namely 0.091 .

Furthermore, the instruments above are reliable. It is shown that r-alpha $(\alpha)$ or Cronbach's test 0.916 has a higher positive value than r-table 0.091 . So can be conclude based on the validity and reliability analyses that the cultural instrument is valid and reliable. Factor analysis was used to lessen cultural variables to become a dominant cultural variable (Table 4).

\subsubsection{The Culture variable validity test}

KMO and Bartlett's test performed resulted a value of 0.924 and significant at 0.000 level. The point is over 0.5 and significantly below $0.05(0.000<0.05)$. So the variables can be used for further analysis. Moreover in anti-image correlation, especially on correlation identified with superscript "a". Supercript "a" indicates measures of sampling adequacy (MSA). MSA is found for self-fulfillment (c1), excitement (c2), sense of accomplishment (c3), self-respect (c4), sense of belonging (c5), being well respected (c6), security (c7), fun and enjoyment in life (c8), and warm relationships with others (c9) with values more than 0.5 . It means that the nine of culture variables can be utilised in the further analysis (Table 5).

\subsubsection{The Culture variable rotation}

All nine variables are researched through the factoring process and can be reduced to become just one factor as seen in Table 8. This table of component matrix in factor analysis displays the nine variables as one factor. The one factor consists of self-fulfillment vs. no self-fulfillment (c1), excitement vs. sadness (c2), sense-accomplishment vs. sense-foolishness (c3), self-respect vs. no self-respect (c4), sense of belonging vs. sense of consuming (c5), being well respected vs. being unrespected (c6), security vs. insecurity (c7), fun and enjoyment in life vs. displeasure in life (c8), and warm relationships with others vs. cold relationship with others (c9) variables (Table 6).

\subsubsection{The questionnaire test of saving}

The reliability analysis indicates that some statements regarding the saving product are valid i.e., when these institutions promise to do something by a certain time, they should do so ( $\mathrm{p} 1$ ), when customers have problems, these institutions should be sympathetic and reassuring (p2), these institutions should be dependable (p3), they should provide their saving services at the time they promise to do so (p4), they should keep their records accurately (p5), they should not be expected to tell their customers exactly when saving services will be performed (p6), it is not realistic for customers to expect prompt service from employees of these institutions (p7), their employees do not always have to be willing to help customers (p8), it is okay if they are too busy to respond to customer requests promptly (p9), customer should be able to trust employees of these institutions (p10), customer should be able to feel safe in their transactions with these institutions' employees (p11), their employees should be polite (p12), their employees should get adequate support from these institutions to do their jobs well (p13), these institutions should not be expected to give customers individual attention (p14), employees of this institution cannot be expected to give customers personal attention (p15), it is unrealistic to expect these institutions to have their customers' best interest at heart (p16), it is unrealistic to expect employees to know what the needs of their customers are (p17), they should not be expected to have operating hours convenient to all their customer (p18), they should have up-to-date equipment and technology (p19), their physical facilities should be visually appealing (p20), their employees should be well dressed and appear neat (p21) and the appearance of the physical facilities of these institutions should keep up with the type of service provided (p22). Results from the corrected item-total correlation or r-account positive (Table 7) are more than the r-table 0.091 in degree of freedom $(\mathrm{df}=200-2) 198$ and significance level 5\%.

Furthermore, the variables above are reliable. It is shown that $r$-alpha 0.949 is more positive than the r-table 0.091 . So based on reliability analysis, the twenty-two variables of saving product service quality are valid and reliable. Likewise, the saving instrument underwent the similar process as the cuoltural instrument above. Factor analysis was used to lessen SERVQUAL instrument for saving to become some factors.

\subsubsection{The saving variable validity test}

$\mathrm{KMO}$ and Bartlett's test were performed to test the feasibility of the saving variables. The result of the test indicated that the value of KMO and Bartlett test were 0.916 and significant at .000 level as seen in Table 8 . The point is $>0.5$ 
and significant point $<0.05(0.000<0.05)$ then the variables and samples can be used for the next analysis. Moreover in anti-image correlation, especially on correlation identified with superscript " $\mathrm{a}$ " MSA. MSA was found to be more than 0.5 i.e., when these institutions promise to do something by a certain time, they should do so ( $\mathrm{p} 1$ ), when customers have problems, these institutions should be sympathetic and reassuring (p2), these institutions should be dependable (p3), they should provide their saving services at the time they promise to do so (p4), they should keep their records accurately (p5), they should not be expected to tell their customers exactly when saving services will be performed (p6), it is not realistic for customers to expect prompt service from employees of these institutions (p7), their employees do not always have to be willing to help customers (p8), it is okay if they are too busy to respond to customer requests promptly (p9), customer should be able to trust employees of these institutions (p10), customer should be able to feel safe in their transactions with these institutions' employees (p11), their employees should be polite (p12), their employees should get adequate support from these institutions to do their jobs well (p13), these institutions should not be expected to give customers individual attention (p14), employees of this institution cannot be expected to give customers personal attention (p15), it is unrealistic to expect these institutions to have their customers' best interest at heart (p16), it is unrealistic to expect employees to know what the needs of their customers are (p17), they should not be expected to have operating hours convenient to all their customer (p18), they should have up-to-date equipment and technology (p19), their physical facilities should be visually appealing (p20), their employees should be well dressed and appear neat (p21) and the appearance of the physical facilities of these institutions should keep up with the type of service provided (p22). It means that twenty-two of the saving service quality variables can be analyzed further (Table 8).

\subsubsection{The saving variable rotation}

All the twenty-two variables researched through the factoring process can be reduced to just three factors. Table rotated component matrix in factor analysis displays the twenty-two variables on the three factors (Table 9).

The first factor is named SSERVQUAL-1. This factor expresses that when these institutions promise to do something by a certain time, they should do so (p1), when customers have problems, these institutions should be sympathetic and reassuring (p2), these institutions should be dependable (p3), they should provide their saving services at the time they promise to do so (p4), they should keep their records accurately (p5), it is not realistic for customers to expect prompt service from employees of these institutions (p7), their employees do not always have to be willing to help customers (p8), it is okay if they are too busy to respond to customer requests promptly (p9), customer should be able to trust employees of these institutions (p10), customer should be able to feel safe in their transactions with these institutions' employees (p11). In SSERVQUAL-1, it is evident that saving product customers want reliability, responsiveness and assurance from the product they use. Customers' perception of reliability of this institute is very dominant in this case. In providing saving services to its customers, financial institutions ensure their continued existence. Technology does not determine service, it merely gives the character of extending the service. Service is very much determined by service quality from employers of the financial institutions.

The second factor is named SSERVQUAL-2, asserting that employees should be polite (p12), it is unrealistic to expect these institutions to have their customers' best interest at heart ( $\mathrm{p} 16)$, they should not be expected to have operating hours convenient to all their customer (p18), they should have up-to-date equipment and technology ( 19 ), their physical facilities should be visually appealing (p20), their employees should be well dressed and appear neat (p21) and the appearance of the physical facilities of these institutions should keep up with the type of service provided (p22). In this case, customers that have experiences would accept and support adequate service facilities provided by the bank. Superior service is deemed the best customer experience.

The third factor is named SSERVQUAL-3, which outline that financial institutions should not be expected to tell their customers exactly when saving services will be performed (p6), their employees should get adequate support from these institutions to do their jobs well (p13), these institutions should not be expected to give customers individual attention (p14), employees of this institution cannot be expected to give customers personal attention ( $\mathrm{p} 15)$, and it is unrealistic to expect employees to know what the needs of their customers are (p17). This differ from the original SERVQUAL by Parasuraman, Zeithaml, and Berry as illustrated in the table 15. Goleman (1995) expressed that empathy represents one of the abilities that are most important apart from one's emotional intelligence. One should not only be able to recognize another person's emotions and self-awareness, manage his emotion, and motivate oneself, more than that he also should be able to know and feel the emotional feelings of others. This capacities and abilities are called empathy. Empathy have big role in forming customer experience because service "unforeseen" which is given as the result of employees' ability to feel what a customer feels can seldom awaken memorable experience to the customer.

\subsubsection{The questionnaire test of credit}

The validity analysis indicates that 22 statements of credit product are valid i.e., when these institutions promise to do something by a certain time, they should do so (p1), when customers have problems, these institutions should be sympathetic and reassuring (p2), these institutions should be dependable (p3), they should provide their credit services 
at the time they promise to do so (p4), they should keep their records accurately (p5), they should not be expected to tell their customers exactly when credit services will be performed (p6), it is not realistic for customers to expect prompt service from employees of these institutions ( $\mathrm{p} 7$ ), their employees do not always have to be willing to help customers (p8), it is okay if they are too busy to respond to customer requests promptly (p9), customer should be able to trust employees of these institutions (p10), customer should be able to feel safe in their transactions with these institutions' employees (p11), their employees should be polite (p12), their employees should get adequate support from these institutions to do their jobs well (p13), the statements of these institutions should not be expected to give customers individual attention (p14), employees of this institution cannot be expected to give customers personal attention (p15), it is unrealistic to expect these institutions to have their customers' best interest at heart (p16), it is unrealistic to expect employees to know what the needs of their customers are (p17), they should not be expected to have operating hours convenient to all their customers (p18), they should have up-to-date equipment and technology (p19), their physical facilities should be visually appealing (p20), their employees should be well dressed and appear neat (p21) and the appearance of the physical facilities of these institutions should keep up with the type of service provided (p22), where corrected item-total correlation or r-account positive more than r-table in degree of freedom $(\mathrm{df}=200-2) 198$ and significant level $5 \%$ namely 0.091 . Furthermore, the variables above are reliable. It is shown that $r$-alpha 0.947 is a higher positive value than r-table 0.091 (Table 10).

\subsubsection{The credit variable validity test}

$\mathrm{KMO}$ and Bartlett's test performed at 0.919 with significance 0.000 . The point is over 0.5 and it significance is below $0.05(0.000<0.05)$ then the variables and samples can be used for the further analysis. Moreover in anti-image correlation, especially on correlation point "a" sign as seen in Table 11 MSA was found to exceed 0.5 , i.e., when these institutions promise to do something by a certain time, they should do so (p1), when customers have problems, these institutions should be sympathetic and reassuring (p2), these institutions should be dependable (p3), they should provide their credit services at the time they promise to do so (p4), they should keep their records accurately (p5), they should not be expected to tell their customers exactly when credit services will be performed (p6), it is not realistic for customers to expect prompt service from employees of these institutions (p7), their employees don't always have to be willing to help customers (p8), it is okay if they are too busy to respond to customer requests promptly (p9), customer should be able to trust employees of these institutions (p10), customer should be able to feel safe in their transactions with these institutions' employees (p11), their employees should be polite (p12), their employees should get adequate support from these institutions to do their jobs well (p13), the statements of these institutions should not be expected to give customers individual attention (p14), employees of this institution cannot be expected to give customers personal attention (p15), it is unrealistic to expect these institutions to have their customers' best interest at heart (p16), it is unrealistic to expect employees to know what the needs of their customers are (p17), they should not be expected to have operating hours convenient to all their customers (p18), they should have up-to-date equipment and technology (p19), their physical facilities should be visually appealing (p20), their employees should be well dressed and appear neat (p21) and the appearance of the physical facilities of these institutions should keep up with the type of service provided (p22). It means that the twenty-two variables of credit service quality can be involved in further analysis (Table 11).

\subsubsection{The credit variable rotation}

The variables above can be reduced to become just three factors. It is a different classification compared to the original SERVQUAL by Parasuraman, Zeitham and Berry as seen in Table 12.

The first factor is named CSERVQUAL-1. Fifty percent (11 out of the credit 22) service variable were included in this factor. That is when these institutions promise to do something by a certain time, they should do so ( $\mathrm{p} 1$ ), when customers have problems, these institutions should be sympathetic and reassuring (p2), these institutions should be dependable (p3), they should provide their credit services at the time they promise to do so (p4), they should keep their records accurately (p5), it is not realistic for customers to expect prompt service from employees of these institutions (p7), their employees do not always have to be willing to help customers (p8), it is okay if they are too busy to respond to customer requests promptly (p9), customer should be able to trust employees of these institutions (p10), customer should be able to feel safe in their transactions with these institutions' employees (p11), and their employees should be polite (p12). In credit product (CSERVQUAL-1), customers also want reliability, responsiveness and assurance, which means that the product they use can solve the business problem they face. Total variable explained by CSERVQUAL-1 is $50.1 \%$.

The second factor is named CSERVQUAL-2. In this factor 6 out of 22 credit service were included (27.3\%). Within this factor, it is unrealistic to expect these institutions to have their customers' best interest at heart (p16), they should not be expected to have operating hours convenient to all their customers ( $\mathrm{p} 18$ ), they should have up-to-date equipment and technology (p19), their physical facilities should be visually appealing (p20), their employees should be well dressed and appear neat (p21), and the appearance of the physical facilities of these institutions should be in keeping 
with the type of service provided (p22). CSERVQUAL-2 indicates that credit customer want visual facilities support from bank supporting to its business road and accepted memorable experience from employee. This matter is not absolute for the Minangkabau customers, where they have by generations become Bank Nagari customer. Total variance explained by CSERVQUAL-2 is $12.1 \%$

The third factor is named CSERVQUAL-3. Within this factor, only 5 out of 22 credit services included i.e., financial institutions should not be expected to tell their customers exactly when credit services will be performed (p6), their employees should get adequate support from these institutions to do their jobs well (p13), the statements of these institutions should not be expected to give customers individual attention (p14), employees of this institution cannot be expected to give customers personal attention (p15) and it is unrealistic to expect employees to know what the needs of their customers are (p17). Customer will improve usage of credit product if it is associated with good memorable experience. Parallel to that, if the faith level customer to a product has been good and memorable hence his faith will become excelsior. For the case of Bank Nagari its credit product is observed to have SERVQUAL-3, stressing empathy to service quality, meaning there were frictions from previous service quality. Total variance explained by CSERVQUAL-3 is only 5\%. Referring to the finding by Parasuraman, Zeitham and Berry in Kartajaya al et. (2003), ${ }^{60}$ reliability is among the five service dimensions assumed to be most important by customers. The five dimensions contribution are reliability (32\%); responsiveness (22\%); assurance (19\%); empathy (16\%); and tangibles (11\%).

\subsubsection{The questionnaire test of income}

The validity analysis indicates that food (y1), celebration (y3), housing (y6) and credit (y10) are valid variables because the reliability analysis in corrected item-total correlation more than $\mathrm{r}$-table on $\mathrm{df}=200-2=198$, significant level $(\alpha) 5 \%$ and r-table 0.091. Conversely, clothing (y2), education (y4), health (y5), recreation (y7), transportation (y8), saving (y9), and other (y11) are invalid as the value of the corrected item-total correlation is less than $\mathrm{t}$-table $(\mathrm{df}=198, \alpha=5 \%), 0.091$. As a result, income variables have to be retested. Reliability test eventually shows that r-alpha; 0.2221 is more than $r$-table; 0.091 indicating reliability of the income variable.

The second validity test of income instruments indicate that food (y1), celebration (y3), housing (y6), and credit (y10) are valid, and reliability test shows the income instruments are reliable (Table 13b).

\subsubsection{The income variable validity test}

The value of KMO and Bartlett's test performed was 0.529 which was significant at 0.000 . The value is over 0.5 and significant below $0.05(0.000<0.05)$ than the variables and samples can be used for the next analysis. Moreover, in anti-image correlation, especially on correlation point "a" sign MSA found for food (y1), housing (y6) and credit (y10) were more than 0.5. It means that the three income variables can be analyzed further. It is summarized in Table 16a and Table 16b. Thus, celebration (y3) have to be dropped of the analysis because the variability is less than 0.50 . The re-factor analysis found that $\mathrm{y} 1, \mathrm{y} 6$ and $\mathrm{y} 10$ are more than 0.50 , meaning that only three variables can be used for the next analysis (Table 14).

\subsubsection{The income variable rotation}

The variables above can be reduced to become just one factor consisting of food (y1), housing (y6) and credit (y10). Housing expenditures include expenditures in utility bills: water, electricity, telephone and hand phone while credit incorporates expenditure in the Bank credit repayment. There are two distinct behaviors in the expenditure pattern of Minangkabau and Chinese households concerning food, housing and credit. The Minangkabau behavior in the expenditure on food more have the character of sustaining their living, that is the tendency earn only sufficiently for daily and expenses without concerning themselves with future plans. Capital accumulation is only attained through addition efforts and future consumption depends on future conditions. Besides that, the amount of saving generated by this ethnic group is relatively small and expensive purchases need the support from local banks. Minangkabau expenditures for housing and credit are always not supported. Minangkabau customers use their houses only as residence while they trade at different places. House represents a separate pride to a Minangkabau customer. Ownership of other facilities such as cars is a second any matter. Home ownership is important for a Minangkabau family. They will strive to get homes either through their achievements work or until they can afford to build good house. Besides that, home ownership is important because the Minangkabau society embraces their mother lineages (matriarchal families).

\subsection{Binomial Logistic Regression Results}

\subsubsection{Credit Products}

Table 15 and 16 present the mean and standard deviation of credit, culture and income variables. Generally the mean value of credit products, culture, and income are bigger than the standard deviation value of credit, culture, and income. It can be concluded that each of the variables are feasible for the next analysis. Additionally, the means for housing and credit are smaller than their standard deviations meaning that both variables must be excluded from analysis. 
Table 17 indicates that the model is feasible for the next analysis because its probability point or Hosmer and Lemeshow Goodness-of-Fit Test is .075 which is more than .050 . It means there is no real difference between predicted and observed result. As for the results of the t-test in Table 17, all of the variables are significant statistically (see significant point), but income coefficient have a negative sign. It is really different from the theoretical concept above. In equation form of credit binomial logistic regression can be rewritten as follow:

$\mathrm{C}_{\text {credit }}=3,095+1,728 \times 1 \mathrm{t}+0,657 \times 2 \mathrm{t}-3,917 \times 3 \mathrm{t}$

where the probability of Minangkabau credit consumption is $1 /\left(1+\mathrm{e}^{-(3,095+1,728 \times 1++0,657 \times 2 t-3,917 \times 3 \mathrm{t})}\right)$ and the probability of Chinese credit consumption is $1 /\left(1+\mathrm{e}^{3,095+1,728 \times 1 t+0,657 \times 2 t-3,917 \times 3 \mathrm{t}}\right)$. The interpreting of Minangkabau credit consumption is Minangkabau consumption changes is $1,728 \mathrm{p}^{\wedge}\left(1-\mathrm{p}^{\wedge}\right)$ due to changes in the culture is 1 . Minangkabau consumption changes is $0,657 \mathrm{p}^{\wedge}\left(1-\mathrm{p}^{\wedge}\right)$ due to changes in the credit SERVQUAL is 1. Thus, Minangkabau consumption changes is $-3,917 \mathrm{p}^{\wedge}\left(1-\mathrm{p}^{\wedge}\right)$ due to changes in the income is Rp.1,-

Whereas for Chinese credit consumption as follow: The interpreting of Chinese credit consumption is Chinese consumption changes is $-1,728\left(1-p^{\wedge}\right) p^{\wedge}$ due to changes in the culture is 1 . Chinese consumption changes is $-0,657(1-$ $\left.\mathrm{p}^{\wedge}\right) \mathrm{p}^{\wedge}$ due to changes in the credit SERVQUAL is 1 . Thus, Chinese consumption changes is $3,917\left(1-\mathrm{p}^{\wedge}\right) \mathrm{p}^{\wedge}$ due to changes in the income is Rp.1,-

Furthermore there are some reason for the negative sign of income namely income psychometric and disconnected consumption (money decision) to income. In this case all customers were asked to compare their expenditure and determine which expenditure is larger from the other. In doing the comparison, subjects are not allowed to express that two expenditures are of equal size, so that they are obliged to determine that one expenditure is larger than the other. Therefore, the level of customer expenditure can be established. Expenditure level in its influence to consumption gives negative inclination. In fact, customer choices with existence of the make-up of earnings are indirectly related and to make-up of usage of financial products. Whereas, the real consumption for example food, payment of water bill, electricity, hand-phone and telephone are directly correlated.

From the ethnic consumption model (Minangkabau-Chinese) of credit products above it can be concluded that ethnic consumption is determined by culture and customer perception from consuming the credit product, and a positive relation means that the make-up of cultural values and customer perception to credit proportionally improve ethnic consumption.

\subsubsection{Saving Products}

Furthermore, Table 18 below exhibits that means for saving products are bigger than standard deviation. It indicates that each variable is feasible for the next analysis. The next analysis is presented in Table 18. Table 19 indicates that the model is doubtful in its significance value at .05 .

Thus, table 19 indicates that the significant probability of Hosmer and Lemershow goodness-of-fit test is small and equal with $.05(\leq .05)$. It indicates that the saving model can be concluded as an feasible model for the next analysis because the probability point or Hosmer and Lemeshow Goodness-of-Fit Test is at .05, which means that there is not real difference between prediction and observation classification. Results of the t-test presented in this table show that culture, saving, and income variables are statistically significant (see significance point).

In equation form of saving binomial logistic regression can be rewritten as follow:

$\mathrm{C}_{\text {saving }}=3,192+1,630 \times 1 \mathrm{t}+0,754 \times 2 \mathrm{t}-3,862 \times 3 \mathrm{t}$

where the probability of Minangkabau saving consumption is $1 /\left(1+\mathrm{e}^{-(3,192+1,630 \times 1+t+0,754 \times 2 t-3,862 \times 3 t)}\right)$ and the probability of Chinese saving consumption is $1 /\left(1+\mathrm{e}^{3,192+1,630 \times 1+t+0,754 \times 2 \mathrm{t}-3,862 \times 3 \mathrm{t}}\right)$. The interpreting of Minangkabau saving consumption is Minangkabau consumption changes is $1,630 \mathrm{p}^{\wedge}\left(1-\mathrm{p}^{\wedge}\right)$ due to changes in the culture is 1 . Minangkabau consumption changes is $0,754 \mathrm{p}^{\wedge}\left(1-\mathrm{p}^{\wedge}\right)$ due to changes in the saving SERVQUAL is 1 . Thus, Minangkabau consumption changes is $-3,862 \mathrm{p}^{\wedge}\left(1-\mathrm{p}^{\wedge}\right)$ due to changes in the income is Rp.1,-

Whereas for Chinese saving consumption as follow: The interpreting of Chinese saving consumption is Chinese consumption changes is $-1,630\left(1-\mathrm{p}^{\wedge}\right) \mathrm{p}^{\wedge}$ due to changes in the culture is 1 . Chinese consumption changes is $-0,754(1-$ $\left.\mathrm{p}^{\wedge}\right) \mathrm{p}^{\wedge}$ due to changes in the saving SERVQUAL is 1 . Thus, Chinese consumption changes is $3,862\left(1-\mathrm{p}^{\wedge}\right) \mathrm{p}^{\wedge}$ due to changes in the income is Rp.1,-

From the ethnic consumption model between the Minangkabau and Chinese in saving products above one can conclude that at significance level 0.05 ethnic consumption is determined by culture and consumer perception from consuming the saving products, and has a positive relation which means that the make-up of culture and customer perception to saving proportionally improve ethnic consumption.

\subsection{Analysis of Varian (ANOVA)}

From Table 20 below the result shows that ANOVA of Culture, SERVQUAL, and income among Minangkabau and Chinese customers have significantly probability. The significant (Sig.) of culture is .000 less than 0.05 . Its means there 
is difference in the LOV among Minangkabau and Chinese customers. The sig. of saving (.000) and credit (.000) SERVQUAL are less than 0.05. Its means there is difference in saving and credit SERVQUAL among Minangkabau and Chinese customers. Thus, the sig. of income is .000 less than 0.05. Its mean there is difference in income among Minangkabau and Chinese.

Generally, Infer that from results of the ANOVA, there are significant differences of culture, saving, credit, and income in relation to ethnic consumption of the Minangkabau and Chinese customers. The difference in culture, SERVQUAL, and income are explained in sub-heading types of the Minangkabau and Chinese customers.

\subsection{Discussion}

Result obtained show that culture, saving, credit and income variables are valid and reliable. This matter is seen from each r-account and r-alpha values, which are higher compared to r-table. Result of variable validity test by using factor analysis through KMO and Bartlet's test and anti-image correlation obtained show that culture, saving, credit, and income variables are bigger than .50, meaning the sample and variable can be used for the further analysis. Moreover, The factor analysis recommends that there is one factor to culture variable, three factors to saving variable, three factors to credit variable, and one factor to income variable. Credit and saving variables show that every factor has value of above .50. This means each factor strongly contributes to the formation of factor. Then this variabel regresses to its probability by using logistic regression. This consumption model is significant at test by partial by using significant probability .05 and test by totally Hosmer and Lemershow Goodness-of-Fit-Test .05. From this model can be concluded that there are difference consume among saving product and credit from ethnic Minangkabau and Chinese.

Both of ethnic differentiate in Culture, SERVQUAL, and Income. The difference is caused by the consumption motive, perception and average income are difference. On Minangkabau customers are not only business orientation to use the Bank Nagari products. There is kenagarian factors. Whereas Chinese customers are business orientation. Chinese customers always request SERVQUAL highly. Conversely Minangkabau customers receive average in SERVQUAL. Minangkabau customers have average in income. If compared with Chinese customers have highly income. They give contribution highly in the Bank Nagari profit. Hence they get highly SERVQUAL.

\section{Conclusions}

The following specific conclusions could be drawn from this study:

(1) The Minangkabau and Chinese consumption model of credit and saving products significantly are dependent on culture values, customer perception to SERVQUAL, and household expenditure. For both ethnic and products that culture values and customer perception to SERVQUAL have a positive relation means that the make-up of cultural values and customer perception to both products proportionally improve ethnic consumption. Conversely household expenditure have a negative relation means that the make-down of household expenditure to both products proportionally improve ethnic consumption.

(2) Both the consumption models uses the binary logistic model. The differences of Minangkabau and Chinese consumption model are probability each of the model. Probability expectation from Minangkababu consumption is more than Chinese consumption. The probability of Minangkabau credit consumption namely $1 /\left(1+\mathrm{e}^{-(3,095+1,728 \times 1++0,657 \times 2 t-3,917 \times 3 t)}\right)$ and The probability of Minangkabau saving consumption namely $1 /\left(1+\mathrm{e}^{-(3,192+1,630 \times 1++0,754 \times 2 t-3,862 \times 3 t)}\right)$. Thus, The probability of Chinese credit consumption namely $1 /(1+$ $\left.\mathrm{e}^{3,095+1,728 \times 1 t+0,657 \times 2 t-3,917 \times 3 \mathrm{t}}\right)$ and The probability of Chinese saving consumption namely $1 /\left(1+\mathrm{e}^{3,192+1,630 \times 1+t+0,754 \times 2 t-3,862 \times 3 \mathrm{t}}\right)$.

(3) The interpreting of Minangkabau credit consumption is Minangkabau consumption changes is $1,728 \mathrm{p}^{\wedge}\left(1-\mathrm{p}^{\wedge}\right)$ due to changes in the LOV is 1 . Minangkabau consumption changes is $0,657 \mathrm{p}^{\wedge}\left(1-\mathrm{p}^{\wedge}\right)$ due to changes in the credit SERVQUAL is 1 . Thus, Minangkabau consumption changes is $-3,917 \mathrm{p}^{\wedge}\left(1-\mathrm{p}^{\wedge}\right)$ due to changes in the income is Rp.1,-

(4) The interpreting of Chinese credit consumption is Chinese consumption changes is $-1,728\left(1-p^{\wedge}\right) p^{\wedge}$ due to changes in the LOV is 1 . Chinese consumption changes is $-0,657\left(1-\mathrm{p}^{\wedge}\right) \mathrm{p}^{\wedge}$ due to changes in the credit SERVQUAL is 1 . Thus, Chinese consumption change is 3,917 (1- $\left.\mathrm{p}^{\wedge}\right) \mathrm{p}^{\wedge}$ due to changes in the income is Rp.1,-

(5) The interpreting of Minangkabau saving consumption is Minangkabau consumption changes is $1,630 \mathrm{p}^{\wedge}\left(1-\mathrm{p}^{\wedge}\right)$ due to changes in the LOV is 1 . Minangkabau consumption changes is $0,754 \mathrm{p}^{\wedge}\left(1-\mathrm{p}^{\wedge}\right)$ due to changes in the saving SERVQUAL is 1 . Thus, Minangkabau consumption changes is $-3,862 \mathrm{p}^{\wedge}\left(1-\mathrm{p}^{\wedge}\right)$ due to changes in the income is Rp.1,-

(6) The interpreting of Chinese saving consumption is Chinese consumption changes is $-1,630\left(1-p^{\wedge}\right) p^{\wedge}$ due to changes in the LOV is 1 . Chinese consumption changes is $-0,754\left(1-p^{\wedge}\right) p^{\wedge}$ due to changes in the saving SERVQUAL is 1 . Thus, Chinese consumption changes is $3,862\left(1-\mathrm{p}^{\wedge}\right) \mathrm{p}^{\wedge}$ due to changes in the income is Rp.1,-

(7) The implication of the finding has on the consumption theory is consumption is not only function of income. In context consumption is only for daily goods consumption. But business consumption for financial products is determined by culture values, customer perception to SERVQUAL, and household expenditure. 
(8) The result of factor analysis indicates that there are three dimensions of saving products and three dimensions of credit products. The dimensions for saving products are labelled SSERVQUAL-1 (certain time, sympathy and reassurance, dependability, saving service, accurate records, prompt service, willingness to help consumers, prompt response to consumer request, trusted employees, and safe feeling), SSERVQUAL-2 (politeness, best interest at heart, convenient hours, up-to-date equipment and technology, visual appeal, well dressed and neat appearance and service type), and SSERVQUAL-3 (consumer information, adequate support, individual attention, personal attention and consumer needs).

(9) Whereas, the dimensions of credit products are labelled CSERVQUAL-1 (certain time, sympathy and reassurance, dependability, credit service, accurate records, prompt service, willingness to help consumers, prompt response to consumer request, trusted employees, safe feeling, and politeness), CSERVQUAL-2 (best interest at heart, convenient hours, up-to-date equipment and technology, visual appeal, well dressed and neat appearance and service type), and CSERVQUAL-3 (consumer information, adequate support, individual attention, personal attention and consumer needs).

\section{Recommendations and Further Studies}

The following points could be considered for recommendations and further studies:

(1) The findings of the study can be used by Regional Development Banks, Bankers and financial customers. It hopes to facilitate Regional Development Bank, in attaining optimal profit. Bankers would be able to offer optimal service to its customer. This will encourage customers to use banking products and services and provide alternatives to customers in the use of banking services.

(2) The study could also be used in identifying and developing relevant policies in helping the traders (especially small traders) managing credit and savings.

(3) The limitation of secondary data hence measurements of consumption function by considering customer behavior, cultural aspects and perception.

(4) Extensive studies are required on other different ethnic groups to provide a broader comparison between them for example studies on the Javaness-Chinese, Chinese-Tapanuli, Minangkabau-Tapanuli, Minangkabau-Javaness and Javaness-Tapanuli ethnics. Moreover, researchers can focus on the Chinese families and clans, which educate them to become natural entrepreneurs. The structure of the certainty of Rights in Minangkabau and Tapanuli, according to Ong Hock Ham in Roziqin (1997) could possibly impose a successful link in commerce.

(5) Visual analysis is necessary, by using the geography Information System (GIS) along with cluster analysis, factor analysis, and logistic regression. Such method is beneficial for obtaining more accurate consumption model. GIS analysis will also be of benefit to entrepreneurs as they will have access to information regarding earlier behavior of ethnic customers in an area.

\section{References}

Febrianto, Danu (1998, July/August). Independensi Bank Indonesia Antara Harapan dan Kenyataan. Bank \& Manajemen, 22-24.

Idris, La Ode. (1997, October). INFOBANK, pp. 36-43.

Kimball, R. C. and Gregor, W.T. (1995). How Distribution is Transforming Retail Banking Changes Leading Banks are Making. Journal of Retailing Banking Service, 17 (Autumn), 1-9.

Chakravarty, S.,Feinberg,R.A, and Winddows, R. (1995). What Do Customers Want from Banks?. Journal of Retail Banking, 17 (Summer), 15-19.

Glassman, C.A. (1995). Industry Structure: Erosion of Banks' Franchise. Journal of Retail Banking Service, 17 (Autumn), 53-58.

Utung Ada Bank Nagari. (2000, March 13). Mimbar Minang.

Bersama Membangun Ekonomi Ranah Minang. (2001, April). INFOBANK.

Salah Satu Penggerak Ekonomi Sumatera Barat. (2001, March). INFOBISNIS, pp. 42-43.

Hebat, BPD Sumbar Kembangkan Sayapnya Ke Pekanbaru dan Jakarta. (2000, September 28). Harian Haluan.

Junus, Umar. (1990, May). Minangkabau Suatu Paradoks. TEMPO, p. 109.

Roziqin, M.Khoerur. (1997). Keberhasilan Bisnis Cina di Indonesia : Sebuah Catatan. Artikel Media Akuntansi, 21, vi-xi.

Hoyt, Elizabeth Ellis. (1976). The Consumption of Wealth. New York : MacMillan pp.9-10.

Kyrk, Hazel. (1976). A Theory of Consumption. New York : Arnos-Press. pp.172-189. 
Keynes, J,M. (1936). General Theory of Empoyment Interest and Money. London : MacMillan pp.96-108.

Duesenberry, James S. (1949). Income, Saving and the Theory of Consumer Behavior. London: Oxford University Press pp.19,110-116.

Assael, Hendry. (1998). Consumer Behavior and Marketing Action ( $6^{\text {th }}$ ed). Ohio: South-Western College pp. 92,95, $423,459,470,479$

Schiffman, Leon G and Kanuk, Leslie Lazar. (1991). Consumer Behavior $\left(4^{\text {th }}\right.$ ed). USA: Prentice Hall Englewood Cliffs p.424.

Kahle, LYNN, R., Beatty, Sharon E, \& Homer, Pamela (1986). Alternative Measurement Approaches to Consumer Values: The List of Value (LOV) and Values and Life Style (VALS). Journal of Consumer Research, 13, 405-409.

Riddle, D. (1992). Leveraging Cultural Factors in International Service Delivery. Advances in Services Marketing and Management, 1, 297-322.

Pucik, V and Katz, J. (1986). Information, Control and Human Resource Management in Multinational Firm. Human Resource Management, 25, 121-132.

Bolton, Ruth N and Drew, James H. (1991). A Longitudinal Analysis of the Impact of Service Changes on Customer Attitudes. Journal of Marketing, 56(January) ,1-9.

Parasuraman, A.,Zeitham, Valarie A , \& Berry, Leonard L. (1988). SERVQUAL: A Multiple-Item Scale for Measuring Customer Perception of Service Quality. Journal of Retailing, 64(Spring), 12-40.

Bitner, Mary Jo. (1990). Evaluating Service Encounter: The Effects of Physical Surroundings and Employee Responses. Journal of Marketing, 54(April), 69-82.

Woodruff, Robert B, Codotte, Ernest R and Jenkins, Roger L. (1983). Modeling Consumer Satisfaction Processes Using Experience-Based Norms. Journal of Marketing Research, 20(August), 296-304.

Brown, Stephen and Swartz, Teresa A. (1989). A Gap Analysis of Professional Service Quality. Journal of Marketing, 53(April) ,92-98.

Carman, James M.(1990). Consumer Perceptions of Service Quality: An Assessment of the SERVQUAL Dimensions. Journal of Retailing, 66(1), 33-55.

Teas, R Kenneth. (1993). Expectations, Performance Evaluation, and Consumers' Perception of Quality. Journal of Marketing, 57(October), 18-34.

Babakus, Emin and Boller, Gregory W.(1992). An Empirical Assessment of the SERVQUAL Scale. Journal of Business Research, 24, 253-268.

Cronin, J Joseph Jr. and Taylor, Steven A. (1992). Measuring Service Quality: A Reexamination and Extension. Journal of Marketing, 56(July), 55-68.

Boulding, William, Kalra, Ajay, Staelin, Richard and Zeithaml, Valarie. (1993). A Dynamic Process Model of Service Quality: From Expectation to Behavioral Intentions. Journal of Marketing Research, 30(February), 7-27.

Cronin, J Joseph Jr. and Taylor, Steven A. (1994). SERVPERF Versus SERVQUAL: Reconciling Performance-Based and Perception-Minus-Expectations Measurement of Service Quality. Journal of Marketing, 58(January), 125-131.

Teas, R Kenneth. (1994). Expectations as a Comparison Standard in Measuring Service Quality: An Assessment of a Reassessment. Journal of Marketing, 58(January), 132-139.

Brown, Tom J, Churchil, JR Gilbert A and Peter, J Paul. (1993). Research Note: Improving the Measurement of Service Quality. Journal of Retailing, 69(1), 127-139.

Parasuraman, A., Zeitham, Valarie A \& Berry, Leonard L. (1994). Alternative Scales for Measuring Service Quality: A Comperative Assessment Based on Psychometric and Diagnostic Criteria. Journal of Retailing, 70(3), 201-230.

Bitner, M. (1992). Servicescope: The Impact of Physical Surroundings on Customer and Employee. Journal of Marketing, 56, 69-82.

Lawson, R. (1997). Consumer Decision Making Within a Goal Driven Framework. Psyschology \& Marketing, 14(5), 427-449.

Dube, L. (1990). The Power of Affective Report in Predicting Satisfaction Judgements. Advances in Consumer Research, 17, 571-576.

MaCracken, Grant. (1986). Culture and Consumption: A Theoretical Account of the Structure and Movement of the Cultural Meaning of Consumer Goods. Journal of Consumer Research, 13, 71-84. 
Tan, Chin Tiong and Farley, John V. (1987). The Impact of Cultural Patterns on Cognition and Intention in Singapore. Journal of Consumer Research, 13, 540-544.

Donthu, Naveen and Cherian, Joseph. (1994). Impact of Strength of Ethnic Identification Hispanic Shopping Behavior. Journal of Retailing, 70(4), 383-393.

Bearden, William O and Teel, Jesse E (1983). Selected Determinants of Consumer Satisfaction and Complaint Reports. Journal of Marketing Research, 20(February), 21-28.

Oliver, Richard L. (1980). A Cognitive Model of the Antecedents and Consequences of Satisfaction Decision. Journal of Marketing Research, 17(November), 460-469.

Oliver, Richard L and Swan, John E. (1989). Consumer Perception of Interpersonal Equity and Satisfaction in Transaction: A Field Survey Approach. Journal of Marketing, 53(April), 21-35.

LaBarbera, Priscilla A and Mazursky, David. (1983). A Longitudinal Assessment of Consumer Satisfaction/Dissatisfaction: The Dynamic Aspect of the Cognitive Process. Journal of Marketing Research, 20(November), 393-404.

Taylor, Steven A and Baker, Thomas L. (1994). An Assessment of the Relationship Between Service Quality and Customer Satisfaction in the Formation of Consumers' Purchase Intentions. Journal of Retailing, 70(2), 163-178.

Donthu, Naveen and Yoo, Boonghee. (1998). Cultural Influences on Service Quality Expectations. Journal of Service Research, 1(2), 178-186.

Mantra, Ida Bagoes and Kasto (1989). Penentuan Sampel, in Masri Singarimbun and Sofian Effendi (ed) Metode Penelitian Survai. Jakarta: LP3ES pp.159-162.

Parasuraman, A. (1986). Marketing Research. Canada :Addison-Wesley.pp.372-469.

Salvatore, Dominick. (2001). Managerial Economic (4 $4^{\text {th }}$ ed). Canada :Wesley. Pp. 372-469.

Twang Peck Yang. (1998). The Chinese Business Elite in Indonesia and the Transition to Independence 1940-1950. Singapore : Oxford University Press pp.18-69.

Paim, Laily. (1993). A Model for Measuring Poverty. Unpublished Doctoral Dissertation, University of Illinois, Urbana-Champaign.

Hunt, Selby, Sparkman, Richard D, and Wilcox, James B. (1982). The Pretest in Survey Research: Issues and Prelimary Findling. Journal of Marketing Research, 19, 269-273.

Nunnally, J.C. (1978). Psychometric Theory. New york: McGraw Hill Book Company.

Peter, J.P. (1979). Reliability: A Review of Psychometric Basic and Recent Marketing Practices. Journal of Marketing Research, 16 (February), 6-17

Tay, Angeline. (1998). A Psychographic Study and Discriminant Analysis of Urban Working Women in Apparel Purchase. Malaysian Journal of Consumer and Family Economics, 1, 116-131.

Santoso, Singgih. (2001). Buku Latihan SPSS Statistik Non Parametrik. Jakarta: PT Elex Media Komputindo pp. 118-126.

Ramanathan, Ramu. (1992). Introductory Econometrics with Appliation (2 $\left.{ }^{\text {nd }} e d\right)$. Florida : Harcourt Brace Javanovich, Inc. pp.183, 513-526.

Lehmann, Donald, Gupta, R Sunil and Steckel, Joel H. (1998). Marketing Research. USA : Addison-Wesley pp.565-715.

Goleman, Daniel. (1995). Emotional Intelligence: Why It Can Matter More Than IQ. New York: Bantam Books.

Kartajaya, Hermawan, Yuswohady, Madyani, Dewi and Indrio, Bembi Dwi. (2003). Marketing in Venus. Jakarta: PT Gramedia Pustaka Utama pp.83-95.

Notes

Note 1. Indonesia has central bank, is called Indonesia Bank. Indonesia Bank controls commercial, syahriah, and people credit banks (BPR). BPR bank is especially for micro banking. There is different definition between micro and small banking. Micro banking is banking activities in rural areas and provides credit up to Rp. 1 million and small banking is banking activities bigger than micro banking and it provides credit more than Rp. 1 million.

Note 2. Giro is a checking account. Giro is divided into saving and credit giro. Saving giro is checking account in saving and credit giro is checking account in credit.

Note 3. TAMI is special saving for micro /small business. KUMI and KUKI are micro/small credit for small business. KUMI and KUKI have credit maximum from Rp. 1 million up to Rp. 5 million. SIMPEDA is cooperation saving with 
other Regional Bank in Indonesia and KESRA is cooperation saving with other private bank in Indonesia. Both of them are general saving.

Table 1. The network "Self-Supporting Bridge Cash (ATM)" of Government and private banks in Padang

\begin{tabular}{|c|c|c|}
\hline Banks & Unit & $\%$ \\
\hline \multicolumn{3}{|l|}{ Government Banks } \\
\hline 1. Bank Nagari BPD Sumbar & 2 & 2 \\
\hline 2. $\quad$ BNI $\left.1946^{*}\right)$ & 21 & 26 \\
\hline 3. BRI $\left.^{*}\right)$ & 4 & 5 \\
\hline 4. $\mathrm{BTN}$ & 1 & 1 \\
\hline 5. $\quad$ BTPN & 1 & 1 \\
\hline 6. $\quad$ Bank Mandiri $\left.{ }^{*}\right)$ & 18 & 22 \\
\hline \multicolumn{3}{|l|}{ Private Banks } \\
\hline 7. Bank BCA & 13 & 17 \\
\hline 8. Bank Bukopin & 5 & 6 \\
\hline 9. Bank Mega & 1 & 1 \\
\hline 10. Bank Permata & 1 & 1 \\
\hline 11. Bank Mestika & 1 & 1 \\
\hline 12. Bank Lippo & 5 & 6 \\
\hline 13. Bank Danamon & 4 & 5 \\
\hline 14. Bank BII & 5 & 6 \\
\hline 15. Bank Muamalat & 0 & 0 \\
\hline BPR & 0 & 0 \\
\hline Total & 82 & 100 \\
\hline
\end{tabular}

") including syariat bank

Source: Personal communication with relevant banks. 
Table 2. SERVQUAL Battery

\begin{tabular}{|c|c|}
\hline Dimension & Component \\
\hline Reliability & $\begin{array}{l}\text { 1. Providing service as promised. } \\
\text { 2. Dependability in handling consumers' service problems. } \\
\text { 3. Performing services right the first time. } \\
\text { 4. Providing service at the promised time. } \\
\text { 5. Maintaining error-free records. }\end{array}$ \\
\hline Responsiveness & $\begin{array}{l}\text { 6. Keeping consumers informed about when service will be performed. } \\
\text { 7. Prompt service to consumers. } \\
\text { 8. Willingness to help consumers. } \\
\text { 9. Readiness to respond to consumers' requests. }\end{array}$ \\
\hline Assurance & $\begin{array}{l}\text { 10. Employees who instill confidence in consumers. } \\
\text { 11. Making consumers feel safe in their transactions. } \\
\text { 12. Employees who are consistently courteous. } \\
\text { 13. Employees who have the knowledge to answer consumers' } \\
\text { questions. }\end{array}$ \\
\hline Empathy & $\begin{array}{l}\text { 14. Giving consumers individual attention. } \\
\text { 15. Employees who deal with consumers in a caring fashion. } \\
\text { 16. Having the consumers' best interest at heart. } \\
\text { 17. Employees who understand the needs of their consumers. } \\
\text { 18. Convenient business hours. }\end{array}$ \\
\hline Tangibles & $\begin{array}{l}\text { 19. Modern equipment. } \\
\text { 20. Visually appealing facilities. } \\
\text { 21. Employees who have neat, professional appearance. } \\
\text { 22. Visually appealing materials associated with the service. }\end{array}$ \\
\hline
\end{tabular}

Source: Parasuraman, A., Zeitham, Valarie A \& Berry, Leonard L (1994) 
Table 3. Profile of Respondents

\begin{tabular}{|c|c|c|}
\hline & $\begin{array}{c}\text { Frequency } \\
\qquad(\mathrm{n}=\mathbf{2 0 0})\end{array}$ & Percentage \\
\hline \multicolumn{3}{|l|}{ Ethnicity } \\
\hline Minangkabau & 150 & $75.0 \%$ \\
\hline Chinese & 50 & $25.0 \%$ \\
\hline \multicolumn{3}{|l|}{$\operatorname{Sex}$} \\
\hline Male & 151 & $75.5 \%$ \\
\hline Female & 49 & $24.5 \%$ \\
\hline \multicolumn{3}{|l|}{ Status } \\
\hline Married & 197 & $98.5 \%$ \\
\hline Separated & 3 & $1.5 \%$ \\
\hline \multicolumn{3}{|l|}{ Age } \\
\hline $30-34$ & 14 & $7.0 \%$ \\
\hline $35-39$ & 22 & $11.0 \%$ \\
\hline $40-44$ & 51 & $25.5 \%$ \\
\hline $45-49$ & 32 & $16.0 \%$ \\
\hline $50-54$ & 27 & $13.5 \%$ \\
\hline $55-59$ & 18 & $9.0 \%$ \\
\hline $60-64$ & 27 & $13.5 \%$ \\
\hline $65-69$ & 9 & $4.5 \%$ \\
\hline \multicolumn{3}{|l|}{ Educational Level } \\
\hline $\begin{array}{l}\text { Primary School \& } \\
\text { Lower }\end{array}$ & 11 & $5.5 \%$ \\
\hline Junior High School & 43 & $21.5 \%$ \\
\hline Senior High School & 94 & $47.0 \%$ \\
\hline Diploma & 3 & $1.5 \%$ \\
\hline Bachelor's degree & 49 & $24.5 \%$ \\
\hline \multicolumn{3}{|l|}{ Profession } \\
\hline Trader & 189 & $94.5 \%$ \\
\hline Manufacturer & 3 & $1.5 \%$ \\
\hline Distributor & 5 & $2.5 \%$ \\
\hline Other & 3 & $1.5 \%$ \\
\hline
\end{tabular}


Table 4. The Validity and Reliability Analyses of Cultural Instruments

\begin{tabular}{|c|c|}
\hline & $\begin{array}{c}\text { Corrected } \\
\text { Item-Total } \\
\text { Correlation }\end{array}$ \\
\hline $\mathrm{C} 1$ & .7086 \\
\hline $\mathrm{C} 2$ & .7428 \\
\hline $\mathrm{C} 3$ & .7508 \\
\hline $\mathrm{C} 4$ & .5331 \\
\hline $\mathrm{C} 5$ & .7656 \\
\hline $\mathrm{C} 6$ & .7071 \\
\hline $\mathrm{C} 7$ & .7159 \\
\hline $\mathrm{C} 8$ & .7477 \\
\hline $\mathrm{C} 9$ & .7522 \\
\hline$\alpha$ & .9162 \\
\hline
\end{tabular}

Table 5. The Feasibility Test of Culture Variables

\begin{tabular}{|c|c|}
\hline & LOV Variables \\
\hline Kaiser-Meyer-Olkin & \\
(KMO) & .924 \\
Measure of Sampling & \\
\hline C1equacy (MSA) & \\
C2 & .915 \\
C3 & .959 \\
C4 & .906 \\
C5 & .939 \\
C6 & .927 \\
C7 & .903 \\
C8 & .891 \\
C9 & .947 \\
\hline
\end{tabular}

Table 6. Factor Loadings of the LOV

\begin{tabular}{|l|c|}
\hline \multicolumn{1}{|c|}{ Instrument } & Factor \\
\hline self-fulfillment vs. no self-fulfillment & .771 \\
\hline excitement vs. sadness & .807 \\
\hline sense-accomplishment vs. sense-foolishness & .808 \\
\hline self-respect vs. no self-respect & .608 \\
\hline sense of belonging vs. sense of consuming & .822 \\
\hline being well respected vs. being unrespected & .783 \\
\hline security vs. insecurity & .793 \\
\hline fun and enjoyment in life vs. displeasure in life & .816 \\
\hline $\begin{array}{l}\text { warm relationships with others vs. cold relationship with } \\
\text { others }\end{array}$ & .817 \\
\hline
\end{tabular}


Table 7. The Validity and Reliability Analyses of Saving Instruments

\begin{tabular}{|c|c|}
\hline & Corrected Item-Total Correlation \\
\hline $\mathrm{p} 1$ & .5986 \\
\hline $\mathrm{p} 2$ & .6513 \\
\hline p3 & .5477 \\
\hline $\mathrm{p} 4$ & .6858 \\
\hline p5 & .6941 \\
\hline p6 & .5062 \\
\hline $\mathrm{p} 7$ & .6896 \\
\hline $\mathrm{p} 8$ & .7177 \\
\hline p9 & .6921 \\
\hline p10 & .7311 \\
\hline $\mathrm{p} 11$ & .7045 \\
\hline $\mathrm{p} 12$ & .7007 \\
\hline $\mathrm{p} 13$ & .6856 \\
\hline $\mathrm{p} 14$ & .5776 \\
\hline $\mathrm{p} 15$ & .6071 \\
\hline $\mathrm{p} 16$ & .6485 \\
\hline p17 & .5707 \\
\hline $\mathrm{p} 18$ & .7194 \\
\hline p19 & .7443 \\
\hline $\mathrm{p} 20$ & .7429 \\
\hline $\mathrm{p} 21$ & .7199 \\
\hline $\mathrm{p} 22$ & .6833 \\
\hline$\alpha$ & .9490 \\
\hline
\end{tabular}


Table 8. The Validity Test of Saving Variables

\begin{tabular}{|c|c|}
\hline & Saving Variables \\
\hline $\begin{array}{l}\text { Kaiser-Meyer-Olkin } \\
\text { (KMO) }\end{array}$ & \multirow[t]{2}{*}{.916} \\
\hline Measure of Sampling Adequacy (MSA) & \\
\hline $\mathrm{p} 1$ & .937 \\
\hline $\mathrm{p} 2$ & .921 \\
\hline p3 & .884 \\
\hline $\mathrm{p} 4$ & .954 \\
\hline $\mathrm{p} 5$ & .890 \\
\hline p6 & .853 \\
\hline p7 & .911 \\
\hline $\mathrm{p} 8$ & .921 \\
\hline p9 & .931 \\
\hline $\mathrm{p} 10$ & .935 \\
\hline $\mathrm{p} 11$ & .913 \\
\hline $\mathrm{p} 12$ & .934 \\
\hline p13 & .914 \\
\hline p14 & .872 \\
\hline p15 & .886 \\
\hline p16 & .943 \\
\hline $\mathrm{p} 17$ & .888 \\
\hline p18 & .920 \\
\hline p19 & .906 \\
\hline $\mathrm{p} 20$ & .919 \\
\hline $\mathrm{p} 21$ & .941 \\
\hline p22 & .927 \\
\hline
\end{tabular}


Table 9. Factor Loadings of the Saving SERVQUAL Instruments

\begin{tabular}{|c|c|c|}
\hline \multicolumn{2}{|c|}{ Present Study } & \multirow{2}{*}{$\begin{array}{l}\text { Parasuraman et al } \\
\text { Instrument }\end{array}$} \\
\hline Questions & Factors & \\
\hline & SSERVQUAL-1 & Reliability \\
\hline $\begin{array}{l}\text { When these institutions } \\
\text { promise to do something by a } \\
\text { certain time, they should do } \\
\text { so }\end{array}$ & .663 & Providing service as promised \\
\hline $\begin{array}{l}\text { When customers have } \\
\text { problems, these institutions } \\
\text { should be sympathetic and } \\
\text { reassuring }\end{array}$ & .683 & $\begin{array}{l}\text { Dependability in handling } \\
\text { customers' service problems }\end{array}$ \\
\hline $\begin{array}{l}\text { These institutions should be } \\
\text { dependable }\end{array}$ & .837 & $\begin{array}{l}\text { Performing services right the } \\
\text { first time }\end{array}$ \\
\hline $\begin{array}{l}\text { They should provide their } \\
\text { saving services at the time } \\
\text { they promise to do so }\end{array}$ & .705 & $\begin{array}{l}\text { Providing service at the } \\
\text { promised time }\end{array}$ \\
\hline $\begin{array}{l}\text { They should keep their } \\
\text { records accurately }\end{array}$ & .621 & $\begin{array}{l}\text { Maintaining error-free } \\
\text { records }\end{array}$ \\
\hline $\begin{array}{l}\text { It is not realistic for } \\
\text { customers to expect prompt } \\
\text { service from employees of } \\
\text { these institutions }\end{array}$ & .670 & Responsiveness \\
\hline $\begin{array}{l}\text { Their employees do not } \\
\text { always have to be willing to } \\
\text { help customers }\end{array}$ & .743 & $\begin{array}{l}\text { Keeping customers informed } \\
\text { about when service will be } \\
\text { performed }\end{array}$ \\
\hline $\begin{array}{l}\text { It is okay if they are too busy } \\
\text { to respond to customer } \\
\text { requests promptly }\end{array}$ & .669 & Prompt service to customers \\
\hline $\begin{array}{l}\text { Customer should be able to } \\
\text { trust employees of these } \\
\text { institutions }\end{array}$ & .625 & Willingness to help customers \\
\hline $\begin{array}{l}\text { Customer should be able to } \\
\text { feel safe in their transactions } \\
\text { with these institutions' } \\
\text { employees }\end{array}$ & .616 & $\begin{array}{l}\text { Readiness to respond to } \\
\text { customers' requests }\end{array}$ \\
\hline \multirow[t]{2}{*}{ Total Variance Explained } & $49.5 \%$ & Assurance \\
\hline & SSERVQUAL-2 & $\begin{array}{l}\text { Employees who instill } \\
\text { confidence in customers }\end{array}$ \\
\hline $\begin{array}{l}\text { Their employees should be } \\
\text { polite }\end{array}$ & .546 & $\begin{array}{l}\text { Making customers feel safe in } \\
\text { their transactions }\end{array}$ \\
\hline
\end{tabular}




\begin{tabular}{|c|c|c|}
\hline $\begin{array}{l}\text { It is unrealistic to expect } \\
\text { these institutions to have their } \\
\text { customers' best interest at } \\
\text { heart }\end{array}$ & .603 & $\begin{array}{l}\text { Employees who are } \\
\text { consistently courteous }\end{array}$ \\
\hline $\begin{array}{l}\text { They should not be expected } \\
\text { to have operating hours } \\
\text { convenient to all their } \\
\text { customers }\end{array}$ & .707 & $\begin{array}{l}\text { Employees who have the } \\
\text { knowledge to answer } \\
\text { customer questions }\end{array}$ \\
\hline $\begin{array}{l}\text { They should have up-to-date } \\
\text { equipment } \& \text { technology }\end{array}$ & .659 & Empathy \\
\hline $\begin{array}{l}\text { Their physical facilities } \\
\text { should be visually appealing }\end{array}$ & .716 & $\begin{array}{l}\text { Giving customers individual } \\
\text { attention }\end{array}$ \\
\hline $\begin{array}{l}\text { Their employees should be } \\
\text { well dressed and appear neat }\end{array}$ & .711 & $\begin{array}{l}\text { Employees who deal with } \\
\text { consumers in a caring fashion }\end{array}$ \\
\hline $\begin{array}{l}\text { The appearance of the } \\
\text { physical facilities of these } \\
\text { institutions should keep up } \\
\text { with the type of service } \\
\text { provided }\end{array}$ & .822 & $\begin{array}{l}\text { Having the customer's best } \\
\text { interest at heart }\end{array}$ \\
\hline \multirow[t]{2}{*}{ Total Variance Explained } & $8.9 \%$ & $\begin{array}{l}\text { Employees who understand } \\
\text { the needs of their customers }\end{array}$ \\
\hline & SSERVQUAL-3 & Convenient business hours \\
\hline $\begin{array}{l}\text { These institutions should not } \\
\text { be expected to give customers } \\
\text { individual attention. }\end{array}$ & .822 & Tangibles \\
\hline $\begin{array}{l}\text { They should not be expected } \\
\text { to tell their customers exactly } \\
\text { when saving services will } \\
\text { be performed }\end{array}$ & .806 & Modern equipment \\
\hline $\begin{array}{l}\text { Their employees should get } \\
\text { adequate support from these } \\
\text { institutions to do their jobs } \\
\text { well }\end{array}$ & .653 & Visually appealing facilities \\
\hline $\begin{array}{l}\text { Employees of this institution } \\
\text { cannot be expected to give } \\
\text { customers personal attention }\end{array}$ & .791 & $\begin{array}{l}\text { Employees who have a neat, } \\
\text { professional appearance }\end{array}$ \\
\hline $\begin{array}{l}\text { It is unrealistic to expect } \\
\text { employees to know what the } \\
\text { needs of their customers are }\end{array}$ & .570 & $\begin{array}{l}\text { Visually appealing materials } \\
\text { associated with the service }\end{array}$ \\
\hline Total Variance Explained & $5.3 \%$ & \\
\hline
\end{tabular}


Table 10. The Validity and Reliability Analyses of Credit Instruments

\begin{tabular}{|c|c|}
\hline & Corrected Item-Total Correlation \\
\hline $\mathrm{p} 1$ & .6284 \\
\hline $\mathrm{p} 2$ & .6686 \\
\hline $\mathrm{p} 3$ & .5865 \\
\hline $\mathrm{p} 4$ & .7102 \\
\hline p5 & .7292 \\
\hline p6 & .3718 \\
\hline p7 & .7290 \\
\hline $\mathrm{p} 8$ & .7469 \\
\hline p9 & .7167 \\
\hline $\mathrm{p} 10$ & .7676 \\
\hline p11 & .7331 \\
\hline $\mathrm{p} 12$ & .7139 \\
\hline p13 & .5447 \\
\hline p14 & .4604 \\
\hline $\mathrm{p} 15$ & .4935 \\
\hline p16 & .6951 \\
\hline p17 & .4784 \\
\hline p18 & .7499 \\
\hline p19 & .7629 \\
\hline p20 & .7628 \\
\hline $\mathrm{p} 21$ & .7478 \\
\hline $\mathrm{p} 22$ & .7189 \\
\hline$\alpha$ & .9466 \\
\hline
\end{tabular}


Table 11. The Validity Test of Credit Variables

\begin{tabular}{|c|c|c|}
\hline & & Credit Variables \\
\hline \multicolumn{2}{|c|}{$\begin{array}{l}\text { Kaiser-Meyer-Olkin } \\
\text { (KMO) }\end{array}$} & \multirow[t]{2}{*}{.919} \\
\hline \multicolumn{2}{|c|}{$\begin{array}{l}\text { Measure of Sampling Adequacy } \\
\text { (MSA) }\end{array}$} & \\
\hline & $\mathrm{p} 1$ & .952 \\
\hline & $\mathrm{p} 2$ & .934 \\
\hline & p3 & .901 \\
\hline & $\mathrm{p} 4$ & .965 \\
\hline & p5 & .908 \\
\hline & p6 & .794 \\
\hline & p7 & .916 \\
\hline & p8 & .931 \\
\hline & p9 & .939 \\
\hline & p10 & .943 \\
\hline & $\mathrm{p} 11$ & .928 \\
\hline & p12 & .942 \\
\hline & $\mathrm{p} 13$ & .855 \\
\hline & p14 & .825 \\
\hline & p15 & .841 \\
\hline & p16 & .961 \\
\hline & p17 & .831 \\
\hline & p18 & .924 \\
\hline & p19 & .914 \\
\hline & p20 & .924 \\
\hline & $\mathrm{p} 21$ & .945 \\
\hline & p22 & .925 \\
\hline
\end{tabular}


Table 12. Factor Loadings of the Credit SERVQUAL Instruments

\begin{tabular}{|c|c|c|}
\hline \multicolumn{2}{|c|}{ Present Study } & \multirow{2}{*}{$\begin{array}{l}\text { Parasuraman et al } \\
\text { Intrument }\end{array}$} \\
\hline Questions & Factors & \\
\hline & CSERVQUAL-1 & Reliability \\
\hline $\begin{array}{l}\text { When these institutions } \\
\text { promise to do something by } \\
\text { a certain time, they should } \\
\text { do so }\end{array}$ & .727 & Providing service as promised \\
\hline $\begin{array}{l}\text { When customers have } \\
\text { problems, these institutions } \\
\text { should be sympathetic and } \\
\text { reassuring }\end{array}$ & .742 & $\begin{array}{l}\text { Dependability in handling } \\
\text { customers' service problems }\end{array}$ \\
\hline $\begin{array}{l}\text { These institutions should be } \\
\text { dependable }\end{array}$ & .856 & $\begin{array}{l}\text { Performing services right the } \\
\text { first time }\end{array}$ \\
\hline $\begin{array}{l}\text { They should provide their } \\
\text { saving services at the time } \\
\text { they promise to do so }\end{array}$ & .741 & $\begin{array}{l}\text { Providing service at the } \\
\text { promised time }\end{array}$ \\
\hline $\begin{array}{l}\text { They should keep their } \\
\text { records accurately }\end{array}$ & .694 & $\begin{array}{l}\text { Maintaining error-free } \\
\text { records }\end{array}$ \\
\hline $\begin{array}{l}\text { It is not realistic for } \\
\text { customers to expect prompt } \\
\text { service from employees of } \\
\text { these institutions }\end{array}$ & .714 & Responsiveness \\
\hline $\begin{array}{l}\text { Their employees do not } \\
\text { always have to be willing to } \\
\text { help customers }\end{array}$ & .767 & $\begin{array}{l}\text { Keeping customers informed } \\
\text { about when service will be } \\
\text { performed }\end{array}$ \\
\hline $\begin{array}{l}\text { It is okay if they are too } \\
\text { busy to respond to customer } \\
\text { requests promptly }\end{array}$ & .710 & Prompt service to customers \\
\hline $\begin{array}{l}\text { Customer should be able to } \\
\text { trust employees of these } \\
\text { institutions }\end{array}$ & .690 & Willingness to help customers \\
\hline $\begin{array}{l}\text { Customer should be able to } \\
\text { feel safe in their transactions } \\
\text { with these institutions' } \\
\text { employees }\end{array}$ & .675 & $\begin{array}{l}\text { Readiness to respond to } \\
\text { customers' requests }\end{array}$ \\
\hline $\begin{array}{l}\text { Their employees should be } \\
\text { polite }\end{array}$ & .545 & $\begin{array}{l}\text { Employees who instill } \\
\text { confidence in customers }\end{array}$ \\
\hline \multirow[t]{2}{*}{ Total Variance Explained } & $50.1 \%$ & Assurance \\
\hline & CSERVQUAL-2 & $\begin{array}{l}\text { Making customers feel safe in } \\
\text { their transactions }\end{array}$ \\
\hline
\end{tabular}




\begin{tabular}{|c|c|c|}
\hline $\begin{array}{l}\text { It is unrealistic to expect } \\
\text { these institutions to have } \\
\text { their customers' best interest } \\
\text { at heart }\end{array}$ & .578 & $\begin{array}{l}\text { Employees who are } \\
\text { consistently courteous }\end{array}$ \\
\hline $\begin{array}{l}\text { They should not be expected } \\
\text { to have operating hours } \\
\text { convenient to all their } \\
\text { customers }\end{array}$ & .682 & $\begin{array}{l}\text { Employees who have the } \\
\text { knowledge to answer } \\
\text { customer questions }\end{array}$ \\
\hline $\begin{array}{l}\text { They should have up-to-date } \\
\text { equipment } \& \text { technology }\end{array}$ & .690 & Empathy \\
\hline $\begin{array}{l}\text { Their physical facilities } \\
\text { should be visually appealing }\end{array}$ & .755 & $\begin{array}{l}\text { Giving customers individual } \\
\text { attention }\end{array}$ \\
\hline $\begin{array}{l}\text { Their employees should be } \\
\text { well dressed and appear neat }\end{array}$ & .703 & $\begin{array}{l}\text { Employees who deal with } \\
\text { consumers in a caring fashion }\end{array}$ \\
\hline $\begin{array}{l}\text { The appearance of the } \\
\text { physical facilities of these } \\
\text { institutions should keep up } \\
\text { with the type of service } \\
\text { provided }\end{array}$ & .839 & $\begin{array}{l}\text { Having the customer's best } \\
\text { interest at heart }\end{array}$ \\
\hline \multirow[t]{2}{*}{ Total Variance Explained } & $12.1 \%$ & $\begin{array}{l}\text { Employees who understand } \\
\text { the needs of their customers }\end{array}$ \\
\hline & CSERVQUAL-3 & Convenient business hours \\
\hline $\begin{array}{l}\text { These institutions should not } \\
\text { be expected to give } \\
\text { customers individual } \\
\text { attention. }\end{array}$ & .833 & Tangibles \\
\hline $\begin{array}{l}\text { They should not be expected } \\
\text { to tell their customers } \\
\text { exactly when saving } \\
\text { services will be performed }\end{array}$ & .805 & Modern equipment \\
\hline $\begin{array}{l}\text { Their employees should get } \\
\text { adequate support from these } \\
\text { institutions to do their jobs } \\
\text { well }\end{array}$ & .750 & Visually appealing facilities \\
\hline $\begin{array}{l}\text { Employees of this institution } \\
\text { cannot be expected to give } \\
\text { customers personal attention }\end{array}$ & .826 & $\begin{array}{l}\text { Employees who have a neat, } \\
\text { professional appearance }\end{array}$ \\
\hline $\begin{array}{l}\text { It is unrealistic to expect } \\
\text { employees to know what the } \\
\text { needs of their customers are }\end{array}$ & .658 & $\begin{array}{l}\text { Visually appealing materials } \\
\text { associated with the service }\end{array}$ \\
\hline Total Variance Explained & $5.0 \%$ & \\
\hline
\end{tabular}


Table 13. The Validity and Reliability Analyses of Income Instruments

a. Test I

\begin{tabular}{|c|c|}
\hline & $\begin{array}{c}\text { Corrected Item-Total } \\
\text { Correlation }\end{array}$ \\
\hline $\mathrm{y} 1$ & .3641 \\
\hline $\mathrm{y} 2$ & .0177 \\
\hline $\mathrm{y} 3$ & .3958 \\
\hline $\mathrm{y} 4$ & .0117 \\
\hline $\mathrm{y} 5$ & .0827 \\
\hline $\mathrm{y} 6$ & .3813 \\
\hline $\mathrm{y} 7$ & -.0479 \\
\hline $\mathrm{y} 8$ & -.0007 \\
\hline $\mathrm{y} 9$ & .0668 \\
\hline $\mathrm{y} 10$ & .3945 \\
\hline $\mathrm{y} 11$ & -.0873 \\
\hline$\alpha$ & .2221 \\
\hline
\end{tabular}

\section{b. Test II}

\begin{tabular}{|c|c|}
\hline & $\begin{array}{c}\text { Corrected Item-Total } \\
\text { Correlation }\end{array}$ \\
\hline $\mathrm{y} 1$ & .3902 \\
\hline $\mathrm{y} 3$ & .3908 \\
\hline $\mathrm{y} 6$ & .4987 \\
\hline $\mathrm{y} 10$ & .4382 \\
\hline$\alpha$ & .2529 \\
\hline
\end{tabular}


Table 14. The Feasibility Test of Income Variables

a. Test I

\begin{tabular}{|c|c|}
\hline & $\begin{array}{c}\text { Household Expenditure } \\
\text { Variables }\end{array}$ \\
\hline $\begin{array}{c}\text { Kaiser-Meyer-Olkin } \\
(\mathrm{KMO})\end{array}$ & .529 \\
\hline Measure of Sampling Adequacy (MSA) & .580 \\
\hline $\mathrm{y} 1$ & $.396^{*}$ \\
\hline $\mathrm{y} 3$ & .518 \\
\hline $\mathrm{y} 6$ & .562 \\
\hline $\mathrm{y} 10$ & \\
\hline
\end{tabular}

$*$ MSA $<.50$ as a result $\mathrm{y} 3$ out of the model.

b. Test II

\begin{tabular}{|c|c|}
\hline & $\begin{array}{c}\text { Household Expenditure } \\
\text { Variables }\end{array}$ \\
\hline $\begin{array}{c}\text { Kaiser-Meyer-Olkin } \\
(\mathrm{KMO})\end{array}$ & .601 \\
\hline Measure of Sampling Adequacy (MSA) & .585 \\
\hline $\mathrm{y} 1$ & .566 \\
\hline $\mathrm{y} 6$ & .741 \\
\hline $\mathrm{y} 10$ & \\
\hline
\end{tabular}

Table 15. Mean and Standard Deviation (Credit Products)

\begin{tabular}{|l|c|c|}
\hline \multicolumn{1}{|c|}{ Variables } & Mean & $\begin{array}{c}\text { Standard } \\
\text { Deviation }\end{array}$ \\
\hline \multicolumn{1}{|c|}{ Reliability } & 6.36 & 2.89 \\
\hline $\begin{array}{l}\text { When these institutions promise to do } \\
\text { something by a certain time, they should do so }\end{array}$ & 6.51 & 2.90 \\
\hline $\begin{array}{l}\text { When customers have problems, these } \\
\text { institutions should be sympathetic and } \\
\text { reassuring }\end{array}$ & 6.03 & 6.63 \\
\hline These institutions should be dependable & 6.17 & 2.73 \\
\hline $\begin{array}{l}\text { They should provide their credit services at the } \\
\text { time they promise to do so }\end{array}$ & 6.82 & 2.80 \\
\hline They should keep their records accurately & 6.74 & 2.88 \\
\hline $\begin{array}{l}\text { It is not realistic for customers to expect } \\
\text { prompt service from employees of these } \\
\text { institutions }\end{array}$ & $\begin{array}{l}\text { Their employees do not always have to be } \\
\text { willing to help customers }\end{array}$ & 3.02 \\
\hline It is okay if they are too busy to respond to & & \\
\hline
\end{tabular}




\begin{tabular}{|c|c|c|}
\hline customer requests promptly & & \\
\hline $\begin{array}{l}\text { Customer should be able to trust employees of } \\
\text { these institutions }\end{array}$ & 6.80 & 2.78 \\
\hline $\begin{array}{l}\text { Customer should be able to feel safe in their } \\
\text { transactions with these institutions' employees }\end{array}$ & 7.07 & 2.70 \\
\hline Their employees should be polite & 6.99 & 2.79 \\
\hline \multicolumn{3}{|l|}{ Tangibles } \\
\hline $\begin{array}{l}\text { It is unrealistic to expect these institutions to } \\
\text { have their customers' best interest at heart }\end{array}$ & 6.64 & 2.82 \\
\hline $\begin{array}{l}\text { They should not be expected to have operating } \\
\text { hours convenient to all their customers }\end{array}$ & 6.76 & 2.80 \\
\hline $\begin{array}{l}\text { They should have up-to-date equipment and } \\
\text { technology }\end{array}$ & 6.74 & 2.69 \\
\hline $\begin{array}{l}\text { Their physical facilities should be visually } \\
\text { appealing }\end{array}$ & 6.64 & 2.90 \\
\hline $\begin{array}{l}\text { Their employees should be well dressed and } \\
\text { appear neat }\end{array}$ & 6.68 & 2.92 \\
\hline $\begin{array}{l}\text { The appearance of the physical facilities of } \\
\text { these institutions should keep up with the type } \\
\text { of service provided }\end{array}$ & 6.72 & 2.90 \\
\hline \multicolumn{3}{|l|}{ Empathy } \\
\hline $\begin{array}{l}\text { These institutions should not be expected to } \\
\text { give customers individual attention }\end{array}$ & 4.63 & 3.46 \\
\hline $\begin{array}{l}\text { They should not be expected to tell their } \\
\text { customers exactly when credit services will } \\
\text { be performed }\end{array}$ & 5.62 & 3.48 \\
\hline $\begin{array}{l}\text { Their employees should get adequate support } \\
\text { from these institutions to do their jobs well }\end{array}$ & 4.28 & 3.30 \\
\hline $\begin{array}{l}\text { Employees of this institution cannot be } \\
\text { expected to give customers personal attention }\end{array}$ & 4.32 & 3.28 \\
\hline $\begin{array}{l}\text { It is unrealistic to expect employees to know } \\
\text { what the needs of their customers are }\end{array}$ & 4.65 & 3.35 \\
\hline
\end{tabular}


Table 16. Mean and Standard Deviation (Culture and Income Variables)

\begin{tabular}{|c|c|c|c|c|c|}
\hline Variables & Mean & $\begin{array}{l}\text { Standard } \\
\text { Deviation }\end{array}$ & $\begin{array}{c}\text { Varia-ble } \\
\text { s }\end{array}$ & Mean & $\begin{array}{l}\text { Standard } \\
\text { Deviation }\end{array}$ \\
\hline $\begin{array}{l}\text { self-fulfilling vs.not } \\
\text { self-fulfilling }\end{array}$ & 2.11 & 1.73 & & & \\
\hline excited vs. sad & 2.19 & 1.74 & & & \\
\hline $\begin{array}{l}\text { sense-accomplished } \\
\text { vs. sense-foolish }\end{array}$ & 2.24 & 1.88 & & & \\
\hline $\begin{array}{l}\text { self-respecting vs. not } \\
\text { self-respecting }\end{array}$ & 2.77 & 2.30 & & & \\
\hline $\begin{array}{l}\text { sense of belonging vs. } \\
\text { sense of consuming }\end{array}$ & 2.14 & 1.95 & & & \\
\hline $\begin{array}{l}\text { being well respected vs. } \\
\text { being unrespected }\end{array}$ & 1.82 & 1.73 & & & \\
\hline Secure vs.insecure & 1.76 & 1.70 & Food & 1165.25 & 879.27 \\
\hline $\begin{array}{l}\text { fun and enjoyment in life } \\
\text { vs. unpleasure in life }\end{array}$ & 1.99 & 1.71 & Housing & 893.91 & 1040.28 \\
\hline $\begin{array}{l}\text { Warm relationships with } \\
\text { others vs. cold } \\
\text { relationships with others }\end{array}$ & 2.10 & 1.92 & $\begin{array}{l}\text { loan } \\
\text { payment/ } \\
\text { credit } \\
\text { liabili-ties }\end{array}$ & 4326.90 & 7096.37 \\
\hline
\end{tabular}

Table 17. Credit Binomial Logistic Regression Results

\begin{tabular}{|l|r|r|r|l|}
\hline $\begin{array}{c}\text { Independent } \\
\text { Variable }\end{array}$ & \multicolumn{1}{|c|}{ B } & Exp ( $\beta)$ & Wald & Sig. \\
\hline LOV & 1.728 & 5.632 & 10.316 & .001 \\
\hline CREDIT & .657 & 1.928 & 6.442 & .011 \\
\hline INCOME & -3.917 & .020 & 28.851 & .000 \\
\hline CONSTANT & 3.095 & 22.085 & 24.298 & .000 \\
\hline Negelkerke R Square .877 \\
\hline
\end{tabular}

Table 18. Mean and Standard Deviation (Saving Products)

\begin{tabular}{|l|c|c|}
\hline \multicolumn{1}{|c|}{ Variables } & Mean & $\begin{array}{c}\text { Standard } \\
\text { Deviation }\end{array}$ \\
\hline \multicolumn{1}{|c|}{ Reliability } & 5.04 & 2.86 \\
\hline $\begin{array}{l}\text { When these institutions promise to do } \\
\text { something by a certain time, they should do so }\end{array}$ & 5.22 & 2.93 \\
\hline $\begin{array}{l}\text { When customers have problems, these } \\
\text { institutions should be sympathetic and } \\
\text { reassuring }\end{array}$ & & \\
\hline
\end{tabular}




\begin{tabular}{|c|c|c|}
\hline These institutions should be dependable & 4.72 & 2.98 \\
\hline $\begin{array}{l}\text { They should provide their saving services at the } \\
\text { time they promise to do so }\end{array}$ & 5.30 & 2.70 \\
\hline They should keep their records accurately & 5.99 & 2.86 \\
\hline $\begin{array}{l}\text { It is not realistic for customers to expect } \\
\text { prompt service from employees of these } \\
\text { institutions }\end{array}$ & 5.59 & 2.87 \\
\hline $\begin{array}{l}\text { Their employees do not always have to be } \\
\text { willing to help customers }\end{array}$ & 5.51 & 2.91 \\
\hline $\begin{array}{l}\text { It is okay if they are too busy to respond to } \\
\text { customer requests promptly }\end{array}$ & 5.06 & 3.00 \\
\hline $\begin{array}{l}\text { Customer should be able to trust employees of } \\
\text { these institutions }\end{array}$ & 5.53 & 2.78 \\
\hline $\begin{array}{l}\text { Customer should be able to feel safe in their } \\
\text { transactions with these institutions' employees }\end{array}$ & 5.91 & 2.81 \\
\hline \multicolumn{3}{|l|}{ Tangibles } \\
\hline Their employees should be polite & 5.80 & 2.93 \\
\hline $\begin{array}{l}\text { It is unrealistic to expect these institutions to } \\
\text { have their customers' best interest at heart }\end{array}$ & 5.38 & 2.83 \\
\hline $\begin{array}{l}\text { They should not be expected to have operating } \\
\text { hours convenient to all their customers }\end{array}$ & 5.52 & 2.85 \\
\hline $\begin{array}{l}\text { They should have up-to-date equipment and } \\
\text { technology }\end{array}$ & 5.46 & 2.92 \\
\hline $\begin{array}{l}\text { Their physical facilities should be visually } \\
\text { appealing }\end{array}$ & 5.39 & 3.04 \\
\hline $\begin{array}{l}\text { Their employees should be well dressed and } \\
\text { appear neat }\end{array}$ & 5.69 & 3.10 \\
\hline $\begin{array}{l}\text { The appearance of the physical facilities of } \\
\text { these institutions should keep up with the type } \\
\text { of service provided }\end{array}$ & 5.50 & 3.04 \\
\hline \multicolumn{3}{|l|}{ Empathy } \\
\hline $\begin{array}{l}\text { These institutions should not be expected to } \\
\text { give customers individual attention }\end{array}$ & 3.72 & 3.62 \\
\hline $\begin{array}{l}\text { They should not be expected to tell their } \\
\text { customers exactly when saving services will } \\
\text { be performed }\end{array}$ & 4.70 & 3.62 \\
\hline $\begin{array}{l}\text { Their employees should get adequate support } \\
\text { from these institutions to do their jobs well }\end{array}$ & 3.31 & 3.40 \\
\hline $\begin{array}{l}\text { Employees of this institution cannot be } \\
\text { expected to give customers personal attention }\end{array}$ & 3.31 & 3.33 \\
\hline $\begin{array}{l}\text { It is unrealistic to expect employees to know } \\
\text { what the needs of their customers are }\end{array}$ & 3.62 & 3.37 \\
\hline
\end{tabular}


Table 19. Saving Binomial Logistic Regression Results

\begin{tabular}{|l|r|r|r|c|}
\hline $\begin{array}{l}\text { Independent } \\
\text { Variable }\end{array}$ & \multicolumn{1}{c|}{ B } & Exp ( $\beta)$ & Wald & Sig. \\
\hline LOV & 1.630 & 5.106 & 8.539 & .003 \\
\hline SAVING & .754 & 2.126 & 8.243 & .004 \\
\hline INCOME & -3.862 & 0.21 & 27.126 & .000 \\
\hline CONSTANT & 3.192 & 24.331 & 23.086 & .000 \\
\hline Negelkerke R Square.884 \\
\hline Hosmer and Lemeshow Test .05 \\
\hline
\end{tabular}

Table 20. The ANOVA of Culture, SERVQUAL, and Income among

Minangkabau and Chinese Customers

\begin{tabular}{|c|c|c|c|c|c|c|}
\hline & & $\begin{array}{l}\text { Sum of } \\
\text { Squares }\end{array}$ & df & $\begin{array}{c}\text { Mean } \\
\text { Square }\end{array}$ & $\mathbf{F}$ & Sig. \\
\hline \multirow[t]{3}{*}{ Culture } & Between Groups & 38.370 & 1 & 38.370 & 47.297 & .000 \\
\hline & Within Groups & 160.630 & 198 & .811 & & \\
\hline & Total & 199.000 & 199 & & & \\
\hline \multirow{3}{*}{ SAVING } & Between Groups & 86.814 & 1 & 86.814 & 33.692 & .000 \\
\hline & Within Groups & 510.186 & 198 & 2.577 & & \\
\hline & Total & 597.000 & 199 & & & \\
\hline \multirow[t]{3}{*}{ CREDIT } & Between Groups & 37.088 & 1 & 37.088 & 13.115 & .000 \\
\hline & Within Groups & 559.912 & 198 & 2.828 & & \\
\hline & Total & 597.000 & 199 & & & \\
\hline INCOME & Between Groups & 123.701 & 1 & 123.701 & 325.274 & .000 \\
\hline & Within Groups & 75.299 & 198 & .380 & & \\
\hline & Total & 199.000 & 199 & & & \\
\hline
\end{tabular}




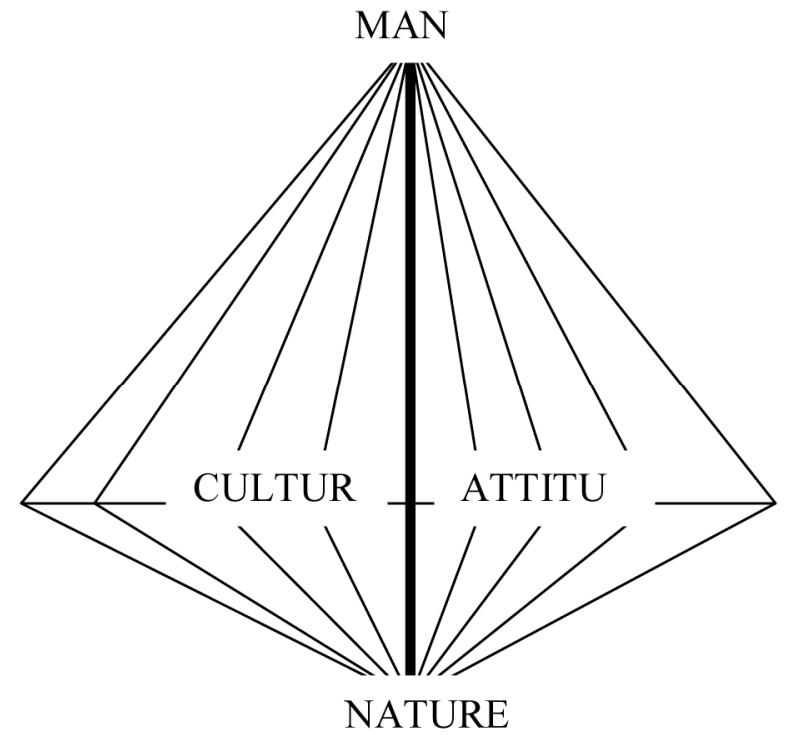

Figure 1. Man and Nature

Source : Hoyt, Elizabeth Ellis (1976)

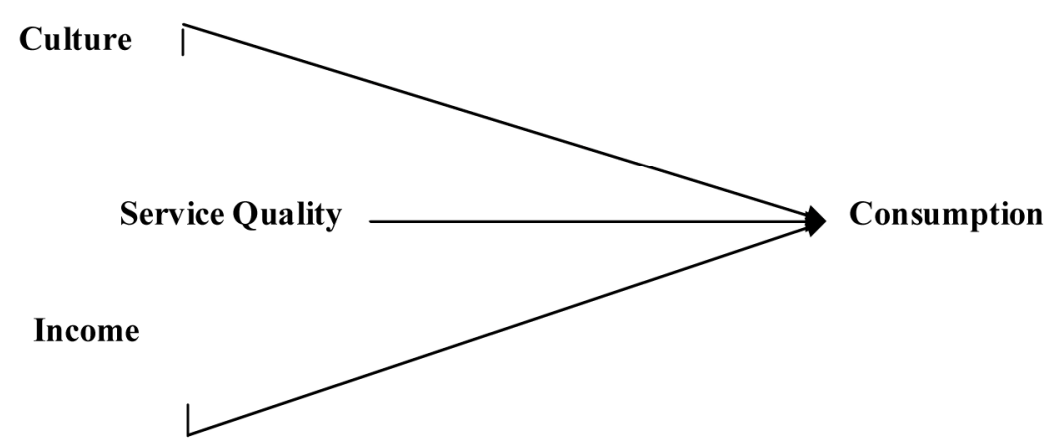

Figure 2. Conceptual Model for Consumption 


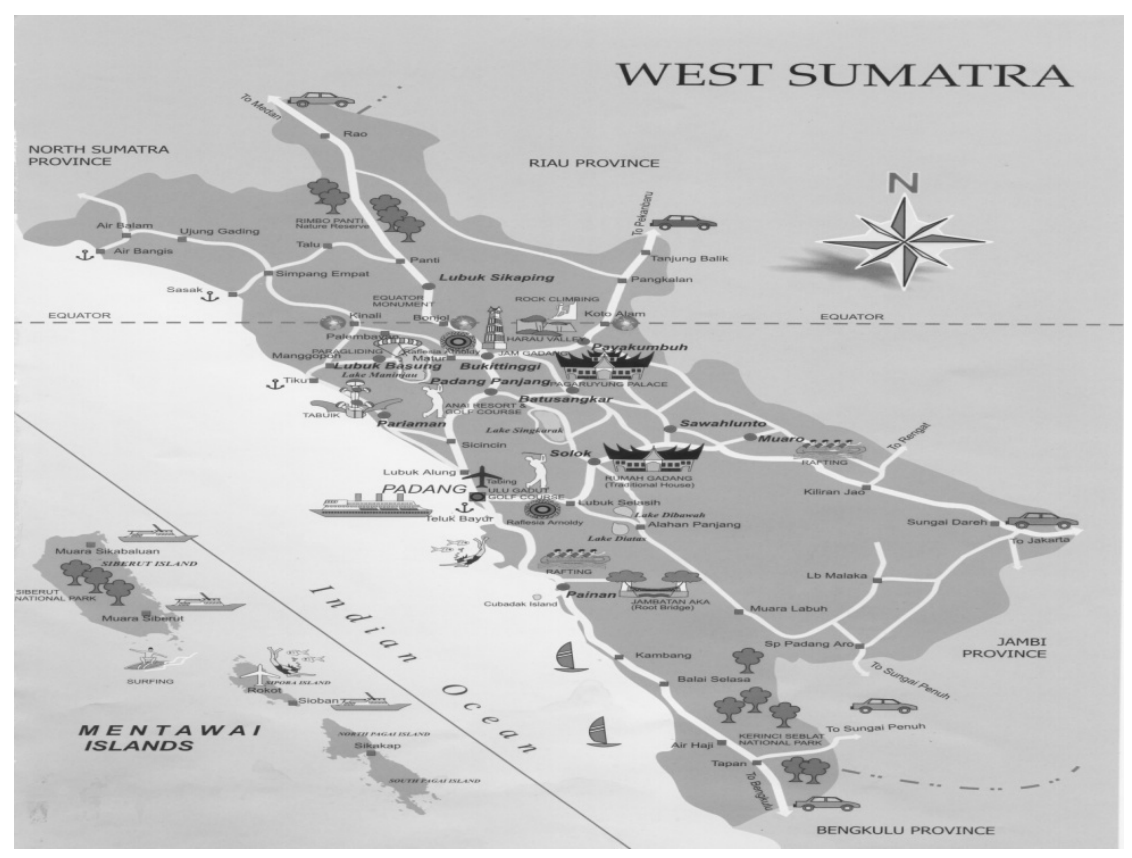

Figure 3. Research Location 


\title{
The Business Strategy of Mcdonald's
}

\author{
Jing Han \\ School of Economics, Yunnan University \\ No.2Green lake north Road, Kun Ming, Yunnan 650031, China \\ E-mail: hanjing0928@hotmail.com
}

\begin{abstract}
As one of the most successful fast food chain in the world, throughout the development of McDonald's, we could easily identify many successful business strategy implementations. In this paper, I will discuss some critical business strategies, which linked to the company's structure and external environment. This paper is organized as follows: In the first section, I will give brief introduction to the success of McDonald's. In the second section, I will analyze some particular strategies used by McDonald's and how these strategies are suitable to their business structure. I will then analyze why McDonald's choose these strategies in response to the changing external environment. Finally, I will summarize the approaches used by McDonald's to achieve their strategic goals.
\end{abstract}

Keywords: Strategy, McDonald's structure

\section{Introduction}

McDonald's, originated in California, USA, 1954, has become one of the most recognized and respected brands in the world. The success achieved includes that they have established more than 30,000 franchising stores in 119 countries, serving more than 47 million people each day, and generating about \$15 billions revenues annually. McDonald's also continuously enhances its brand imagine through different social activities and the sponsorship of special events and sports i.e. as a major sponsor of the world cup since 1994 and the Champions League football in England from 1996 to 2000.(www.McDonalds.com)

How can McDonald's achieve such success? There are many formulating strategies, which we could use for our analysis of their recipe of success such as Porter's competitive strategies model, which includes differentiation and low-cost leadership; or Miles and Snow's 'strategy typology', which defined prospector, defender, analyzer, and reactor strategy. Obviously, it is extremely important for McDonald's to choose the most appropriate strategy to be successful. From my personal point view, to be an Analyzer is the most suitable strategic position for them to develop their business as a whole especially when they facing an extreme complex continuously changing world.

As Miles and Snow defined that "The analyzer tries to maintain a stable business while innovating on the periphery. It seems to lie midway between the prospector and the defender. Some products will be targeted toward stable environment in which an efficiency strategy designed to keep current customers is used. Others will be targeted toward new, more dynamic environment, where growth is possible." (Richard L.Daft)

It is also very important to consider how McDonald's applies these strategies and how their strategies interact with their business structure and the external environment.

\section{How McDonald's business structure influences its strategy?}

The McDonald's business structure is based upon a geographic structure. When log on their website, you will be asked to choose the country that you are interested in. Actually, McDonald's divided its operations into five geographical divisions.

(www.McDonalds.com)

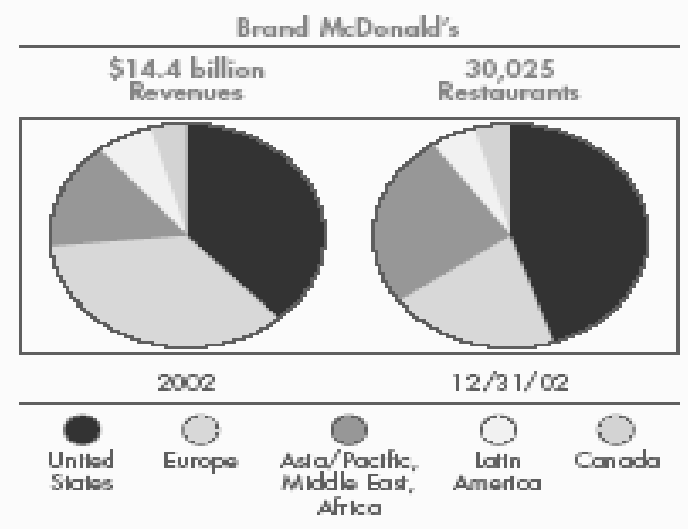


As shown in above pie charts that around 65\% of McDonald's restaurants and approximately $75 \%$ of its revenues are generated in the United State and Europe. So, to McDonald's, the most important strategic approach for maintaining its leading position is to keep their major markets at the same time expanding their business into the other emerging markets. However, different consumer groups in different countries may have very different tastes and/or requirements. So each full functional geographic unit of McDonald's was required to wholly response for producing and marketing its products in that region. Through this regional structure, McDonald's could not only satisfy the local consumers' needs in different geographical areas but also pursuing 'maximum local development'. Actually they produce and market slightly different types of products in different areas, and they even have different prices. As Jim Skinner, the vice-chairmen of McDonald's illustrated that 'if you are looking for a command center with one push button that operate our restaurant in every corner of the world, you won't find it'. However, their philosophy of QSC\&V-quality, service, cleanliness and value is same for everywhere. And McDonald's targets the similar consumer segments that need fast service, affordable price and good standard hygiene. So their main products are similar in most countries, where they provided service, including beef, chicken, bread potatoes and milk. As the consumers in different countries having different foods requirements, McDonald's keep launching new products for their regional consumers. In this case China and France can be very good examples.

\section{McDonald's in China:}

In 1990, McDonald's opened their first store in shenzhen (near HongKong). But before they actually started their business, McDonald's had already carried out 5 years business research and all sorts of information gathering such as the income level of the Chinese people, the kind of foods they enjoy etc. Moreover, their re-design of the counter, chairs and desks also reflected their considerations of the height and body shape of Chinese people. They made lots of efforts to promote their American burgers, and wanted to repeat the same success in China market as they has done elsewhere. Unfortunately, they are not as successful as KFC, their biggest rival, in China now. There are lots of reasons to explain it, one important issue which has once been ignored by McDonald's is that Chinese people are more prefer chicken dishes than beef burgers, which are their main products. After identified this problem, McDonald's has tried to adapt more Chinese tastes by adding more chicken meals into their menu for attracting more customers.(Chinese website)

\section{McDonald's in France:}

In France, where customers has been resentful of the fast-food chain's incursion, McDonald's has boosted it sales by remodeling restaurants i.e. hardwood floors, wood-beam ceilings, comfortable armchairs, and also by adding new menu items such as espresso, brioche and more upscale sandwiches. Actually they have successfully responded to the preferences of the local area. (Richard L.Daft)

In the other countries the situation is the same. For example, in Canada, McDonald's has introduced new Canadian feature breakfast. In Belgium, the McCicken Premiere has been added to the menu. Although McDonald's has been regarded as the ultimate example of standardization for the world market.

\section{How the strategy is influenced by external environment?}

The external environment can be divided into several sectors. In this section, I will only discuss two important parts: competitors, social concept (healthy problem) and uncertainty situation, which can greatly influence McDonald's strategies. Then at the last part of this section, I will discuss one particular strategy they used which served for their future development purpose.

\section{Competitor:}

It's unlikely that McDonald's can always be No.1. In an annual consumer satisfaction survey, McDonald's has been scored dead last among fast-food restaurants since 1992. In the fourth quarter of 2002, McDonald's disclosed its first-ever quarterly loss, one reason why McDonald's is struggling is that the consumers began to switch to its competitors, such as Burger King, Wendy's, and Subway. These companies emphasized on offering fresher, hotter, high-quality foods at lower price with faster service. On the other hand, McDonald's decided to close 719 poorly performing restaurants around world. All of these simply proved that McDonald's might no longer be competitive in the fast-food market. And if McDonald's cannot adapt external environment change, they might be gradually diminished and even replaced by other competitors. In order to keep their market share, increasing sales and profits. McDonald's has to respond to the threat of competitors. In 2003, McDonald's offered the McGriddles sandwiches in the US and the Canada feature breakfast. Meanwhile, McChicken Premiere and a zesty chicken have been introduced in the UK, France, Italy and Belgium. McDonald's was trying to satisfy customer's desire for premium products at affordable prices. Furthermore, McDonald's is providing more choice with respond to offer ' Happy Meal' to keep the children. For example, Happy meal now including chicken selects, and no-sugar -add fruit drink (juice and low-fat drink) and also to produce McDonald's coffee which appeals to adult. Those products have been made to attract existing customer and develop new customers.(www.McDonalds)

Moreover, in addition to the innovative menu, McDonald's is also rebuilding and even relocating some of their restaurants to make the environment more attractive. At the same time, McDonald's is differentiating itself by creating 
more relevant experiences such as allowing the customers to access the Internet with the wireless technology platform. This innovative way not only attracts the teenagers, but also perfectly fitting the modern professionals' requirements.

\section{Social problem -healthy issue}

With the economic development, people's living standards have increased dramatically these years. People are becoming more concerned about their health issues. It cannot be denied that McDonald's has attempted to make itself more convenience for the people. However, people also believe that such kinds of fast food are not good for their health. The world health organization's report presented that those food not only can cause the obesity of children, but also is part of the reason of causing cancer. Healthy issues became the biggest stumbling block to the development of McDonald's. Customers were switching to healthier offering, such as Subway's sandwiches, or KFC's mashed potato instead of fried potato. McDonald's has responded to this healthy trend. In order to compete, McDonald's has added salads and other lighter options into their menu. If a mother comes in, she is not only buy the happy meal for her children, she will also be likely to buy herself a meal too the lighter options also encourage existing customers to come back more often, because there is a greater variety of choices.

\section{Focus on Children}

No matter how different the tastes and the local needs are, McDonald's has paid considerable attention to the children in every country. They built 'happy land' for them, offering fantastic "happy meals" with novelty toys to them. Furthermore, McDonald's has just launched computers with games that were designed to inspire the children's imagination at the same time shape their personal characteristics. There are three main reasons for McDonald's to focus on the children:

(1) Children are one of the biggest consumers groups to McDonald's. And McDonald's has been regarded, as their favorite place to go .The brand culture "happiness" is known by children.

(2) McDonald's believe that focusing on children can build the stable business, and will provide the best engine to encourage the whole family to come to McDonald's. For example, one happy meal for a child only cost $\$ 5$ but McDonald's can produce more new products in addition to happy meal to offer the whole family.

(3) By Building a brand loyalty with the children, McDonald's more likely to be successfully today and in the future. In my opinion, McDonald's is not just selling the happy meal to children; it is selling the American culture to the children - the enjoyable individual life.

Actually this strategy with focused children segment is fully worked for their future development purpose. Whatever how the environment changes this strategy can always develop future generation customers' loyalty. And the "happy children" can also bring in the whole "happy families".

\section{Conclusion}

To sum up, there is a strong possibility that if the company fails to recognize the new competitions, shifting of consumer interests, and the social trends or innovative technologies, it will loose its market share. Previously, McDonald's emphasis on adding new restaurants for near 5 years, more than $50 \%$ of increase in new restaurants opened. Unfortunately, there was only $2 \%$ of increase in the sale of the food. So, in the year 2003 McDonald's decided to change its focus on increasing sales at existing restaurant and reduced capital spending which allows for a sizeable amount of cash be returned to shareholder. For achieving their objectives, the McDonald's strategy should be attract more new customers, encourage existing customers to visit McDonald's more often, build brand loyalty and, ultimately, create enduring profitable growth for the company.

\section{References}

Edström. A., \& Galbraith, J.R. (1977). Transfer of managers as a coordination and control strategy in multinational organizations. Administrative Science Quarterly, 22, June, 248-263.

Egelhoff, W.G. (1984). Patterns of control in U.S., U.K. and European multinational corporations. Journal of International Business Studies, Fall, 73-83

Fatehi, K. (1996). International Management, New Jersey: Prentice Hall.

Geringer, J.M. \& Hebert, L. (1989). Control and performance of international joint ventures. Journal of International Business Studies, Summer, 235-253

Hodgetts, R.M., Luthans, F. (1994). International Management, New York: McGraw-Hi

Richard L.Daft,(2005).Organization Theory and Design, 8th edition, Thomson, south-western(Chapter 10)

Mead, R. (1994). International Management. Cross Cultural Dimensions, Oxford: Blackwell.

http://baike.baidu.com/view/4676.htm

http://www.mcdonalds.com/ 


\title{
Optimization of Security Investment Portfolio Based on
}

\section{Improved Simulated Annealing Algorithm}

\author{
Lin Xiao \& Zhongyuan $\mathrm{Wu}$ \\ School of Management, Tianjin Polytechnic University, Tianjin 300384, China
}

\begin{abstract}
Considered of multi-local optimal solution in investment portfolio, the paper proposed an improved Simulated Annealing Algorithm. This algorithm applied multiplicator function which transform security investment model into nonrestraint optimization problem, optimized key process and parameter of basal Simulated Annealing Algorithm. It also solved initial temperature and how to get the result, balanced speed and precision, then improved efficiency of algorithm. At last, this paper used date to validate the feasibility of algorithm.
\end{abstract}

Keywords: Simulated Annealing Algorithm, Security investment portfolio, Parameter optimization

\section{Foreword}

The aim of security investment is achieve return while the investor should take on risk. In order to increase return and avoid or decrease risk, security investment portfolio which use mathematics to seek balance between expected return and investment risk. Markowitz-an America economist found a new model, which means Mean-Variance model. This model applied mean and variance of investment portfolio return distributing to represent expected return and risk, which is the basic of modern investment portfolio. Classical M-V model:

$$
\begin{array}{cc}
\text { Min } & f(X)=X^{\mathrm{T}} V X \\
\text { s.t } & R^{\mathrm{T}} X=\delta \\
& \sum_{i=1}^{n} x_{i}=1 \\
x_{i} \geq 0 \quad i=1,2, \mathrm{~L}, n
\end{array}
$$

Where $n$ the number of security investment, the expected return of security is $i$ is $r_{i}, X_{i}$ means funds proportion of security $i$ in total funds, $V=\left(\sigma_{i j}\right)$ and $\delta$ stand for Covariance matrix of $r_{i}$ and Expected profit.

Solve a More restrictive conditions is the crux of model, so the difficult issue is solving universal optimization. Most non-linear programming model has much solution with a lot of portion optimization. Therefore, different initial solution has different optimization. Until now, many scholars research the issue. An iterative algorithm base on gradient slope is the most fundamental algorithm. This paper proposes an optimization of security investment portfolio based on improved Simulated Annealing Algorithm.

\section{Simulated Annealing Algorithm}

Simulated Annealing Algorithm base on the annealing solid principles, which is thermodynamic process: solid will be heated to melt, and then slowly cooled until solidified into a regular crystal. When heating, with the internal temperature rises, solid particles gradually turns into a state of disorder, then internal energy increase; while slowly and gradually cooling at the orderly, then each temperature achieves a balanced, finally reaches ground state at normal atmospheric temperature so internal energy reduces into minimum. In 1982, Kirkpateick first realizes the similarity between solid annealing process and combinatorial optimization problems, then introduce into Metropolis criteria, which using Monte Carlo to simulate the process of solid achieving thermal equilibrium in a normal atmospheric temperature and cooling schedule with the control algorithms. With each temperature $\mathrm{T}$ of decreasing process, an iterative process-"new judge to accept or discard" is continuing. Simulated Annealing Algorithm is a heuristic, which not only can iterate to the direction of objective function reducing, but also accept deterioration in a certain range, therefore simulated annealing algorithm can jump out the "trap" of local optimization to have overall optimal solution of portfolio optimization problem. In theory, as long as the simulation process is fully, simulated annealing algorithm can convergence into achieve global optimum with a probability. 
The steps of simulated annealing algorithm can be expressed as follows:

Step1: Initialization. Given the initial temperature $T=T_{0}$, randomly generated initial state $X=X^{0}$, determine the temperature of each iteration times $L$;

Step2: In temperature $T, k=1,2, \mathrm{~L}, L$ repeat step3 and step6

Step3: Produce a neighboring state $X^{\prime}$;

Step4: Calculate the incremental evaluation function $\Delta f=f(X)-f\left(X^{\prime}\right)$;

Step5: If $\Delta f<0$, accept new solution; while, if $\exp (-\Delta f / T)$ more than a random number

Between 0 and 1 accepted.

Step6: If the conditions met termination then output the current optimal solution, ending calculation.

Step7: Annealing, turn into step2.

\section{Algorithm and choice of key parameters}

\subsection{Portfolio optimization model}

This problem to solve is model (1); we apply multiplication function which can transform model M-V into unconstrained optimization problem of penalty coefficients to solve:

$$
\begin{aligned}
& \min \quad L(x)=f(X)+M\left(\max \left(0,\left(\delta-R^{\mathrm{T}} X\right)\right)+\left|\sum_{i=1}^{n} x_{i}-1\right|\right) \\
& \text { s.t. } \quad X^{c} \leq X \leq X^{f}
\end{aligned}
$$

Where $X^{c}$ and $X^{f}$ is ceiling and threshold, in this paper $X^{c}$ and $X^{f}$ is 0 and $1, \mathrm{M}$ is penalty function.

When using simulated annealing to solve these problems, the algorithm relies on a set of parameters to control the process, the selection of parameters directly related to the algorithm's merits. Then the following discusses the key parameters.

\subsection{The choice of initial temperature T}

One of the important factors, which affect research possibility of simulated annealing, is the setting of initial temperature $T_{0}$. The higher initial temperature also with the possibility of a global optimum, so the number of iterative will be substantially increased and reducing the possibility of the algorithm; instead, the global search capabilities will be affected. Therefore, the initial temperature is set at a reasonable time, which can maximize the quality of the final solution. After several experiments, we use the following formula to determined initial temperature.

$$
T_{0}=\frac{\overline{\Delta f^{+}}}{\ln \frac{m_{2}}{m_{2} \chi-m_{1}(1-\chi)}}
$$

In the formula, $m_{1}$ and $m_{2}$ stands for reduce of objective function and increase of number respectively, $\Delta f^{+}$is average incremental, $\chi$ is the initial acceptance rate of new solution-must approach 1 .

\subsection{Terminal temperature and length of Markove Chain}

Along with the slowly reduced, simulated annealing algorithm gradually converges into global optimal solution. Only the terminal temperature is fully small, algorithm can get high quality of the optimal solution; however, in order to reduce the amount of computation, terminal temperature should not be too high. Usually the length of Markove Chain is $100 n, n$ is dimension of solution.

\subsection{Formation of adjacent state}

Adjacent state is that from current to achieve with one moving, just new solution. The formation of new state generally with a random number generator, then select an initial state and zoom it. Assuming at one state, $x^{k}$ is $\left(X_{1}, X_{2}, \mathrm{~L} X_{n}\right)$, format function at adjacent state is

$$
x_{i}^{k+1}=x_{i}^{k} \pm \alpha(b-a)
$$

Where, $\alpha$ is a random number at $(0,1)$, the range of $X_{i}$ is $[a, b]$. 


\subsection{Attenuation function of temperature}

We use attenuation function of temperature to simulate the process of cooling down, only in small decrement can simulate solid that has minimal energy at lowest temperature. So, the process of attenuation is naturally lower cooling, can reach balance at each state and finally achieve ground state. This paper approaches heuristic criteria for cooling:

$$
T_{k}=\frac{T_{0}}{k^{m}}, k=1,2, \mathrm{~L}
$$

Where $T_{0}$ is initial temperature; $m$ is constant above or equal 1 , generally $3 ; T_{k}$ is temperature after $k$.

\subsection{Acceptance criteria of adjacent state}

When $X$ turned from $x^{k}$ to $x^{k+1}$, it should have a criterion that judges which state can accept. This paper adopts Metropolis criteria, with the corresponding transfer probability:

$$
p=\exp (\Delta f / T)
$$

Where $\Delta f$ is the change in the value of objective function. Form this formula, we can see that simulated Annealing Algorithm not only accept optimum solution but also accept deterioration in certain range.

\section{Examples}

We assume security investment portfolio $X=\left(X_{1}, X_{2}, X_{3}\right)$ which formed by the three securities, where $X_{1}, X_{2}, X_{3}$ stands for the proportion of funds. According to the historic data between 1981 and 2000, we calculate expect rate of profit $E(X)=(11.30,18.50,7.55)$,risk $\delta^{2}(X)=(2.74,11.02,0.08)$, covariance matrix

$$
\operatorname{Cov}(X)=\left[\begin{array}{ccc}
1 & -0.1959 & -0.0289 \\
-0.1959 & 1 & -0.0134 \\
-0.0289 & -0.0134 & 1
\end{array}\right]
$$

Assume expect rate of profit is $13 \%$, the globally optimal solution is $X=(0.51,0.32,0.17)$, optimal objective function is 0.0151 .

We use simulated annealing algorithm to solve the problem and then according to formula 3 determine the initial temperature after 50 tests, accept probability $\chi$ is 0.95 ; terminal temperature is 0.001 ; length of Markove Chain is 300 ; attenuation function of temperature is 3 .

Table 1. the solution of simulated annealing algorithm

\begin{tabular}{|c|c|c|}
\hline Initial temperature & Value of objective function & Relative error (\%) \\
\hline$(0.3,0.3,0.4)$ & 0.01510 & 0 \\
\hline$(0,0,1)$ & 0.01498 & 0.794701987 \\
\hline$(0.5,0.5,0)$ & 0.01510 & 0 \\
\hline$(0.1,0.5,0.4)$ & 0.01510 & 0 \\
\hline$(0,1,0)$ & 0.01511 & 0.033225166 \\
\hline
\end{tabular}

From table 1, we can see that the algorithm has not sensitive to initial temperature. Global optimal solution could achieve at any initial value with small error.

\section{Conclusions}

In this study, we proposed simulated annealing to solve the model which based on investment portfolio model of Markowitz, and its key processes and parameters were optimized to achieve a balance between speed and accuracy, so that has strong robustness. According to the results of research, we can see that the simulated annealing algorithm has the advantages to solve the problem.

\section{References}

Michael W.Trosset. (2001). What is simulated annealing, Optimization and Engineering. 2,201-213.

S.Kirkpatrick, C.D.Gelatt. (1983). Science, Optimization by Simulated Annealing, 220:617-680.

E.H.L. (1989).Aarts, Simulated Annealing and Boltzmann machines, John Wiley and Sons.

Zhang,Wei, Zhou, Qun \& Sun, Denbao. (2001). Genetic Algorithm for the optimal security investment portfolio. Quantitative and Technical Economics. 10:114-116. 


\title{
Do Producer Prices Cause Consumer Prices?
}

\section{Some Empirical Evidence}

\author{
Mohd Fahmi Ghazali (Corresponding author) \\ Labuan School of International Business and Finance \\ Universiti Malaysia Sabah-Labuan International Campus \\ Jalan Sg. Pagar, 87000 Labuan, Malaysia
}

Tel: 087-466715 E-mail: mohdfahmi_ghazali@yahoo.com

Ooi Ai Yee

Labuan School of International Business and Finance

Universiti Malaysia Sabah-Labuan International Campus

Jalan Sg. Pagar, 87000 Labuan, Malaysia

Tel: 087-466713 E-mail: ooiaiyee@yahoo.co.uk

Mohd Zulkifli Muhammad

Labuan School of International Business and Finance

Universiti Malaysia Sabah-Labuan International Campus

Jalan Sg. Pagar, 87000 Labuan, Malaysia

Tel: 087-460492 E-mail: zulrider@yahoo.com

\begin{abstract}
The main purpose of this paper is to examine the relationship between consumer price index (CPI) and producer price index (PPI) in Malaysia. This research considers monthly data of consumer price index and producer price index from January 1986 to April 2007. The Johansen cointegration method suggests that there is long-run equilibrium relationship between these two variables. Both Engle Granger and Toda-Yamamoto causality tests find that there is uni-directional causality running from PPI to CPI.
\end{abstract}

Keywords: Causality, Consumer price, Producer price, Malaysia

\section{Introduction}

This paper investigates the relationship between consumer price index (CPI) and producer price index (PPI) in Malaysia using monthly data over the period January 1986 to April 2007. Nowadays, empirical analysis on CPI and PPI relationship has received greater attention, as there are considered as indicators of inflation. The traditional or production chain view concerning the causal relationship between CPI and PPI is one in which changes in PPI lead or cause CPI as result of changes in producer prices which are passed on to consumers. This is merely a standard supply-side or cost-push explanation of changes in consumer prices. Colclough and Lange (1982) argue that an alternative view of the causal relationship between CPI and PPI which stresses the demand side seems equally plausible. According to this view, changes in the demand for final consumer goods exert an influence on input prices through the impact of changes in the prices of consumer goods on the derived demands for inputs. Uni-directional causality from CPI to PPI would characterize this particular viewpoint (Jones, 1986).

The directions of causality between CPI and PPI have been tested in many countries over various periods of time. The results have yielded conflicting evidence. For example, Caporale et al. (2002) investigated the causality issue using Toda and Yamamoto (1995) for G7 countries for the period January 1976 to April 1999. They found that PPI lead CPI in France and Germany. On the other hand, data of the United States suggest the result expected under the alternative view, which is CPI lead PPI. Data from Italy, Japan and the United Kingdom indicate feedback relations, whereas that of Canada fails to reveal any recognizable pattern. 
Jones (1986) has examined causal chain among CPI and PPI in the United States using monthly data for the sample period January 1947 to December 1983, as well as for the two sub-samples, January 1947 to June 1971 and May 1974 to December 1983. The results reveal that there is a bi-directional causality between CPI and PPI.

Cushing and McGarvey (1990) indicated that feedback from PPI to CPI is greater than that from CPI to PPI from January 1952 through December 1987 in the United States. Recent study by Shahbaz and Nasir in Pakistan from January 1992 to June 2007 also found two way causality but stronger from PPI to CPI.

Mehra (1991) and Huh and Trehan (1995) study in the United States found that in the long run CPI leads labour cost, which is a major component of the PPI, a finding that contradicts the production chain view. Gordon (1988), on the other hand, analyzed data from 1954 to 1987 in the United States and concluded that there is no significant statistical relationship between CPI and PPI.

The motivation of this study is, at least very recently, most existing studies have been biased towards the larger and more developed countries. In addition, this is the first study that focuses exclusively in Malaysia. More technically, this research applies the modified-Wald test (MWald) test approached by Toda and Yamamoto (1995) to reinvestigate the causal relations between CPI and PPI.

The rest of the paper is organized as follows. In the next section, we give a brief discussion about the data set used in the present paper and outline the methodology employed. In section three we discuss the empirical results, while section four we provide concluding remarks.

\section{Data and methodology}

\subsection{Data}

In order to perform the causality analysis, we use monthly data for CPI and PPI (in 2000 prices). The data set was drawn for the period from January 1986 to April 2007, which comprises 256 observations in total. The variables are obtained from various issues of the International Financial Statistics (IFS) published by the International Monetary Fund (IMF) and transformed into natural logarithm scale prior to analysis.

\subsection{Johansen Cointegration Tests}

A preliminary issue regarding the methodological procedure is related to the fact that the data generating process for most of the economic series exhibits a unit root. Time series properties, namely order of integration and cointegration, have been examined by applying the full information multivariate procedure proposed by Johansen (1988).

The cointegration methodology basically characterizes the existence of a long-run relationship. According to Johansen (1988), a $p$-dimensional vector autoregression (VAR) of order $k$ [VAR( $k)]$ can be specified as follows:

$$
Z_{t}=d+\prod_{1} Z_{t-1}+\ldots+\prod_{k} Z_{t-k}+\omega_{t}(t=1 \ldots T)
$$

We can rewrite this expression as,

$$
\Delta Z_{t}=d+\prod_{k} Z_{t-k}+\sum_{i=1}^{k-1} \theta_{i} \Delta Z_{t-i}+\omega_{t}
$$

Here $\Delta$ is the first difference operator, $\Pi$ and $\theta$ are $p$-by-p matrices of unknown parameters and $\omega_{t}$ is a Gaussian error term. Long-run information about the relationship between CPI and PPI in Malaysia is contained in the impact matrix $\Pi$. When the matrix $\Pi$ has full column rank, it implies that all variables in $Z_{t}$ are stationary. When the matrix $\Pi$ has zero column rank, the expression is a first differenced VAR involving no long-run elements. If, however, the rank of $\prod$ is intermediate meaning that $0<\operatorname{rank}(\Pi)=r<p$, there will be $r$ cointegrating vectors that make the linear combinations of $Z_{t}$ become stationary or integrated.

There are two Johansen cointegration tests. First, the maximum likelihood estimation procedure provides a likelihood ratio test, called a trace test, which evaluates the null hypothesis of, at most, $r$ cointegrating vectors versus the general null of $p$ cointegrating vectors. A second, likelihood ratio test is the maximum eigenvalue test, which evaluates the null hypothesis of $r$ cointegrating vectors against the alternative of $(r+1)$ cointegrating vectors.

\subsection{Causality Tests}

The hypothesis of non-causality can be tested in three ways depending on the order of integration. If the variables are integrated or order 1, denoted, I(1) and cointegrated, causality can be tested using the levels of the variables as in Equations (3) and (4) where the null-hypothesis of non-causality relates to the significance of $\varphi$ and $\gamma$ :

$$
L C P I_{t}=\alpha+\sum_{i=1}^{k} \zeta_{i} L C P I_{t-i}+\sum_{j=1}^{l} \varphi_{j} L P P I_{t-j}+\varepsilon_{t}
$$


$L P P I_{t}=\psi+\sum_{i=1}^{r} \chi_{i} L P P I_{t-i}+\sum_{j=1}^{s} \gamma_{j} L C P I_{t-j}+\eta_{t}$

Alternatively, if the variables are I(1) and cointegrated, the variables can be first-differenced (denoted $\Delta$ ) and the error-correction term (ECM henceforth) from the cointegrating regression added as in Equations. (5) and (6). In this case, in addition to the significance of $\varphi$ and $\gamma$, the significance of $\xi$ and $\phi$ can establish the direction of causation:

$\Delta L C P I_{t}=\alpha+\sum_{i=1}^{k} \zeta_{i} \Delta L C P I_{t-i}+\sum_{j=1}^{l} \varphi_{j} \Delta L P P I_{t-j}+\xi E C M_{t-1}+\varepsilon_{t}$

$\Delta L P P I_{t}=\psi+\sum_{i=1}^{r} \chi_{i} \Delta L P P I_{t-i}+\sum_{j=1}^{s} \gamma_{j} \Delta L C P I_{t-j}+\phi E C M_{t-1}+\eta_{t}$

If the variables are I(1) and not cointegrated, the variables must be rendered stationary by differencing, as in Equations (5) and (6), but the test of causality does not include the lagged ECM term as Equations (7) and (8) show:

$$
\begin{aligned}
& \Delta L C P I_{t}=\alpha+\sum_{i=1}^{k} \zeta_{i} \Delta L C P I_{t-i}+\sum_{j=1}^{l} \varphi_{j} \Delta L P P I_{t-j}+\varepsilon_{t} \\
& \Delta L P P I_{t}=\psi+\sum_{i=1}^{r} \chi_{i} \Delta L P P I_{t-i}+\sum_{j=1}^{s} \gamma_{j} \Delta L C P I_{t-j}+\eta_{t}
\end{aligned}
$$

In addition to the Engle-Granger approach (1987), we also employed a modified version of the Granger causality test to consider the robustness of the results based upon knowledge of the order of integration. This procedure was suggested by Toda and Yamamoto (1995) with the objective to overcome the problem of invalid asymptotic critical values when causality tests are performed in the presence of non-stationary series. Zapata and Rambaldi (1997) explained that the advantage of using the Toda-Yamamoto procedure is that in order to test Granger causality in the VAR framework, it is not necessary to pre-test the variables for the integration and cointegration properties, provided the maximal order of integration of the process does not exceed the true lag length of the VAR model. According to Toda and Yamamoto (1995), Toda-Yamamoto procedure however does not substitute the conventional unit roots and cointegration properties pre-testing in time series analysis. They are considered as complimentary to each other.

The Toda-Yamamoto procedure basically involves the estimation of an augmented VAR $\left(k+d_{\text {max }}\right)$ model, where $k$ is the optimal lag length in the original VAR system, and $d_{\max }$ is the maximal order of integration of the variables in the VAR system. The Toda-Yamamoto procedure uses a modified-Wald test (MWald) test for zero restrictions on the parameters of the original VAR $(k)$ model. The remaining $d_{\text {max }}$ autoregressive parameters are regarded as zeros and ignored in the VAR $(k)$ model. This test has an asymptotic chi-squared distribution with $k$ degrees of freedom in the limit when a VAR $\left(k+d_{\text {max }}\right)$ is estimated. The dynamic causal relationship between prices and money supply would be as follows:

$$
\begin{gathered}
L C P I_{t}=\alpha+\sum_{i=1}^{k+d} \beta_{i} L C P I_{t-i}+\sum_{j=1}^{l+d} \gamma_{j} L P P I_{t-j}+u_{t} \\
L P P I_{t}=a+\sum_{i=1}^{m+d} b_{i} L P P I_{t-i}+\sum_{j=1}^{n+d} c_{j} L C P I_{t-j}+v_{t}
\end{gathered}
$$

where $L C P I$ and $L P P I$ are, respectively, the logarithm of CPI and PPI, $t$ is time period, $k, l, m$, and $n$ is the optimal lag length, $d$ is the maximal order of integration of the series in the system and $u$ and $v$ are error terms that are assumed to be white noise. The initial lag lengths $k, l, m$ and $n$ are chosen using the Akaike Information Criteria. However, the initial lag lengths are augmented with extra lag(s) depending on the likely order of integration $(d)$ of the series $L C P I_{t}$ and $L P P I_{t}$. If $L C P I_{t}$ and $L P P I_{t}$ is likely to be $\mathrm{I}(1)$ (as it is with most macroeconomic data) then one extra lag is added to each variable in Equations (9) and (10). If both variables are assumed $\mathrm{I}(0)$, no extra lag is added in the equation, and the Toda Yamamoto test is equivalent to the Granger causality test. Wald tests are then used to test the direction of causality. For example, in Equation (9), the lags of $P P I_{t}$, excluding the extra lag added to capture maximum order of integration, are tested for their significance. If the null hypothesis that the lags are jointly equal to zero is accepted, then $P P I_{t}$ does not cause $C P I_{t}$. Testing for the joint significance of $C P I_{t}$, excluding the extra lag added, in Equation (10) allows tests for uni-directional or bi-directional causality.

\section{Estimation results}

The first stage involves establishing the order of integration using the Augmented Dickey-Fuller (ADF) and Phillips-Perron (PP), with and without a deterministic trend. Table 1 presents the results of the unit root tests for the two variables, CPI and PPI. The results indicate that all the variables are not stationary in their levels. On the other hand, all data are stationary at first difference and therefore indicating that all variables are I (1).

Given the variables are I(1), the cointegration hypothesis between the variables is examined using the methodology developed in Johansen (1991) in order to specify the long-run relationship between the variables. The results of the 
cointegration tests are reported in Table 2 . The null hypothesis of no cointegrating vector $(r=0)$ is rejected. Thus, CPI and PPI are cointegrated, indicated that there is a long-run relationship.

Because all the variables are I(1) and cointegrated, we transform the variables by taking their difference to induce stationary and test for standard Granger causality using Equation (5) and (6) with adding an error correction term lagged one period. Table 3 shows that there is statistical uni-directional Granger causality runs from PPI to CPI but there is no feedback causality from CPI to PPI.

To consider the robustness of this result the Toda-Yamamoto approach is also used. The results using this approach are presented in Table 4. Since all the variables are in levels, the results provide information about the long-run causal relationships among non-stationary variables in the system. The causality results are qualitatively the same as the results presented in Table 3. The results indicate that the null hypothesis that CPI do not Granger cause PPI cannot be rejected. These suggest that the PPI does not respond to lagged changes in CPI in the system. On the other hand, the hypothesis that PPI do not Granger causes CPI can be rejected at the 5 percent significance level.

\section{Conclusions}

This paper examined empirically the relationship between CPI and PPI for Malaysia. We employed monthly data and applied cointegration using the Johansen approach, application of standard Granger causality tests and the Toda-Yamamoto causality approach to study the CPI and PPI interaction. Using Johansen cointegration approach, our results show long-run association between CPI and PPI, in line with previous research in other countries (see for example Dorestani and Arjomand (2006)). This means that CPI and PPI move together in the long-run. Using standard Granger causality test and Toda-Yamamoto approach, we found evidence of a uni-directional link from PPI to CPI without significant feedback. The empirical evidence is consistent with the conventional wisdom that the causal relation between CPI and PPI is from the latter to the former, in line with Caporale et al. (2002) work in France and Germany.

Analyzing the relationship between the CPI and the PPI has been a target of many studies. The link is important since it allows policy makers to predict future inflation by using PPI. Through the analysis provided in this study, policy makers maybe better prepared to avoid, or at least mitigate, the negative consequences of inflation. This finding can help policy makers to rely more on the link between CPI and PPI and use changes in PPI to predict changes in CPI. Nevertheless, as shown in Caporale and Pittis (1997), leaving out "relevant" variables can invalidate causality inference. Therefore, we suggest that the significant of our results could possibly be improved upon by inclusion the money supply, real gross domestic product, and the interest rate aims at capturing the transmission mechanism of monetary policy.

\section{References}

Al-Yousif, Y. K. (1999). On the role of exports in the economic growth of Malaysia: a multivariate analysis. International Economic Journal, 13, 67-75

Caporale, G. M., Katsimi, M. \& Pittis, N. (2002). Causality links between consumer and producer prices: some empirical evidence. Southern Economic Journal, 68, 703-711

Caporale, G. M. \& Pittis, N. (1997). Causality and forecasting in incomplete system. Journal of Forecasting, 16, 425-437

Colclough, W. G., \& Lange, M. D. (1982). Empirical evidence of causality from consumer to wholesale prices. Journal of Econometrics, 19, 379-384

Cushing, M. J. \& McGarvey, M. G. (1990). Feedback between wholesale and consumer inflation: a re-examination of the evidence. Southern Economic Journal, 56, 1059-1072

Dorestani, A. \& Arjomand, L. H. (2006). An empirical study of the relationship between consumer and producer price index: a unit root test and test of cointegration. The Coastal Business Journal, 5, 33-38

Engle, R. F. \& Granger, C. W. J. (1987). Cointegration and error correction: representation, estimation and testing. Econometrica, 55, 251-276

Gordon, R. J. (1988). The role of wages in the inflation process. American Economic Review, 78, 276-283

Huh, C. G. \& Trehan, B. (1995). Modeling the time series behavior of the aggregate wage rate. Federal Reserve Bank of San Francisco Economic Review, No. 1, 3-13

Johansen, S. (1988). Statistical analysis of cointegration vectors. Journal of Economic Dynamics and Control, 12, 231-254

Jones, J. D. (1986). Consumer prices, wholesale prices, and causality. Empirical Economics, 11, 41-55

Mehra, Y. (1991). Wages growth and the inflation process: an empirical note. American Economic Review, 81, 931-937

Shahbaz, Muhammad \& Najeeb, Nasir. (2008). Producer \& consumer prices nexus: ardl bounds testing approach. Munich Personal RePEc Archive, Paper No. 9285 
Toda, H. Y. \& Yamamoto, T. (1995). Statistical inference in vector autoregressions with possibly integrated processes. Journal of Econometrics, 66(1/2), 225-250

Zapata, H. O. \& Rambaldi, A. N. (1997). Monte Carlo evidence on cointegration and causation. Oxford Bulletin of Economics and Statistics, 52, 285-298

Table 1. Results of the Unit Root Tests

\begin{tabular}{|l|l|l|l|l|}
\hline \multirow{2}{*}{ Panel A: ADF and PP Unit Root Tests at Level } \\
\hline \multirow{2}{*}{ Variables } & ADF & $\tau_{\tau}$ & PP \\
\cline { 2 - 5 } & $\tau_{\mu}$ & $\tau_{\mu}$ & $\tau_{\tau}$ \\
\hline LCPI & $-1.3429(12)$ & $-1.2378(12)$ & $-0.5989(4)$ & $-0.8248(4)$ \\
\hline LPPI & $0.1600(1)$ & $-2.8203(1)$ & $0.3153(3)$ & $-2.8668(4)$ \\
\hline Panel B : ADF and PP Unit Root Tests at First Difference & \multicolumn{2}{|l}{} \\
\hline \multirow{2}{*}{ Variables } & ADF & $\tau_{\tau}$ & $\tau_{\mu}$ & $\tau_{\tau}$ \\
\cline { 2 - 5 } & $\tau_{\mu}$ & $-3.1002(11)$ & $-14.3575(3)^{* * *}$ & $-14.3462(3)^{* * *}$ \\
\hline$L C P I$ & $-2.9565(11)^{* *}$ & $-13.5448(0)^{* * *}$ & $-13.5268(1)^{* * *}$ & $-13.5271(1)^{* * *}$ \\
\hline
\end{tabular}

Notes: The null hypothesis is that the series is non-stationary, or contains a unit root. The rejection of the null hypothesis for both ADF and PP tests is based on the MacKinnon critical values. Values in parentheses are optimal lag lengths according to the Akaike Information Criteria and Newey-West Bandwidth. $\tau_{\mu}$ and $\tau_{\tau}$ are constant and trend and constant, respectively. Asterisk (***) and $(* *)$ denotes that a test statistic is significant at the $1 \%$ and $5 \%$ significance level, respectively.

Table 2. Testing for Bivariate Cointegration

\begin{tabular}{|l|l|l|l|l|l|l|l|}
\hline$H_{0}$ & $H_{l}$ & Eigenvalue & Trace Statistics & $\begin{array}{l}5 \% \text { Critical } \\
\text { Value }\end{array}$ & $\begin{array}{l}\text { Max-Eigen } \\
\text { Statistics }\end{array}$ & $\begin{array}{l}5 \% \text { Critical } \\
\text { Value }\end{array}$ & VAR \\
\hline$r=0$ & $r=1$ & 0.1842 & $55.6030 * * *$ & 19.96 & $51.5122 * * *$ & 15.67 & 2 \\
\hline$r \leq 2$ & $r=2$ & 0.0160 & 4.0908 & 9.24 & 4.0908 & 9.24 & \\
\hline
\end{tabular}

Notes: VAR is order of the variance. *** denotes statistically significant at the $1 \%$ level. $H_{0}$ and $H_{l}$ denote the null and alternative hypothesis respectively and $r$ denotes the number of cointegrating vectors.

Table 3. Causality Tests Between Exchange Rate, Stock Prices and Interest rate: Engle Granger Approach

\begin{tabular}{|c|c|c|c|c|c|}
\hline \multirow{2}{*}{$\begin{array}{l}\text { Dependent } \\
\text { Variables }\end{array}$} & \multirow{2}{*}{$\begin{array}{l}\text { Independent } \\
\text { Variables }\end{array}$} & \multirow[t]{2}{*}{ Order of Lag } & \multirow{2}{*}{$\begin{array}{l}\mathrm{ECM}_{t-1} \\
\text { ( } t \text {-statistics) }\end{array}$} & \multicolumn{2}{|c|}{$\begin{array}{l}\text { Joint Test of Zero Restrictions of } \\
\text { Variables Added in Column } 2\end{array}$} \\
\hline & & & & $F$-Statistics & $p$-values \\
\hline$\triangle L C P I$ & $\triangle L P P I$ & 1 & $-2.1006^{* *}$ & $6.1585^{* *}$ & 0.0137 \\
\hline$\triangle L P P I$ & $\triangle L C P I$ & 1 & -1.1492 & 0.9273 & 0.3970 \\
\hline
\end{tabular}

Notes: $\Delta$ denotes a first difference. $* *$ denotes statistically significant at the $5 \%$ level. The lag length selection was based on Akaike criterion test results (not reported in this paper). ECM is the error correcting variable lagged one period.

Table 4. Causality Tests between Consumer Price Index and Producer Price Index: Toda-Yamamoto Approach

\begin{tabular}{|l|l|l|l|l|l|}
\hline \multirow{2}{*}{$\begin{array}{l}\text { Dependent } \\
\text { Variables }\end{array}$} & $\begin{array}{l}\text { Independent } \\
\text { Variables }\end{array}$ & Lag Structure & \multirow{2}{*}{ VAR Order } & \multicolumn{2}{l}{$\begin{array}{l}\text { Joint Test of Zero Restrictions of } \\
\text { Variables Added in Column } 2\end{array}$} \\
\cline { 4 - 6 } & & & $(3)$ & $4.6047^{* *}$ & 0.0109 \\
\hline$L C P I$ & LPPI & 2 & $(4)$ & 0.9313 & 0.4262 \\
\hline
\end{tabular}

Notes: The $[\mathrm{k}+\mathrm{d}(\max )]$ th order level VAR was estimated with $\mathrm{d}(\max )=1$ since the order of integration is 1. The lag length selection was based on Akaike criterion test results (not reported in this paper). ** denotes statistically significant at the $5 \%$ level. 


\title{
The Rhetoric and Translation of English Advertisement
}

\author{
Xiang Xu \\ College of Foreign Language, Qingdao University of Science and Technology, Qingdao 266061, China \\ E-mail:stephenxu10@163.com
}

\begin{abstract}
Advertisement is the major way of promoting sales. To achieve this aim, the AD language gets used to reinforce the effect with the help of rhetoric devices such as simile, metaphor, personification, pun, rhyme, etc. In term of the difference between English and Chinese, some translation methods including Literal Translantion, Free Translation and Modulation could be skillfully used during the time of translating rhetoric devices. Because almost all kinds of subject knowledge and commerce knowledge are involved in translation course, not only should the translator have abundant language skills and fertile fanciful abilities, but also understand commerce psychology and sales strategy. Thus, the translation contents could be pricisely restored. With the beautiful words and expressions and the easiness of reciting aloud, the final version of translation can be able to serve the purpose of promotinmg sales.
\end{abstract}

Keywords: English advertisement, Rhetoric, Translation

\section{The significance of studying English Advertisement}

The forming of the word Advertisement dates back to Lantin language Adverture, with its meaning of "attaction". In the middle ages of English (around 1302-1475), it varied into the word Advertise, and the meaning also changed into "attracting somebody to notice something", or "informing somebody so as to attract him". Until the end of the $17^{\text {th }}$ century, England set out to hold commercial activities in great dimension. At that time, the word Advertisement became popular and used widely. The meaning of advertisement refers to not only one piece of advertisement, but a series of advertising activities. Advertisement Time Weekly defines the word, "individual, commodity, labour, campaign, regarding printing, handwriting, dictating or painting as presenting way, paied by advertiser to make public propaganda to promote its aim by sale, usage, vote, or agreement." In modern societies, following the deepening and developing of the international work dividing and the daily strengthening of the tendency according to the one system of global economy, the communication of commodities among the world gets more frequent. In order to catch hold of the markets, each country competes to promote his products. One of the best methods is to introduce national goods and producer's reputation by advertisement. So the study of the advertisement through many view angles is sure to be the focal point of linguistics and translation.

The advertisement language is named as commercial language, belonging to the area of advertisement in written form. This form consisits of five parts, including headline, bodytext, slogan, trademark and illustration. The former three being verbal and the latter two non-verbals. This paper aims at the study of the rhetoric devices about verbal part and the translating problems they cause.

\section{The significance of the rhetoric devices in advertisement and the skill of translation}

Rhetoric is a science of studying language art. It chooses appropriate language method and expressing way chiefly according to communicating contents and language settings, etc. As a science whose purpose is the research for the regulation rule of the effects of language expression, it cannot be easily divided by the art of advertisement language. The key to study the effects of Rhetorics in advertisement is to be familiar with the rhetoric devices and their usage. The rhetoric device is the name of the rhetoric skills in language types, being the core of Rhetoric. It concludes simile, metaphor, personification, pun, hyperbole, antithesis, etc, usually being used for the stress of atmosphere and colour.

Language is one part of language and a carrier of culture. It reflects a nation's characteristics, ont only containing the background of this nation's history and culture, but their life view, life style and thinking way. In the constant development of society and culture, the two nations, England and China, have formed their special own rhetoric devices. There are many same or different places when they are compared with each other. The difficulty in the rhetoric devices of English and Chinese translation comes into being, owning to their difference among many sides, such as word forming, word style changing, syntax structure, language order, and so on, also adding the difference from word matching area and language rhythm.

From the view of translation, the rhetoric devices may be divided into three types: able, hardly able, disable (to be translated). According to this condition, "we'd better find proper way that can express the original meaning to conduct 
its best effect perfectly into the translated script.”(Feng Qinghua, 2002:151) according to Teng Weiguo, the three principles of translation are honesty, simpleness and vivdness.

The three methods of translation of the rhetoric devices are Literal Translation, Free Translation and Modulation.

\subsection{Literal Translation}

Literal Translation refers to the perfect keeping for the contents and styles of the original, especially its simile or metaphor, image and national elements. The leading condition is not to disobey the laguage rules and cannot be easily caused by false imagination. Literal Translation can be used safely when there is some common nature in Chinese and English, especially there is some corresponding device.

\subsection{Free Translation}

Free Translation indicates the method for mending the blank of word lacking and the difference of language structure. Thre are quite a few devices interfering with unique language feature and habits, or culture custom, according to different background which cannot be familiar with language importing countries. Thus it drives the translator to search for their own national idioms, selecting proper sentences or phrases to send the message or main meaning which are faithful to the original scripts.

\subsection{Modulation}

Modulation should be mastered from grand view. It's hard for us to express the devices completely in a translated script, so the traslator is supposed to deal with them from the whole text, adding or deleting some places, particularly using rescuing method to cope with some disable translated parts.

This paper stresses on the types of the rhetoric devices in English Advertisement and how to translate them.

\section{The rhetoric in English Advertisement}

Advertisement is called sub-literature. In order to conduct effective message of commodity, the advertisement language is pursuing the aim at attracting more customers by colorful and various advertisement language.

\subsection{Simile}

Simile shows the similarity of the two different things - the describing object and the described object. In English, it is connected with Like and as, in Chinese corresponded by "hao xiang"or "wan ru". The first example is an advertisement about spectacles: Featherwater, light as a feather.Feather is its brand,and "light as a feather"can be Literal Translated as "qing ru hong mao". This advertisement touches the reader by the spectacle's feature-light weight, which is used so vividly. Another baverage advertisement is "Breakfast without orange juice is like a day without sunshine". Only being literally translated into "Mei you ju zhi de zao can jiu xiang meiyou yang guang de ri zi"can the function of the products be presented vividly and charmingly to the face of the reader with the characteristics of touching his heart.

\subsection{Metaphor}

Metaphor indicates the superposition of the describing object and the described object. In the sentence the two things with commom feature or inner connection, but only one appears in the text. They usually be connected with the verb "to be". Given four examples of commercial advertisement, no exception of using "life is."

Nissan car: life is a journey. Enjoy the ride. (Sheng huo jiu shi yi ci lu xing, zhu nin lu tu yu kuai);

Gatorade drink: life is a sport, drink it up. (Sheng huo jiu shi yi chang yun dong, he xia ta );

Tequila liquor: life is harsh, your tequila shouldn't be.(sheng huo shi ku se de, er nin de tequila jiu que bu shi;

Wolderness system: life is discovery, and we have directions to get you there.(sheng huo jiu shi fa xian, rang wo men qu fa xian ba )

The above four sentences connect the describing object with life; using the link verb "is"directly. The pattern of the translation is almost the same as the original, simple but easy to catch the reader's imagination.

Here is a liquor advertisement: Sophisticated, sweet-to-drink Pink Lady. (gao ji ke kou de hong fen jia ren ). The simple words make us feel that a pretty girl wearing pink is coming to us flirtatiously. Another lipstick advertisement is: The most sensational place to wear satin on your lips. The script describes the lipstick as satin. The colour on one's lips is just as bright and soft as satin. Someone translates it into "si ban rou hua de kou hong ca zai chun shang zhe ge zui fu you ji qing de di fang". it seems nothing left untranslated, however, the rhyme is a little less than the original. The styles of modern poem can be used to translate it as "si ban rou hua de kou hong, ca zai ning ju ji qing de chun shang". The superlative degree "most" cannot be corresponded by "zui", but the word "ji" expresses the meaning precisely, and another kind of rhyme appears.

\subsection{Personification}

Personification is the device to describe some non-humans as real human beings. They've given human's emotion or 
action to achieve the requirement of being vivid. This skill is usually carried out so as to make the commodity alive, full of emotion, easy to be near by people. For example, "She has her own spirit and it graces everyone she comes near". This advertisement personifies the perfume. The word "she"refers to not only the representative beauty, but the perfume itself, and women are the only users. This sentence can be richer than directly shows the advantanges of products. The quality of this advertisement can touch those women who are pursuing beauty desperately.

\subsection{Pun}

Pun shows that one word suggests two or more meaning or different imagination. It seems like a word game, being the traditional rhetoric feature of English advertisement. For example, Give your hair a touch of spring.(gei ni de tou fa yi lu shun se). Here, the word spring has double meanings. At one side means the spring of hair, at another, prosperous sping season. As for the translation, "zhan" is corresponded with touch, and "chun" is followed by "se". another example, From sharp minds.Come Sharp products.(xia pu chan pin lai zi min jie de si wei).it is well-known that "sharp" here means both the copy machine and the meaning of being smart and not blunt.

\subsection{Rhetocical Qustion}

Rhetocical Qustion means that the author set out a question on purpose though he knows the answer well. Three conditions are included: ask and answer by oneself, ask but not answer by oneself and complete retocical question.

Here is a chocolate advertisement,

Have you ever noticed what a remarkable effect Godiva Chocolate has on people?

The mere glimpse of the scintillating gold box foretells of many luscious moments to come--

(ni ke ceng xiang dao Godiva qiao ke li dui ren de ying xiang you duo da ma? Zhi yao pie yi yan na jin guang shan shan de he zi, li ke jiu hui gan dao xiang wei you ren----)

The answer is properly correlated with the question, vividly and full of curiosity to the reader.

Another black hair spray: Are you going gray too early? (nin de wu fa shi fou bai de you dian tai zao?) The rhetoric questions are perfectly placed in above classic examples.

\subsection{Rhyme}

Rhyme is one of the skills of English poem, roughly divided into two types - alliterration and end rhyme, making proper rhythm for the reader to recite.

\subsubsection{Alliterration}

Alliterration refers to the repetition of similar sounds, usually consonants or consonant clusters in a group of words. Usually this occurs at the beginning of those words. Alliterration in advertisement looks eyes-catching, and sounds pleasant to the ears. There are two examples,

Spare,shapely and sensational—one step dressing.(jie sheng, yun chen, ji qing—yi bu qun);

Health, humor and happiness - It's a gift we'd love to give. (jian kang, you mo, kuai le --- zhe jiu shi wo men gei nin de li wu).

The repetitions of allteration in the two sentences appear with the value of notice and memory, easily producing strong emotional effects. The space of readers imagination is produced.

\subsubsection{End Rhyme}

If both rhyming words occur at the ends of lines, it's called end rhyme. It also makes a series of sentences sound vivid. Here is the advertisement of lady's swimming suit --Flash, dash, Classic splash. (shan guang, xuan yao, jing dian de fei jian). Three vowel [s]s construct a wonderland of lotus diving into water colourfully and spalshed drops flying everywhere. Another product's promoting advertisement: Big thrills, small bills (da ci ji, xiao hua fei). The two consonant[s]s also builds some special taste. So, end rhyme adheres some features of being easily recognized and artistically superposed. Then the atmosphere is constructed successfully.

Besides the types mentioned above, other rhetoric devices in English advertisement are hyperbole, parallelism, repetition, antithesis, and so on. Those are supposed not to be discussed owing to the length limitation.

\section{Conclusion}

This paper is mainly about the rhetoric devices and translation of English advertisement. In the practical process of translation, the best result needs deep considering action, good methods and ability of precise choices. This resaerch can give us more opportunity to understand the feature of English and master the highlight of English advertisement. Having the knowledge of the culture, value opinion and custom, we are certain to advocate national products so as to lauch them in international markets effectively. 


\section{References}

Jin, Qiuhua. (2003). The Characteristics of Advertisement Language, Journal of Liao ning College.

Feng, Qinghua. (2008). A Practical Course for Tanslation, Shanghai: Shanghai Foreign Language Eduction Press

Beckwith, Harry. (1997). Selling the Invisible: A Field Guide to Modern Marketing, Warner Books

Bly, Bob. (1998). Business to Business Direct Marketing: Proven Direct Response Methods to Generate More Leads and Sales, NTC Business Books

Caples, John. (1983).How to Make Your Advertising Make Money, Prentice Hall 


\title{
From American Westward Movement to
}

\section{Chinese Western Development}

\section{------ General Analysis of Relationships between Institutions and \\ Economic Development as Well as the Enlightenment for China}

\author{
Xijing Sun, Lanhui Wang \& Huancheng Du \\ School of Economic Management, Beijing Forestry University, Beijing 100083, China \\ E-mail: jinger2050@163.com
}

\begin{abstract}
This paper starts from the description of the concept and importance of institutions. Then it takes American Westward Movement as an example to illustrate in details about the relationship between institutions and economic development as well as the significant influence that institutions exert. After analyzing the current institutional obstacles (the lagged-behind government functional system and market system, and the super sticky institutional change) that stand in the way of the Western Development Program in China, this paper finally puts forward several practical approaches to improve this situation according to the theory of system innovation. (The additional statistical analysis better proves that the innovations on institutions did improve the average standard of living and comfort level of local citizens.)
\end{abstract}

Keywords: Institutions, Western Development Program, American Westward Movement, Institutional change, System innovation

\section{The institution concept and its importance}

Veblen, T., a founder of institutionalism, thinks that institutions are the stable and common thinking habits for most people. Commons, J., another founder, defines institutions as group activities that control, liberate, and expand human behaviors. North, D., a representative of new institutional economics, regards institutions as social game rules designed by people and also a mechanism that drives the interaction of politics, economy, and society, including formal constraints and informal constraints. The former includes political rules, economic rules, and contracts. The later includes values, ethics, customs, and ideologies (the core is ideology). Coase, R.H., from England, thinks that because of transaction costs, institutions will affect the efficiency of resources allocation. Market malfunction may happen but can be solved by certain institutional arrangement. The production arrangement and its reform centered on property right system and contract system usually drive or obstruct the modernization process. Economic modernization is institutional modernization.

Therefore, institutions may come into being in social members naturally or be constituted by special groups. Institutions include a series of rules, procedures, systems, and groups' internal cultures. The purpose of institutions is to coordinate and guarantee the coherence of social members' behaviors and restrain the relationships between internal groups and the exterior. Both the inner natural effect and the outer enforcing effect contribute to the realization of institutions. Institutions are characterized with coordination, enforcement, and rigidity.

Because institutions are capable of decreasing transaction costs, cultivating economy of scale, driving internalization of externality, and offering guarantees for people's activities, institutions determine the incentive mechanism, social transaction costs, fair allocation, and conflict solution. Therefore, institutions bring about orders and stability for complex and uncertain economic relationships. Perfect institutional system exerts vital effects and impacts on economic development.

\section{The experiences and lessons from American Westward Movement in the establishment of institutions}

According to international experiences, by developing undeveloped regions, countries with large areas can enlarge economic development spaces, explore wider markets, drive optimization of industrial structure and adjustment of products structure, and improve overall national strengths effectively. The most typical representative is American Westward Movement. It is a large-scale migration and colonization movement driven by government institutions based on pure capitalism. The rise of American West offers rich experiences and profound lessons for the development of other countries, including the undeveloped regions in developing countries. 


\subsection{What the valuable experiences we can get from American Westward Movement}

In a sense, without participation of American government, constitution and implementation of relevant policies, it is impossible to develop the expansive western land in such a short period.

(1) American Westward Movement takes large-scale migrations and transportations as the base

In order to drive American Westward Movement, the federal government carried out the free migration policy, encouraging foreigners to move in America. Besides, an unprecedented trans-regional migration happened in America. From 1790 to 1910, the population center moved 557 miles westward, yearly 4 miles in average. During regional development, giving priority to transportation development affected American Westward Movement and national economic growth profoundly. First of all, transportation enhanced regional specialization of western economy. Secondly, transportation drove the form of unified national market. Finally, transportation facilitated western economy as well as national economic growth.

(2) Take commercial and private capitals as main investment resources

The transportation development policy attracted amounts of private capitals for the construction of western transportation system, which directly influenced the progress of Westward Movement. It was the land speculators, the poor, and the planters who pushed American Westward Movement. Their investment funds were mainly from commercial and private capitals. A majority of funds for American Westward Movement were acquired by marketization and commercialization. That is an important character of American Westward Movement.

(3) Push agricultural development energetically

In 1784,1785 , and 1787 , the federal government made up three land acts respectively, establishing three principles of dealing with western lands for the first time in American history. In 1862, Lincoln government issued the Homestead Act, arousing people's enthusiasm for the Westward Movement. To strengthen agricultural management as well as agricultural technological research and popularization were also important policies constituted by the federal government for the Westward Movement. In 1862, American government founded the Ministry of Agriculture to direct the development of western agriculture. In 1887, it set up agricultural experiment management bureaus and employed many agricultural scientists for special researches. Besides, it tried hard to popularize mechanization. Many state governments founded lots of agricultural and relevant colleges and institutes on the lands endowed by the federal government, cultivating kinds of talents for Westward Movement.

(4) Guided by economic integration, the Movement benefited from the effects of government and market

American Westward Movement basically realized the market unification and economic integration between the west and the east, gradually shortening the economic gap, and pushing the coordinative development of regional economy. Till late $19^{\text {th }}$ century, a basic economic pattern with economic specialization, primary market unification, and complement economy between the east and the west in USA came into being: The Great Lakes Region in the northeast became the largest manufacturing zone in the world; The Midwest was the largest grain production and distributing center in the world; and the west remote mountain areas provided irreplaceable mines in USA.

\subsection{Lessons from American Westward Movement}

(1) Ecological environment suffered from grave damages

In American Westward Movement, because of the predatory nature of bourgeois and the indifference of federal government, ecological environment suffered from long-lasting damages in a large scale. Forests, soils, and biological resources were ruined thoroughly. In explorers' opinions, America had unexhausted resources. They focused on explorations but not cared about conserving resources. Considering the ecology, American economic development was at the price of environmental damages and even irreparable losses for certain regions.

(2) Expel, plunder, and slaughter Indian

Almost all people who moved toward the west stepped on Indian bones and blood. Because Indian fought back, the year 1876 witnessed a brutal war suppressing Indian. Afterward, batches of miners run into the mountain areas. Numerous suppresses led to a sharp decrease of Indian population.

(3) Land speculation and land monopoly made farmers suffer from heavy burdens

The imperfect land policies broke the coherence of land acts and caused large-scaled land speculation and land monopoly. As a result, most properties were controlled by land masters on one hand. On the other hand, farmers suffered from heavier burdens. But we should know that land speculation, as a way adopted by bourgeois in American Westward Movement, benefits primitive capital accumulation.

\section{The institutional obstructs in front of China Western Development Program}

The "three-step" strategy advanced by Xiaoping Deng allows and encourages some regions and some people to become rich firstly, by which driving the overall development, and gradually achieving the ultimate socialist goal ------ common 
prosperity. He also put forward the "two overall situations" thought. One overall situation is to expedite the opening process and develop the east seaside regions first. Then, after a period of development, the east should help the Midwest expedite the development. That is also an overall situation. At the turn of the century, in order to achieving the "three-step" strategic goals, President Zemin Jiang advanced the Western Development Strategy based on China's overall situations, advocating to construct a new west region with prosperous economy, social progress, stable life, united nations, and beautiful sceneries during decades of years or even the whole $21^{\text {st }}$ century. As the Western Development Program has been carried out for eight years, the state kept in offering financial support for infrastructure construction, ecological environment protection, and social economic causes in the western region. The west has already achieved fast development. However, some institutional problems obstruct the western economic development. In specific, they are:

\subsection{The lagged-behind government function system in western regions}

In many western regions, local governments are arranged unscientifically and have grave overlaps. Multiple managements are still common. Local governments play not only as judges but also as athletes in economic operations, and behave terribly. No institutions ensure the government to act following a scientific and rational way. In other words, the functional confusion and inefficiency of western governments are originated from the lagged-behind government function system.

\subsection{The lagged-behind market system in western regions}

Western economic operations, from the production to consumption, lag behind the east. In many regions, economy operates in an explicit market with implicit plans. In the aspect of constructing a socialist market economy system, the west and the east start at the same time. But after nearly ten years' development, the market system in western regions is far behind that in the east. The lagged-behind market system inevitably results in low efficiency of economic operation, which will lead to governments' blind interference. That is a vicious circle. As a result, government functions become more confusing and market mechanism can not exert its effectiveness completely.

\subsection{The super sticky character displayed by supply-and-demand relationships in western institutional changes}

Institutional changes mean to break up primary institutions in the forming and amending institutions due to time changes. The closeness of western regions makes it impossible to realize institutional changes internally. Because of poverty, lagged-behind transportation, undeveloped logistics, poor information communication, and difficult exchange between inside and outside, the west have to spend more in institutional innovations, which reduces chances of profitability in a sense. Therefore, informal institutions, such as customs, work for a long period. That seriously obstructs regional technological progresses on one hand. On the other hand, it strengths the super-stable equilibrium of informal institutions. Besides, the institutional changes in western regions have prominent path dependence. In analyzing the "path dependence", Professor North thinks that there is a wage increment and self-reinforcement mechanism in institutional changes. Its predetermined direction will achieve self-reinforcement in next development. If the primitive direction is correct, institutional changes will follow a virtuous circle. If the primitive direction is not exact, institutional changes may walk into a wrong way and even be locked in an inefficient state. Institutional changes have to take market maturity degree, industrial structure, economic strength, and government functions and performances evaluations into consideration. These conditions are also factors of institutional path dependence in western regions.

\section{Feasible approaches based on institutional innovations (with data analysis in appendix)}

Institutional innovations are significant institutional changes. Institutional innovation subjects are people who start and join in institutional innovations because they can precisely predict the extra return generated by institutional innovations. North and Thomas think that institutional innovations are the fundamental reasons for modern economic growth. To construct institutions aims at reducing transaction costs, shortening the distance between individual income and social return, encouraging individuals and organizations undertake production activities, and achieving economic growth. If a society can not realize economic growth, it means the social institutions are incapable of guaranteeing what innovative subjects had expected to return. Considering China's Western Development Program, institutional innovations include:

(1) Some institutional variables, such as the level of non-nationalization, the degrees of marketization and opening, are significant factors that determine regional differences of economic growth during the transition period. In order to shorten and reduce regional differences of economic growth, expediting western development, an effective choice is to emphasize on reforms and institutional innovations, aiming at improve the ability of using market opportunities, expand the levels and degrees of opening, and develop non-state economy. Construct and perfect the factor markets, including labor market, capital market, and technology market. Deepen the reform of price and circulation system for western agricultural products. Enhance the specialization of regions and make the west exert its comparative advantages.

(2) Improve regional legislation and keep coherence of policies. Compared with regional policies, regional legislation has stronger institutional coordinative function. According to experiences from foreign countries, a series of regional policies, including key projects supported by regional finance, are all based on these laws and regulations. In England, the primitive regional policies were from the "special regional act". Then, its regional policies developed together with 
a series of activities related with legislation on the whole. The former federal Germany extremely stressed the legislation of regional policies. China's Western Development Program should be guaranteed by a series of detailed laws and regulations.

(3) Expedite changes of western informal institutions, and encourage individuals and organizations make institutional innovations. Because of geographical location, the social culture in the west has been restrained in a closed environment for a long period. So, the west can not immediately accept new outer things and information easily. Therefore, we should try our best to improve the education, science and technology levels, construct an opening labor circulation mechanism, and enhance information engineering. Those are important ways for expediting informal institutional changes, improving the compatibility of formal rules and informal rules in institutional changes. In addition, it is the government who serves as the subjects of western institutional changes. However, the institutional changes driven by administrative forces can not help the west dig out its potential interests, what leads to an institutional supply "bottleneck". Therefore, as we try to adjust property relationships, we should encourage state-owned and non-state economic organizations, local governments, and individuals to make institutional innovations, satisfying institutional services, and breaking up the institutional supply "bottleneck".

\section{Enlightenment and conclusion}

To sum up, rational institutional system is vital for national economic development. Besides American Westward Movement, more experiences from other countries show that only sufficient financial support for undeveloped regions but without institutional changes can not result in satisfying development. Take Italy for example. After the World War II, Italian governments input amounts of materials and capitals in the south. But the south still has a great distance from the north in economic development. In essence, it is the incomplete institutional reform that obstructs social and economic progresses from many aspects. All countries that reached better achievements in developing lagged-behind regions stress on regional institutional improvement. For example, Spain took advantages over social reforms in developing lagged- behind regions, by which the industrial structure, capitals, and organizations are more in accord with modernization. British government removed limits that harmed regional economic development in supporting undeveloped regions, gradually constructing new energetic economy there, and improving its attractiveness to capitals and skilled labors.

Therefore, the key to drive western development is to improve the opening degree, change traditional thinking, create a loose policy environment, promote governments and economic management bureaus' services and efficiencies, make the west exert its advantages completely, and attract more capitals from the east or the abroad. If western institutional changes lag behind and market economy can not develop well, the beneficial policies for the west and transfer payment will turn into approaches of safeguarding backwardness.

\section{Appendix}

Data analysis demonstration and explanation ------ effects of institutional changes on people's living standard

In order to research whether a series of changes of market, laws, and social institutions impact people's (considering the large distance between counties and cities and the fact that rural population accounts for more than $70 \%$ of total western population, here we take rural population as the representative) living standard significantly since the Western Development Program, especially after the "tenth five-year" plan. Here, Y means the per capita income of rural population. $\mathrm{X}$ is the per capita GDP of 12 provinces in the west. Analyze the effects of GDP on rural population's income quantitatively.

Data in the next table:

\begin{tabular}{|l|l|l|l|l|l|l|l|l|l|l|}
\hline & 1997 & 1998 & 1999 & 2000 & 2001 & 2002 & 2003 & 2004 & 2005 & 2006 \\
\hline $\begin{array}{l}\text { Per } \\
\text { capita } \\
\text { incom } \\
\text { e of } \\
\text { rural } \\
\text { popula } \\
\text { tion }\end{array}$ & 2290.9 & 2352.5 & 2403.7 & 2496.4 & 2608.2 & 2718.3 & 2836.7 & 3196.0 & 3646.0 & 4223.1 \\
\hline $\begin{array}{l}\text { Per } \\
\text { capita } \\
\text { GDP } \\
\text { in the } \\
\text { west }\end{array}$ & 3960.7 & 4212.2 & 4444.9 & 4778.9 & 5101.0 & 5753.8 & 6565.2 & 7950.2 & 9126.4 & 10194.3 \\
\hline
\end{tabular}

Resource:

(Unit: RMB) 
China Regional Economy Statistic Yearbook. China Statistics Press.

China Yearbook of Rural Household Survey. China Statistics Press.

In order to study whether the law that reflects the effects of economic yield on rural residents' income along with changes of GDP in recent ten years or not, we research changes of rural residents' income and GDP along with time changes. See figures as follow.
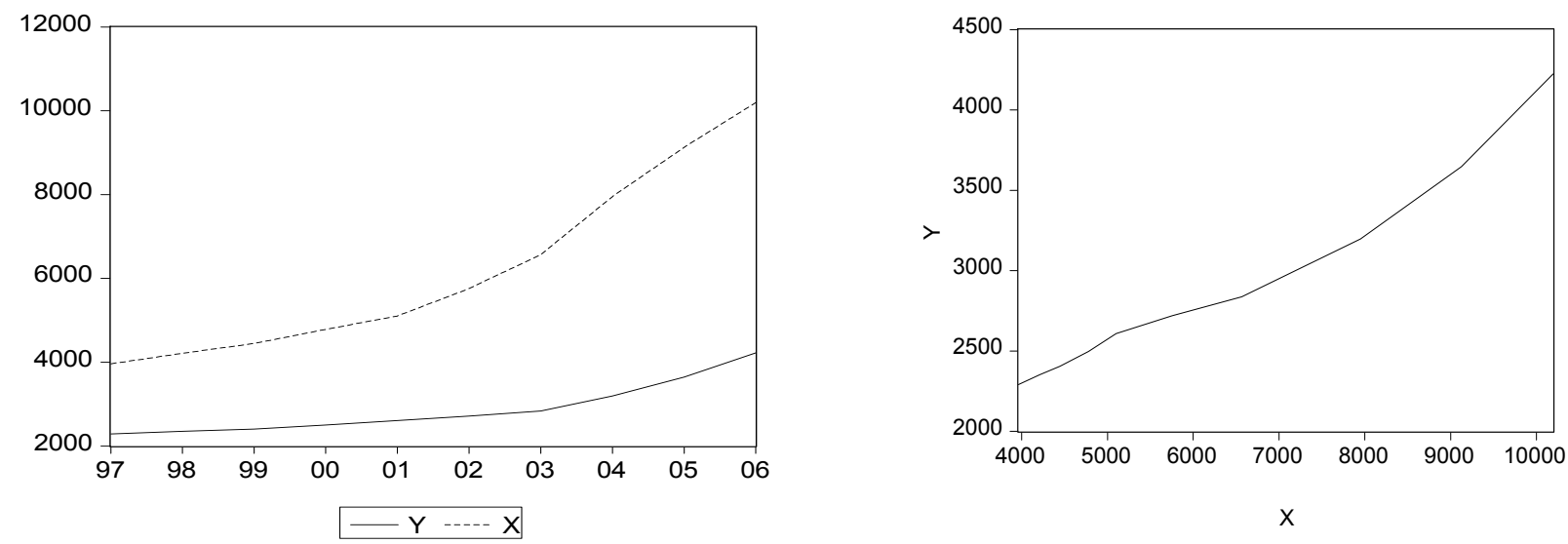

In the two figures we find out similar phase characters. The year $\angle$ vos is an eviuemı turnmy point. Inırouuce ıne following virtual variable model.

$\mathrm{Y}_{\mathrm{t}}=\beta_{1}+\beta_{2} \mathrm{X}_{\mathrm{t}}+\beta_{3}\left(\mathrm{X}_{\mathrm{t}}-6565.2\right) \mathrm{D}_{\mathrm{t}}+\mathrm{U}_{\mathrm{t}}$

Here, $\mathrm{Dt}=1, \mathrm{t}$ means the time after 2003

$=0, \mathrm{t}$ means the time before 2003 and the year 2003

Make regression as follow:

Dependent Variable: Y

\begin{tabular}{|c|c|c|c|c|}
\hline \multicolumn{5}{|l|}{ Method: Least Squares } \\
\hline \multicolumn{5}{|c|}{ Date: $03 / 05 / 08 \quad$ Time: $12: 36$} \\
\hline \multicolumn{5}{|l|}{ Sample: 19972006} \\
\hline \multicolumn{5}{|c|}{ Included observations: 10} \\
\hline Variable & Coefficient & Std. Error & t-Statistic & Prob. \\
\hline $\mathrm{C}$ & 1593.011 & 164.5952 & 9.678354 & 0.0000 \\
\hline $\mathrm{X}$ & 0.185528 & 0.032093 & 5.780893 & 0.0007 \\
\hline$(\mathrm{X}-6565.2)^{*} \mathrm{DUM}$ & 0.174623 & 0.052877 & 3.302425 & 0.0131 \\
\hline R-squared & 0.988109 & \multicolumn{2}{|c|}{ Mean dependent var } & 2877.180 \\
\hline Adjusted R-squared & 0.984712 & \multicolumn{2}{|c|}{ S.D. dependent var } & 631.7219 \\
\hline S.E. of regression & 78.10992 & \multicolumn{2}{|c|}{ Akaike info criterion } & 11.79744 \\
\hline Sum squared resid & 42708.12 & \multicolumn{2}{|c|}{ Schwarz criterion } & 11.88821 \\
\hline Log likelihood & -55.98718 & \multicolumn{2}{|c|}{ F-statistic } & 290.8418 \\
\hline Durbin-Watson stat & 1.459290 & \multicolumn{2}{|c|}{ Prob(F-statistic) } & 0.000000 \\
\hline
\end{tabular}

$\mathrm{Yt}=1592.011+0.185528 \mathrm{Xt}+0.174623(\mathrm{Xt}-6565.2) \mathrm{Dt}$

$\mathrm{se}=(164.5952) \quad(0.032093) \quad(0.052877)$

$\mathrm{t}=(9.678354) \quad(5.780893) \quad(3.302425)$

$\mathrm{R}^{2}=0.988109 \bar{R}^{2}=0.984712 \mathrm{~F}=290.8418$ 
Because the $t$ of very coefficient is bigger than 3 , it means the coefficient of independent variable is not equal to 0 significantly. The regression model of per capita income of rural population is:

$\mathrm{Yt}=1592.011+0.185528 \mathrm{Xt}+\hat{\mathrm{e}} 1$

$\mathrm{Yt}=2738.44592+0.360151 \mathrm{Xt}+\hat{\mathrm{e}} 2$ $(1996<\mathrm{t} \leq 2003)$

Therefore, studies show that along with the implementation of Western Development Program since 2000, western people's, represented by rural residents, living standard has been improved in general. Especially the issue of a series of policies and measures for the sake of driving institutional changes benefits western people to a great degree. The year 2003 was a turning point. Since then, the government began to emphasize on the western state-owned enterprise reform, the strategic adjustment of state-owned economy layout, the construction of modern enterprise system in state-owned large and medium-sized enterprises, and the shareholding system transformation. Enterprises' capital structure is optimized further and lots of leading enterprises successfully list in market. Up to now, non-public economy has already accounted for $31.4 \%$ of total production value. Rural taxation reform works well, exempting agricultural taxes comprehensively, starting many rural integrated and coordinated reform pilots, and the reform of grains circulation mechanism achieves breakthrough progresses. An investment pattern with multiple investors comes into being. The reform of administrative approval institution tends to be more effective. And the reform of financial management system gains new achievements.

Apparently, if we want to further improve western people's living standards and qualities, we must persist in promoting development by reforms, taking institutional changes and institutional innovations as important drives for development. Make non-public economy exert important effects on western national economy. Deepen the investment system reform further and prevent lagged-behind government functions and market as well as break the super stick character of western demand-and-supply relationship. Enhance the reforms on science \& technology, education, culture, sanitation, and residential house.

In sum, we should try our best to carry out a series of approaches for institutional innovations, such as developing market economy, improving regional legislation, and expediting informal institutional changes, and take references from other countries' experiences and lessons in institutional innovation, which will inevitably help us to build the west into a beautiful and prosperous region.

\section{References}

Cai, Jin. (2000). Similarities and differences of China regional economic growth: enlightenment for Western Development Program. Economic Review. No.10.

Chen, Dongsheng. (2001). Economic status quo and developmental countermeasures for western regions in China. China Industrial Economics. No.3.

Li, Qirong. (2006). On lessons of the U.S. Westward Movement. Journal of Huazhong Normal University (Humanities and Social Sciences). No.5.

Lu, Xiaofu. (2005). Western Development Program and institutional innovation. Guangming Daily. $1^{\text {st }}$, Nov.

Qiao, Xinsheng. (2006). Method choice and system innovation of West Development Program. China Economic Times. $11^{\text {th }}$, Sep.

$\mathrm{Xu}$, Songyan. (2005). The western development in contemporary USA. Guangming Daily. $17^{\text {th }}$, Mar.

$\mathrm{Xu}$, Zhihong \& Qin, Xuan. (2nd Edition). Review of Deng Xiaoping Theory and the Important Thought of "Three Represents". Beijing: China Renmin University Press.

China Regional Economy Statistic Yearbook. China Statistics Press.

China Yearbook of Rural Household Survey. China Statistics Press. 


\title{
Examining the Relationship between Work Life Conflict, Stress
}

\section{And Turnover Intentions among Marketing Executives in Pakistan}

\author{
Sarooj Noor \\ Faculty of Business Administration and Management Sciences \\ Army Public College of Management Sciences, Rawalpindi, Pakistan \\ Ordnance Road, Near Ordnance Officers Mess, Rawalpindi Pakistan \\ Tel: 92-0321-5879158Ｅ-mail: elevated_saroj@hotmail.com \\ Nazia Maad \\ Faculty of Business Administration and Management Sciences \\ Army Public College of Management Sciences, Rawaplindi, Pakistan \\ Ordnance Road, Near Ordnance Officers Mess, Rawalpindi Pakistan \\ Tel: 92-0331-5171060Ｅ-mail: innocenteyez_101@yahoo.com
}

\begin{abstract}
This study examines the antecedents of turnover intentions among marketing executives in Pakistan. Relationship between stress and work life conflict with turnover intentions was examined. The research data was collected from 248 marketing executives working in different organizations across Pakistan. The results suggest that of work life conflict and stress have a significant positive relationship with turnover intentions. Recommendations and strategies are also discussed.
\end{abstract}

\section{Introduction}

Turnover at work place has received attention by many researchers (Richer, Blanchard \& Vallerandi, 2002). Mangers and researchers consider turnover a problem because of costs associated with it (Lucas et al., 1987 and Soon et al., 2005). Kirschenbaum \& Weisberg (2002) considers turnover inevitable. Similarly West (2007) found that the impact of turnover on a business can be quite costly in a number of different ways. "Replacing a long tenured manager is quite visible; however, replacing a manager, particularly a marginally effective one, has positive effects outweighing the cost" (Mitchel, 1981). Ling \& Phillips (2006) consider increased working hours a cause of work stress and turnover intentions.

Pakistan is an under researched country (Aycan et al., 2000) and social research in Pakistan has to be established as a recognized field (Baig, 2006). Research becomes a backbone from the day multinational companies entered into our country. Along with other disciplines there has been no significant research on Marketing Executives in Pakistan. The participants of this research Marketing Executives are considered to be the key people because they are so much involved in quitting if facing stress or having work life conflict. Marketing Executives encounter greater challenges due to competing market courses, both micro \& macro levels. Marketing executives face more conflicts (Ikeda, Oliveira \& Campomar, 2005). "Professionals are finding very difficult to balance professional commitments. So, stress-sufferers would be those with high responsibility high-pay jobs and better career profiles" (Leontaridi \& Ward, 2002). Work Life Conflict has an imperative effect on turnover intentions because marketing executives feel difficult \& complex to handle both the situations efficiently.

Stress contains good and bad aspects (Abushaikha \& Sheil, 2006). Giga \& Hoel (2003) \& Sheridan \& Abelson(1983) have related stress with reduced worker and organizational performance. Cropanzano, Rupp \& Byrne (2003) found a positive relationship between emotional exhaustion and turnover intentions while DeVries \& Wilkerson (2003) consider stress a major cause of employee disability. "Difficulty of managing work and family demands has increased rapidly, and therefore many view family-friendly policies as an important attraction and retention strategy"(Batt \& Valcour, 2003). "Those who attempt to leave stress at work or keep lingering stress to themselves; stress is likely to have a pernicious effect on the emotional balance" (Roberts \& Levenson, 2001). Secret (2002) recommended a gap to identify the family, job and workplace characteristics associated with employees, governing its importance.

"Organizations that want the turnover rate low are advised to pay close attention to their human resource management systems with perceived fairness"(Griffeth \& Gaertner, 2001). Employee retention can be enhanced if they develop an 
emotional attachment with the organization. (Paré, Tremblay \& Lalonde, 2000; Paré \& Tremblay, 2000). "Stress management training may rapidly reduce stress symptoms; it also has the advantage of being inexpensive and easy to implement" (Sauter et al., 1999). Thus, Otis \& Pelletier (2005) consider it important to study harmful effects of stress.

\section{Literature Review}

The purpose of this literature review is to present the real meaning of information concerning to turnover intentions, work life conflicts, and stress experienced by marketing executives. "Organizations of all types are giving increased attention to a common problem of business today i.e. employee turnover" (Lucas et al., 1987). Various factor correlate with turnover (West, 2007) while, Leontaridi \& Ward (2002) consider stress the key factor. "Organizations must revisit current work processes, systems, structures, and practices to determine which ones lead to work inefficiencies, which in turn may create unnecessary stress and overwork for employees" (Thompson, Andreassi, \& Prottas, 2003).

\subsection{Work-Life Conflict}

Work-life conflict is defined as "...a form of inter-role conflict in which work and family demands are mutually incompatible, meeting demands of both the domains is difficult" (Higgins, Duxbury \& Lyons, 2007). This conflict does affect psychological functioning (Schieman, McBrier \& Gundy, 2003). Valcour \& Batt (2003) suggest that employers who raise the importance of work-life policies send a signal throughout the organization that work-life issues are important. "Work-life policies are artifacts or surface level indicators of an organization, prioritizing work over family or family over work" (Thompson, Andreassi, \& Prottas, 2003).

Morrell, Clarke \& Wilkinson (2004) \& Glass \& Riley (1998) consider turnover an important issue for organizations and $\mathrm{Yu}$ (2008) favors friendly work life policies to reduce turnover, Valcour \& Batt (2003) also supports friendly policies for reduced turnover while Riley (2006) did not find a significant relationship between work life conflict and turnover intentions. Organizations are searching for policies which can be adopted to reduce turnover (Hom \& Kinicki, 2001). In Pakistan some researchers e.g. Bashir \& Ramay (2008) have recently attempted to highlight the importance of work life policies. "Work-life programs are effective in reducing work-family conflict, and efficient in improving attitudes" (Konrad \& Mangel, 2000).

Now companies are more conscious about work life balance and are offering more friendly work life policies (Yasbek, 2004). "High turnover rates disrupt continuity of care, and also harm workers'abilities to achieve critical case management functions" (Thaden, 2007). "Most effective organizational responses to work family conflict and to turnover are those that combine work family policies with other human resources practices including work redesign and commitment enhancing incentives" (Batt \& Valcour , 2003; Abeysekera, 2007). "Work-Life harmony is a critical business strategy to reduce employee turnover, and to improve overall firm performance" (Soon et al., 2005). More flexility can address the problem of work life balance (Marks \& Scholarios, 2001). "Because the objective of flexible work arrangements is to improve inter-role conflict, and it also seems reasonable to assume that flexible arrangements will be attractive to workers, especially those faced with competing demands"(Rau \& Hyland, 2002).

Work-life balance policies help in reducing stress (Yasbek, 2004). While Hudson (2005) considers it an antecedent of organizational commitment. "Execute such changes in your organization which fulfill the basic policies \& requirements of your employees' by which the turnover intentions ratio can be reduced easily. Organizations must design and put into practice those benefits and policies to help employees balance their work and lives (e.g., flexible work schedules, dependent care supports)"(Thompson, Andreassi, \& Prottas, 200. "The more the physical/psychological symptoms, and turnover intention and the greater the work-family imbalance reported among participants" (Ling \& Phillips, 2006).

H-1: Work Life Conflict is significantly correlated with Turnover Intentions among Marketing Executives in Pakistan.

\subsection{Stress}

"Stress is defined as a nonspecific response of the body to a stimulus or event"(Kavanagh, 2005). In English, stress is defined as the "pressure or anguish resulting from difficult situations" (Alves et al., 2004). "Stress refers to workers not being able to adapt to work and, therefore, involves some biological and psychological reaction" (Hsieh, Huang \& Su 2004).Several studies on various occupations regarding stress have been conducted (Rusli, Edimansyah \& Naing, 2006). "Stress on family life may arise from both the schedule and the content of work" (MacDermid et al., 1994) while White, Wilson \& Pfoutz, (2006) consider it unavoidable. It affects negatively the individual and organization both.(Leontaridi \& Ward, 2002) it prepares body for defense(Sauter et al., 1999). "Work overload has a strong influence on work exhaustion" (Moore 2000; Ahuja et al., 2007) and sooner or later causes a number of diseases (Wofford, Goodwin \& Daly, 1999). General Stress includes "three scales measuring general stress, emotional stress, and social stress with their consequences" (Davis, Orzeck \& Keelan, 2006).

Conflict of expectations between the management and customers causes stress (Parkington \& Schneider, 1979). Yasbek (2004) argues that reduction in stress enhances employee productivity. Stress can enhance turnover (Moore, 2000). Stress is basically a form of unpleasant emotion and as per Côté \& Morgan (2002), it has got the potential to increase employee turnover. Sheridan \& Abelson (1983) suggest that "increased withdrawal of retained employees would be obvious in job dissatisfaction moreover resulting low job commitment, or works stress as a result of increasing job 
tension, or a combination representing both dissatisfaction and stress". Thaden (2007) found that "work load increases due to large duties, insufficient staffing, and additional work handed down by management, workers became more stressed and therefore quit, especially during critical incidents".

Kemery, Mossholder, \& Bedeian (1987) studied that, job-related tension has a causal impact on job satisfaction, which then influence turnover intentions. Otis \& Pelletier (2005) argue that emotional exhaustion leads to more turnover intention, whereas work satisfaction leads to less turnover intention. Leontaridi \& Ward (2002) found significant relationship between stress levels and quitting intentions. "Job stress and its effects on psychiatric symptoms are also associated with an employee's propensity to leave the job"(Braaten, 2000). Higher stress leads to higher employee turnover intentions (Kavanagh, 2005; Cropanzano, Rapp, and Bryne, 2003). Job stress is positively related to intent to leave current employment (Williams, 2003). "The amount of stress has a significant positive effect on turnover intentions" (Layne, Hohenshil \& Singh, 2001).

H-2: Stress is significantly correlated with Turnover Intentions among Marketing Executives in Pakistan

\subsection{Turnover Intentions}

"Turnover (actual exit) - intentions to exit are positively associated with turnover" (Brigham, Castro \& Shepherd, 2007). Manger \& Eikeland (1990) cites that job turnover research has focused on the relation between the intention to leave the organization and actual leaving. "Greater the complementarily, the effect on satisfaction and intentions to leave (turnover intentions) will be greater" (Shalley, Gilson, \& Blum, 2000). Naumann (1992) defines turnover as it "typically refers to the separation of an employee from the firm". Birdseye \& Hill (1995) have broadened the intent-to-turnover concept to include two internal turnover variables (intent-to-leave the location and intent-to-leave the job) as well as the more widely used external turnover measure (intent-to-leave the organization). "Focusing on the causes of employee intentions to stay or leave has been one of the recent research approaches in an organizational turnover literature" (Martin, 1979). Hochwarter et al (2001) elucidates that when employee performance is consistently poor, threats or punishment lead many individuals either to be dismissed (involuntary turnover), or threatened punished enough to leave (voluntary turnover). Similarly Lachman \& Diamant (1987) found that "self-actualization, interpersonal relations, directly can influence employees' affective reactions to their job, which in turn influences their turnover intentions".

"Turnover is an important issue for management, particularly in the tight labor markets prevalent at the turn of the twenty-first century" (Batt \& Valcour, 2003). Attention given to the concept of organizational commitment signifies that it is related with turnover (Cohen, 1993). The turnover traditional factors, organizational commitment and work exhaustion were related to turnover intention (Ahuja et al., 2007). "The goal of 'effective management of turnover' dictates that a high level of sophistication particularly needs to be achieved by organizations to selectively influence the turnover process" (Morrell, Clarke \& Wilkinson, 2001).

Ingersoll (2001) considers turnover important due to its relationship with organizational performance. Leontaridi \& Ward, (2002) concluded that the normal turnover of workers is beneficial to growth and development. Whereas other studies refers that the best performers were the most likely to leave because external opportunities would be plentiful (Jackofsky, 1984; Hochwarter et al., 2001). Ahuja et al., (2007) suggests "that turnover intention does not always result in turnover because a number of other factors enter the equation". Turnover intentions were hypothesized to eventually translate into turnover behavior over time by Richer, Blanchard \& Vallerandi (2002)."Several behavioral consequences of reduced job involvement, weakened performance, and low job satisfaction would definitely lead to absenteeism, and turnover" (Bhagat, 1983). Although the role of intentions in the turnover process was supported and even highlighted, the study questions the direct effect of personal and organizational variables on turnover or intentions (Mitchel, 1981). The above study reveals the importance of turnover intentions among various labor markets. Management styles vary and turnover issues are possible future topics for research (Birdseye \& Hill, 1995).

\section{Theoretical Framework}

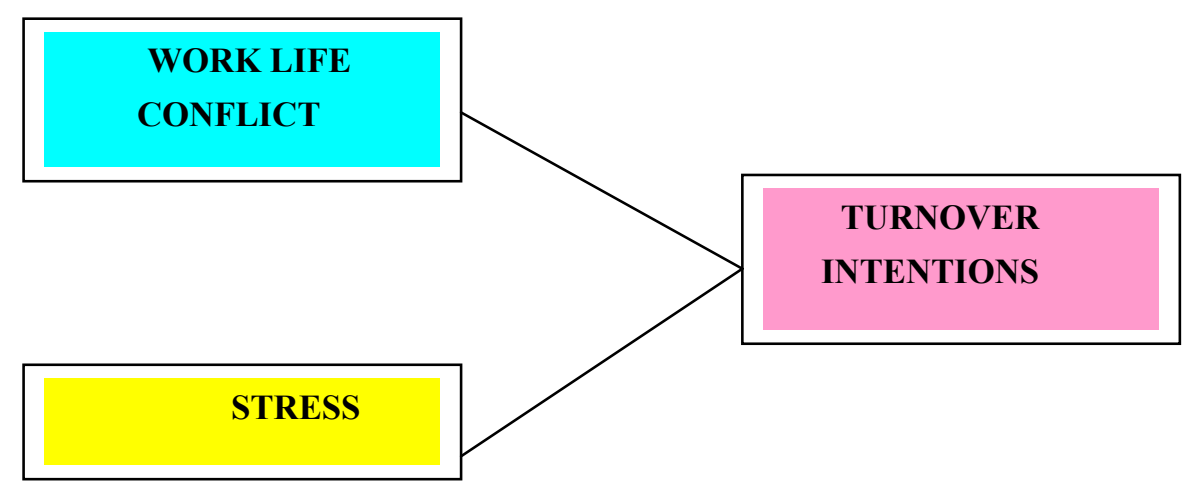




\section{Research Methodology}

300 personally administered questionnaires were randomly distributed to marketing executives across Pakistan.

\subsection{Questionnaire}

Questionnaire contained four main parts having a total of 22 items. Item were measured using Likert scale (1 representing strongly disagree and 5 representing strongly agree). Turnover intentions and work life conflict were measured using instrument developed by Pare, Tremblay, \& Lalonde, 2001. The alpha values were 0.76 and 0.81 respectively. Job Stress was measured using instrument developed by Sosik and Godshalk (2000). The alpha value was 0.73. Questions were also asked about tenure, gender, age, qualification, native language \& marital status.

\subsubsection{Sampling}

Sampling is a fundamental method of inferring information about an entire population without going into any trouble or expense of measuring every member of the population (White, Wilson \& Pfoutz, 2006). The target population consists of marketing executives in Pakistan. Questionnaires were sent to 300 respondents but 248 valid filled questionnaires were returned.

\subsubsection{Data Analysis \& Findings}

Research data was analyzed using the SPSS. The results are given in the tables below:

Table 1. Demographics

\begin{tabular}{|c|c|c|c|}
\hline Description & Range & Frequency & \%age \\
\hline \multirow{3}{*}{ Age } & $16-24$ & 32 & 85 \\
\cline { 2 - 4 } & $25-33$ & 211 & 2 \\
\cline { 2 - 4 } & 43 -above & 5 & 6 \\
\cline { 2 - 4 } & Matric & 52 & 21 \\
\cline { 2 - 4 } & Inter & 124 & 22.5 \\
\cline { 2 - 4 } & Graduate & 57 & 65 \\
\hline \multirow{3}{*}{ Genducation } & Masters & 161 & 35 \\
\cline { 2 - 4 } & Male & 87 & 56.85 \\
\hline \multirow{5}{*}{ Language } & Female & 141 & 22.1 \\
\cline { 2 - 4 } & Urdu & 55 & 13 \\
\cline { 2 - 4 } & English & 31 & 0.8 \\
\cline { 2 - 4 } & Punjabi & 02 & 7.25 \\
\cline { 2 - 4 } & Sindhi & 18 & 0 \\
\hline
\end{tabular}

In addition to the above statistics, these demographic variables were relatively important because of distressing the emotional \& behavioral intentions of the labor to get involved in different positive prospects. Frequencies \& percentages were also calculated for the exact responses of the respondents'. Executives' average age is 26 years ranging from 25 years to 35 years. To avoid any cultural \& societal differences, we divided the part of demographic section; language into six types where the respondents initiated a friendly behavior. Translation was also made where it was required to solve up the questionnaire.

Of all the questionnaire survey, the standard education level Urdu (56.85) was middling to the majority graduates (50.5). Layne, Hohenshil \& Singh (2001) found a significant relationship between gender and occupational stress.

Similarly this country carries male dominating societies so therefore $65 \%$ of male executives were surveyed \& $35 \%$ of the female executives lied among the gender variable. The descriptive data can also be characterized in exploring the relationship of other different demographics with the research.

\subsection{Descriptive Statistics}

Our research covers three variables. The dependent variable, turnover intentions inclined by two independent variables work life conflict \& stress. Data accumulation specified higher levels of Work life conflict (2.89) compared with turnover intentions \& also experienced high level of interaction of stress (2.57) along with turnover intentions. 
Table 1 represents the types of demographics added in our research, \& their relative ranges, frequency, \& percentages. Correlations among the variables are shown in Table 2.

4.2.1 Table 2. Correlation Analysis

\begin{tabular}{|c|c|c|c|c|c|}
\hline \multirow[b]{2}{*}{ VARIABLES } & \multirow[b]{2}{*}{ Mean } & \multirow[b]{2}{*}{ S.D. } & \multicolumn{3}{|c|}{ PEARSON CORRELATION } \\
\hline & & & $\begin{array}{l}\text { Turnover } \\
\text { Intentions }\end{array}$ & WLC & STRESS \\
\hline $\begin{array}{l}\text { Turnover } \\
\text { Intentions }\end{array}$ & 2.9698 & .87826 & 1 & - & - \\
\hline WLC & 2.8958 & .44718 & $.604(* *)$ & 1 & - \\
\hline STRESS & 2.5701 & .36336 & $.742(* *)$ & $.292(* *)$ & 1 \\
\hline
\end{tabular}

$\mathrm{N}=248, \mathrm{WLC}=$ Work Life Conflict, S.D. $=$ Standard Deviation

$* \mathrm{p}<.05, * * \mathrm{p}<.01, * * * \mathrm{p}<.001$

Correlation Analysis above shows a significant relationship between the variables with the description of their mean \& standard deviations. Turnover Intentions shows a high positive relation with Work life conflict $0.604(* *)$. While Paré \& Tremblay (2000) found the Pearson coefficient of work-life policies to turnover intentions $0.136(\mathrm{p}<.01)$, initiating a normal positive relation in between each other. Riley (2006) found that turnover intentions were highly significantly related to family-to-work conflict $(\mathrm{r}=.30, \mathrm{p}<.01)$, along with this indicating that most respondents experienced low levels of family-to-work conflict ( $(\mathrm{skew}=.80$ ). Turnover Intentions is positively correlated with stress $.742(* *)$. Where as Layne, Hohenshil \& Singh (2001) found that the only variable with statistically significant influence on turnover intentions was stress (.402), which is considered to have a large effect, these results indicate that as an individual's stress level increases, they are more likely to leave their position as a counselor and seek alternative positions either within the field or in another industry.

\subsubsection{Table 3. Regression Analysis}

\begin{tabular}{|c|c|c|c|}
\hline & B & t & Sig. \\
\hline WLC & .833 & 11.876 & .000 \\
\hline STRESS & 1.493 & 17.308 & .000 \\
\hline
\end{tabular}

$\mathrm{R}$ Square $=.71, \mathrm{~F}=306.5$, Sig. $=0.000, \mathrm{n}=248$, Dependent Variable: Turnover Intentions

The value of the R Square is .714 which indicates that almost $70 \%$ of the variance in marketing executives is verified by only two independent variables, Work life conflict \& Stress equally.

Valcour \& Batt (2003) initiated from the Regression Analysis Table 19.2 and presented the results (coefficients and overall model fit) of the regression analyses of work-family conflict, employee control over work, and turnover intentions for wives and husbands, respectively \& proved a strong positive impact on each other. The two independent variables are flexible to this research.

\section{Discussion}

This study tested that work life conflict $\&$ stress have positive relationships with turnover intentions. The findings $\&$ the data empirically proofs the facts detailed in the literature review. "There is no-one-size-fits-all solution to the issue of work-life conflict, so different policies, practices and strategies will be needed to reduce work-life conflict examined in his study" (Higgins, Duxbury \& Lyons, 2007). An organization would follow that strategy which will reduce the symptoms of work life conflict \& the causes of stress. "Conflicts should be explored in future, for instance, in terms of styles and consequences in distinct functional areas and across different cultures and countries" (Ikeda, Oliveira \& Campomar, 2005). Cultural differences in this society have met across abruptly. With this reason, policies, practices, organizational strategies differ from one organization to another. Riley (2006) stated that work overload and work-to-family conflict in his sample did not have a significant correlation with turnover intentions. However, our results from Table no. $1, \&$ the descriptive statistics; correlation analysis, regression analysis reveals that the community of marketing executives is very demanding that discloses work life conflicts. People do not want change in their on-going policies, time tables, daily schedules, \& this leads to turnover intentions. Lack of awareness, lacking job satisfaction \& commitment, leads an individual to have low job involvement which in the long run directs to turnover. Parkington and Schneider (1979) hypothesized that "perceiving oneself as more bureaucratic and management as more 
enthusiastic are related to positive employee outcomes because these views serve to increase an employee's feeling of integration with the organization". If every employee is provided with the built-in opportunity with himself \& his work within the organization, there would an immense decrease of turnover ratio.

Stress also increases because the environment is dynamic (Huff, Huff \& Thomas, 1992). Apparently hard business plans, organization new practices \& programs usually encounters the marketing executives in to a stressful state. The potential for maintaining a substantial amount of resistance at every step by our marketing executives is not simple. Because if these individuals are stressed out of their tasks \& duties then they will be no more satisfied to their job, to the environment of their organization, won't seek their own colleagues satisfyingly \& so far affect the organizational culture. Those individuals reporting to experience at least some stress in their current position are 25 percent more likely to hold intentions to quit than those without, with the probability of intending to quit increasing with successively higher job stress (Leontaridi \& Ward, 2002).

Marketing executives strive to remain competitive in the market because area of influence of marketing executives is large $\&$ wild. They design progressive and sustainable strategies to achieve customer satisfaction. Marketing executives are frequently required to re-design their schedules which affect their work \& personal life. To be constantly active, progressive \& competitive generates mental pressure \& work stress on these people. If they can't generate desirable revenue, some become disappointed and frustrated. Then they get highly stressed from their work \& turnover intentions increase. "The understanding of organizational environment and the relationship between the organization's members is vital for the effective functioning of the areas, including marketing" (Ikeda, Oliveira \& Campomar, 2005). "If workers frequently exposed to job stress are associated with high turnover rates and absenteeism further research on the subject would allow for active stress management policies to be more beneficial for the individual and the economy as a whole" (Leontaridi \& Ward, 2002).

\section{Implications \& recommendations}

This present research found supportive evidence proving the relationship among work life conflict \& stress with turnover intentions. This study also carries some limitations, as all articles carry. It is not necessary that only these two independent variables would account with turnover intentions, a research study can focus more other variables relative to turnover intentions. Increasing the number of respondents in future studies would suggest the results more significantly. This study also recommends that Board of Governors (BOG) / Directors (BOD) should be sensitive to this issue and set realistic quarterly targets for marketing executives. This study also recommends that marketing executives should be given periodic respite from their stressful routines and offered short leave abroad with their families at picturesque islands/ picnic spots. These measures will reduce turnover intentions and work life conflict. Compensation Management should also take in to account the stressful conditions/environment in which marketing executives operate suitable monetary compensation. This empirical study examines that the intensity of these kinds of variables is greater in many organizations because of the work load.

Furthermore, future researchers should analyze the importance of turnover. Continued research is required to understand the relationship of stress and turnover intentions. All these limitations point to the need for more research on the influence of flextime and flex place on work and work and family balance (Hill et al., 2001).

\section{Acknowledgements}

We are grateful for the guidance of Mr. Sajid Bashir, who supervised this research. We would also like to thank Higher Education Commission (HEC) for their help, support \& guidance.

\section{References}

Abeysekera, R. (2007). The Impact of Human Resource Management Practices on Marketing Executive Turnover of Leasing Companies in Sri Lanka. Contemporary Management Research Pages 233-252, Vol.3, No. 3.

Abushaikha, L. \& Sheil, E.P. (2006). Labor Stress and Nursing Support: How do They Relate? Journal of International Women's Studies Vol. 7 \#4.

Ahuja, M.K., Chudoba, K.M., Kacmar, C.J., McKnight, D.H., \& George, J.F. (2007). IT Road Warriors: Balancing Work Family Conflict, Job Autonomy, and Work Overload to mitigate Turnover Intentions. MIS Quarterly Vol. 31 No. 1, pp. 1-17/March 2007.

Alves, M.G.M., Chor, D., Faerstein, E., \& Werneck, C.G.L. (2004). Short version of the "job stress scale": a Portuguese-language adaptation. Rev Sauda Publica; 38(2).

Aycan, Z., Kanungo, R.N., Mendonca, M., Yu, K., Deller, J., Stahl, G., \& Khurshid, A. (2000). Impact of Culture on Human Resource Management Practices: A 10-Country Comparison. Applied Psychology: An International Review, 49 (1), 192-221.

Baig, Q. (2006). Social Research in Pakistan: An Overview. Journal of Health Management, 8, 2 (2006). 
Bashir, S. \& Ramay, M.I. (2008). Determinants of Organizational Commitment A Study of Information Technology Professionals in Pakistan. Institute of Behavioral and Applied Management, Pages 226-238.

Batt, R. \& Valcour, P.M. (2003). Human Resources Practices as Predictors of Work-Family Outcomes and Employee Turnover. Industrial Relations, Vol. 42, No. 2.

Bhagat, R.S. (1983). Effects of Stressful Life Events on Individual Performance Effectiveness and Work Adjustment Processes within Organizational Settings: A Research Model. Academy of Management Review, Vol. 8, No. 4, 660-671.

Birdseye, M.G. \& Hill, J.S. (1995). Individual, Organizational/Work and Environmental Influences on Expatriate Turnover Tendencies: An Empirical Study. Journal of International Business Studies, Vol. 26, No. 4, (4th Qtr), pp. 787-813.

Braaten, D.J. (2000). Occupational Stress in Mental Health Counselors. A Research Paper: Submitted in Partial Fulfillment of the Requirements for the Master of Science Degree.

Brigham, K.H., Castro, J.O.D., \& Shepherd, D.A. (2007). A Person-Organization Fit Model of Owner-Managers' Cognitive Style and Organizational Demands. Baylor University (1042-2587).

Cohen, A. (1993). Organizational Commitment and Turnover: A Meta-Analysis. The Academy of Management Journal, Vol. 36, No. 5, pp. 1140-1157.

Côté, S. \& Morgan, L.M. (2002). A Longitudinal Analysis of the Association between Emotion Regulation, Job Satisfaction, and Intentions to Quit. Journal of Organizational Behavior, Vol. 23, No. 8, pp. 947-962.

Cropanzano, R., Rupp, D.E., \& Byrne, Z.S. (2003). The Relationship of Emotional Exhaustion to Work Attitudes, Job Performance, and Organizational Citizenship Behaviors. Journal of Applied Psychology, Vol. 88, No. 1, 160-169.

Davis, H., Orzeck, T., \& Keelan, P. (2006). Psychometric item evaluations of the Recovery-Stress Questionnaire for athletes. Psychology of Sport and Exercise.

DeVries, M.W., \& Wilkerson, B. (2003). Stress, work \& mental health: A global perspective. Review Article; Blackwell Munksgaard: 15:44-53.

Giga, S.I., \& Hoel, H. (2003). Violence and stress at work in financial services. Sectoral Activities Programme: Working Paper, WP.210. International Labor Organization, Geneva.

Glass, J.L., \& Riley, L. (1998). Family Responsive Policies and Employee Retention Following Childbirth. Social Forces, Vol. 76, No. 4, pp. 1401-1435.

Griffeth, R.W., \& Gaertner, S. (2001). A Role for Equity Theory in the Turnover Process: An Empirical Test. Journal of Applied Social Psychology, 31, 5, pp. 1017-1037.

Grzywacz, J.G., Almeida, D.M., \& McDonald, D.A. (2002). Work-Family Spillover and Daily Reports of Work and Family Stress in the Adult Labor Force. Family Relations, Vol. 51, No. 1, pp. 28-36.

Higgins, C., Duxbury, L., \& Lee, C. (1994). Impact of Life-Cycle Stage and Gender on the Ability to Balance Work and Family Responsibilities. Family Relations, Vol. 43, No. 2, pp. 144-150.

Higgins, D.C., Duxbury, D.L., \& Lyons, S. (2007). Reducing Work-Life Conflict: What Works? What Doesn't? Executive Summary.

Hill, E.J., Hawkins, A.J., Ferris, M., \& Weitzman, M. (2001). Finding an Extra Day a Week: The Positive Influence of Perceived Job Flexibility on Work and Family Life Balance. Family Relations, Vol. 50, No. 1, pp. 49-58.

Hochwarter, W.A., Ferris, G.R., Canty, A.L., Frink, D.D., Perrewe, P.L., \& Berkson,H.M.(2001). Reconsidering the Job-Performance-Turnover Relationship: The Role of Gender in Form and Magnitude. Journal of Applied Social Psychology, 31, 11, pp. 2357-2377.

Hom, P.W., \& Kinicki, A.J. (2001). Toward a Greater Understanding of How Dissatisfaction Drives Employee Turnover. The Academy of Management Journal, Vol. 44, No. 5, pp. 975-987.

Hudson (2005). 20:20 Series $\mid$ A Hudson initiative to help businesses compete and succeed in the future The Case for Work/Life Balance: Closing the Gap between Policy and Practice.

Huff, J.O., Huff, A.S., \& Thomas, H. (1992). Strategic Renewal and the Interaction of Cumulative Stress and Inertia. Strategic Management Journal, Vol. 13, Special Issue: Strategy Process: Managing Corporate Self-Renewal, pp. 55-75.

Hsieh, H.L., Huang, L.C., \& Su, K.J. (2004). Work stress and job performance in the hi-tech industry: a closer view for vocational education. World Transactions on Engineering and TechnologyEducation Vol.3, No.1.

Ikeda, A.A., Oliveira, T.M.V., \& Campomar, M.C. (2005). Organizational Conflicts Perceived by Marketing Executives. EJBO; Electronic Journal of Business Ethics and Organization Studies, Vol.10, No.1. 
Ingersoll, R.M. (2001). Teacher Turnover and Teacher Shortages: An $\quad$ Organizational $\quad$ Analysis. American Educational Research Journal, Vol. 38, No. 3, pp. 499-534.

Jackofsky, E.F. (1984). Turnover and Job Performance: An Integrated Process $\quad$ Model. The Academy of Management Review, Vol. 9, No. 1, pp. 74-83.

Jordan, J.S. (2004). Science \& Consciousness Review. Consciousness on the edge. Department of Psychology.

Kavanagh, J. (2005). Stress and Performance: a Review of the Literature and Its Applicability to the Military. Technical Report.

Kemery, E.R., Mossholder, K.W., \& Bedeian, A.G. (1987). Role Stress, Physical Symptomatology, and Turnover Intentions: A Causal Analysis of Three Alternative Specifications. Journal of Occupational Behavior, Vol. 8, No. 1, pp. $11-23$.

Kirschenbaum, A. \& Weisberg, J. (2002). Employee's Turnover Intentions and Job Destination Choices. Journal of Organizational Behaviour, Vol. 23, No. 1, pp. 109-125.

Konrad, A.M., \& Mangel, R. (2000). The Impact of Work-Life Programs on Firm $\quad$ Productivity. Strategic Management Journal, Vol. 21, No. 12, pp. 1225-1237.

Lachman, R. \& Diamant, E. (1987). Withdrawal and Restraining Factors in Teachers' Turnover Intentions. Journal of Occupational Behaviour, Vol. 8, No. 3, pp. 219-232.

Layne, C.M., Hohenshil, T.H., \& Singh, K. (2001). The Relationship of Occupational Stress, Psychological Strain, \& Coping Resources to the Turnover Intentions of Rehabilitation Counselors.

Leontaridi, R.M., \& Ward, M.E. (2002). Work-Related Stress, Quitting Intentions and Absenteeism. Department of Economics, Discussion Paper No. 493.

Ling, S.O., \& Phillips, D.R. (2006). Research on Family-friendly Employment Policies and Practices (FEPPs) in Hong Kong. Commissioned by theEqual Opportunities Commission and the Women's Commission.

Loy, M.B., \& Wharton, A.S. (2002). Employees' Use of Work-Family Policies and the Workplace Social Context. Social Forces, Vol. 80, No. 3, pp. 813-845.

Lucas, G.H., Parasuraman, A., Davis, R.A., \& Enis, B.M. (1987). An Empirical Study of Salesforce Turnover. Journal of Marketing, Vol. 51, No. 3, pp. 34-59.

MacDermid, S.M., Williams, M., Marks, S., \& Heilbrun, G. (1994). Is Small Beautiful? Work-Family Tension, Work Conditions, and Organizational Size. Family Relations, Vol. 43, No. 2, pp. 159-167.

Manger, T., \& Eikeland, O.J. (1990). Factors Predicting Staff's Intentions to Leave the University. Higher Education, Vol. 19, No. 3, pp. 281-291.

Marks, A., \& Scholarios, D. (2001). Work-life integration and the psychological contract: an examination of work outcomes for software professionals. Department of Human Resource Management.

Martin, T.N. (1979). A Contextual Model of Employee Turnover Intentions. The Academy of Management Journal, Vol. 22, No. 2, pp. 313-324.

Mitchel, J.O. (1981). The Effect of Intentions, Tenure, Personal, and Organizational Variables on Managerial Turnover. The Academy of Management Journal, Vol. 24, No. 4, pp. 742-751.

Moore, J.E. (2000). One Road to Turnover: An Examination of Work Exhaustion in Technology Professionals. MIS Quarterly, Vol. 24, No. 1, pp. 141-168.

Morrell, K., Clarke, J.L., \& Wilkinson, A. (2001). Unweaving Leaving: The use of models in management of employee turnover. International Journal of Management Reviews, Vol. 3, Issue. 3, pp. 219-244.

Morrell, K., Clarke, J.L., \& Wilkinson, A. (2004). The Role of Shocks in Employee Turnover. British Journal of Management, Vol. 15, 335-349.

Nadeem, S., \& Metcalf, H. (2007). Work-life policies in Great Britain: What $\quad$ works, where and how? Employment Relations Research Series no. 77.

Naumann, E. (1992). A Conceptual Model of Expatriate Turnover. Journal of International Business Studies, Vol. 23, No. 3, (3rd Qtr.), pp. 499-531.

Otis, N., \& Pelletier, L.G. (2005). A Motivational Model of Daily Hassles, Physical Symptoms, and Future Work Intentions among Police Officers. Journal of Applied Social Psychology, 35, 10, pp. 2193-2214.

Parasuraman, S., \& Alutto, J.A. (1984). Sources and Outcomes of Stress in Organizational Settings: Toward the Development of a Structural Model. The Academy of Management Journal, Vol. 27, No. 2, pp. 330-350. 
Paré, G., \& Tremblay, M. (2000). The Measurement and Antecedents of Turnover Intentions among IT Professionals. Scientific Series.

Paré, G., Tremblay, M., \& Lalonde, P. (2000). The Impact of Human Resources Practices on IT Personnel Work Attitude, Extra-role Behaviors \& Turnover Intentions. Cahier du GReSI no 00-07.

Parkington, J.J., \& Schneider, B. (1979). Some Correlates of Experienced Job Stress: A Boundary Role Study. The Academy of Management Journal, Vol. 22, No. 2, pp. 270-281.

Rau, B.L., \& Hyland, M.M. (2002). Role Conflict \& Flexible arrangements: The Effects on Attraction Applicant. Personnel Psychology, 55.

Richer, S.F., Blanchard, C., \& Vallerandi, R.J. (2002). A Motivational Model of Work Turnover. Journal of Applied Social Psychology, 32, 10, pp. 2089-2113.

Riley, D. (2006). Turnover Intentions: The Mediation Effects of Job Satisfaction,Affective Commitment, \& Continuance Commitment. A thesis submitted in partial fulfillment of the requirements for the degree of Master of Applied Psychology.

Roberts, N.A., \& Levenson, R.W. (2001). The Remains of the Workday: Impact of Job Stress and Exhaustion on Marital Interaction in Police Couples. Journal of Marriage and the Family, Vol. 63, No. 4, pp.1052- 1067.

Rusli, B.N., Edimansyah, B.A., \& Naing, L. (2006). Prevalence and Associated Factors of Stress in Dental Healthcare Workers of a Higher Institution of Learning in Kelantan. Archives of Orofacial Sciences; 1: 51-56.

Sauter, S., Murphy, L., Colligan, M., Swanson, N., Hurrell, J., Scharf, F., Sinclair, R., Grubb, P., Goldenhar, L., Alterman, T., Johnston, J., Hamilton, A., \& Tisdale, J. (1999).Stress...At Work. Prepared by a NIOSH working group. Publication No. 99-101

Schieman, S., McBrier, D.B., \& Gundy, K.V. (2003). Home-to-Work Conflict,Work Qualities, and Emotional Distress. Sociological Forum, Vol. 18, No. 1, pp.137-164.

Secret, M. (2000). Identifying the Family, Job, and Workplace Characteristics of Employees Who Use Work-Family Benefits. Family Relations, Vol. 49, No. 2, pp. 217-225.

Shalley, C.E., Gilson, L.L., \& Blum, T.C. (2000). Matching Creativity Requirements and the Work Environment: Effects on Satisfaction and Intentions to Leave. The Academy of Management Journal, Vol. 43, No. 2, pp. 215-223.

Sheridan, J.E., \& Abelson, M.A. (1983). Cusp Catastrophe Model of Employee Turnover. The Academy of Management Journal, Vol. 26, No. 3, pp. 418-436.

Soon, A., Quazi, H.A., Tay, C., \& Kelly, K. (2005). Studies on the Impact of Work-Life Initiatives on Employee \& Firm Performance. Executive Report for Public release.

Thaden, E. (2007). Understanding Attrition \& Predicting Employme Durations of Former Staff in a Public Sector Social Service Organization. Community Research and Action.

Thompson, C.A., Andreassi, J., \& Prottas, D. (2003). Work-Family Culture and Climate.

Valcour, P.M., \& Batt, R. (2003). Work-Life Integration: Challenges and Organizational Responses. Faculty Publications - Human Resource Studies; Pages 310-331.

West, L.S. (2007). Examining the relationship between employee-superior conflict and voluntary turnover in the workplace: A comparison of companies across industries. Master of Science (Psychology), 49 pp., 7 tables, references, 55 titles.

White, R.A., Wilson, L.M., \& Pfoutz, S.K. (2006). Perceived Stressors, Coping Strategies, and Burnout Pertaining to Psychiatric Nurses Working on Locked Psychiatric Units. Master of Science in Nursing.

Whittock, M., Edwards, C., McLaren, S., \& Robinson, O. (2002). The tender trap': gender, part-time nursing and the effects of 'family-friendly'policies on career advancement. Sociology of Health \& Illness Vol. 24 No. 3, pp. 305-326.

Wilson, S.M., Larson, J.H., \& Stone, K.L. (1993). Stress among Job Insecure Workers and Their Spouses. Family Relations, Vol. 42, No. 1, pp. 74-80.

Williams, A. (2003). Job Stress, Job Satisfaction, and Intent to Leave Employment among Maternal-Child Health Nurses. Thesis submitted to The Graduate College of Marshall University. In partial fulfillment of the Requirements for the Degree of Master's of Science in Nursing.

Wofford, J.C., Goodwin, V.L., \& Daly, P.S. (1999). Cognitive-Affective Stress Propensity: A Field Study. Journal of Organizational Behavior, Vol. 20, No. 5, pp. 687-707. 
Yasbek, P. (2004). The business case for firm-level work-life balance policies: a review of the literature. Labour Market Policy Group, Department of Labour.

Yu, C.H. (2008). The effect of work-life balance policies on women employees turnover. OSIPP Discussion Paper: DP-2008-E-008. Japan Society for the Promotion of Science (JSPS) Fellow. 


\title{
Analysis of Cultural Differences between
}

\section{West and East in International Business Negotiation}

\author{
Peng Luo \\ Economic Management College, Dalian University, Dalian 116622, China \\ E-mail: pengluo@126.com
}

\begin{abstract}
Economic globalization brings increasing communication of economy and trading among countries, and the negotiation has been the important part of international business activity in this process. The international business negotiation is not only the communication and cooperation in the economic domain, but the communication of culture among various countries. In the process of negotiation, negotiants' idea and behavior are controlled by their own national cultures. There are large differences in thinking pattern, value view, group consciousness, negotiation style, benefit consciousness and law consciousness between western and eastern cultures, and these differences largely influence the process and result of negotiation and they are important factors we should consider in the negotiation.
\end{abstract}

Keywords: International business negotiation, Cultural difference

Economic globalization brings increasing communication of economy and trading among countries, and the negotiation has been the important part of international business activity in this process. The international business negotiation is not only the communication and cooperation in the economic domain, but the communication of culture among various countries. In the process of negotiation, negotiants' idea and behavior are controlled by their own national cultures. As a developing country, China urgently needs to abstract advanced scientific technology, management mode and trading rule of developed countries in the course of globalization economy, and has to follow the regulations and methods constituted by developed countries to large extents, and these regulations and methods are not only limited by the special rules of relative specialties, but influenced by relative cultures in the process of their productions and developments. Therefore, in the international business negotiation, these regulations and methods could not automatically replace the behavior mode of local culture and relative thinking mode and value view, and traditional research mode and expression pattern. So, we are necessary to know the culture backgrounds and differences between western countries and eastern countries, and foster strengths and circumvent weaknesses based on that, and constitute reasonable negotiation strategies, which could help us to acquire successes in international business activities.

\section{Difference of thinking pattern}

Thinking mode, value view and behavior rule composes the distinct character which knows one nation from another nation. As a sort of long term cultural accumulation, thinking mode exerts a subtle influence on human social lives, and it has obvious differences.

The east culture emphasizes deduction and it is accustomed to reason from common to specific, i.e. deducting common principle to specific conclusion. But west culture emphasizes induction and it is accustomed to reason from specific to common, i.e. finding out common essential of the same sort of thing from the characters of many specific things. The east culture favors comprehensive thinking, i.e. uniting various parts of the object as one entity. English and American cultures favor analysis thinking, i.e. decomposing one complete object into various composing parts and aspects from idea. The east culture emphasizes unification and gives priority to the entity of thinking, and the west culture emphasizes opposition and gives priority to the part of thinking.

Different thinking modes embody bright cultural characters, and the western thinking mode represented by American is "beeline", but the eastern thinking mode represented by Chinese is "loop". Different thinking modes will largely influence the negotiation process. Generally speaking, occidentals incline to divide the main content of negotiation into various parts and consider and analyze them one by one, and finally obtain the conclusion. But oriental emphasizes the negotiation pattern first principle then detail and they like to set up one basic principle frame firstly, and they like first discussing recapitulative proceedings, then constituting many details of negotiation, and they always arrange concrete contents in the final part of the negotiation, and they think it is propitious to future haggle. In the initial stage of the negotiation, Asian negotiation focus is out the present special business, but in the human relationship with long term cooperation, and for European and North American, the negotiation focus is in the essential content of the negotiation, 
and they will directly enter into the topic after giving the time of day.

\section{Difference of value view}

Value view is the important composing of culture, and it dominates human idea and social behaviors.

In the business activity, western countries pursue the value view of equality and persist in the reasonable principle of justice and double-winning, which is obviously different to Chinese operators' strategy of single-winning which has the economic characters of western early market. For the business relationship, American bargainor always treat purchaser as people with same status, but oriental would represent inequality in business activities because of the influence of grading consciousness. For the time concept, people in developed countries have strong time concept because their quick work and life rhythm, and so they always cherish time in business negotiation. But in some undeveloped countries or in some countries with dense feudalism consciousness, people always pay no attention to the time, for example, the time concept in Middle East and Latin America cultures is weak, and they think time is stretch, and the time should be enjoyed. But for eastern countries, Japanese endurance in negotiation is very famous in the world, and for an ideal trade, they could wait without any complaint, and only to achieve the anticipated intension, time is not the most important factor. For the decision-making, Japanese decision procedure is very numerous, and the time is very long, but they would implement very quickly. At the same time, Japanese culture emphasizes mutual relationship, and for long term fellowship, they like to devote abundant time and expense to establish individual friendship, then they will implement business negotiation based on that. For the social consciousness, east culture emphasizes collectivism and group consciousness, and people are loyal to national authority and collective benefit, and they think it is a sort of virtue to oppress their individuality and it is the representation of selfish desire to emphasize individual benefit, but the western culture advocates self-consciousness and individual struggle, and people open out their personalities, and they thought people should pursue their own benefits, and if national benefit is on the individual benefit, the human rights will lose. In international business negotiation, Chinese emphasize the group including individuals, and negotiants always need to consider interior harmony of the collectivity, and they pay more attention to national and collective benefits than occidental, and the nation and government have large influences on decision-making of enterprise, but they responsibility consciousness is less than occidental, and they also lack independent personality and self-decision ability.

\section{Difference of group consciousness}

The group consciousness means belief, value and criterion possessed by most members in the group, and it reflects the attitude of group members and their cognition to mutual psychological character for the group they belong. It is formed in the group information spread and communication process.

The difference of group consciousness is the important embodiment of east and west cultural difference in the business negotiation. The businessmen in Asian countries have strong group consciousness, but the negotiants in occident countries always pay attention to individual consciousness. Taking Japan with representative east character and US with representative west character as examples, Japan possesses intensive group consciousness and development desire of group survival. The value concept and spirit tendency figured by Japanese culture take collectivism as the core. It teaches people melt their individual wills into the collective will. For the decision-making, Japanese must consult with other departments in the company before negotiation, and the items of the contract are decided through collective research, and the concrete contents in the negotiation must be transmitted back to the headquarters of the company in Japan, and various departments would pass round the contents for perusal, and the contents are available after they are recognized by the collectivity. Occidental think Japanese decision-making time is long because of group consciousness. Canada, Italy and France all advocate individualism, and US is the most representative one. US negotiant fully embodies intensive self-consciousness on the negotiation desk. Because American thinks that human is independent individual who has responsibility and rights, so everyone should exert individual enthusiasm, hold the initiative right of negotiation through his endeavor to achieve the established aim, and they regard right using and adventure are good moral characters. So US businessmen would meet many Chinese or Japanese negotiation opponents without help, and they will represent self decision-making and creation in the process of negotiation. For the negotiation style, they are full of confidence, directness, bluffness, and even haughty and aggressive characters. Because the important decisions in the negotiation are made by the people with top level, so American likes to talk with the opponent in control of the right. They regard the negotiation as competition, and they hop the result of negotiation would bring actual economic benefits for their party and bring development opportunities for their individual future.

\section{Difference of negotiation style}

The negotiation style means negotiants' main tolerance and style characters represented in the negotiation. The negotiation style has deep cultural brands. The culture not only decides negotiants' ethics, but influences their thinking mode and individual behavior, so negotiants with different cultural backgrounds will form different negotiation styles. For example, American possesses confident, decisive, extroverted and practical style. Germen always have sufficient 
preparations, but they lack agility in the negotiation. Englishmen are confident, and they don't easily apologize or acknowledge the corn when they are wrong. People in North European are composed, calm and ease in the negotiation. Arabs keep open doors, and they emphasize the relationship among friends, but they lack time concept. Japanese has strong time concept, but sometimes they look fussy, and they always occur by the weak appearance to try to gain opponents' sympathy, and make them come to terms unconsciously. In the negotiation, it is very important to know well opponents' negotiation style in order to hold the direction and schedule of negotiation and exert the strategy of negotiation purposefully.

\section{Difference of benefit consciousness}

The benefit consciousness means human psychology of identification and pursuing for benefits, and this sort of psychology is the unification of human sensibility and sense, and it is the subjective drive headspring of human practice. The benefit consciousness runs through the whole human consciousness and instructs human behaviors.

In modern society, west and east negotiants have benefit consciousness, and they all represent certain benefit main bodies, and they all labor for their own economic benefits. However, occidental's benefit consciousness is more extensive, because the base of western society is the modern market economy which takes the market exchange and market competition as main characters, and the human relationship formed in that society mainly is benefit relationship, and occidental emphasizes the exchange of economic resources and the function of benefit mechanism. Taking Americans as an example, they always take the profit as their only intention in the business. They persist in the "principle negotiation method" in the western negotiation theory, and they would objectively face human and things. When they deal with the relationship between benefit and human feelings, they will do official business according to official principle. In the process of negotiation, they are always interested in the benefit problem with essential because they believe that there are not eternal friends but only eternal benefits. Americans like to implement pure operation communication, and the private fellowship is shallow. Even there is personal friendship, but business is business and friend is friend. For the human relationship, they like informal relationship without ceremony, and they don't like externalism, traditional limitation and prim doings. Under most situations, both sides have never met before, but if the condition is proper, they can begin to negotiate. If both sides may cooperate again, they will decide to communicate continually. They thought that good business relationship would bring good individual relationship. However, easterners' relationship consciousness is deeper. Chinese negotiants' benefit consciousness occurs late, and it is not so definite and extensive than Americans. For the mode to acquire benefit, Americans brightly point to the benefit in the negotiation, but Chinese always establish the benefit on the human relationship though circuitous mode. For the result of negotiation, American pursues maximum economic benefits, but Chinese emphasizes reputation. Because of the influence of traditional economy and confucian culture, Chinese society emphasizes the relative relationship and human relationship, and people pay attention to the feelings exchange but not the benefit exchange. Chinese very emphasizes harmonious human relationship, and they pay attention to ceremony and friendship when getting along with others. They like to celebrate some normal ceremonies to establish and solidify the friendship in social communication, and they always make friends first then do business, and look for business partners and business opportunities through relations and friends. In the negotiation, Chinese are very orthodox and good-mannered, and they try to avoid full-face frictions, and if there is difference in benefit, they won't directly reject the other side, and they thought that would harm both relationship. Humility, endurance and self-restraint are regarded as good qualities. Mutual respect and friendship is the base of trade and long-term business activity among negotiants.

\section{Difference of law consciousness}

The law consciousness include human idea, concept and cognition to law, and it is the thinking base that human keeps the peace consciously, evaluate their and others' behaviors, and it instructs human daily behaviors. In modern society, all business activities are implemented under the law relationship, but because of the differences of social economy and cultural backgrounds, the obvious differences exist in western and eastern law concepts. China experienced lengthy feudalism society, and we are still influencing by grading concept, officer standard and relationship consciousness up to now, so the legal system is shallow and uncompleted, which induces Chinese negotiants sometimes are accustomed to depend on the functions of human relationship, public opinion and moral or the organization to solve the problem when they face economic activities including the disposal of economic dissension, and they always consider few legal measures. In the dissension disposal, Chinese first depends on feelings before argument, and then legal measure. As for the status of law and authority, Chinese more advocates authority, and they sometimes let technical experts, trading experts and financing experts except for the lawyer to participate in the negotiation. The western society is the legal society, and the capitalism legal system has been very mature after hundreds years' development, and human legal consciousness has been rooted. To study the law, understand the lay and use the lay has been westerners' necessary qualities. So, occidentals won't waste time in feelings, and they are inclined to standardize the business activities through the law. In international business negotiation, they are required to work according to the procedure, and they claim solving the problem according to normal approach once difference and issue occur in the contract management 
and continuous communication after the negotiation. Western lawyer industry is very developed, and taking US as the example, its population is only $10 \%$ of the global population, but its amount of lawyer is $70 \%$ of the global lawyer, and there are about one million lawyers in US, because they always depend on legal measure to solve the problem but not the conscience and feeling. Many corporations and individuals engage counselor and lawyers, and they are accustomed to negotiate with lawyer, and in the whole negotiation from the draw of contract item to the complement of trade, counselor and lawyer play very important roles, and when disputation and dissension occur, lawyers appear personally to solve the problem. It is the important character to ensure individual rights and perform regulated obligations by the law in western society.

\section{References}

Baiyuan. (2002). Case Analysis and Practice of International Business. Beijing: China Renmin University Press.

Chen, Rongjie. (2000). Cross-culture Negotiation. Huhehaote: Neimenggu People Press.

Liu, Wenguang. (2001). International Business Negotiation. Beijing: Higher Education Press.

Yang, Qunxiang. (2001). Convenance in Business Negotiation. Dalian: Dongbei University of Finance \& Economics Press.

Zuo, Xiaoping. (2004). Cultural Factors in International Business Negotiation. Commercial Research. No.6.

Zuo, Xiaoping. (2004). Influences of Consciousness Difference for International Business Negotiation. Beijing: Magazine Press of Commercial Times. 


\title{
Research Framework of Human Resource Development Based on
}

\section{Competency about Knowledge Enterprise}

\author{
Jianfeng Jia \\ School of Business Administration, Northeastern University, Shenyang 110004, China \\ Tel: 86-24-8367-9954Ｅ-mail: englishjjf@126.com \\ Lili Fan \\ Tianjin College, University of Science and Technology Beijing, Tianjin 301830, China \\ Tel: 86-22-2241-0736_E-mail: fanlili_2005@163.com
}

\begin{abstract}
Former studies of competency focus on individuals, regarding individuals as primary units of understanding enterprise performance. Beginning from the competency, this paper constructs a systematic research framework for knowledge enterprise. The framework is based on the theory of human capital, theory of knowledge management, theory of team role, and the theory of organizational learning, taking enterprise strategy as the core, chiefly studying the development of competency of individuals, teams, and organizations in knowledge enterprises. Its ultimate objective is to improve the performance of individuals, teams, and organizations.
\end{abstract}

Keywords: Competency, Knowledge enterprise, Human resource development, Research framework

\section{Introduction}

The competency concept was firstly advanced by a professor in Harvard University, McClelland (1973) in a thesis "Testing competence rather than intelligence" (McClelland D.C., 1973, p1-14). This thesis has aroused a tide of studying competency in both academic and industrial fields. Bovatzis (1982) applied the competency concept to management and made it popular soon (Boyatzis R.E., 1982). Raven (1984) carried out the studies of competency in practice (John Riven, 1995). Spencer \& Spencer (1993) summarized relevant studies and practices in nearly twenty years and advanced The Iceberg Model and The Onion Model, forming a database of competency models (Spencer L.M \& Spencer S.M, 1993). In 2006 in the Development Strategies for Management Sciences, the Department of Management Sciences of National Natural Science Foundation in China took competency-based human resource management as an important project in organizational behavior and human resource management fields and gave it prior financial support (Department of Management Sciences of National Natural Science Foundation in China, 2006). Today, the competency model has already become a mainstream practice in human resource development. In America a survey shows that about $75 \%$ or so enterprises have implemented the competency idea into human resource management practice to a different degree and achieved excellent performances (Schippmann J.S \& Ash R.A, Battista M, et al, 2000, p703-740).

\section{Literature review and comment}

\subsection{Literature review}

Viewing all literatures of competency, typical representatives are: Yukl (1989) concluded competencies of managers into technology, interpersonal relationship, and concept (Yukl G., 1989). Spencer (1993) systematically studied more than 200 occupations in industries and organizations, including science and technology field, education field, manufacture industry, distribution industry, services, government institutions, military, medical and health care, and religion, analyzed amounts of activities related with excellent work performances, summarized others' studies in twenty years, and advanced five universal competency models, including special technologists, salesmen, community workers, managers, and entrepreneurs. Each model consisted of more than ten different competency factors (Spencer L.M \& Spencer S.M., 1993). Paul Sandwich (1993) put forward a competency model for organizational training by researching a large organization. Based on former studies, he defined five fields for manager competencies: concept, leadership, interpersonal relationship, administration, and technology (Paul Sandwich, 1993, p43-62). Lawson \& Limbrick (1996) studied the competency model of top human resource managers, including objective and activity management, human resource management technique, functional and organizational lead, influence management, and commercial knowledge 
(Lawson T.E \& Limbrick V., 1996, p67-85). McClelland (1998) adopted the Behavioral Event Interview (BEI) to help two transnational companies construct a competency model for top managers (McClelland D.C., 1998, p331-339). Siu thought that managers at the save level have similar competencies and belong to a same competency model, based on which Siu chiefly studied the competency model of middle-level managers (Siu, V., 1998, p253-273). Pepermans took junior managers in a hospital as objects in a research and studied the competency model by observation and interview (Pepermans R, Mentens C \& Goedee M, et al., 2001, p281-295). Kan Shi, Jicheng Wang and Chaoping Li (2002) adopted the Behavior Event Interview (BEI) and made an empirical research on the competency of managers in China telecommunication industry (Kan Shi, Jicheng Wang and Chaoping Li, 2002, p306-311). Chongming Wang and Minke Chen (2002) analyzed competencies of junior managers and senior managers in China and concluded that manager competencies consists of two dimensions, management quality and management skill. But in specific aspect, managers at different levels possess different competency structures (Chongming Wang \& Minke Chen, 2002, p513-516). Aguta, Graub \& Peiro (2003) selected 80 senior managers in restaurants and hotels in Spain and studied their competency model (Aguta S, Graub R \& Peiro J.M., 2003, p281-295). Lifeng Zhong and Kan Shi (2004) adopted the BEI method and studied the competency model of senior managers in China's family firms (Lifeng Zhong \& Kan Shi, 2004, p110-115). Shuming Zhao and Juan Du (2007) assessed the competencies of professional managers and concluded that managers must possess abilities of scientific decision, communication, organization, learning, and social activity (Shuming Zhao \& Juan Du, 2007, p33-40).

\subsection{Literature comment}

By reviewing literatures, we find that former studies of competency focus on individuals (especially the competency of managers), taking individuals as primary units of understanding enterprise performance. Along with changes of business environment, former relatively steady environment becoming more complex and changeable, roles of human resource development changes constantly. In a steady environment, the function of human resource development centers on providing with necessary skill training for employees based on organizational needs. This role aims at supporting the enterprise strategy. Due to globalization of economy, especially since 80 s last century, enterprises face an external environment with higher uncertainties, what arouses challenges for traditional theories of human resource development that focus on simply improving employees' certain work skill. Organizations usually face a dilemma: the improvement of employee's individual competency can not bring about the improvement of team or organizational performance. In the new environment, many enterprises convert their pyramid organizational structures into flatten ones or procedure-driven configurations. Team work becomes an important way. Therefore, researches of competency-based human resource development should not focus on merely individuals but also teams and even the organization. It inspires us that researches of competency-based human resource development should focus on not only individual competency but also competencies of teams and organization.

Meanwhile, for the sake of deep researches, we discuss the competency-based human resource development in certain kind of enterprises. Because of coming of knowledge economy, knowledge enterprises play an important role in knowledge economy. Knowledge workers gradually become the principal part today. The work of knowledge workers widely concern processing of information and uses of knowledge, which is far different from traditional industrial workers. It is relatively more complex, unpredictable and non-in-time-supervising. Besides, because of the indirect explicitness of knowledge activities results and the collectivity displayed by many knowledge creative activities means higher requirements for knowledge enterprises and competencies of knowledge workers. Therefore, this paper focuses on studying competency-based knowledge enterprises' human resource development.

Wilson in his Consilience: the Unity of Knowledge emphasizes "the inner unity of knowledge". He thinks that for studies of social sciences, the theoretical consilience, based on facts by trans-sciences and fields, is necessary. Taking the competency as a trigger, this paper is to study related problems on human resource development in knowledge enterprises. Therefore, we need to construct a systematic research framework ------ use it to make an overall summarize for the main contents, necessary theories, analysis methods, and relevant technologies of the research.

\section{Research framework}

\subsection{Basic concepts}

(1) Knowledge enterprise

Knowledge enterprises take knowledge as the production factor, management factor, and resource allocation factor. In knowledge enterprises, knowledge runs through every aspect of enterprises. Enterprises' existence and development mainly depend on their products and services' knowledge contents. Knowledge has already become a key factor in value creation.

(2) Knowledge worker

Knowledge workers are the most important resource for knowledge enterprises. To completely develop and use their knowledge can bring about more returns for knowledge enterprises. In this paper, we define the concept of knowledge 
worker as: employee who increases values of enterprises by producing, creating, developing, and applying knowledge in work.

\section{(3) Competency}

Former studies of competency focus on individuals but seldom teams or the organization. In this paper, the competency chiefly includes individual competency, team competency, and organizational competency. In specific, the connotations are:

Individual competency means the collection of personalities that drives knowledge workers to use all kinds of work skills and behaviors $r$ to achieve excellent work performance under the specific background of enterprise strategy and enterprise culture. It reflects the knowledge, skills, incentives, personalities, and drives displayed by different ways.

Team competency is the integrated capability of knowledge workers' individual competency displayed in specific work flow and tasks under the guidance of certain enterprise aim.

Organizational competency refers to, on one hand, the capability of integrating the enterprise and the external market, realizing a match of organization and environment. On the other hand, it is the capability of cultivating, developing, integrating, and allocating organizational resources, implementing strategies, and realizing strategic aims in the enterprise strategy framework.

(4) Human resource development

The two connotations of human resource in macro and micro aspects determine the two meanings of human resource development in the two aspects. This paper merely discusses the human resource development in micro aspect. Therefore, we define the human resource development as: a series of human-resource-oriented development and practice activities in a specific organization for the sake of improving performances of individuals, teams, and the organization.

\subsection{Construction of research framework}

Based on literature review and basic concepts, this part aims at constructing a research framework for the competency-based knowledge enterprises' human resource development. See to figure 1. We use it to direct further studies. This framework is chiefly used to define the competency-based knowledge enterprises' human resource development's main contents, theoretical bases, analysis methods, and main technologies. In specific:

(1) The competency-based knowledge enterprises' human resource development chiefly begins from individuals, teams, and the organization. Knowledge workers are the most important resource for knowledge enterprises. To completely develop and use their competencies is an important task of knowledge enterprise. Therefore, development of individual competency is the base and start of the whole study. The team work of knowledge workers and the inseparability of individual performance and team performance determine that knowledge enterprises must enhance and emphasize on development of team competency based on development of individual competency. Knowledge enterprise is in nature a system of capabilities and a net of skills. Its capability connects closely with individual capabilities and team capabilities. The knowledge, skills incentives, and drives of individual and team capabilities are deeply endowed with characters of the organization. Therefore, based on researches on the development of individual competency and team competency, we should further discuss the development of organizational competency. The development of organizational competency and that of individual and team competency have close connections and are interdependent. It is a gradual process from the development of individual competency to that of team competency and that of organizational competency. The former serves as the base and precondition of the later. However, from the development of organizational competency to that of team competency and that of individual competency, it reflects knowledge enterprise competencies' vertical conformity. The three connect mutually and form the core of competency-based knowledge enterprises' human resource development. The ultimate objective is to improve performances of individuals, teams and the organization in knowledge enterprise. The development of competency at the three levels must take enterprise strategy as the base. Meanwhile, the results of development can support the implementation of enterprise strategy. Therefore, in figure 1 the arrows connecting enterprise strategy and competencies at three levels are bidirectional.

(2) The framework of competency-based knowledge enterprises' human resource development is based on many theoretical researches. Its theoretical bases include theory of human capital, theory of knowledge management, theory or team role, and theory of organizational learning.

(3) In order to realize the goal of this research, we adopt some theoretical analysis methods, mainly including systematic analysis, case analysis, goal programming, logistic deduction, and decomposing analysis.

(4) The competency-based knowledge enterprises' human resource development needs the support of a series of relevant technologies, mainly including training skills, enterprise tutor system, professional career programming, individual learning, team learning, and organization learning. 


\section{Conclusion}

Due to the coming of knowledge economy, the knowledge enterprise plays a more important role in knowledge economy. How to perform effective human resource development becomes an urgent issue. Taking the competency as a trigger, this paper constructs a systematic research framework for knowledge enterprises. This framework is based on theory of human capital, theory of knowledge management, theory of team role, and theory of organization learning. It takes the enterprise strategy as the core and focuses on the development of individual, team, and organizational competencies. The ultimate goal is to improve performances of individuals, teams and the organization. The construction of this framework will benefit the knowledge enterprises' human resource development that can start from the individual, team, and organizational aspects.

\section{References}

Aguta S, Graub R \& Peiro J.M. (2003). Competency needs among managers from spanish hotels and restaurants and their training demands. International Journal of Hospitality Management. 22(5). p281-295.

Boyatzis R.E. (1982). The Competent Management: A Model for Effective Performance. New York: John Wliey.

Department of Management Sciences of National Natural Science Foundation in China. (2006). Development Strategies for Management Sciences ----- Prior Support Fields of Management Sciences in "Tenth Five-Year Plan”. Beijing: Science Press.

John Riven. Translated by Qian, Lanying. (1995). Work Competence in Modern Society ------ Competence Identification, Development, and Exertion. Xiamen: Xiamen University Press.

Lawson T.E \& Limbrick V. (1996). Critical competencies and cevelopmental experiences for top HR executives. Human Resource Management. 35(1). p67-85.

McClelland D.C. (1973). Testing for competence rather than for intelligence. American Psychologist. 28(1). p1-14.

McClelland D.C. (1998). Identifying competencies with behavioral event interviews. Psychological Science. 9(5). p331-339.

Paul Sandwich. (1993). A hierarchy of management training requirements: the competency domain model. Public Personnel Management. 22(1). p43-62.

Pepermans R, Mentens C \& Goedee M, et al. (2001). Differences in managerial behavior between head nurses and medical directors in intensive care units in Europe. International Journal of Health Planning and Management. 16(4). p281-295.

Schippmann J.S \& Ash R.A, Battista M, et al. (2000). The practice of competency modeling. Personnel Psychology. 53(3). p703-740.

Shi, Kan., Wang, Jicheng \& Li, Chaoping. (2002). Assessment on competency model of senior managers. Acta Psychologica Sinica. 34(3). p306-311.

Siu, V. (1998). Managing by competencies: a Study on the managerial competencies of hotel middle managers in Hong Kong. International Journal of Hospitality Management. 17(3). p253-273.

Spencer L.M \& Spencer S.M. (1993). Competence at Work: Models for Superior Performance. New York: John Wiley \& Sons, Inc.

Wang, Chongming. \& Chen, Minke. (2002). Managerial competency modeling: a structural equation testing. Psychological Science. (5). p513-516.

Yukl G. (1989). Leadership in Organizations. N.J.Prentice- Hall, Inc

Zhao, Shuming. \& Du, Juan. (2007). A study of enterprise managers' competency and evaluation theory. Foreign Economies and Management. 29(1). p33-40.

Zhong, Lifeng. \& Shi, Kan. (2004). The competency model of senior managers in Chinese family firms. Acta Psychologica Sinica. 36(1). p110-115.

levels are bidirectional. 


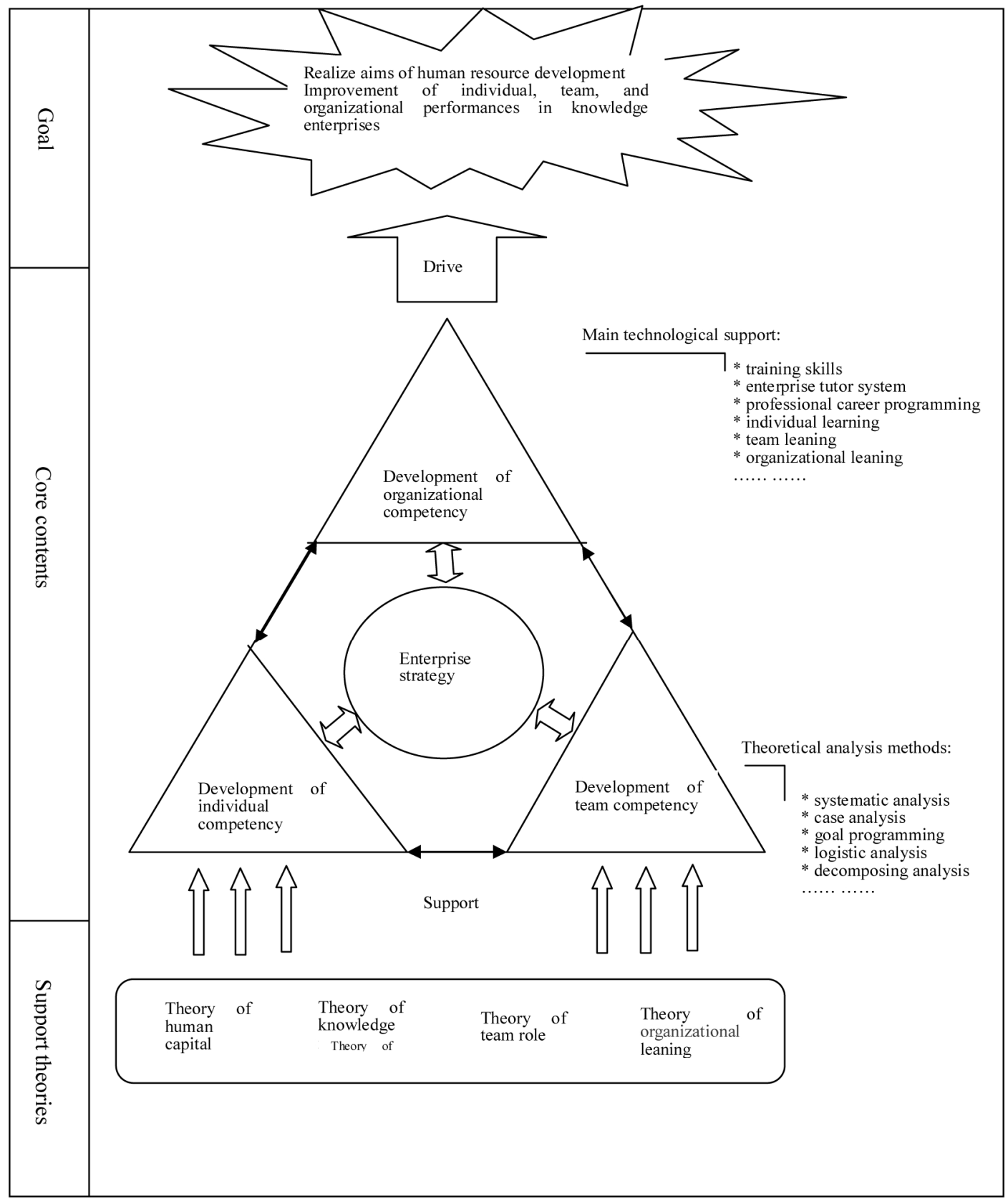

Figure 1. The Research Framework of Human Resource Development

Based on Competency about Knowledge Enterprise 


\title{
Managers Behaviors Trough Economic Crisis at
}

\section{Agro-Industries in Turkey: A Case Study in Sanliurfa Province}

\author{
Yusuf Çelik \\ Department of Agricultural Economics, University of Selcuk, 42079 Konya, Turkey \\ Tel: 90-332-231-2870Ｅ-mail: yucelik@selcuk.edu.tr \\ Kenan Peker \\ Department of Agricultural Economics, University of Selcuk, 42079 Konya, Turkey \\ Tel: 90-332-231-2877Ｅ-mail: kenanpeker@selcuk.edu.tr \\ Abdullah Karaman \\ Program of Tourism and Hotel Management, University of Selcuk, 42079 Konya, Turkey \\ Tel: 90-332-223-2290Ｅ-mail: akaraman@selcuk.edu.tr
}

\begin{abstract}
The statutes of understanding managers to the crisis factor affecting the firms' activities, profits, and continuity and the way they were affected from the economic and political crisis occurred during the period of November 2000-February 2001 in agro industries in Sanliurfa province in Turkey were determined in this study. The study was carried out on a sample consisting 53 agro industries operated. According to the results, most of managers, $83.3 \%$, evaluated the economic uncertainties and fluctuations defined as external crisis factors to their businesses ranked as first degree of importance. It is preferred to do with less stock in response to prevent the external crisis factors. Not perceiving the crisis early and thus not enough handling on crisis management, and the ability of not knowing the internal and external market environment defined as internal crisis factors were observed. A set of provisions such as signboard, motivation and educations personals against the internal crisis factors were determined. In addition, the crisis occurred affecting all businesses and resulting in lowering the ratios of operated capacities were obtained in Sanliurfa.
\end{abstract}

Keywords: Economic Crisis, Agro-Industries, Sanliurfa -Turkey

\section{Introduction}

The main purpose of business is producing and marketing various goods and services in order to maximize their benefit at the end of production period under conditions present and to ensure accumulation of equity capital. In other words, the aim of any entrepreneur is to preserve and increase the capital invested to business, in a broader sense, the goods of business (Erkuş et al., 1995).

There are many sources of crisis factors forcing managers to make decision a risky, ever changing environment (Figure 1). In the external environment, technology (internet, computer, nana technology, biotechnology, food technology, and precision technology) is the most important indicator for agribusiness. Also, economy (the range of development between and within countries, natural resources, income per capita, infrastructure, the ratio of currency, and other economic conditions), social and cultural environment (language, social value of the society, population, and demographic indicators), law and policy (punishment, taxes, tariffs, conjuncture, stability of the government, terrorism, and government supports), and the rule of international organization such as World Trade Organization (WTO), European Union (EU) are the other indicators of ago-industries (Peker, 2006).

These factors are the main causes of income fluctuations at firms. There is always existing of predictable risks and unpredictable uncertainties at all economic activities. Although higher risk and uncertainty could be occurred especially in agriculture sector in natural conditions, it is likely to be happened during some period of time that some industrial businesses to meet risk and uncertainty resulted from socio-economic or internal conditions of business. Besides, it is widely accepted that the businesses have a risk function at production activity. The entrepreneurs have to shoulder the responsibility of risks and uncertainties which could be faced against economic activities, so managers have to take some measures at pre-crisis, at-crisis and post-crisis periods in order to prevent possible risks, i.e. economic crisis as 
well as various risk factors, and to minimize and decrease the possible losses.

Risk management strategies are developed to provide some protection in situations in which the consequences of a decision are not known when the decision is made. The various risk management strategies have different effects on the business, but none of the responses can provide protection from all types of risk (Patrick, 1998). To reduce effects of risk or survive in the poor conditions for firm activities, it is necessary to use risk strategies. The selection of good risk strategies depends on the firm operator, the financial situation and risk attitudes of the manager (Kay and Edwards, 1994; Hardaker et al., 1997; Musser, 1998).

Societies couldn't keep up the same activity level not only before the industrial revolution occurred in the 17 th century but also afterwards. As for producers and sellers, welfare terms and crisis terms were followed each other in some periods (Unay, 1992). The examples include Asian crisis, Argentina crisis and the economic crisis in Turkey were adversely affected all of economic sectors recently. Since last century, economics has been representing a disorder of improvement at global and sector levels resulted from the economical fluctuating and crisis.

Within the second half of November 2000 in Turkey, the troubles especially suffered in banking fraction such as increased short term rate of interest, decreased prices of draft, bond and share, and inclusion of private banks to SDIF (Savings Deposits Insurance Bank) gave rise to economical crisis. A set of provisions were carried out in the period of November-December 2000 in order to the crises not to be deeply rooted. Resulted from the provisions against the crisis of November 2000 and agreement with International Monetary Fond, financial fluctuation couldn't be settled even though it has partially been overcome. The political crisis occurred in February 19, 2001 adversely affected financial markets (e.g. interests rose extremely and stock exchange was decreased) and fluctuation rate of foreign exchange was carried out by rates of foreign exchange in February 22, 2001.

Agro-industries as well as all sectors were adversely affected by those two crises occurred in November 2000 and February 2001 in Turkey. This negative interaction was expressed as both troubles unable to find credit due to crisis in financial markets and reflection of increased rates of interests and exchange fluctuation to cost. These factors were reflected in prices of goods purchase and amounts of production. Businesses are in such an obligation to determine a set of strategically decisions in order to survive against negativity resulted from economical conditions of the country. Those decisions and behaviors through them result from the attempt of adaptation to external environment. Some of decisions are consciously and strategically made leading towards adaptation to crisis conditions while some may be the behaviors as a result of market coercion.

Some research works have been conducted on the economic crisis exposure and crisis coping strategies of firms (Deming, 1996; Anonymous, 1998; Erçel, 1998; Katırcığlu, 1999; Tutar, 2000; Çelebi, 2000; Malatyalı, 2000; Yücel, 2001; Gerçek, 2002, Ayaz and Asma, 2002), On the other hand, it was appeared that not there was study associated with the being affected levels of agro-industries from the economic crisis, while there were existed some studies on risks and uncertainties in agriculture (Ceyhan, 1996; Nelson, 1997; Martin and McLeay, 1998; Musser, 1998; Coble et al., 1999; Harwood et al, 1999; Keith, 1999; Babcock et al, 2000; Akcaoz, 2001; Akcaoz and Özkan, 2002, Akcaoz et al, 2006).

In this study the behaviors of managers during the crises and the effect of crises in November-December 2000 and February 2001 was determined on agro-industries in Sanliurfa province, Turkey. The most of agro-industries operated in Sanliurfa province has been established, especially after irrigation and other infrastructural works established under the South-east Anatolia Project (SAP) exist in 1995. For example, the number of industries in the province reached to 277 (which of 158 agro industries) in 1995-2001, while there were only 37 industrial business in 1990 (Anonymous, 2002). Consequently most of managers in the province do not have enough experience on principles of management and the factors affecting the firms.

\section{A Case Study in Sanliurfa Province}

The main material of the study consists of primer data obtained by survey that applied by researchers from 53 agro-industries at the center of municipality of Sanliurfa in Turkey. Additionally, the results of some various researches on this task and records of related governmental and private organizations were used. The survey forms were prepared as to examine some various literatures and obtain required data by researchers. The questionnaires were filled in by means of conversation to the managers of agro-industries in December 2002.

The data were analyzed by taken into consideration internal and external environment of agro-industries as it explained figure 1. Internal and external crises factors were determinate by understanding of agro-industries manager' priorities.

\subsection{Approach of mangers to crisis factor in examined agro-industries}

Although industrial expectations are mostly to benefit under free competition conditions, activity is realized in respect of adverse factors resulted from domestic structure or external market. The successes of businesses are mostly depending on their sensitivity against possible crisis factors, and foresight and precautions associated with this period. 
When it was asked to the managers in order to examine whether they considered facing any crisis factor while they were establishing industry, almost all of the managers informed that they were likely to face various crisis factors after activity term started. When it was asked to the managers about which of crisis factors against their businesses might be efficient, i.e. internal crisis factors, external crisis factors, the majority (83.4\%) were accept both internal and external crises factor, while the rest $(16.6 \%)$ were only external factors could be adversely efficient for their businesses. None of the managers was state only internal factors an importance as a crisis factor.

\subsection{The external crisis factors considered as causing a crisis in agro-industries}

The external environment of business is a combination of economical, technological, socio-cultural, legal-political and natural environment factors. The managers have to analyze external environment of the business in order to determine the associations between external factors and the business activities. Especially in the business operating as open system, i.e. the ones gathering inputs from environment and producing outputs through markets, this analysis become great importance. The efficiency and productivity are provided by precise relationship between input-output in business. If the interaction of input-output was non systematic, there seems to have some crisis symptoms at the beginning, thereafter it will start to occur the crisis (Tutar, 2000).

When it was asked to the managers about external crises factors which mostly affect the examined agro-industries, it was stated by $83.3 \%$ of managers that generally-economical uncertainty and fluctuations had primarily importance, and as for $16.7 \%$ of managers they ranked as second degree of importance. Political crises factors were accepted by $75.0 \%$ of the managers as secondary important factors, while primary and third were $8.3 \%, 8.3 \%$ respectively. The obsolete of technologies was accepted by $33.3 \%$ of the managers as fourth important factors, while $45.9 \%$ of the managers were not accepting as a crises factor (Table 1).

On the other hand, strong competition and natural forces were not considered as external crisis factors by the managers. Indeed $79.2 \%$ of managers didn't consider the strong competition as important, while $87.5 \%$ didn't consider the natural forces as important factor (Table 3.1). What the effective on this result is the considerations that their strength against competition or their influence level was higher compared to the other factors and that the natural forces were valid for anyone.

In examined agro-industries, general economical uncertainties and fluctuations were considered by most of managers to have influence on crisis at first level of importance. They also were started to cause losing the price balance of input-output, decreased demands resulted from economical and psychological reasons, export-import imbalance and decreased exportation, decreased investments and decreased profitability. $70.8 \%$ of managers considered the effect of overall economical uncertainties and fluctuations on input-output price imbalance ranked as first degree of importance while $25.0 \%$ deemed as second degree (Table 2).

Again, $70.8 \%$ of managers considered the effect on import-export balance ranked as totally first, second and third degree of importance for general economical uncertainties and fluctuations. On the other hand, $29.2 \%$ of the managers stated that the effect on export-import balance was negligible or ignorable. $84.3 \%$ of managers considered the effect on decreased profitability and decreased investments realized by business important ranked as totally second, third, fourth and fifth degrees, while $16.7 \%$ considered as negligible. $63.5 \%$ of managers stated that the factor addressed as generally-economical uncertainty and fluctuations affecting business due to the lack of credit and source was of importance ranked as first, second, third and fourth degrees. $37.5 \%$ stated that this factor was negligible.

There were existing wide varieties of precautions against external crisis factors at examined agro-industries. $41.7 \%$ of managers took some measures following a more flexible production policy towards external crisis factors, while $41.8 \%$ realized it by implementing Research and Development (R\&D). 75.0\% of managers were prefer to make business with a smaller amount of stock, $50.0 \%$ preferred to reinforce their prestige, $8.3 \%$ preferred to organize some special sales campaign, $41.7 \%$ preferred to decrease the number of employee and to cut expenses, $16.8 \%$ preferred insurance, and $8.3 \%$ preferred to work with experienced staff (Table 3).

Consequently, most of the managers preferred to make business with less stock, however it seemed that $40-50 \%$ of managers preferred to take strategically precautions such as implementing R\&D studies and adopting a more flexible production policy. A very small number of managers stated that arranging special sales campaigns and working with experienced staff is a strategically method. Regarding to working with experienced staff, some managers stated that they had experienced staff; while some stated that they didn't have experienced staff so new staff would be paid to higher wages.

Following a more flexible production policy against to external crises factors were accepted precaution by $70.0 \%$ of managers as a first important degree, while $20.0 \%$ considered it important as second and $10.0 \%$ considered as fifth degrees. At the same time, $50.0 \%$ of managers preferred to implement R\&D studies important as fourth degree and the rest $50 \%$ as fifth degree (Table 4 ).

$44.4 \%$ of managers who preferred to work with less stock considered this factor an important solution ranked as first 
degree, while $38.9 \%, 11.1 \%$ and $5.6 \%$ considered as second, third and fourth degree important, respectively.

Out of managers who preferred to reinforce their prestige in markets by means of making payments at time, $16.7 \%$ considered this factor important ranked as first degree, while $25.0 \%, 41.7$ and $16.6 \%$ considered as second, third and fourth degrees, respectively. All the managers who preferred to arrange special sales campaigns esteemed this factor important ranked as fourth degree.

$50.0 \%$ of the managers who preferred to decrease both the number of staff and other expenses considered this factor important ranked as first degree, while $30.0 \%, 10.0 \%$, and $10.0 \%$ considered as second, third and fourth degree important, respectively. $25.0 \%$ of managers who preferred to have business insurance considered this factor important ranked as first degree, while $50.0 \%$ and $25.0 \%$ deemed as second and fifth degree important, respectively. $50.0 \%$ of managers who preferred to work with experienced staff considered this factor important ranked as first degree, while other $50.0 \%$ considered as third degree important.

\subsection{The internal crisis factors considered as causing a crisis in agro-industries}

One of the most important factors leading to give rise a crisis in examined agro-industries is "internal insufficiency and problems". Actually, although the external environment which is not possible to be managed to control entirely, even if it seem crises occur from external factor, business could be effected by internal factors.

When internal crises factors in the agro-industries were asked to the managers, general internal crises factor were remarked by managers as follow;

Internal crises factors were accepted by $45.8 \%$ of managers as inability of perceiving foreign and domestic markets and the managerial insufficiency, while $54.2 \%$ stated that this factor didn't constitute a crisis factor for their agro-industries (Table 5). With respect to inability of realizing crisis terms early and insufficiency of crisis management, $91.7 \%$ of managers considered this factor important leading to crisis, while $8.3 \%$ didn't define it as an important factor.

As to inability of adaptation to developments induced by managerial norms and behaviors, $16.7 \%$ of the agro-industries considered as an internal crisis factor, while $83.3 \%$ didn't consider so. The factor which includes failure in planning income-expenses equilibrium and in savings was considered as a crisis reason by $20.8 \%$ of the agro-industries while $79.2 \%$ didn't consider it as a crisis factor.

As to the lack of field experience in which agro-industries operate, 20.8 of managers considered this factor as domestic crisis factor while $79.2 \%$ didn't stated so. Lack of managers experience in the market were accepted as on other internal crises factor by $20.8 \%$ of the managers, while $79.2 \%$. As to the factor including fault, neglect and inexperience of staff, $8.3 \%$ of managers considered as domestic crisis factor while $91.7 \%$ didn't think so.

When the managers, who considered internal crisis factors important for their agro-industries were asked to classify those factors, they explained; the most important factors was the inability of perceiving both inability of realizing crisis terms early and insufficiency of crisis management. That was followed by inability of adjusting income-expenses balance and inexperience of managers at the business they operated. On the other hand, all of whom considered the inability of adapting through developments due to managerial norms and manners as a crisis factor found this factor important as second and third degrees (Table 6).

Among the precautions taken against internal crisis factors, the highest rate as $83.3 \%$ of manager was keeping records and works systematically, that followed by presence of warning signboards at place of employment, motivation of staff, and education of personnel, respectively.

\subsection{The affectability of examined agro-industries from 2000-2001 crises in Turkey}

Economical and political crises were occurred in November 2000 and February 2001 in Turkey. These crises affected all over the country as well as agro-industries operating in Sanliurfa. Indeed, when asked to managers of the agro-industries whether they were affected from November 2000 and February 2001 crises, all the managers stated that they were adversely affected.

The crises factors which mention above were affected agro-industry by the force of different factors. When the managers were asked of which factors they were affected from those crises, the answers included failure to perceive the developments at time (31.7\%), inadequate finance (20.6\%), inability of taking precautions $(17.5 \%)$, wrong decisions and activities after precautions (12.7), inadequate and inappropriate sources (6.3\%), inflexible organizational structure and failure in perceiving changes at time $(4.8 \%)$, and other factors such as fluctuation of exchanges and uncertainty $(1.6 \%)$ (Table 7).

\subsection{The effect of economical crisis in agro-industries}

The effect on capacity usage; the ratio of operated capacity was determinate by raw material amount (ton/year, piece/year) divided to per present capacity of business ( $t / y e a r$, piece/year). In order to determine any change at capacity usage ratios resulted from crisis in examined agro-industries, they were investigated regarding to their present capacity, 
capacity at normal terms (mean value before 2000) and capacity during crisis. There has been observed a decreased ratio of operated capacity in all agro-industries due to the crisis. Indeed, the ratio of operated capacity at normal term in flour industry decreased from $45.9 \%$ to $35.7 \%$, in cotton gin industry $71.6 \%$ to $62.1 \%$, in crops oil industry $77.2 \%$ to $55.2 \%$, in cotton mill industry $100 \%$ to $97.8 \%$, and in ready-to-wear industry $44.2 \%$ to $24.6 \%$ (Table 9 ).

In a study carried out in Sanliurfa in 1998, the ratios of operated capacity were determined in flour, crops oil, cotton gin-pressing, cotton mill and confection (textile) industries as $66.7 \%, 24.0 \%, 70.6 \%, 100 \%$ and $18.8 \%$, respectively (Karlı et al, 1999). In examined agro-industries during crisis terms, the managers stated that financial inadequacy, crisis in domestic market and decreased exportation possibilities had influence on decreased capacity.

In order to determine any change at the number of staff in the industries, the managers were asked whether they fired any worker or not. Most of agro-industries stated not to fire any worker $(70.8 \%)$, while $29.2 \%$ of industries stated that they had ever fired workers. It was determined that industries never fired any worker before didn't increase the wages, but in crops oil and cotton gin industries operating seasonally, they made the workers employed in a short time.

Due to crisis occurred in Turkey, the increased inflation, increased rate of exchange, uncertainty and inadequate increase at wages not only deteriorated agro-industries but also consumer's purchasing strength. Consequently a demand crisis was occurred as a result of decreased purchasing power of consumers as well as increased prices of product producing at a higher input prices.

In order to determine how this situation affected on domestic sales, producers were asked about any change at domestic sales. All of the managers stated that there had been no increase at domestic sales due to the crisis, while $69.6 \%$ stated that there occurred a decrease at domestic sales and $30.4 \%$ quoted no change was happened.

Increased exchange prices due to crisis favor to exportation. However, fluctuations at exchange rates including crisis period indicates the state of uncertainty in Turkey. Considering those conditions as well, the managers were asked about how changes happened at external sales in such a term. $58.3 \%$ of managers stated that there was no sale to foreign countries both pre-crisis and during crisis, while $8.3 \%$ stated an increase at export, $16.7 \%$ stated a decrease at export, and other $16.7 \%$ stated no exportation has changed.

The managers of agro-industries were asked about any change in exporting raw materials and other services during crisis, $75.0 \%$ of managers stated that they had no importation at pre-crisis and during crises. $12.5 \%$ of the manager stated that there was an increase at export, $4.1 \%$ a decrease at export and $8.3 \%$ reported no change at exportation.

The managers were asked whether they had ever looked for an alternative market in order to decrease the influence of crisis, $62.5 \%$ of managers stated that they had looked for a new market. It was also reported that before the crisis, marketing activities were carried out towards the province and other provinces around, while after crisis it was managed to follow all of the alternatives, especially marketing to western of Turkey's provinces. $37.5 \%$ of managers stated that they couldn't afford to enter new markets.

When asked to agro-industries managers whether they operated any alternative activity in order to remove the stagnation at their own activity fields due to the crisis; $4.2 \%$ reported that they were making business at other fields such as trade, service purchasing and delivering in order to decrease the adverse effect of crisis. $33.3 \%$ of managers stated that they thought of changing the activity field or working at another fields besides present occupation but they weren't able to realize those considerations. $62.5 \%$ of managers stated that they never thought of working at another activity field.

\section{Conclusions}

The improvement of industry in Sanliurfa has gained acceleration after the year 1990. The factor which affected this acceleration was the inclusion of Sanliurfa to "rgions with the highest priority in development" in 1992, establishment of organized industry area, the transfer of irrigation from Ataturk Dam to Harran Plain in scope of SAP in 1995 took place therefore increased cotton production contributed to improvement of industry, and encouraged of the industries by the government. There were only 37 industries in the province in 1990, however the number of industries reached up to 277 between 1991 and 2001.

The ideas and crisis management of the managers in examined agro-industries in crisis term were summarized as follow; as the results of the study, most of managers with the rate of $83.3 \%$ considered the generally-economical uncertainty and fluctuations as the most important factor. It was also reported by the managers that this factor caused to an imbalance between product price and input prices, decreased investments and decreased profitability, demand shrinkage and export-import imbalance in the agro-industries. It was determined that managers took a set of precautions such as using less stock, reinforcing prestige in market with the help of timely payments, following a flexible production policy and decreased expenses in extend to external crisis factors.

Agro-industries may be affected by a internal crisis factors which resulted from internally as well as external crisis factors. The precautions taken against internal crisis factors in examined agro-industries include controlling on works 
and records in order, using sign boards, providing motivation and education of staff. The economical and political crisis which occurred during 2000-2001 in Turkey affected all the agro-industries operating in the province. The factors were determined such as inability of perceiving the crisis early (31.7\%), insufficiency of finance (20.6\%), inability of acting against the crises (17.5\%), making wrong decisions after acting $(12.7 \%)$, and the other. The ratios of operated capacity were determined to cause decreased in all agro-industries due to the economical and economical and political crisis occurred in 2000-2001 terms. It was also determined that those industries with the rate of $29.2 \%$ fired some workers, while $70.8 \%$ didn't fire but didn't increase the wages. It was determined that $69.6 \%$ of agro-industries stated decreased domestic sales, while $30.4 \%$ stated no change was happened at domestic sales. Fluctuations in exchange rates affected the export of agro-industries in crisis. Especially fast fluctuations in exchange rates reflected an uncertainty state as for the managers and this situation expressed out to foreign trade. It was determined that $8.3 \%$ of stated no exportation, and $58.3 \%$ stated that they had no export both pre-crisis and at crisis. Fluctuations in exchange rates affect exportation as well as import. Especially increased rates of exchange also increase the domestic prices of imported products and consequently decrease the demand. In case of decreased rates of exchange, importation starts to rise. $12.3 \%$ of agro-industries increased import, $4.1 \%$ decreased import, $8.3 \%$ stated no change, and $75.0 \%$ stated that they had no import both pre-crisis and during crisis against the fluctuations. The troubles at markets in crisis oriented the entrepreneurs through alternative market search. It was determined that $62.5 \%$ of agro-industries oriented through alternative markets in this period. Additionally $4.2 \%$ of managers occupied in alternative business, $33.3 \%$ through of alternatives but didn't realize, and $62.5 \%$ never thought of such an alternative business.

As a conclusion, it was determined that the managers in examined agro industries had no more experiences on crisis management. Therefore the managers are preferred to be educated with seminar or to employ professional managers.

Reference to a journal publication:

Van der Geer, J., Hanraads, J. A. J., \& Lupton R. A. (2000). The art of writing a scientific article. Journal of Scientific Communications, 163, 51-59.

\section{References}

Akcaoz ,H., Ozkan, B., Karadeniz, C.F., \& Fert, C. (2006). Risk Sources and Strategies in Agricultural Production: Case Study for Antalya Providence., Journal of the Faculty Agricultural, Akdeniz University 19(1), 89-97.

Akcaoz, H., \& Özkan, B. (2002). Risk Sources and Risk Strategies in Agricultural Production. Turkey: V. Agricultural Economics Congress, 18-20 Sep., Erzurum.

Akcaoz, H.V. (2001). Risk in Agricultural Production, Risk Analysis and Risk Attitudes: Applications for Cukurova Region. Ph.D. Thesis Adana: Department of Agricultural Economics, Cukurova University, Institute of Natural and Applied Sciences, 609, 13.

Ayaz, M.F., \& Asma, M.Z. (2002). The Impact of Economic Crisis in Batman. [Online] Available : www.batman.smmmo.org.tr/ekonomik_kriz.htm (Jun, 2002)

Babcock, B.A., Hart, C.E., Adams, G.M., \& Westhoff, P.C. (2000). Farm Level Analysis of Risk Management Proposals. CARD Working Paper 00-WP 238.

Batte, M. (2006). Strategic Management. Ohio State Universty, 2th. Edition. New York: McGraw-Hill.

Ceyhan, V. ( 1996). Application of Probability Methods on agricultural risk analyses. Journal of Agriculture Faculty Ondokuz Mayls University, 3, 23-32.

Coble, K.H., Patrick, G.F., Knight, T.O., \& Baquet, A.E. (1999). Risk Management for Crop Producer Survey: a Preliminary Summary of Selected Data. A Report from the Understanding Farmer Risk Management Decision Making \&Educational Needs Research Project, Information Report 99-001, Department of Agricultural Economics, USA: Mississippi State University.

Deming, W.E. (1996). Out of The Crisis. Istanbul: Arcelik Published, ISBN:975-94911-0-9.

Dincer, O. (1992). Strategically Management and Operation Policy. Istanbul: Timas Publish Limit Liability Coop. ISBN-975-95598-0-3.

Erkus, A., Bulbul, M., Kiral, T., Acil, A.F., \& Demirci, R. (1995). Agricultural Economics. Ankara: Ankara University Published, No:5.

Hardaker, J.B., Huirne, R.B.M. \& Anderson, J.R. (1997). Copping with Risk in Agriculture. CAB International, Wallingford.

Harwood, J., Heifner, R., Coble, K., Perry, J., \& Somwaru, A. (1999). Managing Risk in Farming: Concepts, Research and Analysis. Agricultural Economic Report No. 774, Market and Trade Economics Division and Resource Economics Division, Economic Research Service, US Department of Agriculture. 
Karlı, B., Çelik, Y., \& Gerger, F. (1999). The Structure and The Problems of Agribusiness and Recommended Solution in Sanliurfa. SAR 1th. Agricultural Congress, 1, 371-380.

Katırcıoğlu, E., 1999. Küçükler ve Büyükler. ISO Journal, Special Issue; The Biggest 500 Industry in Turkey'98.

Kay, R.D., \& Edwards, W.M. (1994). Farm Management. New York: McGraw-Hill International Editions, Agricultural Series.

Keith, K.W. (1999). Optimal Grain Marketing: Balancing Risks and Revenue-Producer's Booklet. National Grain and Feed Foundation [Online] Available: http://www.agrisk.umn.edu (May 2000).

Malatyalı, K. (2002). The Factors Effecting Economic Crisis in Turkey. Journal of Istanbul Stock Market, 4-15.

Martin, S., \& McLeay, F. (1998). The Diversity of Farmers' Risk Management Strategies in a Deregulated New Zealand Environment. Journal of Agricultural Economics, 49 (2).

Musser, W.N. (1998). Risk Management Overview. Mid-Atlantic Risk Management Regional Conference, Williamsburg, VA, 6-7Aug'98.

Nelson, A.G. (1997). Teaching Agricultural Producers to Consider Risk in Decision Making. Department of Agricultural Economics, Faculty Paper Series, FP97-17, Texas A\&M University, College Station.

Patrick, G.F. (1998). Managing Risk in Agriculture. Iowa: North Central Region Extension Publication No. 406.

Peker, K. (2000). Strategic Management for Agribusiness. Buletinul USAMV-CN, 63.

Tutar, H. (2000). Managing in Crisis and Stress Conduction. Hayat Published, 88.

Unay, C. (1992). Economic Conjuncture. Bursa Trade Science Academician, 31.

Yücel, T. (2001). Firm Behaviors Trough Economic Crisis (A research on IMKB Firms). [Online] Available: www.econ.metu.edu.tr/cong2001/abstracts/papers/p146.pdf (Mar.2002).

Table 1. The external crisis factors that evaluated by managers of the agro- industries

\begin{tabular}{|l|r|r|r|r|r|r|r|c|}
\hline Factors & \multicolumn{6}{|c|}{ The level of significance crises factors (\%) } \\
\cline { 2 - 8 } & $\mathbf{1 s t}$ & $\mathbf{2 n d}$ & $\mathbf{3 r d}$ & $\mathbf{4 t h}$ & $\mathbf{5 t h}$ & $\mathbf{6 t h}$ & $\mathbf{7 *}$ & Total \\
\hline Economical uncertainty and fluctuations & 83.3 & 16.7 & 0 & 0 & 0 & 0 & 0 & 100.0 \\
\hline Political crises & 8.3 & 75.0 & 8.3 & 4.2 & 0 & 0 & 4.2 & 100.0 \\
\hline Hard Competition & 0 & 0 & 8.3 & 4.2 & 8.3 & 0 & 79.2 & 100.0 \\
\hline Natural forces (fire, earthquake etc) & 0 & 0 & 0 & 4.2 & 0 & 8.3 & 87.5 & 100.0 \\
\hline The absolution of technology & 0 & 0 & 12.5 & 33.3 & 8.3 & 0 & 45.9 & 100.0 \\
\hline
\end{tabular}

*: ignore level

Table 2. The effects of generally economical uncertainty and fluctuations on examined agro-industries

\begin{tabular}{|l|r|r|r|r|r|r|r|}
\hline Factors & \multicolumn{6}{|c|}{ The level of significance (\%) } \\
\cline { 2 - 7 } & $\mathbf{1 s t}$ & $\mathbf{2 n d}$ & $\mathbf{3 r d}$ & 4th & 5th & \multicolumn{1}{|c|}{ 6* } & Total \\
\hline Imbalance at product input prices & 70.8 & 25.0 & 0 & 4.2 & 0 & 0 & 100.0 \\
\hline $\begin{array}{l}\text { Dampening of demand due to economical and } \\
\text { psychological causes }\end{array}$ & 0 & 16.7 & 12.5 & 16.6 & 12.5 & 41.7 & 100.0 \\
\hline Import-export imbalance and decreased exportation & 20.8 & 25.0 & 25.0 & 0 & 0 & 29.2 & 100.0 \\
\hline Decreased investments and decreased profitability & 0 & 16.7 & 25.0 & 33.3 & 8.3 & 16.7 & 100.0 \\
\hline $\begin{array}{l}\text { Deterioration in growth power of agro0industries due } \\
\text { to insufficient credit and sources }\end{array}$ & 8.3 & 16.7 & 25.0 & 12.5 & 0 & 37.5 & 100.0 \\
\hline
\end{tabular}

*: ignore level 
Table 3. The precautions taken against external crisis factors by managers

\begin{tabular}{|c|c|c|c|}
\hline \multirow[t]{2}{*}{ Factors } & \multicolumn{2}{|c|}{ As to related factor } & \multirow{2}{*}{$\begin{array}{l}\text { Total } \\
(\%)\end{array}$} \\
\hline & $\begin{array}{l}\text { The ones who took } \\
\text { precautions (\%) }\end{array}$ & $\begin{array}{l}\text { The ones who didn't } \\
\text { take precautions }(\%)\end{array}$ & \\
\hline $\begin{array}{l}\text { Following a more flexible production } \\
\text { policy }\end{array}$ & 41.7 & 58.3 & 100.0 \\
\hline Implementing R\&D studies & 41.8 & 58.4 & 100.0 \\
\hline Working with a less stock & 75.0 & 25.0 & 100.0 \\
\hline $\begin{array}{l}\text { Reinforcing the prestige with the help of } \\
\text { timely payments }\end{array}$ & 50.0 & 50.0 & 100.0 \\
\hline Arranging special sales campaign & 8.3 & 91.7 & 100.0 \\
\hline $\begin{array}{l}\text { Decreasing the number of staff and other } \\
\text { expenses }\end{array}$ & 41.7 & 58.3 & 100.0 \\
\hline Making insurance & 16.8 & 83.2 & 100.0 \\
\hline Working with experienced staff & 8.3 & 91.7 & 100.0 \\
\hline
\end{tabular}

Table 4. The importance degrees of precautions taken against external crisis factors by managers

\begin{tabular}{|l|c|c|c|c|c|c|}
\hline \multirow{2}{*}{ Factors } & \multicolumn{5}{|c|}{ The level of significance (\%) } \\
\cline { 2 - 7 } & $\mathbf{1 s t}$ & $\mathbf{2 n d}$ & $\mathbf{3 r d}$ & 4th & $\mathbf{5 t h}$ & Total \\
\hline Following a more flexible production policy & 70.0 & 20.0 & 0 & 0 & 10.0 & 100.0 \\
\hline Implementing R\&D studies & 0 & 0 & 50.0 & 50.0 & 0 & 100.0 \\
\hline Working with a less stock & 44.4 & 38.9 & 11.1 & 5.6 & 0 & 100.0 \\
\hline $\begin{array}{l}\text { Reinforcing the prestige with the help of timely } \\
\text { payments }\end{array}$ & 16.7 & 25.0 & 41.7 & 16.6 & 0 & 100.0 \\
\hline Arranging special sales campaign & 0 & 0 & 0 & 100. & 0 & 100.0 \\
\hline Decreasing the number of staff and other expenses & 50.0 & 30.0 & 10.0 & 10.0 & 0 & 100.0 \\
\hline Making insurance & 25.0 & 50.0 & 0 & 0 & 25.0 & 100.0 \\
\hline Working with experienced staff & 50.0 & 0 & 50.0 & 0 & 0 & 100.0 \\
\hline
\end{tabular}

Table 5. Understandability of internal crisis factors in the agro-industries

\begin{tabular}{|l|c|c|c|}
\hline Internal crisis factors & $\begin{array}{l}\text { Considered as a } \\
\text { internal crisis } \\
\text { factor (\%) }\end{array}$ & $\begin{array}{c}\text { Not considered as a } \\
\text { internal crisis } \\
\text { factor }\end{array}$ & $\begin{array}{c}\text { Total } \\
\text { (\%) }\end{array}$ \\
\hline $\begin{array}{l}\text { Managers inability of perceiving both domestic and } \\
\text { foreign markets, and management failure }\end{array}$ & 45.8 & 54.2 & 100.0 \\
\hline $\begin{array}{l}\text { Inability of perceiving crisis early and crisis } \\
\text { management failure }\end{array}$ & 91.7 & 8.3 & 100.0 \\
\hline $\begin{array}{l}\text { Inability of adapting to developments due to } \\
\text { managerial norms and manners }\end{array}$ & 16.7 & 83.3 & 100.0 \\
\hline $\begin{array}{l}\text { Inability of planning well the income-expenses } \\
\text { balance and inadequate savings }\end{array}$ & 20.8 & 79.2 & 100.0 \\
\hline Inexperience at the business & 20.8 & 79.2 & 100.0 \\
\hline Mistakes, ignorance and inexperience's of workers & 8.3 & 91.7 & 100.0 \\
\hline
\end{tabular}


Table 6. Internal crisis factors in the agro-industries

\begin{tabular}{|l|r|r|r|r|r|r|r|}
\hline \multirow{2}{*}{ Factors } & \multicolumn{7}{|c|}{ Level of significance (\%) } \\
\cline { 2 - 7 } & $\mathbf{1 s t}$ & $\mathbf{2 n d}$ & $\mathbf{3 r d}$ & $\mathbf{4 t h}$ & $\mathbf{5 t h}$ & $\mathbf{6 t h}$ & Total \\
\hline $\begin{array}{l}\text { Inability of knowing both domestic and foreign } \\
\text { markets, and managerial failures }\end{array}$ & 72.7 & 18.2 & 9.1 & 0 & 0 & 0 & 100.0 \\
\hline $\begin{array}{l}\text { Inability of perceiving crisis early and crisis } \\
\text { management failure }\end{array}$ & 54.5 & 45.5 & 0 & 0 & 0 & 0 & 100.0 \\
\hline $\begin{array}{l}\text { Inability of adapting to developments due to } \\
\text { managerial norms and manners }\end{array}$ & 0 & 50.0 & 50.0 & 0 & 0 & 0 & 100.0 \\
\hline $\begin{array}{l}\text { Inability of planning the income-expenses balance } \\
\text { and inadequate savings }\end{array}$ & 20.0 & 20.0 & 20.0 & 40.0 & 0 & 0 & 100.0 \\
\hline $\begin{array}{l}\text { Inexperience at the field } \\
\text { Mistakes, ignorance and inexperience's of workers }\end{array}$ & 0 & 0 & 50.0 & 0 & 0 & 50.0 & 100.0 \\
\hline
\end{tabular}

Table 7. The effective crises factors in agro-industries

\begin{tabular}{|l|c|}
\hline Factors & $\mathbf{( \% )}$ \\
\hline Inability of perceiving developments leading to crises at time & 31.7 \\
\hline Financial inadequacy & 20.6 \\
\hline Managers inability of acting & 17.5 \\
\hline Managers wrong decisions and activities after acting & 12.7 \\
\hline Insufficient sources and inappropriate liquidity & 6.3 \\
\hline Inelastic structure of agro-industries & 4.8 \\
\hline Inability of perceiving changes in business at time & 4.8 \\
\hline Other (Fluctuation at foreign exchange and uncertainty & 1.6 \\
\hline Total & $\mathbf{1 0 0 . 0}$ \\
\hline
\end{tabular}

Table 8 . The changes at industrial capacity operation in crisis terms

\begin{tabular}{|l|c|c|c|c|c|}
\hline Industries & $\begin{array}{c}\text { Established } \\
\text { Capacity } \\
\text { (piece/year) }\end{array}$ & $\begin{array}{c}\text { Normal } \\
\text { Capacity } \\
\text { (piece/year) }\end{array}$ & $\begin{array}{c}\text { Rate of } \\
\text { capacity } \\
\text { utilization (\%) }\end{array}$ & $\begin{array}{c}\text { Capacity at } \\
\text { crisis } \\
\text { (piece/year) }\end{array}$ & $\begin{array}{c}\text { Rate of capacity } \\
\text { utilization at } \\
\text { crisis (\%) }\end{array}$ \\
\hline Flour & 27350 & 12550 & 45.9 & 9765 & 35.7 \\
\hline Cotton gin & 16964 & 12142 & 71.6 & 10535 & 62.1 \\
\hline Crops oil & 22440 & 17330 & 77.2 & 12390 & 55.2 \\
\hline Cotton mill & 3750 & 3750 & 100.0 & 3670 & 97.8 \\
\hline Confection & 1042270 & 460570 & 44.2 & 256340 & 24.6 \\
\hline
\end{tabular}




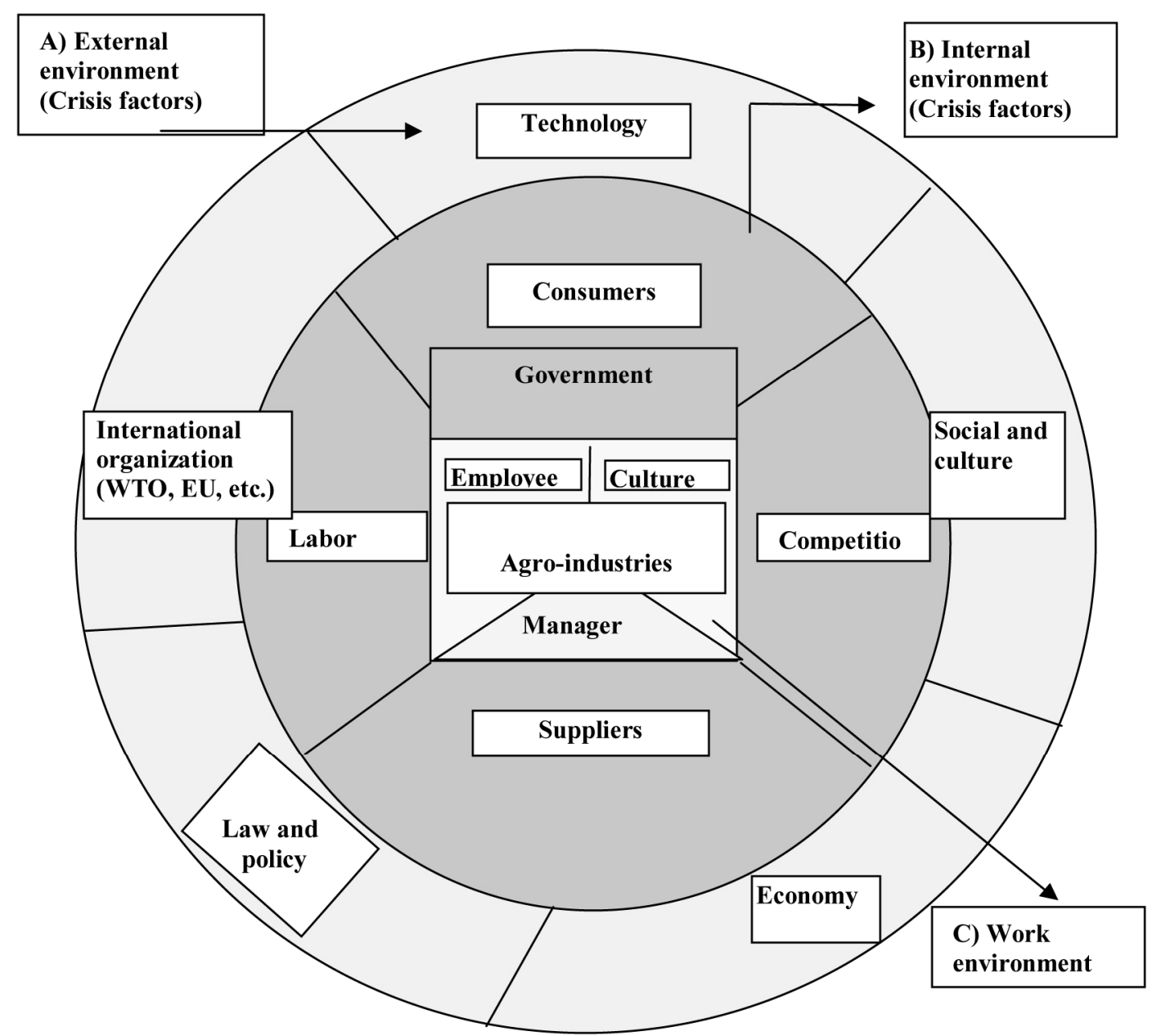

Figure 1. Internal and external environment of agro-industries (Batte, 2006) 


\title{
Study on the Cross-Regional Urban Flexible
}

\section{Management Pattern: The Core Testing Zone of}

\section{Shen-Fu New Town as the Case}

\author{
Feng Han \& Yachen Liu \\ School of Management, Shenyang Jian Zhu University \\ 9 Hunnan East Road, Shenyang 130024, China \\ Tel: 86-24-2469-2209Ｅ-mail: hanf606@163.com
}

The research is financed by Liaoning Social Sciences Association of China. No. 2007lslktjjx-182 (Sponsoring information)

\begin{abstract}
The study on the management pattern for the Shen-Fu new town built between Shenyang and Fushun is a problem in the field of urban management patterns, because as a cross-region new town, its policies and administration area are not uniform, so its management pattern is a big challenge. This paper summarizes the main innovations of urban management patterns and mechanism and the enlightenments for the cross-region urban management pattern, then analyzes the characteristics of overseas cross-region management patterns and the management pattern of domestic new towns. Based on the enlightenments, the paper brings forward the meaning and main content of flexible management pattern and builds the one of the core testing zone of Shenyang-fushun new town.
\end{abstract}

Keywords: Cross-region, Flexible management pattern, Shenyang-Fushun new town

There are more and more cross-region urban management patterns in the process of Chinese urbanization. And there appears a new form which is urban integration in the development of regional economic integration and urban agglomeration. The integration of urban agglomeration in central Liaoning province is a complex system which has seven cities with different relating extent and development emphasis. Shenyang-Fushun integration is an essential part among them. There is an innovation of Shenyang-Fushun integration, which is to build a new town named Shen-Fu new town, composed of two parts with the same areas from the two cities (Shu Wang, 2007). The new town built is just for the two cities to integrate their resources and absorb all kinds of investment and resources, however, its policies and administration area are not uniform. Therefore, the paper brings forward the cross-region urban flexible management pattern and gives suggestions on the measurements with Shen-Fu new town as the case.

\section{The change of urban management patterns and the enlightments}

\subsection{The change of the function of urban management}

The common compact management pattern is changing to the administrative management pattern of simplified government and magnified service and the one with the mechanism of trisection administration systems. For example, Pudong New District of Shanghai city in China takes the management pattern of simplified government and magnified service. In 1993, there were 3 institutions in the district with the same functions of 17 institutions in Puxi district of Shanghai (Lifen Zhang, 2005) (see Tab.1).

The government of Shenzhen established many departments with bureaus to distinguish the decision-making departments and the executive departments, such as the guild service bureau (built in 2004)and the bureau of public works of Shenzhen municipality, based on the experiences of social management and public service of the government of Hong Kong Special Administrative Region (Lifen Zhang, 2005). And it shows that the management pattern of Shenzhen is changing to the one with the mechanism of trisection administration systems.

\subsection{The innovations of the mechanism and methods of urban management patterns}

Chinese representative innovations are the overtime acquiescence mechanism of administrative examination and approval of Nankai District of Tianjin, the one-door mechanism of administrative examination and approval of Pudong New District of Shanghai, and the coordinative and confederate cross-region management mechanism of the Changjiang Delta (Qing Wang, 2006). 


\section{3 enlightenments}

Every pattern is managing to divide administrative powers rationally with the main behalf parts cooperating close and simplify the programs with new technologies and new management methods for the purpose of enhancing the management efficiency.

\section{The typical cross-region urban management patterns and the flexible management trend of Chinese new town management patterns}

The function of Shen-Fu new town is driving Shenyang-Fushun integration and leading to build Shen-Fu metropolitan area by building a cross-region new town, so the patterns used for reference are the overseas urban management patterns of the Metropolitan area and the domestic urban management patterns of new towns.

\subsection{The typical cross-region urban management patterns}

The paper mainly summarizes the characteristics of typical cross-region management patterns for metropolitan area, which are Canadian one, American one and Japanese one. In this paper, their characteristics are summarized as follow(Xiyu Cong, 2006, see figure 2):

(1)the pattern of two-level governments: first, the pattern divides the functions and administrative powers rationally between governments in the two levels, and the governments have no affiliation, so they don't interfere each other and has got high administrative efficiency.(2)the pattern of relaxed united organizations of urban governments: the relaxed characteristic can mobilize the positivity of all the governments, however, with the development of management deeper and deeper, the governments used to influence and oppose the decision-makings of the organization because of their deferent behalves. Therefore, the organization usually changed to have one simple administrative function instead of integrated functions. (3)the pattern of the Metropolitan government from down to up, which means that the information is easy to communicate and feedback from public to the metropolitan government, so the pattern enhances the degree of public participation and furthermore, the metropolitan plannings are more reasonable and meets more people's demand.

\section{2 the flexible management trend of the management patterns of Chinese new towns}

There has appeared the multi-part management pattern in the current management patterns of Chinese new tows. The parts of the pattern are governments, the management administrative frameworks and R\&D institutions and enterprises, furthermore, the pattern is the framework composed of the leading system, performance mechanism, management functions and policies system with the above parts. The main current management patterns of Chinese new towns are the government management pattern, the business-operated one and government-enterprise complementary one (Jianbo Li, 2003)(see Table. 3).

\section{The meaning of the urban flexible management pattern and the main contents of the cross-region urban flexible management pattern}

\subsection{The meaning of urban flexible management pattern}

Urban flexible management pattern is a pattern in which the government, enterprises and nonprofit departments divide the administrative functions according to the principle of minimum transaction cost and cooperate with each other.

The cross-region urban flexible management pattern is the pattern in which governments, enterprises and nonprofit departments in different regions divide the administrative functions according to not only the principle of minimum transaction cost but also the political system and cooperate with each other. And building a cross-region urban flexible management pattern is more difficult than building urban flexible management pattern in one city or town, therefore, its contents have deeper characteristics.

\subsection{The main contents of the cross-region urban flexible management pattern}

(1) the composing of the governments

The key to building the cross-region urban flexible management pattern is how to establish the administrative offices and divide the administrative functions from all the regions. And the administrative framework must include the governments of all the regions, such as, the administrative framework of Shen-Fu new town must be composed of officers from both Shenyang city and Fushun city.

\section{(2) Reasonable functions}

The administrative framework should define its functions according to its administrative rank, and divide the right of making-decision, the one of performance and the one of supervision of all the management functions mainly including economic functions, administrative ones, jurisdiction ones and collectorship. For example, the concerted institutions of the metropolitan areas should divide the functions with the government of cities and the government of the provinces or states, because only on the basis of reasonable and specific division of functions, the institutions can realize the largest functions of the institutions of metropolitan areas. Moreover, the different methods on how to divide the administrative 
functions will make different patterns by different division on the right of making-decision, the one of performance and the one of supervision.

(3) Building the flexible management of functions

The functions of the cross-region management departments will be more and more with deeper influence and wider incidence, which brings forward very elevated requires. The paper suggests the following main measurements:

The one is dividing functions to enterprises and non-profit departments such as guild, environmental protection organizations and academies with experts and scholars. And the limit is the minimum of exchange cost between governments and enterprises or non-profit departments according to the rule of market economy.

The second one is the innovations of management modes by new technologies such as exploring long-distance softwares, rebuilding the process of management etc.

The third one is promoting the information checkless to realize people oriented by using all kinds of advanced communication and collection modes of information such as hearings, the investigations of people and open by the internet.

The forth one is establishing scientific and complete performance evaluation system to evaluate the efficiency of the management departments and managers, and is establishing the corresponding system of rewards and punishment.

The fifth one is encouraging the creation ability of staffs with reward system to reconstruct the flow and integrate functions according to their opinions.

The sixth one is establishing scientific systems of performance evaluation and training the staffs according to their personal needs by the analysis of their performance evaluation with advanced theories of management and the relative specialty knowledge of their working fields to increase their management ability and professional ability.

Therefore, the departments can keep tidy and flat with functions increasing and divided into subsections.

\section{3 the predominance of the flexible management pattern and the problems to establish it}

The main predominance of the flexible management pattern is easy for the pattern to ameliorate the relationships of cross-region administrative frameworks, build the management pattern of multi-harmony and corporation, give prominence to each level of social services and regional corporation, use the limited spatial resource soundly with high efficiency, establish the flat department and innovate processes concertedly with less human resource and financial resource, and build the expedite information routes for decision-making with more pertinence and tying decision-making, performance and supervision together.

The problems are the following:

The pattern needs not only much higher quality and much stronger spirit of corporation of the administrative staffs, especially the persons with ability, but also the administrative frameworks pay equal attention to the function of management and supervision. Furthmore, the above demands need the transverse vinculums and spatial tactility, so the pattern also needs the high cost infrastructures such as computers, networks and pertinent softwares which sometimes need exploring.

\section{The establishment of the flexible management pattern of the core test zone of Shen-Fu New Town}

\subsection{The administrative framework}

Because the management committee of the core zone of Shen-Fu new town belongs to not only government of Shenyang city but also the one of Fushun city (see figure 1), the functions and components of the administrative framework is the key to the flexible management pattern. The paper suggests that the framework is composed of the leading group composed of the officials of the two city governments, the management committee of administrative staffs of the tow cities. The committee has integrative office with management functions of the party, labor union and the committee, country planning management office with the functions of country planning and constructing management, investment office to absorb all kinds of investment and association organization office with the management for the development and corporation association, industry associations, and some associations with a single function such as environment protection etc. (see figure 2)

\subsection{The division of functions}

The administrative framework of the core zone of Shen-Fu new town not only has the right of execution of economy, administration and judicature and strengthens integrative functions of service and management, but also has the one of suggestion and the one of decision-making and self-supervision in some degree.

\section{3 staffs appointed and removed}

The paper suggests that the leaders of Dongling District of Shenyang city and the ones of economy-exploring district of 
Fushun city are the part-time managers of the management committee (or executive board) of the core zone of Shenfu new town. Other main leaders are appointed and removed through the procedure of appointment according to the opinions of both the government of Dongling District of Shenyang city and the one of economic development zone of Fushun city, which are authorized by the lead team of Shen-Fu new town.

\section{4 suggestions on building the functions of the flexible management pattern of the core zone of Shen-Fu new town}

The first one is rebuilding the management processes by technology and adjusting with the up governments. For example, exploring the softwares can examine and approve long-distance projects, or the staffs of Shenyang city or the ones of Fushun city handle the official business in "a door" in the investment office of Shen-Fu new town termly in turn. Therefore, the framework can keep flat.

The second one is outsourcing some functions. The management committee can absorb private capital to promote the marketing process of public service in the field of omnibus public products such as infrastructures, municipal public facilities, environment protection, city planning, social welfare, public education and fire protection. At the same time, the government should play a key role to advance the process by supervision and management. Otherwise, the pattern should broaden the participation of the people in the lawmaking discussions of market operation of the projects, the suggestions of policies and the supervision of the operation progress.

The third one is thinking much of the ingenuity of the staffs in the forefront to rebuild the flows and integrate functions according to their suggestions, and establishing the system of rewards to encourage the staffs in the forefront to create.

The forth one is advancing with the times, which means escalating the functions of the association organization office of Shen-Fu new town and working up self-management groups.

Nowadays, the main function of the association organization should be economic function with the development association composed of the representatives of governments, capable persons of enterprises, authorities, experts and citizens to discuss the key problems in the development progress of the new town. And the paper suggests that the association should carry out the right of supervision and proposal with the representative pattern and make measures which are establishing the special suggestion boxes to receive all the suggestions at any moment everywhere, facilitating the intercommunion between administrative departments and citizens by the technological channels of fax, email and telephone etc., summarizing all the opinions and suggesting the development strategies and innovations of the detailed mechanism to the upper governments such as the favourable investment policies, the spatial development of the financial market, the spatial open for the program examination and approval, and the spatial open of the medi-service departments, and boosting the establishment and development of industrial associations.

And in the long views, the association organization office should boost the establishment of some organization with a single function such as the organization of environment protection to supervise the construction for environment protection of the new town to a certain extend.

In addition, the cross-region coordinate development is a new trend for the development of the new town. Therefore, Shen-Fu new town should build association relationships with the other new towns in Shenyang city and Fushun city and the circumjacent new towns in other region. The association organization office should build an organization for coordinate development of new towns or add the function of cross-region coordinate development to the above development association. The ultimate principle is adding the functions and promoting the integrating comprehensive management ability by advancing with the times on the base of flat frameworks.

\section{References}

Shu Wang. Building the new town for more than 100, 000 people on the connection belt of Shenyang and Fushun. [Online] Available: http://news.nen.com.cn (Jul. 11, 2007).

Lifen Zhang. (2005). A Preliminary Search into Regional Management Modes of Tianjin Binhai New Area. Tianjin: Tianjin normal university.

Qiang Wang. (2006). A book on government's management innovation. Beijing: China Renmin University Press.

Xiyu Cong. (2006). The Research on the Governance Model of Metropolitan Area In China. Shanghai: Shanghai Normal University.

Jianbo Li. (2003). New Considerations for the Improvement of Management Mode of the New Town in China. Modern Urban Research, (4):18-21. 
Table 1. The 3 institutions of Pudong new district and 17 institutions of Puxi district of Shanghai with the same functions

\begin{tabular}{|l|l|}
\hline $\begin{array}{l}\text { The framework of the government of Pudong new } \\
\text { district }\end{array}$ & $\begin{array}{l}\text { The framework of the government of Puxi new } \\
\text { district with the same functions }\end{array}$ \\
\hline Communist party and working committee office & $\begin{array}{l}\text { Party committee office of the district, government } \\
\text { office of the district, archives bureau, public } \\
\text { access office, department affairs bureau, publicity } \\
\text { department, external publicity office, united front } \\
\text { department }\end{array}$ \\
\hline $\begin{array}{l}\text { Organization department (labor and personnel } \\
\text { bureau) }\end{array}$ & $\begin{array}{l}\text { Organization department, work committee for } \\
\text { departments, labor bureau, personnel office, } \\
\text { retired officials administration }\end{array}$ \\
\hline comprehensive planning and land bureau & $\begin{array}{l}\text { Planning bureau for planning commission, system } \\
\text { reform office, house and land bureau, statistic } \\
\text { bureau }\end{array}$ \\
\hline
\end{tabular}

Table 2. The comparative analysis of the management patterns of foreign metropolitan areas

\begin{tabular}{|c|c|c|}
\hline Metropolitan areas & Organization forms & Management patterns \\
\hline $\begin{array}{l}\text { Toronto } \\
\text { metropolitan area } \\
\text { of Canada }\end{array}$ & $\begin{array}{l}\text { Typical two-level } \\
\text { government } \\
\text { organization }\end{array}$ & $\begin{array}{l}\text { 1) building the government of the metropolitan area; 2) dividing } \\
\text { the functions between the governments of the Metropolitan area } \\
\text { and the local ones }\end{array}$ \\
\hline $\begin{array}{l}\text { Washington and } \\
\text { San Francisco } \\
\text { metropolitan area } \\
\text { of America }\end{array}$ & $\begin{array}{l}\text { Combination of the } \\
\text { uniform government } \\
\text { of Metropolitan area } \\
\text { and the coalition } \\
\text { government of cities }\end{array}$ & $\begin{array}{l}\text { 1) building the uniform metropolitan area according to the relation } \\
\text { affairs in the metropolitan area; 2) building the loose coalition } \\
\text { organization with government of cities based on the horizontal } \\
\text { integration; 3) adjusting the administrative regional divisions }\end{array}$ \\
\hline $\begin{array}{l}\text { Osaka and Tokyo } \\
\text { metropolitan areas } \\
\text { of Japan }\end{array}$ & $\begin{array}{l}\text { Building the } \\
\text { governments of } \\
\text { metropolitan areas } \\
\text { with bottom-up } \\
\text { management pattern }\end{array}$ & $\begin{array}{l}\text { 1) building the governments of metropolitan areas from bottom; } \\
\text { 2) the government-oriented public participation; 3) making the } \\
\text { perfect and detailed metropolitan planning from bottom }\end{array}$ \\
\hline
\end{tabular}


Table 3. The comparative analysis of the main management patterns of the new towns in China

\begin{tabular}{|c|c|c|c|}
\hline patterns & $\begin{array}{l}\text { Government management } \\
\text { pattern }\end{array}$ & $\begin{array}{l}\text { Business-operated } \\
\text { pattern }\end{array}$ & $\begin{array}{l}\text { government-enterprise } \\
\text { complementary pattern }\end{array}$ \\
\hline $\begin{array}{l}\text { Management } \\
\text { institutions }\end{array}$ & $\begin{array}{l}\text { The leading group from the } \\
\text { Upper-level government and } \\
\text { the government of the new } \\
\text { town }\end{array}$ & $\begin{array}{l}\text { The development } \\
\text { company of the new } \\
\text { town }\end{array}$ & $\begin{array}{l}\text { The government of the new } \\
\text { town and the construction } \\
\text { development company of the } \\
\text { new town }\end{array}$ \\
\hline $\begin{array}{l}\text { Emphasis } \\
\text { point }\end{array}$ & $\begin{array}{l}\text { management of Multi-level } \\
\text { governments }\end{array}$ & $\begin{array}{l}\text { Enterprise-oriented } \\
\text { management }\end{array}$ & $\begin{array}{l}\text { Macro-management of } \\
\text { governments and detailed } \\
\text { enterprise-oriented } \\
\text { management }\end{array}$ \\
\hline $\begin{array}{l}\text { Main } \\
\text { management } \\
\text { mode }\end{array}$ & Administrative commands & Market regulation & $\begin{array}{l}\text { administrative commands and } \\
\text { market regulation }\end{array}$ \\
\hline $\begin{array}{l}\text { Main } \\
\text { advantages }\end{array}$ & $\begin{array}{l}\text { High integrity and easy to } \\
\text { coordinate }\end{array}$ & $\begin{array}{l}\text { Flexible and flat } \\
\text { framework with high } \\
\text { efficiency }\end{array}$ & $\begin{array}{l}\text { The complementary of the } \\
\text { advantages of governments } \\
\text { and the ones of enterprises }\end{array}$ \\
\hline $\begin{array}{l}\text { Main } \\
\text { disadvantages }\end{array}$ & $\begin{array}{l}\text { Lack of multi-level } \\
\text { coordination mechanism, and } \\
\text { high cost }\end{array}$ & $\begin{array}{l}\text { Deficiency of } \\
\text { macro-control force }\end{array}$ & $\begin{array}{l}\text { The absence and overrun of } \\
\text { governments }\end{array}$ \\
\hline $\begin{array}{l}\text { Common } \\
\text { deficiency }\end{array}$ & \multicolumn{3}{|c|}{$\begin{array}{l}\text { Lack of the necessary coordination mechanism for the new towns with peripheral urban } \\
\text { areas including their mother cities }\end{array}$} \\
\hline
\end{tabular}

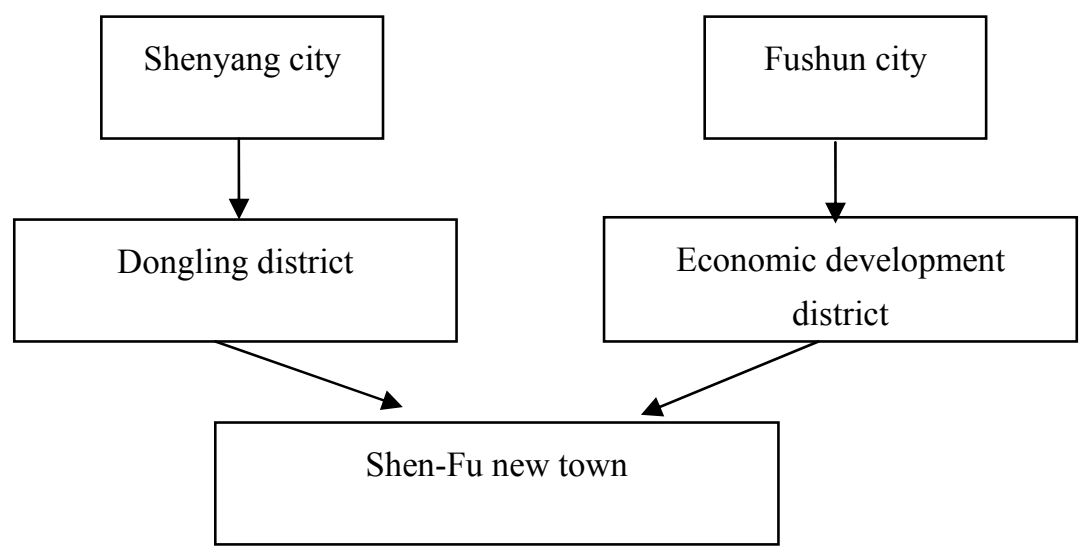

Figure 1. The administrative affiliations from up to bottom for Shen-Fu new town 


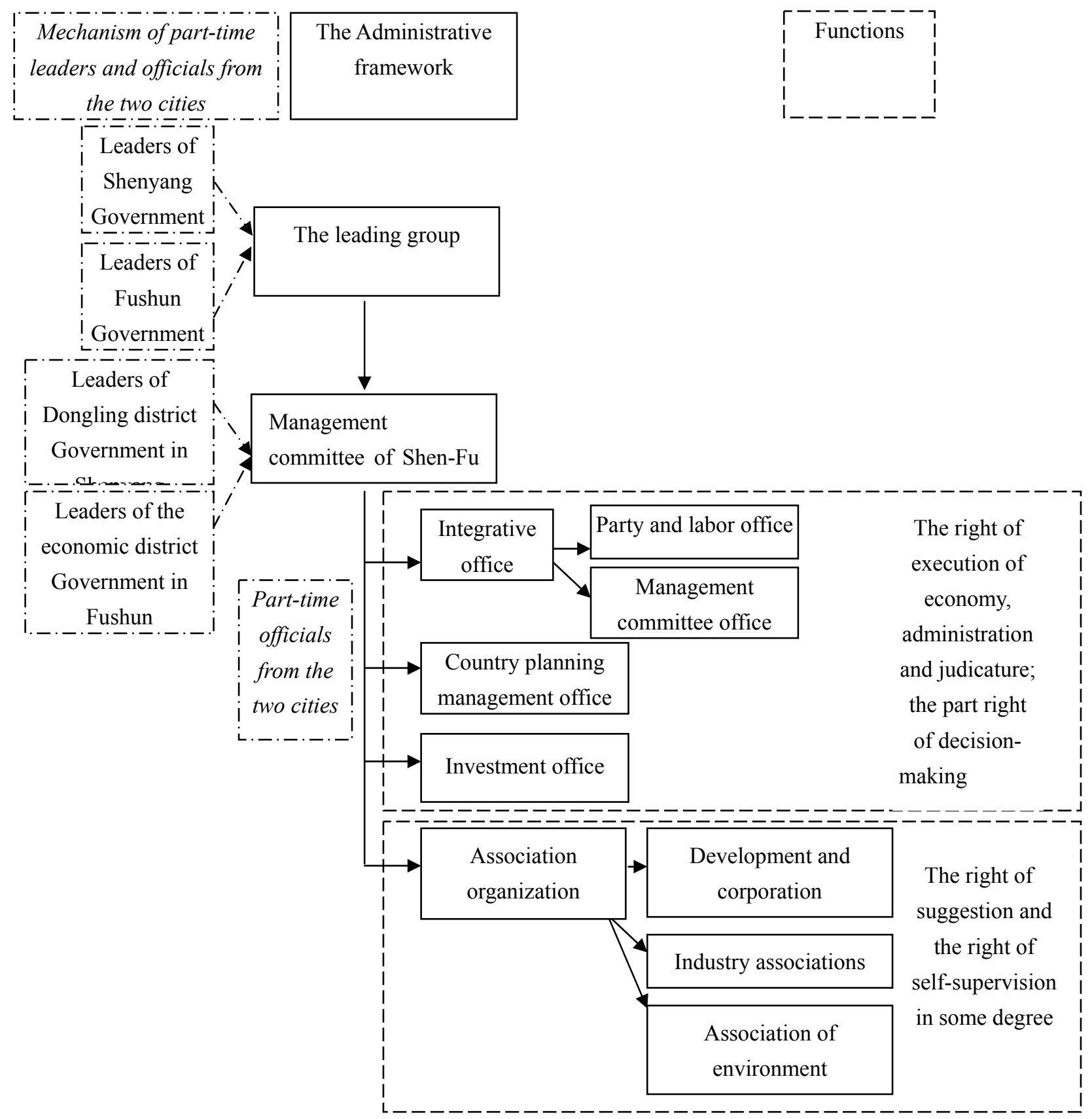

Figure 2. The administrative framework, functions and mechanism of

Officials for the flexible management pattern of Shen-Fu new town 


\title{
An Optimized Supply Chain Planning Model for
}

\section{Manufacture Company Based on JIT}

\author{
Ruilin Guo \& Qi Tang \\ School of Management, Tianjin Polytechnic University, Tianjin 300387, China \\ E-mail: guorl2008@yahoo.cn
}

\begin{abstract}
With an aim to resolve the problem of the increasing costs of supply chain in Manufacture Company, an integrated supply chain management model, driven by market demand, is brought forward in this paper, based on the analysis of existing integrated models of supply chain. The management model integrates purchase, production and sale plans with logistics plans used JIT. In order to build an integrated supply chain system which contains the inside management system and the outside supply chain system of manufacturing firm and a conceptual framework of integrated supply chain planning is also designed. This paper uses a three-stage integrated supply chain planning model to make supply chain plans, and a classification evaluation model is also suggested to analyze the feasibility of planning by comparing the planned cost with the anticipated cost. Research results indicate that this three-stage integrated supply chain planning model can optimize and reduce the costs of supply chain for manufacturing firms very well.
\end{abstract}

Keywords: Integration Model, Manufacture Company, Supply Chain

\section{Introduction}

The globalization of business and the increasingly competitive pressures have driven many manufacturing firms to develop an effective supply chain planning to minimize the supply chain cost; supply chain planning is becoming the crucial element of company management. Supply chains have traditionally been fragmented, failing to integrate the business functions in logistic chain process. Many problems, such as increased inventory carrying costs, longer order lead times, and difficulty in responding proactively to real-time changes, have decreased profits and weakened customer goodwill, which can be resolved by integrating supply chain management systems for warehousing and transportation.

A supply chain may be defined as an integrated process wherein a number of various business entities (i.e., suppliers, manufactures, distributors, and retailers) work together in an effort to: acquire raw materials, convert this raw material into specified final products, and deliver these final products to retailers. The main processes in this integrated process are the production planning, control, distribution and logistics. In these processes, the production-logistics planning is one of the most important parts to support global optimization in supply chain management (SCM), and should be solved within the integrated planning structure.

In a manufacturing firm, sale, production, purchase and logistics planning are the important parts of supply chain planning and they are interactive. The production and purchase planning describes both the design of process and management of entire manufacturing process, while the sale and logistics planning determines how products are sold and delivered from the factory or warehouse to customers. Hence, how to design an integrated supply chain planning which contains sale, production, purchase and logistics planning is critical to the success of a manufacturing firm.

Given the remarkable changes in the manufacturing industry, companies have started to think how to link themselves inside a logistic chain in a way to generate more value for the customers and ultimately also for themselves.

An integrated three-stage supply chain planning model, which contains sale-logistics, production-logistics and purchase-logistics planning sub-model, is developed to support supply chain management in manufacturing firms, and an evaluation model is also designed to determine the feasibility of planning by analyzing the error of planned cost and anticipated cost in this paper.

\section{Supply Chain Planning System}

Supply chain is traditionally characterized by a forward flow of materials and a backward flow of information and often comprised of a set of geographically dispersed facilities where raw materials, intermediate products, or finished products are acquired, transformed, stored, or sold. This supply chain is often represented as a network (See Figure 1). 


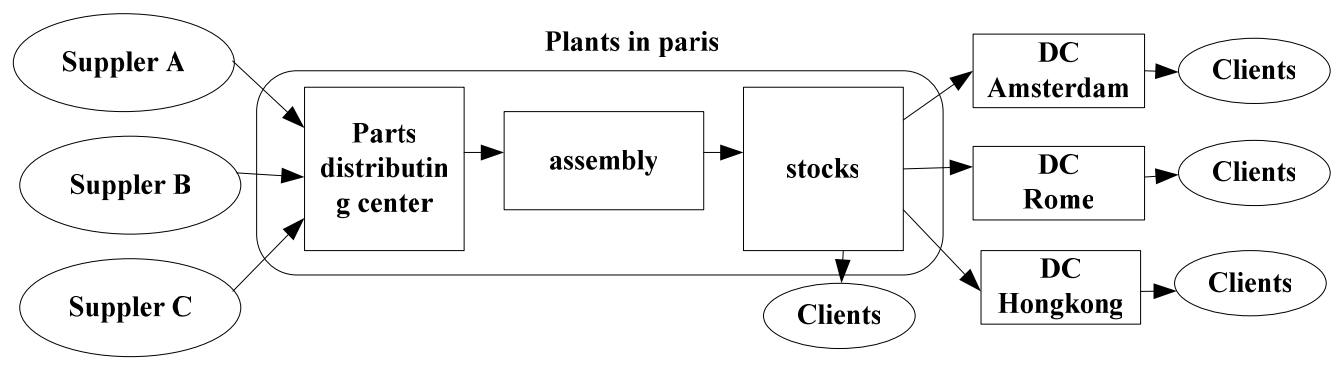

Figure 1. A simplified supply chain system

The network has four levels, products flow from suppliers to plants, the plants to distribution centers (DC), and finally DC to customers. This is a simple supply chain system based on logistics chain, and logistic value is reflected in the system. In fact, the supply chain planning system in a manufacturing firm is very complex. It needs to deal with not only the inside management system including sales, production, purchase and logistics planning, but also the outside supply chain system. The planning system analysis requires the addition of considerable details about plan-made process. An integrated supply chain planning system for manufacturing firms is designed to describe the planning process in detail in this paper (shown in Figure 2).
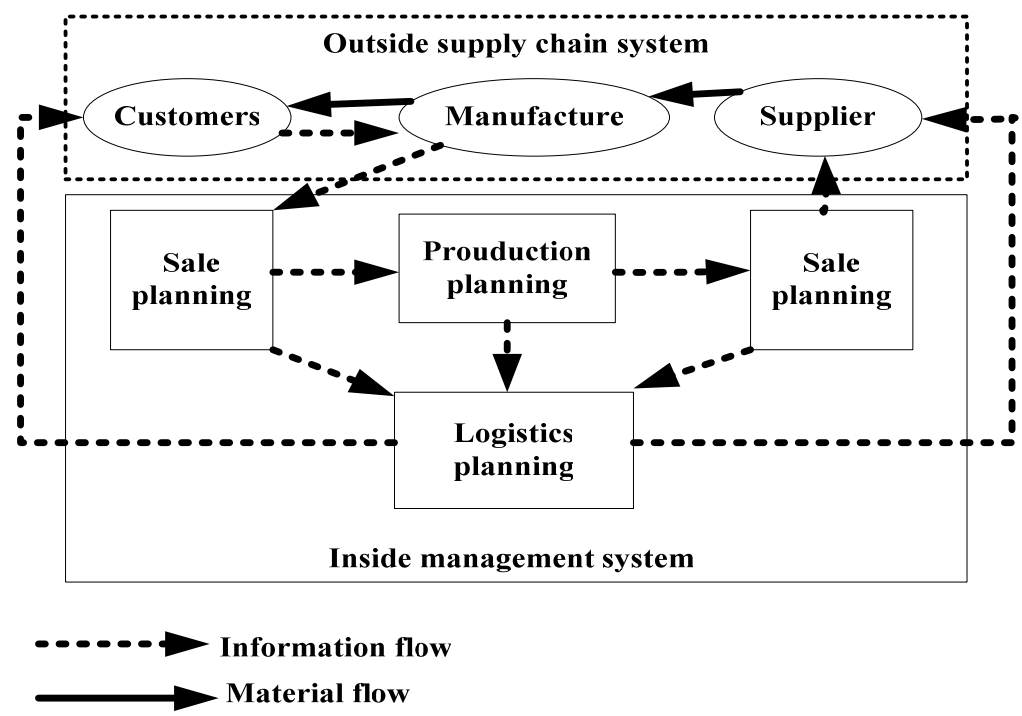

Figure 2. An optimized supply chain system

As Figure 2 suggests, this optimized supply chain planning system includes two parts: inside management system and outside supply chain system. In inside firm management system, sale, production, purchase and logistics planning are made based on market information. Market information (such as demand quantity, time, location, etc.)Gathered from customers, decides sale plans while sale plans exert influence on production plans which forms purchase plans. In this information flow process, logistics planning is integrated with sale, production and purchase planning. In the outside supply chain system, information flow starts from customer to manufacture and then to supplier, while logistics flow starts from supplier to manufacturer and then to customer. The combination of the inside management system and the outside supply chain system is finished by market information, purchasing information and logistics information.

\section{Optimized Planning Model}

\subsection{Conceptual Framework}

The integrated supply chain is the final stage in supply chain evolution and has recently been termed the "seamless supply chain". Integration is no longer constrained by organizational boundaries, and extends to both suppliers and customers. Supply chain models involve making tradeoffs between more than one business processes within the supply chain. Only the models that attempt to integrate different functions of the supply chain are regarded as supply chain models. The types of integrated supply chain models are shown in Figure 33.

The problems of conflicting goals within supply chain management process often arise in manufacturing firms', such as, the conflict between cost reduction and customers' service level Hence, supply chain management need to balance these goals and work out a feasible way to integrate purchase, sale, production and logistics into a supply chain planning 
model. A supply chain planning model which integrates purchase, sale, production and logistics is also proposed in this paper (shown in Figure 4).

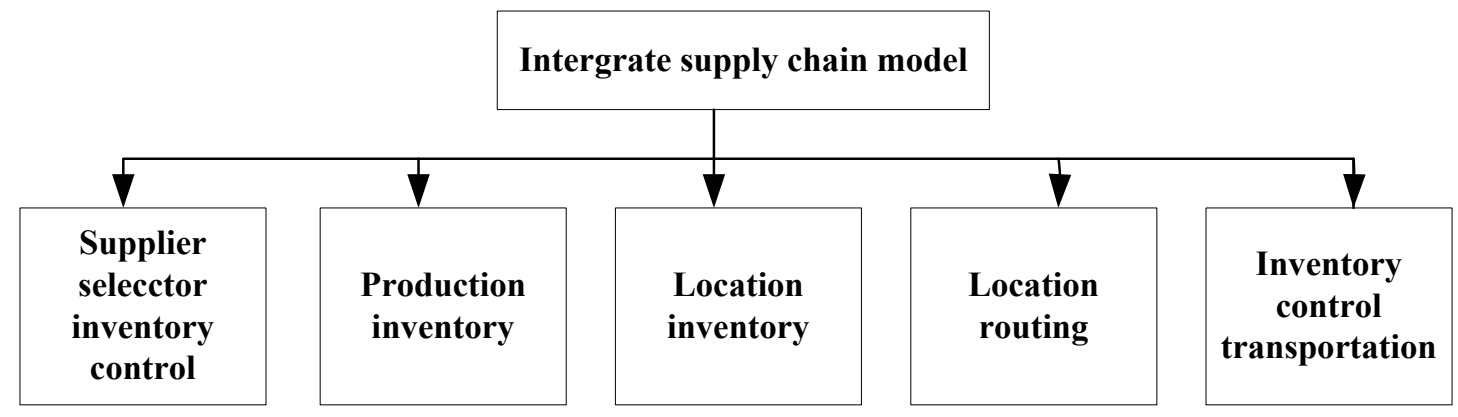

Figure 3. Types of integrated supply chain models

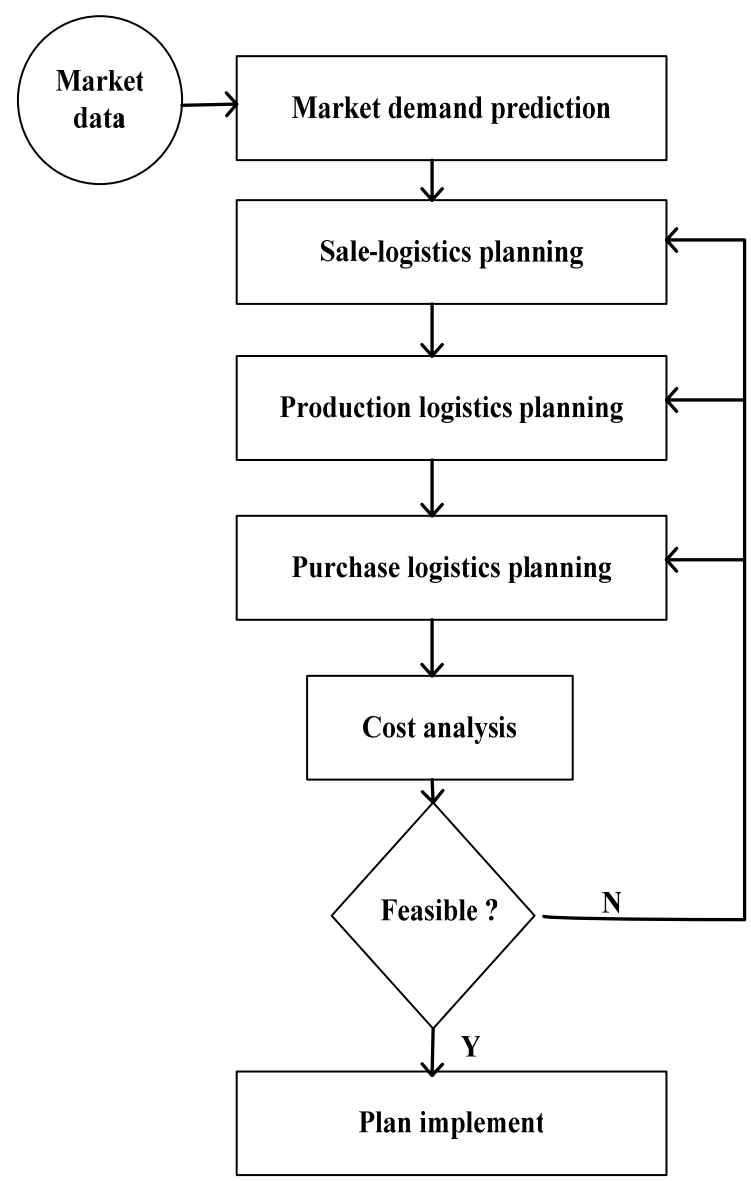

Figure 4. The integrated supply chain planning model

The proposed model consists of five main components:

1) Market demand prediction component. In this component, market data from customers, such as quantity, location, demand time and price, are applied to forecast market demand, and provide market demand information for making sale-logistics planning.

2) Sale-logistics planning component. Given the market demand information, the sale plans can be determined and the associated logistics plans should be determined simultaneously. The integration of sale and logistics planning can satisfy customers' demand well and reduce the costs of sale.

3) Production-logisticsplanning component. Theoretically production plans are made based on sale plans and production capability. However work-in-process inventory can influence production costs. Hence, the material inventory carrying costs must be considered in order to reduce order lead time and production costs, and production decisions need to take logistics plans into account. The integration of production and logistics planning can reduce the costs of production effectively. 
4) Purchase-logistics planning component. When production decisions are made, the associated purchase plans should be made simultaneously. However, purchase quantity and time exert influence on raw material inventory and transportation cost to a great extent, and the combination of purchase and logistics can reduce raw material inventory and transportation costs greatly.

5) Cost analysis component. This component is applied to evaluate the planning effects according to the comparing result of the total planning cost and the anticipated cost; the latter is determined by managers in advance based on their knowledge and experience. If the comparing result implies that the planning cost is less than the anticipated cost, then the planning is feasible, or else the planning needs to be modified.

In this integrated supply chain planning process, the sale-logistics planning sub-model, the production-logistics sub-model and purchase-logistics sub-model, are usually sequential, i.e., in turn, the sale-logistics, the production-logistics and purchase-logistics, and this sequence of steps is so called three-stage planning model.

In the continuing planning process, one of the tasks is to update these market data in time to make sure that the database for planning is complete and accurate, and then make sure that the planning methods are suitable for the type of supply chain.

\subsection{Planning model}

The planning process demonstrated within Figure 4 integrates the market demand prediction model, three-stage planning model and cost analysis model, which is presented as following:

1) Market demand prediction model

$D=f(Q, T, L)$

Hereby

D Market demand

Q Demand quantity

$\mathrm{T} \quad$ Demand time

L Demand location

In this presentation, market demand is the function of demand quantity, time and location derived from customers. Market demand is always changing. Therefore, the accurate, complete and timely market demand information is necessary to finish supply chain planning well.

2) Three-stage planning model

Over the past decade, the traditional purchasing and logistics functions have evolved into a broader strategic approach in terms of materials and distribution management known as supply chain management Manufacturers now have realized to use the concept of supply chain management to improve efficiency across the value chain, and logistics is the very important factor in decision- made process of sale, production and purchase. The relationship among sale, production, purchase and logistics is shown as following:

$$
\begin{aligned}
& S=f(D, L) \\
& P=f(S, L) \\
& P_{u r}=f(P, L)
\end{aligned}
$$

Hereby

$$
\begin{array}{ll}
\text { S } & \text { Sale planning } \\
\text { L } & \text { Logistics planning } \\
\mathrm{P} & \text { Production planning } \\
\mathrm{P}_{\mathrm{ur}} & \text { Purchase planning }
\end{array}
$$

In these planning models, every model (sale planning model, production planning model and purchase planning model) involves integrating with logistics planning separately. The influence of logistics planning on the total cost of supply chain of firm is reflected here. Logistics decisions exist in the total process of firm management. For example, sale process should consider the distribution network, transportation network and modes, and production and purchase process should consider ordering cost, raw material inventory and transportation cost, etc. The integration of logistics and sale, production and purchase planning completes the supply chain planning and suggests the lower cost of supply chain management in a manufacturing firm.

\section{3) Cost analysis model}

It is necessary to evaluate the total cost of supply chain when plans are made, which is called as planning cost. The 
calculation model of planning cost is shown at Equation (5). If the planning cost is very high, the planning must be modified. The planning model uses a classification evaluation model to determine the feasibility of planning by analyzing the comparing result of the planning cost and anticipated cost. The comparing model of cost and the evaluation model of planning feasibility refer to the Equation (6) and (7).

$$
\begin{aligned}
C_{s p} & =\sum_{i=1}^{m} C_{l p r}^{i}+\sum_{i=1}^{m} C_{l p u}^{i}+\sum_{i=1}^{m} C_{l s a}^{i} \\
\Delta c & =C_{s p}-C_{a}
\end{aligned}
$$

Hereby

$$
\begin{aligned}
& C_{a} \quad \text { Anticipated supply chain cost } \\
& C_{s p} \quad \text { Planning supply chain cost } \\
& C_{l p r}^{i} \quad \text { Production-logistics planning cost in market i } \\
& C_{l p u}^{i} \quad \text { Purchase-logistics planning cost in market i } \\
& C_{l s a}^{i} \quad \text { Sale-logistics planning cost in market i } \\
& \Delta c \quad \text { The error of anticipated cost and planning when } \\
& \begin{cases}\Delta c \text { f } 0 & \text { unfeasible } \\
\Delta c \leq 0 & \text { feasible }\end{cases}
\end{aligned}
$$$$
i=1,2,3 \mathrm{~L}, m \text { ( } \mathrm{m} \text { the number of markets) }
$$

Firm manager adjusts this supply chain planning according to the analysis of Equation.

\section{Conclusion}

The optimized planning model is finally possible owing to advances in its information technology. The three-stage integrated supply chain planning model proposed in this paper will help manufacturing companies to understand the complex planning process of supply chain and analyze the main factors of cost- push in firm operations. The implementation of logistics as managerial concept and practices in manufacturing companies is the most important indicator for the development of logistics in the economy as whole. In the three-stage planning model, logistics planning plays an important role in reducing the cost of supply chain. The continuing process of three-stage planning ensures that the supply chain plans will respond to the market demands that are constantly changing, and the level of effort involved in the planning process will depend on the size of customers' market and the complexity of its problems.

\section{References}

Andrew P., Robert M.. (2004). The evolution towards an integrated steel supply chain: A case study from the UK. Int. J. Production Economics 89, 207-216

Beamon and B. M.. (1998). Supply chain design and analysis: models and methods. International Journal of Production Economics, 55, 281-294

Hokey Min and Gengui Zhou. (2002). Supply chain modeling: past, present and future. Computers \&Industrial Engineering, 43, 23 1-249.

Laoucine Kerbachea, James MacGregor Smith. (2004). Queueing networks and the topological design ofsupply chain systems. International Journal of Production Economics 91, 251-272

Marco Perona. (2001). The integrated management of logistic chains in the white goods industry-- A field research in Italy. Int. J Production Economics 69,227-238

Pavel Dimitrov. (2005). Logistics in Bulgarian manufacturing companies. Int. J. Production Economics 93-94,207-215

Scott J. Mason, P. Mauricio Ribera and Jennifer AFarris. (2003). Integrating the warehousing and transportation functions ofthe supply chain. Transportation Research Part E 39, 141-159.

Young Hae Lee and Sook Han Kim. (2002). Production-distribution planning in supply chain considering capacity constraints. Computers \& Industrial Engineering 43, 169-190 


\title{
Audit Expectation Gap in Auditor
}

\section{Responsibilities: Comparison between India and Iran}

\author{
G.H. Mahadevaswamy, PhD in Accountancy \\ Assistant Professor, Maharani's Arts and Commerce College for Women, Mysore, India \\ E-mail: mahadevaswamygh@yahoo.com
}

\author{
Mahdi Salehi, $\mathrm{PhD}$ in Accountancy (Corresponding author) \\ Assistant Professor, Accounting and Management Department, Zanjan University, Iran. Postal Address: D.N 1, Nagilo \\ Alley, Hidaj City, Zanjan Province, Iran \\ E- mail: Mahdi_salehi54@yahoo.com
}

\begin{abstract}
Purpose - This study aims to investigate the existence of an audit expectation gap and to find similarities and differences in responsibilities of audit expectation gap among auditor and investor between two countries, and to measure the magnitude of auditor responsibility.

Methodology - The data for the present study has been collected from auditors and investors being sample respondents of the study. To collect information from respondents, the seven-section questionnaire was prepared and distributed to sample respondents. Sample respondents were chosen from different parts of India and Iran.

Findings - The results found that wide audit expectation gaps in both the countries in the area of auditors' responsibilities exist. There were no much differences between the opinion of auditors as well as investors in both the countries.
\end{abstract}

Limitations - This study covers only the responsibility area it has not covered any other areas like, role, effectiveness, independence etc, and also only auditor and investors were approached to extract the data.

Keywords: Audit, Auditor, Responsibilities, Audit Expectation Gap

\section{Introduction}

The history of auditing is to a large extent determined by the history of accounting. Ancient cultures of Mesopotamia, Egypt, Greece and Italy show evidences of highly developed economic systems. But the economic fact during these periods was limited to the recording of single transactions. Bookkeeping, as a support mechanism for the determination of profit or wealth or as a decision support system for achieving profit maximization was basically unknown.

The attitude of profit maximization emerged only at the end of the middle ages, with the emergence of large merchant houses in Italy. Trading was no longer the domain of the individual commercial travelers. It was now coordinated centrally at the luxurious desks of the large merchant houses in Venice, Florence or Pisa making communication vital. It was also found that entering merely one aspect of the transaction paved the way for heavy embezzlement of cash, which was found difficult to trace in the ordinary course of business. Therefore, the system of double entry bookkeeping was first described by an Italian monk Luca Pacioli in his book Summa de Arithmetica, Geometria, Proportioni et Proportionalita, dated 20 November 1494.

However, the introduction of double-entry bookkeeping was not enough for the emergence of today's auditors. The onset of industrial revolution in Great Britain around 1780 led to the emergence of large industrial companies with complex bureaucratic structures. Gradually, the need to look for external funds in order to finance further expansion on one hand and the divorce between ownership and management on the other gained importance. The result has been the growth in sophisticated securities markets and credit-granting institutions serving the financial needs of large national and increasingly international corporations.

The flow of investor funds to the corporations and the whole process of allocation of financial resources through the securities markets became dependent to a very large extent on reports made by management. At the present juncture, one of the most important characteristics of these corporations is the fact that their ownership is almost totally divorced from their management. Management has control over the accounting systems of these enterprises and is not only 
responsible for the financial reports to investors, but also has the authority to determine the precise nature of the representations that go into the reports.

To increase the confidence of investors and creditors in financial statements, they are provided with an independent and expert opinion on the fairness of the reports. An auditor provides this opinion. Initially, company audits had to be performed by one or more stockholders, who were designated by the other stockholders as their representative. The auditing profession quickly emerged to meet market place needs and legislation was soon required to permit persons other than stockholders to perform the audits, giving rise to the formation of auditing firms. These developments resulted in demand for the services of specialists in bookkeeping and in auditing. Thus the institutionalization of audit as a profession was then merely a matter of time.

\section{Concept of audit}

Etymologically, the word 'audit' is derived from the Latin word, 'audire,' which means 'to here' (Chambers English Dictionary: 1988, 89). Thus in the beginning, the word 'audit' was meant 'to hear' and auditor literally meant a "hearer". The hearing function by the auditor was then aimed at declaring that the accounts kept by the management and the financial statements prepared by them were 'true and correct'. And his function was to give assurance against fraud and intentional mismanagement. Gradually, this hearing function of the auditor was transformed into verifying function. Hence the principal purpose of independent auditing now is to form an opinion on the accuracy, reliability and fairness of representations in the financial statements of enterprises, and to make this information available to external users. Accordingly, the main object of audit also transformed thus making the auditor declare that the accounts prepared by the companies as revealed by their financial statements were "true and fair."

Littleton (1933:260) was of the view that early auditing was designed to verify the honesty of persons charged with fiscal, rather than managerial responsibilities. In the nineteenth century, the role of auditors have been directly linked to management's stewardship function (Flint: 1971) with stewardship being regarded in the narrow sense of honesty and integrity. But the verifying function was on sampling basis because of the burgeoning volume of business activity.

The International Auditing Practices Committee (IAPC: 1980) defines auditing as “... the independent examination of financial information of an entity, whether profit oriented or not, irrespective of its size or legal form, when such an examination is conducted with a view to expressing an opinion thereon."

According to Chow (1982), controlling the conflict of interests among firm managers, shareholders and bondholders is a major reason for engaging auditors.

\subsection{Auditor responsibilities}

The primary responsibility of an auditor is to verify whether the financial statements exhibit a true and fair view of state of affair of the business and their secondary responsibility is the prevention and detection of errors and frauds. The primary responsibility for the prevention and detection of fraud and error rests with both those charged with governance and the management of an entity in spite of the fact that financial statements are the representations of the management. While discharging their duties in accomplishing these two audit objectives, there are also other responsibilities that emerge for the auditors to perform. There seems to be a negative relationship between responsibilities of auditors and audit expectation gap in the sense that higher the responsibilities assumed by the auditors, lower the audit expectation gap. Further, the empirical evidences on audit expectation gap have revealed that one of the major causes for audit expectation gap in many countries is that there are differences in perceptions about the role and responsibilities of auditors with regard to accounting frauds.

\section{Audit expectation gap}

There are users who expect auditors to perform some of the audit procedures while performing the attest function like penetrating into company affairs, engaging in management surveillance and detecting illegal acts and/or fraud on the part of management. It is these high expectations on the part of users of financial statements that create a gap between auditors' and users' expectations of the audit function. In addition, the users also place the responsibility for narrowing the gap on auditors and others involved in preparing and presenting financial statements.

Some of the relevant definitions on audit expectation gap are presented below.

Liggio (1974) defined it as the difference between the levels of expected performance as envisioned by the independence accountant and by the user of financial statements.

The Cohen Commission (1978) on auditors' responsibility extended this definition by considering whether a gap may exist between what the public expects or needs and what auditors can and should reasonably expect to accomplish.

According to Guy and Sullivan (1988:36)], there is a difference between what the public and financial statement users believe accountants and auditors are responsible for and what the accountants and auditors themselves believe they are responsible for.

Godsell (1992) described the expectation gap as "which is said to exist, when auditors and the public hold different 
beliefs about the auditors' duties and responsibilities and the messages conveyed by audit reports."

Jennings et al., (1993), in their study on the use of audit decision aids to improve auditor adherence to a 'standard', are of the opinion that the audit expectations gap is the difference between what the public expects from the auditing profession and what the profession actually provides.

Monroe and Woodliff (1993:62) defined audit expectation gap as "the difference in beliefs between auditors and public about the duties and responsibilities assumed by auditors and the messages conveyed by audit reports."

\section{Objectives and methodology}

The following are the objectives of the study.

To find similarities in responsibilities of audit expectation gap among auditor and investor between two countries;

To find the difference in responsibilities of audit expectation gap among auditor and investor between two countries; and

To measure the magnitude of auditor responsibility.

The data for the present study has been collected from both primary and secondary sources. Primary data on corporate audit expectation gap was collected from auditors and investors being sample respondents of the study. To collect information from respondents, the seven-section questionnaire was prepared and distributed to sample respondents. Sample respondents were chosen from different parts of India and Iran. In India the total number of sample respondents chosen for the study was 950 consisting of 300 auditors and 650 investors. The selection of 300 auditors was based on every fifteenth member from the alphabetically arranged names of chartered accountants enrolled in the southern Indian Regional Committee (SIRC). The selection of the investors numbering 650 was made by personally contacting them on their arrival to do the business in Bangalore Stock Exchange (BSE) and identifying them by oral questions on whether they invested frequently or regularly through initial public offerings. Such visits to BSE took place between February 2006 and June 2006. Out of 950 questionnaires administered to both the groups of respondents, through mail and personal contact, only 225 completed questionnaires were returned with an overall responses rate of 23.68 percent. The number of responses from the auditor group stood at 90 forming 30.00 percent response rate and 135 from investor group forming the response rate of 20.77 percent. Thus auditors consisted of 40.00 per cent of the respondents as against 60.00 per cent of the investors.

In Iran the sample respondents were chosen from Tehran city the capital of Iran, as this city has a larger number of investors in equity capital of Iranian corporate sector and traders in stock exchanges of the country on one hand and a large number of auditors working as professionals in the city. The total number of sample respondents chosen for the study was 1200 consisting of 600 auditors, 600 investors The selection of 600 auditors was based on every fourth member from the alphabetically arranged names of chartered accountants enrolled in the Iranian audit organization and the selection of the 600 investors, identifying the investors by oral questions on whether they invested frequently or regularly through initial public offerings. Such visits to TES took place between March 2006 and June 2006. Out of 1200 questionnaires administered to both the groups of respondents, through personal contact, only 441 completed questionnaires were returned with an overall responses rate of 36.75 per cent. The number of responses from the auditor group stood at 227 forming 51.47 per cent response rate, 214 from investor group forming the response rate of 48.53 per cent.

The questionnaire was designed to ensure that the precise data required would be collected from respondents to achieve the objectives of the present study. The questionnaire consisted of two sections. The first section contained data relating to demographic variables of the sample respondents and the second section contained the perceptions of sample respondents on the actual level of auditor responsibilities and the expected level of auditor responsibilities. The respondents were required to tick their perceptional levels on five-point Likert's scale with five as strongly agree, four as agree, three as moderately agree, two as disagree and one as strongly disagree on both the actual level and the expected level. The results of audit expectation gap taking the actual and expected level of perceptions between auditors and investors were analyzed by using Mann-Whitney test were used to find significant level.

\section{Review of literature}

The responsibility of auditors is 'an amalgamation of public policy consideration' (Chung, 1995) as a result of the deregulation movement demands for the profession to protect the public interest has grown rapidly. In addition, business operations have become much more complex owing to global competition and large-scale industrial restructuring. The investing public has increasingly relied on auditors to monitor and assure the reliability of financial reporting. The 'expectation gap' emerged as the profession has failed to react (Gwilliam, 1992; Francis, 1994). As posited by Power (1998), the 'expectation gap' is derived for a loose coupling between the idealization of auditing and the actual audit practices. However, the 'expectation gap' in relation to auditor's responsibility is mainly a time lag effect.

The responsibility debate has positively affected the development of auditing standards and practices in the developed 
world. By identifying society's need over time, the debate has enabled the profession to realize 'a duty to continuously asses auditing standards in light of the expectations concerns and criticisms of others and develop new standards to bring the auditors' responsibility and performance closer to public expectation' (Porter, 1996). In the USA, the AICPA, though reluctant to extend auditor's responsibility for fraud detection, has made continuing efforts to revise auditing standards in the last two decades to accommodate changing public expectations (Dye, 1993; Kinney and Nelson, 1996; Barnett et al., 1998; Reinstein and Coursen, 1999). Similar efforts have been made in the UK and other countries (Pong and Whittington, 1994; Porter, 1996; Innes et al., 1997).

The responsibilities of auditors and the expectation gap always go together. The expectation gap is due to over-expectations of the auditing function. The profession has challenged this viewpoint on the grounds that audits are designed to assure the conformity of financial statements with GAAP and fraud prevention and detection should be the responsibility of management who bear a legal obligation for truthful financial reporting [Nair and Rittenberg, (1987); Goldberg, (1988); CICA, (1988); Martens and McEnore, (1991); Chapman, (1992).

Auditors have long been asked to detect errors or frauds (Brief, 1975). The history of the development of the auditor's responsibilities concerning the detecting and reporting of fraud and error have shown their construction to be dependent on the reactions and lobbying efforts of the audit profession (Humphrey, 1991). In similar manner, Humphery et al., (19930 noted that auditor's responsibilities concerning fraud have been a recurrent problem as it is clear that public's expectations on this issue is not satisfied.

Guy and Sullivan (1988) made an overview on issue of the nine new standards of Auditing Standards Board. An issue was raised in America about the responsibilities of auditors for uncovering fraud and illegal acts and whether they had taken enough steps for evaluating going concern, by members of congress, financial writers, judges and members of leading accounting firms. In 1987, the ASB issued for comment 10 exposure drafts of professional standards. After reviewing nearly 1200 comment letters, the ASB approved issuance of nine new statements on auditing standards. The expectations gap statements on auditing standards are grouped under four statements, such as (i) Detection of fraud and illegal acts, (ii) More effective audits, (iii) Improved external communications and (iv) Improved internal communications. The authors conclude that if the existing audit expectation gap is too narrow the new standards should bring the auditor's responsibility and performance closer to public expectations.

Auditors have an existing duty to detect material theft of corporate assets by non-managerial employees, which escapes the internal control net, but providing the report such theft to the company's management that is generally where their responsibility ends (Porter, 1990).

The profession's continuing attempts to avoid fraud detection responsibility were motivated to protect its self-interest in order to deflect public pressure and reduce auditor's legal liability (O'Sullivan, 1993; Tidewell and Abrams, 1996).

Another remarkable study on auditor's responsibilities involving various dimensions of the attest function was made by McEnroe et al. (2001), who found that investors had higher expectations for various facts and assurances of the audit than did auditors in the following areas: disclosure, internal control, fraud, and illegal operations.

The literature survey also evinces the fact that any discussion about responsibility of auditor's centers around his responsibilities towards detection of fraud in spite of the fact it has been relegated the second place. In addition, SAS 82 also specifies clearly that it's not the responsibility of auditor to detect and prevent error and fraud, but the users of financial statements still perceive the major responsibility as only the detection of fraud. There is also a wealth of information supporting this viewpoint as any amendment to the existing auditing standards or the inclusion of any new provisions center around the prevention and detection of fraud as the responsibility of auditors.

The empirical study by Humphrey (1991) with reference to England was an extension of the above studies and the main conclusions included expectations gap in auditors' role in fraud detection; the extent of auditors' responsibility to this party; the nature of balance sheet valuation; threats to auditors' independence; and auditors' ability to cope up with risk and uncertainty. He also adds "If any topic can be classified as going to the heart of the audit expectations debate, it is the issue of auditor independence."

Humphrey et al. (1992) identified auditor independence as a key element of the audit expectations gap. The authors identified the main elements of the expectations gap: independence; whom auditors were responsible to; practical abilities; the commercial nature of auditing; and responsibility for detecting fraud.

Monroe and Woodliff (1993) examined the effect of education on students' perceptions about the responsibilities of auditors. It was found that there were no differences between auditing and marketing students at the beginning of the semester about auditors' responsibilities. They believed that auditors had more responsibility and management had less responsibility for the prevention and detection of fraud, and safeguarding assets. But, at the end of semester the auditing students believed that auditors assume a much lower level of responsibility, but there was little change in the marketing students' beliefs. 
Monroe et al. (1994) conducted a classical study on the audit expectation gap taking the case study of Australia. The results of the study suggested that there were significant differences between old reports and new reports, which were significant to auditors. The major areas of differences in perceptions studied in this research included responsibility factor, prospects factor and reliability factor. It was found that (i) the modified wording in the new reports had a significant impact on beliefs about the nature of an audit and auditors and management; (ii) the modified wording eliminated some of the differences but also created some new differences between auditors and various user groups; and (iii) the differences in perceptions were much smaller for sophisticated users than naive users.

The research also suggested that educating the users was one of the approaches to raise the sophistication level of users to reduce the differences in perceptions. Further, the research indicated that wording changes did change beliefs about the messages communicated through audit reports. In other words, audit report wording should become more specific, if the gap was to be decreased.

Best et al. (2001) examined the evidence in support of the long form audit report for audit expectation gap in Singapore. The study extended research on the audit expectation gap in Singapore regarding (i) responsibility, (ii) reliability, and (iii) decision usefulness statements.

The study provided some insight into the nature and extent of the audit expectation gap in Singapore. Evidence was found confirming the existence of a moderate gap. Out of sixteen areas, a significant area of gap concerned the auditors responsible only for detecting all frauds and the auditors not responsible for preventing them. In addition, there was evidence that investors believed that auditors had some responsibility for ensuring an entity of sound internal controls.

Lin and Chen (2004) found that the beneficiaries believed the auditors were responsible for the truthfulness and reliability of financial statements, detecting and reporting errors and frauds, liable for fraudulent or misleading information contained in prospectus disclosure and disclose in the audit report the uncovered frauds, inefficiency or irregularities more than management.

Fadzly et al. (2004) identified the responsibilities of auditors as one of the factor in the areas, which could cause gap between auditors and investors. In his study, he formulated eight statements on responsibility such as the issues of fraud detection and prevention, accounts and financial statements preparation, auditor's objectivity, internal control, scope of auditor's legal responsibility and auditor's culpability in fraud-related business failure. The study proved that the users believed that auditors were responsible for all the above said statements. The largest extent of difference was found in the responsibility to prepare financial statements. Brokers and investors expected auditors to prepare financial statement instead of management (directors).

The study by Siddiqui and Nasreen (2004) focused on identifying the existence of an audit expectations gap in Bangladesh. Students of accounting were chosen as a knowledgeable representative group of the society. The questionnaire consisted of statements regarding three aspects, viz., audit responsibility, audit reliability and decision usefulness of audited financial statements. The mean responses of the two groups were then compared. Audit expectations gap was found in all the three aspects: perceptual differences being widest in the area of auditor responsibility. The findings of this study suggests the existence of a much wider expectation gap between auditors and other societal groups in Bangladesh, as these clusters possess lesser knowledge in auditing than the students of accounting.

The study made by Dixon et al. (2006) in Egypt focused on seven statements of responsibilities like issue of fraud detection and prevention, internal control, scope of auditors legal responsibility, financial statement preparation, auditors objectivity and audit procedures. The auditors as well as the users were in agreement and had strong beliefs that management must have responsibility for producing financial statements. And the users believed that auditors were responsible in the remaining areas. It showed the auditors were responsible in most of the areas.

\section{Survey results: responsibility of external auditors}

The perceptional differences between auditors and investors with regard to the responsibilities of external auditors have been analyzed under (a) Auditors' Responsibility in Measuring Financial Performance; (b) Auditor responsibility in controlling financial aspect; (c) auditors responsibility in financial misstatement; and (d) auditors responsibility on professional discipline.

\subsection{Auditors' Responsibility in Measuring Financial Performance}

Insert table No.1

Table 1 highlights the results of perceptions of the two countries' respondents towards responsibilities of external auditors of India and Iran in measuring the financial performance of client companies. There were 225 respondents of India and 441 respondents of Iran were chosen. This is based on the three variables identified and presented in the table. Regarding responsibilities in producing financial statements the both the respondents of India assigned lower actual mean value of 1.17 by auditors and 1.42 by investors. But Iranian respondents were assigned at moderate level at actual 
mean value of 2.40 by auditors and 2.53 by investors. Here the gap was low in both the cases which stood at 0.25 and 0.13 respectively. In expected level the auditors assigned same values as assigned at the actual level of both countries. But investors expected more from auditors in both the countries by assigning 3.87 by Indians and 3.86 by Iranians with a gap of 2.60 and 1.54 respectively. In conducting $100 \%$ examination in audit procedure Indian investors had a wide gap of 2.30 and on the contrary Iranian investors had a gap of 0.91 . But at expected level there was a gap of 2.03 between auditors and investors of India for the same factor. Auditors' responsibility in giving assurance that the company is in good financial health there is moderate gap between Indian auditors and Iranian auditors which stood at 0.61 and 0.73 at the actual and expected mean level. On the contrary, the Indian investors had a gap of 1.76 and the Iranian investors had a gap of 1.20 for the responsibility of auditors in giving assurance that the company is in good financial health. At the grand mean level Indian investors had a highest gap of 2.16 and the Iranian investors had a gap of 1.18 insisting more responsibility on auditors.

The test showed that there were significant differences between the perceptions of the auditors and investors for both actual and expected level on giving assurance that company is in good financial health in the both countries, both the level of producing financial statement of India and expected level of Iran and both the level of conducting cent per cent examination in audit procedure in Iran and expected level of India, $(p<0.05)$. But there were no significant in perceptional differences existed between these two groups of respondents on the actual level of producing financial statement in Iran and conducting cent per cent examination in audit procedure in India ( $p>0.05)$. This result holds good for both assumed and un-assumed equality of variances.

Insert Table No.2

Auditors' responsibility in controlling financial aspect was depicted in the Table 2 with statistical values of three variables. In the variable maintaining accounting records by the management Indian auditors had assigned an actual mean value of 3.72 whereas, Indian investors assigned an actual mean value of 3.27 . Similarity will be found in case of Iranian study where the auditors assigned an actual mean value of 4.44 and the investors assigned an actual mean value of 2.70. In the responsibility of safeguarding the assets of the company Indian auditors assigned an actual mean value of 3.39 and for which the Indian investors assigned an actual mean value of 2.85 which indicates that the Indian auditors are believed that they are discharging their responsibility in maintaining the assets of the company sufficiently. But the Indian investors had an expectation gap of 1.65 in that aspect. Same expectation was there in case of Iranian investors also who had an expectation gap of 0.89 . In case of responsibilities for prevention of fraud and errors auditors of both the countries believed that the auditor had assumed significantly more responsibility and assigned lesser mean value at actual level than the mean value at expected level. On the contrary investors of both India and Iran had an expectation gap of 1.85 and1.32 respectively. The Indian investors had a gap of 1.54 and Iranian investors had a gap of 1.07 at grand mean level stating that the auditors should assume still more responsibilities in controlling financial aspects. On the contrary the professionals of India and Iran had a gap of 0.37 and 0.40 respectively stating that they are performing their responsibility in financial aspects sufficiently. The responsibility of auditors in preventing frauds and errors had a highest gap of 2.42 at the expected level between auditors and investors of Iran among all the variables. . The grand mean level of Indian investors were assigned 2.88 at actual grand mean level and 4.42 at expected grand mean level with an expectation gap of 2.14 , which shows investors are expecting high responsibility in financial aspects of the company from the auditors .

In significant levels showed that there were significant differences between the perceptions auditors and investors among all the variables $(<0.05)$. but there were no significant difference between auditor and investor in the expected level of maintaining accounting records by the management in both the countries $(>0.05)$.

Insert Table No.3

Table 3 presents the responsibility of auditors in financial misstatement with the statistical results of four variables. The sole statutory responsibility of auditor is to express an opinion on financial statements are fairly presented in accordance with an appropriate disclosed basis of accounting. The investors of both India and Iran had the same opinion. The Indian investors assigned an actual mean value of 2.82 and an expected mean value of 4.44 with an expectation gap of1.62. The Iranian investors assigned an actual mean value of 2.56 and an expected mean value of 3.59 with an expectation gap of 1.03 . In the responsibility of detecting illegal activities by the management auditors of both countries had lesser gap than the investors since the auditor is not a legal expert. On the contrary the investors of both the countries expected more than the actual position that the auditor should assume the responsibility of detecting illegal activities with an expectation gap of 2.38 by Indian investors and 1.29 by Iranian investors. In the responsibility of Reporting all detected frauds and thefts to the relevant authority auditors of both the countries had the same opinion who assigned same mean values at actual level as they are the first line of defense along with the directors, against management fraud and they don't had much expectation at expected level. Whereas, the Indian investors assigned actual mean value of 2.51 and an expected mean value of 4.47 with an expectation gap of 1.96. The Iranian investors assigned actual mean value of 2.33 and an expected mean value of 3.68 with an expectation gap of 1.35 . In the responsibility of 
detecting any deliberate distortion of financial information auditors of Iran assigned a lower mean value of 1.61 at actual level and 1.91 at expected level and on the contrary auditors of India assigned 3.49 at actual level and 4.43 at expected level. But the investors of both the countries had assigned a moderate value at actual level and at expected level believing that it is the responsibility of auditors in detecting any deliberate distortion of financial information .

The test showed there were significant differences between the perceptions of the auditors and investors for both actual and expected level of detecting illegal acts by the management and Detecting any deliberate distortion of financial information of India and Iran, actual level of Iran and expected level of India on enforcing effectiveness of internal control on audit quality and the actual levels of India and Iran on reporting all detected frauds and thefts to the relevant authority $(\mathrm{p}<0.05)$. But no significant perceptional differences existed between these two groups of respondents on the expected level of India and the actual level of Iran on enforcing effectiveness of internal control on audit quality and the expected levels of India and Iran on reporting all detected frauds and thefts to the relevant authority $(\mathrm{p}>0.05)$.

\section{Insert Table No.4}

Table 4 highlights the perceptions of auditors and investors of India and Iran in responsibility of auditors on professional discipline. Both Indian and Iranian auditors assigned a mean value of 3.16 and 2.21 respectively at actual level and a mean value of 4.01 and 2.36 respectively at expected level with an expectation gap of 0.85 and 0.15 respectively showing perceptional difference between both the auditors. But the investors of India and Iran believed that it is the responsibility of auditors in detection of errors and frauds with a highest expectation gap of 0.79 and 1.62 respectively at expected level. In the variable of responsibility in Right procedures followed before authenticating financial statements Indian auditors had an expectation gap of 0.71 and on the contrast Iranian auditors had an expectation gap of 0.29 . Whereas the Indian investors had an expectation gap of 1.64 and the Iranian investors had an expectation gap of 1.04 on the variable of responsibility in Right procedures followed before authenticating financial statements? In the responsibility of certifying accuracy of financial reports both Indian and Iranian auditors assigned in similar manner with mean values of 3.73 and 3.17 at actual level and a mean values 3.94 and 3.29 of at expected level. On the contrary the investors of both the countries had high expectation regarding the responsibility of auditors in certifying accuracy of financial reports with an expectation gap of 1.50 and 0.99 respectively. Expectation gap at moderate level was found at grand mean level between auditors and investors of both countries.

The test showed there were significant differences between the perceptions of the auditors and investors for both actual and expected level of detection of frauds and errors, Certifying accuracy of financial reports in both the countries and both level of Iran and the actual level of India on right procedures followed before authenticating financial statements $(\mathrm{p}<0.05)$. But no significant perceptional differences existed between these two groups of respondents on the expected level of India on right procedures followed before authenticating financial statements $(\mathrm{p}>0.05)$.

\section{Conclusion}

This survey found the existence of an audit expectation gap in the responsibility of auditor as well as comparison of the data of both India and Iran. There were no much differences in the responsibility of auditor in both the countries. But in certain areas like responsibility in producing financial statements, conduct of cent per cent examination, giving assurance that company is in good financial health and detecting any deliberate distortion of financial information differences of opinion were found in actual mean level of auditors. Regarding the significance level similar results were obtained except responsibility in producing financial statements in Iran at actual level, conduct of cent per cent examination in audit producers in Indian at actual level there was no significant difference between auditor and investors perceptions. An opposite significance level can be seen in the statement of enforcing effectiveness of internal control on audit quality at expected level in India and at actual level in Iran. Right procedures followed before authenticating financial statements was assigned no significance at expected level in India. But there was a significant difference at both the level in Iran. Mainly the result showed that both the management and auditors are equally responsible in producing financial statements.

\section{References}

Barnett, A. H., Brown J.E, Fleming, R. and William J. (1998). The CPA as Fraud Buster, Journal of Accountancy, May, pp. 69-73.

Best, P.J., Buckby S., and Tan C. (2001). Evidence of the Audit Expectation Gap in Singapore, Managerial Auditing Journal, pp.134 - 44.

Brief, R. P., (1975). The Accountant's Responsibility in Historical Perspective, The Accounting Review, April, pp. 285-297.

Chapman, B., (1992). Limited Auditor's Liability: Economic Analysis And the Theory of Trot Law, Canadian Business Law journal, Vol. 20, No. 2, pp.180-214.

Chow, C.W., 919820. The Demand for External Auditing: Size, Debt and Ownership Influences, The Accounting 
Review, Vol. LVII, No.2, April, pp. 272-291.

Chung, J., (1995). Auditors' Confidence and the Audit Expectation Gap, Australian Accountants, Vol. 65, No. 5, pp. 26-30.

CICA (1988). Report of the Commission on the Study the Public's Expectation of Audits, Toronto: Canadian Institute of Chartered Accountants.

Cohen Commission (1978). Report of the Commission on Auditors' Responsibilities; Conclusions and Recommendations, New York: American Institute of Certified Public Accountants.

Dixon, R., Woodhead M., and Sohliman M. (2006). An Investigation of the Expectation Gap in Egypt, Managerial Auditing Journal, Vol. 21, No. 3, pp. 293-302.

Dye, R., (1993). Auditing Standards, Legal Liability and Auditor Wealth, Journal of Political Economy, Vol.101, No.5, pp. 887-914.

Fadzly, M.Z., and Ahmad, Z [2004]. Audit Expectation Gap: The case of Malaysia, Managerial Auditing Journal, Volume 19, No. 7, pp. 897-915.

Flint, D., (1971). The Role of the Auditor in Modern Society: An Explanatory Essay, Accounting and Business Research, Autumn, pp.133 - 51.

Francis, J., (1994). Discussion of Lawsuits Against Auditors, Journal of Accounting Research, Vol. 32, Supplement, pp. 95-102.

Godsell, D., (1992). Legal Liability and the Audit Expectation Gap, Singapore Accountant, Vol. 8, November, pp. $25-28$.

Goldberg, V. P., (1988). Accountable Accounts: is Third Party Liability Necessary, Journal of Legal Studies, Vol.17, No.2, pp.295-331.

Guy, D. M., and. Sullivan D (1988). The Expectation Gap Auditing Standards, Journal of Accountancy, April, pp. 36-44. Gwilliam, D., (1992). Auditors' Liability: the Public Policy Arguments, Professional Negligence, vol.8, No. 4, pp. 147-151.

Hudaib, M., (2002). An Empirical Investigation of Audit Perceptions Gap in Saudi Arabia,

Humphrey, C., Moizer P., and Turley, S (1991). Protecting Against Detection: The Case of Auditors and Fraud? Paper presented at the Third Interdisciplinary Perspectives on Accounting Conference, Manchester, July.

Humphrey, C., Moizer P., and Turley, S (1992). The Audit Expectation Gap in the United Kingdom, Accounting and Business Research, Winter, pp.83-84.

Humphrey, C., Turley, S., and Moizer, P (1993). Protecting Against Detection: The Case of Auditors and Fraud, Accounting, Organizations and Society, 16 (4), 313-31.

IAPC (1980). International Auditing guideline No 3, Basic Principles Governing an Audit, IFAC, September.

Innes, J., Brown T. and Hatherly D. (1997). The Expanded Audit Report- A Research Study Within the Development of SAS 600, Accounting, Auditing and Accountability Journal, Vol.10, No. 5, pp.702-717.

Jennings, M., Kneer D.C., and Reckers P.M. (1993). The Significance of Audit Decision Aids and Pre-case Jurist's Attitude on Perceptions of Audit Firm Culpability and Liability, Contemporary Accounting Research, Vol. 9 No.2, pp.489-507.

Kinney, W. R., and Nelson M.W. (1996). Outcome Information and the 'Expectation Gap': the case of loss contingencies, Journal of Accounting Research, Vol.34, No.2, pp.281-297.

Liggio, C. D., (1974). The Expectation Gap: The Accountant's Waterloo, Journal of Contemporary Business, Vol.3, No.3, pp.27-44.

Littleton, A.C., (1933). Accounting Evolution to 1900. New York: American Institute Publishing Co.

Lin, J. Z., and Chen F. (2004). An Empirical Study of Audit 'Expectation Gap' in The People's Republic of China, International Journal of Auditing, Vol. 8, pp. 93-115.

McEnroe, J. E., and. Martens S.C (1991). Inter Professional Struggles Over Definition: Lawyers, Accounts and Illegal Acts, Critical Perspectives on Accounting, Vol.2, No.4, pp.375-384.

McEnroe, J. E., and. Martens S.C (2001). Auditors' and Investors' Perceptions of the Expectation Gap, Accounting Horizons, Vol.15, No.4, December, pp. 345-358.

Monroe, G.S., and Woodliff D.R (1993). The Effect of Education on the Audit Expectation Gap, Accounting and 
Finance, Vol.33, No.1, pp. 61-78.

Monroe, G.S., and Woodliff D.R (1994). An Empirical Investigation of the Audit Expectation Gap: Australian Evidence, Accounting and Finance, May, pp. 47-74.

Nair, R. D., and Rittenberg L.E (1987). Message Perceived from Audit, Review and Compilation Reports: Extension to More Diverse Groups, Auditing: A Journal of Practice \& Theory, fall, Vol. 7, No. 1, pp. 15-38.

Pong, C., and Whittington G. (1994). The Working of Auditing Practice Committee- Three Case Studies, Accounting and Business Research, Vol. 24, No. 94, pp. 157-175.

Porter, B. A., (1996). A Research Study on Financial Reporting and Auditing: Bridging the Expectation Gap, Accounting Horizons, Vol. 10, No. 1, pp. 130-135.

Porter, B.A., (1990). The Audit Expectation-Performance Gap and the Role of External Auditors in Society, Unpublished Ph.D. Dissertation, New Zealand: Massey University.

Power, M., (1998). Auditor Liability in Context, Accounting, Organizations and Society, Vol.23, No.1, pp. 77-79.

Reinstein, A., and Coursen G.A. (1999). Considering the Risk of Fraud: Understanding the Auditors' New Requirements, The National public Accountant, March/April, pp.34-38.

Robinson, J., and Lyttle J. (1991). The Audit Expectation Gap in Ireland, A Report Commissioned by the Auditing Practices Review Committee, Ireland: The Institute of Chartered Accountants in Ireland.

Siddiqui, J., and Nasreen T. (2004). Audit Expectations Gap in Bangladesh: Perceptual Differences Between Accounting Professionals and Students, June, Available at: http://sssm.com/abstract=557542.

Sullivan, N., (1993). Auditors' Liability: Its Role in the Corporate Governance Debate, Accounting and Business Research, Vol. 23, No. 91A, pp.412-420.

Tidewell, G.L., and Abrams A.L. (1996). Auditor's Liability and Responsibility in Finding Fraud, Business and Economic Review, Vol. 42, No. 2, pp.28-32. Available at: www.ex.ac.uk/rbp/research/discussionpapersaccFin/AccFin2002 
Table 1. Auditors' responsibility in measuring financial performance: auditors vs. investors

\begin{tabular}{|c|c|c|c|c|c|c|c|}
\hline $\begin{array}{l}\dot{\mathbf{Z}} \\
\dot{\boldsymbol{H}}\end{array}$ & Level of Auditors' Responsibility in & $\begin{array}{l}\stackrel{\lambda}{E} \\
\text { 总 } \\
\text { ن }\end{array}$ & 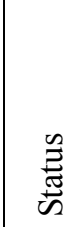 & 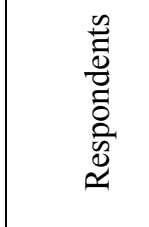 & 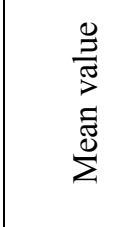 & 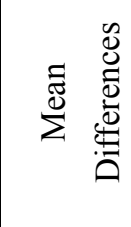 & Sig.* \\
\hline \multirow{8}{*}{1} & \multirow{8}{*}{ Producing the financial statements } & \multirow{4}{*}{ India } & \multirow{2}{*}{ A } & $\mathrm{Au}-90$ & 1.17 & \multirow{2}{*}{-0.25} & \multirow{2}{*}{0.001} \\
\hline & & & & In-135 & 1.42 & & \\
\hline & & & \multirow{2}{*}{$\mathrm{E}$} & Au-90 & 1.27 & \multirow{2}{*}{-2.60} & \multirow{2}{*}{0.000} \\
\hline & & & & In-135 & 3.87 & & \\
\hline & & \multirow{4}{*}{ Iran } & \multirow{2}{*}{ A } & Au-227 & 2.40 & \multirow{2}{*}{-0.13} & \multirow{2}{*}{0.179} \\
\hline & & & & In-214 & 2.53 & & \\
\hline & & & \multirow{2}{*}{ E } & $\mathrm{Au}-227$ & 2.44 & \multirow{2}{*}{-1.54} & \multirow{2}{*}{0.000} \\
\hline & & & & In-214 & 3.98 & & \\
\hline \multirow{8}{*}{2} & \multirow{8}{*}{$\begin{array}{l}\text { Conduct of } 100 \% \text { examination in audit } \\
\text { procedure }\end{array}$} & \multirow{4}{*}{ India } & \multirow{2}{*}{ A } & $\mathrm{Au}-90$ & 2.07 & \multirow{2}{*}{-0.12} & \multirow{2}{*}{0.412} \\
\hline & & & & In-135 & 2.19 & & \\
\hline & & & \multirow{2}{*}{$\mathrm{E}$} & $\mathrm{Au}-90$ & 2.46 & \multirow{2}{*}{-2.03} & \multirow{2}{*}{0.000} \\
\hline & & & & In-135 & 4.49 & & \\
\hline & & \multirow{4}{*}{ Iran } & \multirow{2}{*}{ A } & $\mathrm{Au}-227$ & 1.63 & \multirow{2}{*}{-0.87} & \multirow{2}{*}{0.000} \\
\hline & & & & In-214 & 2.50 & & \\
\hline & & & $\Gamma_{5}$ & $\mathrm{Au}-227$ & 1.88 & 152 & 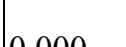 \\
\hline & & & L & In-214 & 3.41 & J & 0.000 \\
\hline & & & $\Delta$ & $\mathrm{Au}-90$ & 1.72 & 120 & مחת \\
\hline & & Indio & & In-135 & 3.01 & | & 0.000 \\
\hline & & & $F_{2}$ & $\mathrm{Au}-90$ & 1.83 & 203 & 0 \\
\hline 3 & Giving assurance that company is in good & & E & In-135 & 4.76 & -2.93 & 0.000 \\
\hline & financial health & & D & $\mathrm{Au}-227$ & 2.33 & 025 & $0 \Omega 1$ \\
\hline & & Ino & & In-214 & 2.68 & & \\
\hline & & & & $\mathrm{Au}-227$ & 2.56 & 20 & $0 \Omega 0$ \\
\hline & & & L & In-214 & 3.88 & -1.52 & 0.000 \\
\hline & & & & Au-90 & 1.65 & & \\
\hline & & It & A & In-135 & 2.21 & -0.50 & \\
\hline & & 110u & $\mathrm{F}_{2}$ & $\mathrm{Au}-90$ & 1.85 & 252 & \\
\hline & Grand Mean & & E & In-135 & 4.37 & $-2 . J 2$ & \\
\hline & & & A & $\mathrm{Au}-227$ & 2.12 & 0,15 & \\
\hline & & $\mathrm{T}$ & A & In-214 & 2.57 & $-0.4 J$ & \\
\hline & & & $F_{2}$ & $\mathrm{Au}-227$ & 2.30 & 15 & \\
\hline & & & L & In-214 & 3.75 & J & \\
\hline
\end{tabular}

*Significance, Note: $\mathrm{Au}=$ Auditors, $\mathrm{In}=$ Investors, $\mathrm{A}=$ Actual, $\mathrm{E}=$ Expectation 
Table 2. Auditor responsibility in controlling financial aspect: auditors vs. investors

\begin{tabular}{|c|c|c|c|c|c|c|c|}
\hline$\dot{\dot{z}}$ & Level of Auditors' Responsibility in & 总 & $\stackrel{0}{\sum_{\pi}^{ \pm}}$ & 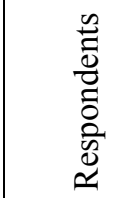 & 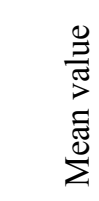 & 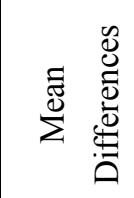 & Sig.* \\
\hline \multirow{8}{*}{1} & \multirow{8}{*}{$\begin{array}{l}\text { Maintaining accounting records by the } \\
\text { management }\end{array}$} & \multirow{4}{*}{ India } & \multirow{2}{*}{ A } & Au-90 & 3.72 & \multirow{2}{*}{0.45} & \multirow{2}{*}{0.001} \\
\hline & & & & In-135 & 3.27 & & \\
\hline & & & $F_{2}$ & Au-90 & 4.28 & 000 & lo 447 \\
\hline & & & [ & In-135 & 4.37 & -0.09 & $0.44 /$ \\
\hline & & \multirow{4}{*}{ Iran } & \multirow{2}{*}{ A } & Au-227 & 4.44 & \multirow{2}{*}{1.74} & \multirow{2}{*}{0.000} \\
\hline & & & & In-214 & 2.70 & & \\
\hline & & & \multirow{2}{*}{ E } & Au-227 & 3.94 & \multirow{2}{*}{0.24} & \multirow{2}{*}{0.661} \\
\hline & & & & In-214 & 3.70 & & \\
\hline \multirow{8}{*}{2} & \multirow{8}{*}{ Safeguarding the assets of the company } & \multirow{4}{*}{ India } & \multirow{2}{*}{ A } & Au-90 & 3.39 & \multirow{2}{*}{0.54} & \multirow{2}{*}{0.001} \\
\hline & & & & In-135 & 2.85 & & \\
\hline & & & \multirow{2}{*}{ E } & Au-90 & 3.96 & \multirow{2}{*}{-0.54} & \multirow{2}{*}{0.000} \\
\hline & & & & In-135 & 4.50 & & \\
\hline & & \multirow{4}{*}{ Iran } & \multirow{2}{*}{ A } & Au-227 & 2.37 & \multirow{2}{*}{-0.50} & \multirow{2}{*}{0.000} \\
\hline & & & & In-214 & 2.87 & & \\
\hline & & & \multirow{2}{*}{ E } & Au-227 & 2.61 & \multirow{2}{*}{-1.15} & \multirow{2}{*}{0.000} \\
\hline & & & & In-214 & 3.76 & & \\
\hline & & & $\Delta$ & Au-90 & 2.80 & 027 & م0 011 \\
\hline & & India & $\left.\right|^{\mathrm{A}}$ & In-135 & 2.53 & 0.21 & 0.011 \\
\hline & & mora & $F_{2}$ & Au-90 & 2.76 & 162 & 0000 \\
\hline 3 & Prevention of frauds and errors & & $D^{\mathrm{L}}$ & In-135 & 4.38 & -1.02 & 0.000 \\
\hline & & & $\Delta$ & Au-227 & 2.18 & 048 & 0000 \\
\hline & & Iran & $\left.\right|^{A}$ & In-214 & 2.66 & -0.40 & 0.000 \\
\hline & & nall & $F_{1}$ & Au-227 & 1.56 & 242 & 0000 \\
\hline & & & $\mathrm{E}$ & In-214 & 3.98 & -2.42 & 0.000 \\
\hline & & & $\Delta$ & Au-90 & 3.30 & 042 & \\
\hline & & India & $\left.\right|^{\mathrm{A}}$ & In-135 & 2.88 & 0.42 & \\
\hline & & Hinda & $F_{2}$ & $\mathrm{Au}-90$ & 3.67 & 075 & \\
\hline & Grand Mean & & ]$^{\mathrm{L}}$ & In-135 & 4.42 & -0.10 & \\
\hline & Uiand ivican & & A & Au-227 & 2.30 & -0.42 & \\
\hline & & Jran & $\Gamma^{A}$ & In-214 & 2.74 & -0.42 & \\
\hline & & nail & $\mathrm{F}_{2}$ & Au-227 & 2.70 & -111 & \\
\hline & & & $D^{2}$ & In-214 & 3.81 & 1011 & \\
\hline
\end{tabular}

*Significance, Note: $\mathrm{Au}=$ Auditors, $\mathrm{In}=$ Investors, $\mathrm{A}=$ Actual, $\mathrm{E}=$ Expectation 
Table 3. Auditors responsibility in financial misstatement: auditors vs. investors

\begin{tabular}{|c|c|c|c|c|c|c|c|}
\hline $\begin{array}{l}\dot{\mathrm{z}} \\
\dot{\mathrm{n}}\end{array}$ & Level of Auditors' Responsibility in & 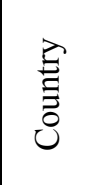 & 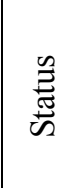 & $\dot{\mathscr{D}}$ & 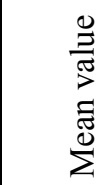 & 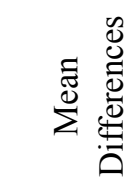 & Sig.* \\
\hline \multirow{8}{*}{1} & \multirow{8}{*}{$\begin{array}{l}\text { Enforcing effectiveness of internal control } \\
\text { on audit quality }\end{array}$} & \multirow{4}{*}{ India } & \multirow{2}{*}{ A } & $\mathrm{Au}-90$ & 3.74 & \multirow{2}{*}{0.92} & \multirow{2}{*}{0.000} \\
\hline & & & & In-135 & 2.82 & & \\
\hline & & & \multirow{2}{*}{ E } & $\mathrm{Au}-90$ & 4.50 & \multirow{2}{*}{0.06} & \multirow{2}{*}{0.551} \\
\hline & & & & In-135 & 4.44 & & \\
\hline & & \multirow{4}{*}{ Iran } & \multirow{2}{*}{ A } & $\mathrm{Au}-227$ & 2.38 & \multirow{2}{*}{-0.18} & \multirow{2}{*}{0.083} \\
\hline & & & & In-214 & 2.56 & & \\
\hline & & & \multirow{2}{*}{$\mathrm{E}$} & Au-227 & 2.61 & \multirow{2}{*}{-0.98} & \multirow{2}{*}{0.000} \\
\hline & & & & In-214 & 3.59 & & \\
\hline \multirow{8}{*}{2} & \multirow{8}{*}{ Detecting illegal acts by the management } & \multirow{4}{*}{ India } & \multirow{2}{*}{ A } & $\mathrm{Au}-90$ & 3.10 & \multirow{2}{*}{0.74} & \multirow{2}{*}{0.000} \\
\hline & & & & In-135 & 2.36 & & \\
\hline & & & \multirow{2}{*}{$\mathrm{E}$} & $\mathrm{Au}-90$ & 4.14 & \multirow{2}{*}{-0.60} & \multirow{2}{*}{0.000} \\
\hline & & & & In-135 & 4.74 & & \\
\hline & & & $\Delta$ & $\mathrm{Au}-227$ & 4.25 & 175 & 0000 \\
\hline & & Iran & H & In-214 & 2.50 & $1.1 \mathrm{~J}$ & 0.000 \\
\hline & & Hall & $F_{1}$ & $\mathrm{Au}-227$ & 4.57 & 078 & 0000 \\
\hline & & & D & In-214 & 3.79 & 0.10 & 0.000 \\
\hline & & & $\Delta$ & $\mathrm{Au}-90$ & 3.58 & 107 & (O) \\
\hline & & India & H & In-135 & 2.51 & 1.07 & 0.000 \\
\hline & & 1110ia & $F$ & $\mathrm{Au}-90$ & 4.46 & 001 & 0871 \\
\hline 3 & Reporting all detected frauds and thefts to & & L & In-135 & 4.47 & 0.01 & $0.8 / 1$ \\
\hline 3 & the relevant authority & & $\Delta$ & $\mathrm{Au}-227$ & 3.54 & 121 & ( $0 \Omega 0 \Omega$ \\
\hline & & Iran & A & In-214 & 2.33 & 1.21 & 0.000 \\
\hline & & Hantil & $\mathrm{F}$ & $\mathrm{Au}-227$ & 3.83 & 015 & 0422 \\
\hline & & & $\mathbf{L}$ & In-214 & 3.68 & $0.1 J$ & 0.422 \\
\hline & & & $A$ & $\mathrm{Au}-90$ & 3.49 & 070 & 0.000 \\
\hline & & India & A & In-135 & 2.79 & 0.10 & 0.000 \\
\hline & & 110uia & $F$ & $\mathrm{Au}-90$ & 4.43 & 032 & 0.030 \\
\hline 4 & Detecting any deliberate distortion of & & E & In-135 & 4.11 & 0.32 & 0.050 \\
\hline 4 & financial information & & $\Delta$ & $\mathrm{Au}-227$ & 1.66 & 005 & (0 \\
\hline & & Iran & A & In-214 & 2.51 & $-0.0 J$ & 0.000 \\
\hline & & II ant & $F$ & $\mathrm{Au}-227$ & 1.91 & 184 & 0000 \\
\hline & & & L & In-214 & 3.75 & T 1.07 & 0.000 \\
\hline & & & $\Delta$ & $\mathrm{Au}-90$ & 3.48 & 086 & \\
\hline & & Ins & A & In-135 & 2.62 & 0.00 & \\
\hline & & 1110ia & $F_{2}$ & $\mathrm{Au}-90$ & 4.38 & 006 & \\
\hline & Crond M Tron & & $\mathrm{E}$ & In-135 & 4.44 & -0.00 & \\
\hline & Uiantu ivicall & & $\Delta$ & $\mathrm{Au}-227$ & 2.96 & 0.10 & \\
\hline & & Iron & A & In-214 & 2.47 & 0.49 & \\
\hline & & II all & $\mathrm{IF}$ & $\mathrm{Au}-227$ & 3.23 & 046 & \\
\hline & & & L & In-214 & 3.69 & -0.70 & \\
\hline
\end{tabular}

*Significance, Note: $\mathrm{Au}=$ Auditors, $\mathrm{In}=$ Investors, $\mathrm{A}=$ Actual, $\mathrm{E}=$ Expectation 
Table 4. auditors' responsibility on professional discipline auditors vs. investors

\begin{tabular}{|c|c|c|c|c|c|c|c|}
\hline $\begin{array}{l}\dot{\mathrm{z}} \\
\dot{\mathrm{i}}\end{array}$ & Level of Auditors' Responsibility in & 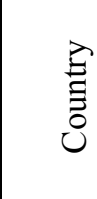 & 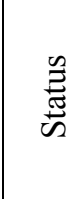 & 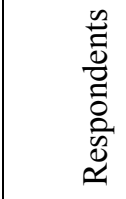 & 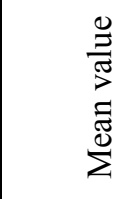 & 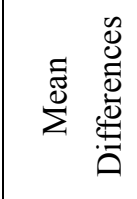 & Sig.* \\
\hline \multirow{8}{*}{1} & \multirow{8}{*}{ Detection of frauds and errors } & \multirow{4}{*}{ India } & \multirow{2}{*}{ A } & $\mathrm{Au}-90$ & 3.16 & \multirow{2}{*}{0.27} & \multirow{2}{*}{0.031} \\
\hline & & & & In-135 & 2.89 & & \\
\hline & & & \multirow{2}{*}{ E } & Au-90 & 4.01 & \multirow{2}{*}{-0.79} & \multirow{2}{*}{0.000} \\
\hline & & & & In-135 & 4.80 & & \\
\hline & & \multirow{4}{*}{ Iran } & \multirow{2}{*}{ A } & $\mathrm{Au}-227$ & 2.27 & \multirow{2}{*}{-0.28} & \multirow{2}{*}{0.043} \\
\hline & & & & In-214 & 2.55 & & \\
\hline & & & \multirow{2}{*}{ E } & $\mathrm{Au}-227$ & 2.36 & \multirow{2}{*}{-1.62} & \multirow{2}{*}{0.000} \\
\hline & & & & In-214 & 3.98 & & \\
\hline \multirow{8}{*}{2} & \multirow{8}{*}{$\begin{array}{l}\text { Right procedures followed before } \\
\text { authenticating financial statements }\end{array}$} & \multirow{4}{*}{ India } & \multirow{2}{*}{ A } & Au-90 & 4.03 & \multirow{2}{*}{0.98} & \multirow{2}{*}{0.000} \\
\hline & & & & In-135 & 3.05 & & \\
\hline & & & \multirow{2}{*}{ E } & $\mathrm{Au}-90$ & 4.74 & \multirow{2}{*}{0.05} & \multirow{2}{*}{0.416} \\
\hline & & & & In-135 & 4.69 & & \\
\hline & & \multirow{4}{*}{ Iran } & \multirow{2}{*}{ A } & Au-227 & 3.70 & \multirow{2}{*}{1.31} & \multirow{2}{*}{0.000} \\
\hline & & & & In-214 & 2.39 & & \\
\hline & & & $\mathrm{F}$ & $\mathrm{Au}-227$ & 3.99 & 0,56 & 0000 \\
\hline & & & | & In-214 & 3.43 & 0.50 & 0.000 \\
\hline & & & & $\mathrm{Au}-90$ & 3.73 & & \\
\hline & & & 11 & In-135 & 3.20 & J & 0.000 \\
\hline & & & & $\mathrm{Au}-90$ & 3.94 & 076 & 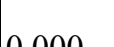 \\
\hline & & & $\mathbf{L}$ & In-135 & 4.70 & $\left.\right|^{-0.10}$ & 0.000 \\
\hline & 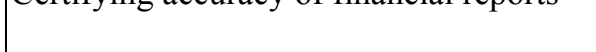 & & $A$ & $\mathrm{Au}-227$ & 3.17 & 020 & 0018 \\
\hline & & $\mathrm{I}_{\mathrm{V}}$ & 11 & In-214 & 2.88 & | 0.2 & 0.010 \\
\hline & & Han & & $\mathrm{Au}-227$ & 3.29 & & \\
\hline & & & & In-214 & 3.87 & -0.00 & 0.000 \\
\hline & & & & Au-90 & 3.64 & & \\
\hline & & Indio & 10 & In-135 & 3.05 & 0.J & \\
\hline & & & $\Gamma_{2}$ & $\mathrm{Au}-90$ & 4.23 & 0 & \\
\hline & Gro & & |L & In-135 & 4.73 & -0.00 & \\
\hline & & & $A_{\mathbf{A}}$ & Au-227 & 3.05 & 16 & \\
\hline & & & 11 & In-214 & 2.60 & | & \\
\hline & & & & $\mathrm{Au}-227$ & 3.12 & & \\
\hline & & & |L & In-214 & 3.76 & ד. & \\
\hline
\end{tabular}

*Significance, Note: $\mathrm{Au}=$ Auditors, $\mathrm{In}=$ Investors, $\mathrm{A}=$ Actual, $\mathrm{E}=$ Expectation 


\title{
Independent Innovation Ability and Industrial Chain Expanding Policies to Firms in Liaoning Province
}

\author{
Lin $\mathrm{Lu}$ \\ School of Management, Dalian University of Technology \\ No.2 Ling Gong Road, Gan Jingzi District, Dalian116024, China \\ E-mail: lulin@dl.gov.cn \\ Yanying Chen \\ Department of Economics, Dalian University of Technology \\ No.2 Ling Gong Road, Gan Jingzi District, Dalian116024, China \\ Tel: 86-411-8470-7221Ｅ-mail: yychen@dlut.edu.cn \\ Binbin Jiang \\ Department of Economics, Dalian University of Technology \\ No.2 Ling Gong Road, Gan Jingzi District, Dalian116024, China \\ Tel: 86-411-8470-0480 E-mail: blueberry1029@126.com
}

\begin{abstract}
After defining industrial chain and its expanding, we analyze the influencing mechanism of industrial chain expanding to firms' independent innovation ability in this paper, and then we discuss how to enhance firms' independent innovation ability through industrial chain expanding. With regard to the actual and specific conditions of industrial chain and innovation system of firms in Liaoning province, we put forward the patterns and ways for expanding of industrial chain of firms in Liaoning Province and the cultivation of their independent innovation ability.
\end{abstract}

Keywords: Industrial chain, Expanding, Independent innovation ability

\section{Introduction}

The independent innovation ability is closely related to the national strategic benefits and safety, and become the drive of the development of economy. Bettina Von Stamen summarized the factors that had an effect on innovation ability and the ways to foster the firms' innovation ability in his paper ${ }^{[1]}$. Yiming Wang, Jun Wang analyzed the interior and exterior factors which could influence the advancement of firms' independent innovation ability in China ${ }^{[2]}$. In recent years, firms in Liaoning Province are facing various kinds of problems in promoting their innovation abilities, such as low innovation inputs, backwardness of innovation system and lack of ability and activeness in independent innovation. It is the problems that mentioned above influence the sustainable development of Liaoning's economy. From this aspect, the enhancement of independent innovation ability is the problem that urgently needs to be solved. Current researches related to firms' innovation ability always concentrate on the necessity, actual situation and deficiencies. And there are also researches on the influencing factors in innovation of a certain kind firms, but few on the cultivation of independent innovation ability from the expanding of industrial chain. In this paper, we firstly define industrial chain and then introduce the patterns of industrial chain expanding in the next section. In the fourth section we analyze the influencing mechanism of industrial chain expanding to innovation ability. At last conclusion is made, and we also propose some policy suggestions and expectations.

\section{Definition of industrial chain and its expanding}

\subsection{Definition of industrial chain}

Industrial chain is a set of economic activities specific to a certain series of interrelated products or service, from resources collection, product manufacturing, and marketing to final consumption. The structure of industrial chain is the inside division structure of industry ${ }^{[3]}$. The market mechanism broadens and lengthens the industrial chain, and it also 
specializes in the industrial division and updates the structural formation of industrial chain. The link that connects the upstream and downstream firms in the industrial chain is the input-output of products; output of the upstream firms is the input of downstream firms. The product-oriented operation mechanism makes the product form of industrial chain the best way to solve actual situations as industrial chain integration, expanding and risk controls.

Figure1 shows a simple chain of steel industry. The mining firms in the chain provide the raw material of iron ore to the casting and smelting firms, which take the separating the mineral, sintering, coking, steel-making and rolling processes according to their own process flows, and then the outputs are used by the automobile and machinery firms to produce the final products for customers. The outputs of casting and smelting firms could also be used in pipeline and tube firms to satisfy the deep demands of customers with further processing. In the production process, coal, electricity and gasoline firms serve the chain with energy resources and the transportation firms provide transportation services, although these processes taken by coal, electricity, and gasoline and transportation firms don't form tangible products, they play an important role in keeping the industrial chain run smoothly.

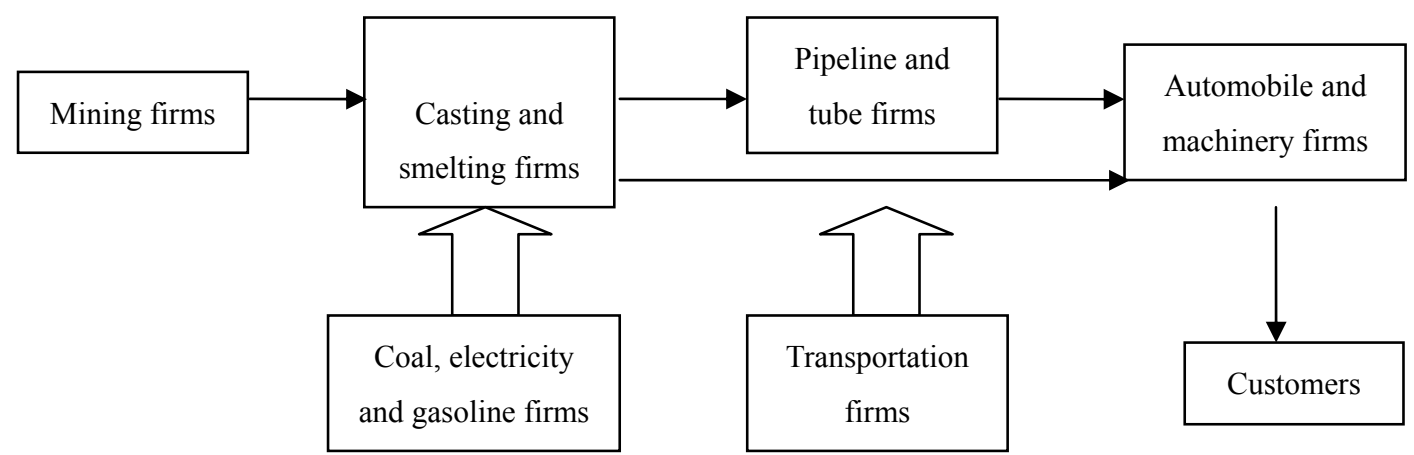

Figure 1. The Industrial Chain of Steel Industry

\subsection{Patterns of industrial chain expanding}

The industrial chain expanding is a process in which enterprise groups of leading industry and corresponding industrial structure forms. Striving for their own competitive advantages, firms reallocate the agent of production under the industrial development rules. The industrial chain expanding could be divided into three categories, horizontal expanding, and vertical expanding and integrated expanding.

Horizontal expanding refers to cooperation, merge or recompose in a certain part of the industrial chain so as to raise the concentration ratio and strengthen the firms' integration abilities. Horizontal merge, which aims at increasing the control power of the market price and profit through the enhancement of market power, is one way to realize horizontal expanding; horizontal alliance is another way, typically the cooperation in price. The existence of asymmetry and incomplete information in reality together with the Prisoners' dilemma makes the horizontal expanding depending on cooperation always hard to sustain. Different with horizontal expanding, vertical expanding related to the merge or recompose of upstream and downstream firms in the chain. The inevitable results of vertical expanding is vertical integration, on one side, it brings the firm with competitive advantages in the horizontal level of the chain; on the other, it can reduce the risks of uncertainties and transaction costs in the industries with greater demand fluctuations ${ }^{[4]}$. Integrated expanding is composed of horizontal expanding and vertical expanding, which in essence is the integration of the firms whose products are highly linked and serves to the same or similar targets, to form the enterprise groups with international competitive power and advantages of scale economy. The merge of several firms to strengthen the integration ability pertains to the horizontal expanding, while the extension of upstream and downstream firms in the chain attributes to the vertical expanding.

\section{The influencing mechanism of industrial chain expanding to firms' independent innovation ability}

\subsection{The influencing factors of firms' independent innovation ability}

The independent innovation ability is the ability a certain firm use to developing new products or service with its own resources. It is this independent $R \& D$ ability that brings firm with technological breakthroughs and realizes commercialization and industrialization of products to gain more profits. Related works points out that the influencing factors focuses on firms' own condition, including technical and industrial conditions.

Such objective factors as firm's scope, management concepts, financial strengths and technological accumulations all affect firm's independent innovation ability, and these factors are also the condition and basis for the cultivation of independent innovation ability ${ }^{[5]}$. To achieve independent innovation, firms need sufficient financial and technological support, which is inseparable to the scope of firm, the management concepts determines the firms whether could judge the innovative risks and choose the right innovation form or not. Technology spillover also influences the independent 
innovation ability. Technology spillover is the technological diffuse results from the non-exclusive attribute of technology. Although patent could reduce the spillover to some extent, the public good attribute of technology always lead the successful technology innovation could be mastered by other firms with very low costs, which decrease the initiative of firms' cultivation of independent innovation ability. Risks in technology, finance and market restrain firms' independent innovation ability too. The uncertainties result in the uncertainties of innovative period, characteristics of new technology and the return of innovation. The great amount of capital in use for innovation also hinders the realization of independent innovation. Imitation innovation is another factor that influences innovation. For a long time, the feeble independent innovation ability makes the international competitiveness of industries in China weakened substantially, from this aspect, it is necessary for firms to pursue the imitation innovation mechanism before the cultivation of independent innovation ability. The life cycle of firms is greatly related to their independent innovation ability. In different stages as start-up, growth, maturity and decline, the changing internal and external conditions of firms call firms strategies to change to fit for the condition.

\subsection{The vertical integration industrial chain and its effects to independent innovation ability}

Vertical integration is the inevitable result of vertical expanding of industrial chain. This kind of R\&D, manufacturing and marketing operation mechanism is adopted widely by firms in the developed countries, because it can boost technology transformation, prevent technology spillover, reduce transaction costs and weaken innovation risks, which would influence the independent innovation ability.

(1) Integrated industrial chain could accelerate the transformation rate of technology and cut down the cycle of value chain. The mechanism of integration could avoid the conflicts between upstream and downstream firms caused by interest allocation, and the R\&D section could serve the production line and customers directly when there is problems happens in product design process, or technological and quality problems arise. The rapid industrialization of innovation result could also reduce the technology spillover efficiently.

(2) Vertical expanding of industrial chain efficiently reduces the transaction costs from R\&D achievements to products, which provides the independent innovation process with solid financial preparation. The operation mechanism pursued by integration could conduct and maneuver resources and strength of different sections directly to reduce the transaction costs between different parts of the industrial chain and shorten the transaction cycles. Vertical integration makes the innovation and production processes coordinate with each other more closely, lowers risks and makes the independent innovation ability guide the production process more powerfully. Such characteristics of firms' independent R\&D as higher input, longer cycle, higher risk, call those firms with greater production and financial capacity to take part in independent innovation to reduce the risks in operation and management.

\subsection{The cultivation effect of imitation innovation to independent innovation ability}

The horizontal expanding of industrial chain, which depends on the merge or cooperation of firms in the same part of the chain, makes full use of their complementary resources to strengthen the core competitiveness and innovative abilities. When a firm uses a certain new technology, other could imitate this technology by their horizontal relations to realize knowledge flow and share of innovation resources. The expanding of industrial chain also decreases the diffuse costs of knowledge makes the diffuse of experience and knowledge possible.

Imitation innovation is kind of gradual innovation behavior which calls for sufficient $R \& D$ strengths to evaluate, design and improve the assimilated technology or products to create products or service more competitive and fits for the customers' demands. The cultivation effect of imitation innovation to firms' independent innovation ability is reflected by its enhancement to the knowledge and technology diffuse between firms, accelerate the accumulation of technology $\mathrm{R} \& \mathrm{D}$ and reduce the costs and risks in independent innovation to a large and possible extent.

\subsection{The extension of firm's life cycle and independent innovation}

The improvement of firms' core competitiveness and enlargement of firms' scale caused by the expanding of industrial chain not only extends the life cycle of firms, affects the intrinsic structure of industrial chain, updates the division of labor, but also extends the market scope and optimizes the industrial structure. The integration process of chain could introduce some firms with competitive advantages to the industry and force the less competitive firms to choose a certain part to reconstruct its advantages. It also helps realize the accumulation of technological experience and human resources and guarantees the cultivation of independent innovation ability.

\section{Measures and suggestions for firms in Liaoning Province to promote independent innovation abilities}

Because of their low level in the industrial chain, firms in Liaoning Province give priority to the rough machining of raw materials in steel, machinery and building materials industries, which were restricted by the varieties and distributions of the mineral resources, and with short and narrow industrial chain. The unreasonable internal structure, low level of division and lack of organic contacts all restricts the cultivation of Liaoning's firms' independent innovation ability. According to the analysis and study above, the governments in Liaoning should take some measures 
to expand the chain of different industries to enhance the cultivation of firms' independent innovation ability.

(1) Such public institutions as governments and guilds should coordinate between firms to provide them with well external environment to expand the industrial chain. In the expanding process, the government could aid firms to get through the channels that connect different firms in the chain, construct efficient factor markets and unblocked logistics networks to realize the diffuse of knowledge and share of innovation resources to cultivate firms' independent innovation ability.

(2) Governments should try their best to reduce the obstacles and unstable factors that disturb the exchange between firms. Governments could increase the financial assistance to the firms because the most influential obstacle for firms in their independent innovation ability is financial restriction. Governments could fund on independent innovation to provide firms with reliable guarantees.

(3) Governments pay more attention to the development of modern logistics industry and build platforms for the industrial chain. The governments should assist and guide the formation of logistics firms and provide the key sections with capital helps to integrate and optimize the supply chain of physical distributions. Integrate the transaction relationships between upstream and downstream firms together based on the value chain.

(4) In the cultivation process, the key link is to attract the industries with high added value. The lack of key techniques is also a bottleneck problem that restricts the development of Liaoning's firms. So the governments should breed large enterprise groups, assist and subsidy them to construct and acquire core capacity. They should formulate some favorable policies to facilitate and attract international investors to transfer the high-end sections into Liaoning's industrial chain to enhance the innovation ability of industrial chain and help cultivating the firms' independent innovation ability.

\section{Conclusion}

In this paper, we introduced the definition and patterns of industrial chain, and studied different aspects that industrial chain expanding influences independent innovation. After the analysis of problems of firms in Liaoning facing in independent innovation, we put forward the measures that governments and firms could take to enhance the independent innovation ability by industrial chain expanding. The measure we proposed here to promote independent innovation ability through industrial chain expanding is only a theoretical analysis, so future studies should set more emphasis on the empirical studies to improve firms' independent innovation ability.

\section{References}

Bettina Von Stamm.(2004). The Innovation Wave: Meeting the Corporate Challenge. Wiley: Chichester

Wang, Yiming \& Wang, Jun. (2005). Issues about the improvement of enterprise independent innovation ability. China Soft Science, 7,10-14

Liu, Gang. (2005). Structure of Knowledge Transitions and Innovations Based on an Industrial Chain. Business Economics and Administration, 11,13-17

Masten, Scott E., Meehan, James W Jr, and Snyder, Edward A. (1989). Vertical integration in the U.S. auto industry: A note on the influence of transaction specific assets." Journal of Economic Behavior and Organization, 12, 2,265-273

Li, Yuan, Li, Xiyao \& Fang, Runsheng. (2007). Analysis on the Internal Factors of Endogenous Innovation in Chinese Enterprises. Group Technology and Production Modernization, 1,9-12 


\title{
On Securitization of International Syndicated Loans
}

\author{
Jing He \\ Yunnan Branch, China Development Bank, Kunming 650031, China \\ Tel: 86-871-3636683 E-mail: jing_he22@126.com
}

\begin{abstract}
Since 80 s, along with the heating-up competition in finance industry and the liberalization trend of financial supervision, a tendency of integration appears in world three financial service fields, namely banking, insurance, and security. It threats the banking business. The banking industry that always possesses the core position in financial system faces enormous challenges. On the other hand, all countries regulate standard rate of interests for commercial banks' deposits and loans. Therefore, the margin between banks' assets and liabilities is limited, which leads to more fierce competition among banks. Under this background, the securitization trend serves as a bridge between direct financing and indirect financing, creating more opportunities for banks reducing costs and increasing profits, and improving banks' competence. Starting from international syndicated loans, this paper analyzes the primary mode and the advanced mode of international syndicated loans' securitization, compares their characteristics, and further studies reasons for securitization of international syndicated loans.
\end{abstract}

Keywords: International syndicated loans, Securitization, Financial innovation

International syndicated loans mean the borrower, in form of mandate letters, ask the leading bank to organize the bank syndicate and provide with loans for them. The traditional ways, namely the most fundamental ways, are: direct participation (or loan syndication) and indirect participation (or loan participation). In the first way, the leading bank organizes all participated banks to sign a contract of loans with the borrower, providing with loans for the borrower according to same items regulated in one contract. Participated banks and the borrower have a direct debtor-creditor relationship. In the second way, the leading bank supplies or promises to supply loans for the borrower firstly. Then, the leading bank transfers loans supplied or supposed to supply to participated banks. Generally, there is no direct debtor-creditor relationship between participated banks and the borrower.

As a matter of fact, the so-called securitization can be classified into two types. For the first type, capital demanders directly get funds from capital suppliers in financial market by issuing stocks and securities. It is a kind of credit financing. By this way, a borrower can directly obtain funds from investors in market in stead of applying for loans from banks or overdraft. This securitization is also named as "first-order securitization" or "financing securitization". The second type is to separate and reengineer the risks and returns of assets that are lack of liquidity but can generate expectable and stable cash flow by certain structural arrangement, and make these assets available for sale and circulation in market. It is also named as "second-order securitization" or "asset securitization" that derives from the issue of mortgage-backed securities in late 60s in America and then is widely used for other assets. Because it has innovative financing structure and effective carriers and satisfies the constantly changing needs of different borrowers and investors, it becomes the most energetic financial innovative product that develops fast in all countries' capital markets today. The securitization of international syndicated loans is just one corner of asset securitization.

\section{The primary mode ------ transferable loan facilities}

In the indirectly participated international syndicated loans, the leading bank transfers the loans supplied or supposed to supply to participated banks by certain ways, such as contract novation, credit assignment, sub-loan, and undisclosed agency. The indirect participation is similar to the transfer of loan participation rights and the sale of goods. Therefore, somebody names it as sales of loan. However, as these traditional sales of loans generate certain effects, some problems do exist. For example, loans are usually transferred among commercial banks and it is the loan-remising bank that signs a contract with potential borrowers of loans. Some transfers need complex procedures and even agreements of the borrower. Apparently, these ways belong to primary and oriented trade market scope and the trade costs are relatively higher.

In mid 80s last century, a brand-new way for sales of loans, transferable loan facilities (TLFs), appears in market. In this way, the leading bank uses written certificates stand for the right of taking due principals and interests back. By the issue and circulation of these written certificates, the leading bank can transfer loans. Participated banks can buy these written certificates and sell them freely in market. Apparently, this way broadens the range of transfer. The transfer of syndicated loans will not be limited among the leading bank and participated banks. Besides, the standard written 
certificates improve the liquidity of transfer, simplifying the boring negotiation and decreasing trade costs. In the practice of syndicated loans, there are three kinds of transferable loan facilities: transferable loan certificates (TLCs), transferable participation certificates (TPCs), and transferable loan instruments (TLIs).

\subsection{Transferable loan certificates (TLCs)}

Transferable loan certificates are based on contract novation. As we know, in contract novation, if the leading bank or participated banks want to transfer their rights and obligations regulated in the loan contract, they must gain agreements of the borrower and other participated banks. Apparently, it increases trade costs and may not gain their agreements. Therefore, in order to improve the liquidity of loans and reduce trade costs, in practice all participators in syndicated loans will pre-agree with future contract novation in the loan contract. Then the agent bank issues a file that stands for interests of the borrower and all participated banks. This file includes an offer issued by the borrower, the agent bank, and other participated banks for any potential transferee of loans. The transferee of loans will be accepted by all participators as a participated bank in syndicated loans, replacing the former bank that sales loans. By this way, this file becomes a transferable loan certificate. It appended to the back of a loan contract. In the legal aspect, it is an agreement that makes future contract novation work. In general, the agent bank will issue and give some TLCs to every participated bank according to the loan contract. If the loans are amortization, TLCs consist of relevant TLCs to every payment date. The TLCs carry specific principals and interests for certain date. If the transferee accepts the offer in TLCs, the transferee can fill out the form and give them to the agent bank and pay certain register fee. After registering the transferee's name, the agent bank will cancel the former TLCs and inform the borrower about the transfer. Then, the agent bank will issue new TLCs that have same contents with the former, which can help the transferee transfer it again. By this way, syndicated loans can be transferred and circulated freely as securities.

\subsection{Transferable participation certificates (TPCs)}

In fact, the transferable participation certificates are a kind of transferable loan certificates. Similarly, it adopts the contract novation method to transfer the rights and obligations of participated banks. And it has similar procedures with transferable loan certificates. The difference is that TPCs are right for participating international syndicated loans indirectly by sub-loans. In this way, participated banks can ask the leading bank to sign transferable participation certificates that includes offers for appropriate institutions (usually banks), allowing these institutions to fill out the TPCs and give them to the leading bank, realizing the novation of the sub-loan agreement. In other words, after the endorser (namely the participated bank) signs the TPCs with the transferee and gives the TPCs to the leading bank, the transferee replaces the endorser and becomes a new participator of the sub-loan agreement (namely the loaner). In practice, the sub-loan agreement that includes transferable participation certificates is also named as "transferable participation agreement". The items that allow to issue transferable participation certificates, and guarantee the validity of syndicated loans in this agreement are the same with relevant items in syndicated loan agreement that can issue transferable loan certificates.

\subsection{Transferable loan instruments (TLIs)}

Transferable loan certificates have two shortcomings. Firstly, if the country where the borrower lives implements foreign exchange control, even though the borrower has permission of getting foreign loans, this permission may become invalid due to contract novation, because after that the borrower will trade with other participators but not former authorized one. Secondly, if the borrower provides with relevant guarantee for syndicated loans, the contract novation may make related warrantors escape from guarantee liability. That is because the new contract between the borrower and the transferee replaces the old one and the former guarantee contract is subject to the old one. According to the law of contract, an invalid principal contract causes invalidation of accessory contract unless the borrower provides with independent guarantee, such as demand guarantee or standby letter of credit.

In order to overcome the two shortcomings, a new loan securitization way, namely transferable loan instruments, appears in practice of international syndicated loans. In essence, transferable loan instruments are a kind of liability warrants or securities. It regulates that the borrower who signs the instrument undertakes certain liability to the "registered holder". As any "registered holder" submits the instrument, the borrower should pay a sum of money on the day predetermined in the instrument unconditionally. In fact, the sum of money regulated in the instrument stands for the due loan paid by the borrower to certain participated bank according to the syndicated loan contract. By transferable loan instruments, participated banks can transfer their loans to transferees by transferring instruments without contract novation. Noticeably, transferable loan instruments are independent and not append to the loan contracts. Participated banks especially ask the borrower sign the instrument according to the loan contract, what is different from transferable loan certificates that are signed by the authorized agent bank and issued for every participated bank. After signing the instrument, the borrower should appoint a registrar to prove its authenticity. Then the instrument becomes validity. Besides, once a transferable loan instrument is signed, the repayment obligation of the borrower will be regulated by it instead of the former syndicated loan contract, what also proves that transferable loan instruments are independent from syndicated loan contracts. 
What's more, what the transferable loan instruments transfer are only the rights of taking back principals and interests but not obligations of supplying loans. Therefore it is actually a kind of development and conversion of international syndicated loans' indirect participation, credit assignment. Because contract novation is not necessary for transferable loan instruments, the two shortcomings of transferable loan certificates are conquered. However, because what transferable loan instruments transfer are merely credits, they are right for conditions in which loaners have already supplied all loans.

According to analyses above, we notice that although transferable loan facilities improve the liquidity of banks' assets in a sense and detract risks, they actually follow the way of indirect participation and mechanically apply some operational procedures, such as contract novation and credit assignment. They just become more flexible in form and more skillful in design. To be strict, these ways do not completely break away from indirect participation. In addition, because this securitization mode has complex structure, investors who do not familiarize with credit analysis can not evaluate and know the assets' quality, credit grades, and rational prices. Then, the transfer of those written files mentioned above is limited to large and medium commercial banks. Therefore, in my opinion, transferable loan facilities are only a primary novation and development of sales of syndicated loans. They are the primary mode of securitization of international syndicated loans in a sense.

\section{The advanced mode ------ SPV mode}

In this securitization mode, the syndicated loans' primary providers, banks, organize and collect their certain assets that are lack of liquidity but have expectable and stable cash flow, and form a "loan pool". Then, these banks can acquire interests by selling the loan pool to a "special purpose vehicle" (SPV). The SPV issues securities by taking the loan pool's expectable cash return flow as warranty. Meanwhile, by means of ranking and promoting credits, SPV enhances the credits of securities in order to attract more investors. The loan pool's cash return flow is firstly used for paying the principals and interests of securities held by investors. Because SPV is the core of the whole securitization trade and also the character of new syndicated loans, therefore, this kind of securitization is named as "SPV mode". In fact, it is the chief mode of assets securitization.

In specific, SPV mode mainly has these operational procedures as follow.

\subsection{Establish securitization objectives and form loan pool.}

Firstly initiators (syndicated loans' primary providers, banks) clear, evaluate, and audit their syndicated loans that can generate expectable and stable cash flow based on the rates of interests, time limits, and types, and reengineer a homogeneous loan pool. Meanwhile, evaluate the potential loses of bad debts and deduct the costs of securitization, establish the expected objectives of securitization, and ensure that the loan pool's expected cash return flow is more than the assets-backed security's (ABS) expected principals and interests.

\subsection{Form SPV, transfer loan assets, and realize a "real sale".}

SPV is an important and irreplaceable carrier for syndicated loans' securitization and also the character of this mode. SPV is an independent entity in a legal sense, aiming at operating assets securitization, which can be formed by initiators or the third party. Usually we set limits as follow for SPV operation: If it can not produce any new asset or liability except securitization business, it can not distribute any dividends before paying investors principals and interests. After forming SPV, initiators can sell the loan pool to SPV by signing trade contract with SPV. In order to guarantee a "real sale", the contract should make it clear that as initiators go bankrupt their assets listed in the loan pool should not be included in bankruptcy property, realizing the bankruptcy remote. It means a separation between the loan pool's quality and the initiators' credits, which can help investors to escape from loss of interests due to the bankruptcy of initiators. In judging whether it is a real sale or not, we should think about whether initiators' activities are allowed by the law of bankruptcy in the country. If the sales of assets are illegal, it is not a real sale.

\subsection{Design and perfect securitization trade structure and perform assets internal appraisal}

After obtaining loan assets, SPV should: Sign a loan assets management contract with initiators or assets management agencies appointed by initiators; Select a trust institution and sign a loan assets trust contract together with initiators; Negotiate and design the assets security structure together with initiators and relevant consultants; Sign underwriting contracts with securities dealers. By signing a series of contracts, the trade structure will be perfect. Then, SPV will invite a credit rating agency to make "internal appraisal" of the trade structure and the designed assets-backed securities. By examining the validity of contracts and files, the credit rating agency completes an internal appraisal of trade structure and assets-backed securities. Based on the appraisal, SPV determines the credit enhancement range necessary for issuing assets-backed securities.

\subsection{Improve assets credits and adopt relevant assistant arrangements}

Because the cash flow of loan assets does not realize a complete reengineering, the internal appraisal is not quite ideal. In order to attract investors as much as possible, SPV will adopt some credit enhancement methods, including internal 
credit enhancement and external credit enhancement, to improve the assets-backed securities' credit rate. Internal credit enhancement methods include: (1) bankruptcy remote; (2) issue prior securities and junior securities. Only when prior security holders get principals and interests, can junior security holders obtain their principals and interests. But junior security has higher interests than prior security, which makes junior security attractive. For external credit enhancement methods, the third party usually provides with warranty. In other words, take banks' letters of credit and insurance companies' insurance policies as warranty for assets-backed securities. Once SPV breaks the contract, banks or insurance companies will pay principals and interests of securities off. Besides, the securitization of syndicated loans can not be completed at once. Therefore, considering risks in its operation, such as shortage of cash flow, currency, and rate of interests, SPV must sign warranty investment contract, liquidity facilities contract, financial swaps and foreign exchange trade contract with relevant parties. By these assistant arrangements for loan risks management, SPV can decentralize loan operating risks and realize maximum returns and minimum risks.

\subsection{Prepare for securities issue rating and arrange the issue and sale of securities'}

After credit enhancement, SPV will invite some well-known rating agencies to make formal issue rating for assets-backed securities. Then, SPV declares the results of rating, prepares legal files for securities issue, and deals with necessary legal procedures. Finally, SPV sign underwriting contracts with securities dealers who sell securities to investors. After SPV gets return from securities issue, it pays initiators funds for loan assets.

\subsection{Manage securitized assets and pay off principals and interests of securities at term}

It is the initiators or loan assets management agencies appointed by initiators who are in charge of management of loan pool. They are responsible for taking in and recording the loan pool's cash return and saving them in trust institutions' special accounts for accounts receivable. Trust institutions establish accumulation funds (used for paying principals and interests of securities) according contracts and hand in the funds to SPV. After getting accumulation funds, SPV should firstly use the funds for repaying off investors instead of distributing dividends or bankruptcy. Besides, SPV should pay for services during the securitization trade syndicated loans.

Comparing with the SPV mode, transferable loan facilities do not change original loans' legal form and property. Transferable loan facilities help to transfer loan assets to transferees without updating original loan contracts. They are limited to the legal framework of original loans. So they can not decentralize risks effectively. In contrast, SPV, the new securitization mode, operates in a new legal framework that takes securities issue and relevant warranties as main contents. It transfers original loans from loan market (credit market) to capital market. By this way, it can solve the capital liquidity issue of banks. What's more, commercial banks will not be the center of risks. Investors who prefer to winning returns from risks become the real carriers of risks. Besides, along with the development of direct financing that takes market as the medium, the indirect financing business that takes banks and other financial institutions as medium suffers from great impacts. Disintermediation and financial disintermediation appear. The SPV mode serves as an effective financing channel for borrowers and investors, simplifying traditional financial medium, offering different financial tools with different terms and denominations for investors, being an effective way for communication between traditional direct financing and indirect financing. Therefore, comparing with transferable loan facilities, the SPV mode is more appropriate for market, what makes it develop better and faster.

\section{Reasons for securitization of international syndicated loans}

W. Silber in his theory of financial innovation's constraints points out: financial product innovation is an organization's (banks or enterprises) response to suffered constraints. Main constraints include laws, risks, and competitions. Securitization of international syndicated loans is a kind of assets management innovation emerged in the reforming tide of financial industry. It comes into being in conflicts between financial activities and financial environment. Therefore, we can use theory of constraints to analyze its emergence.

\subsection{Shun external pressures from banking supervision}

The rise of international syndicated loans' securitization is chiefly caused by the stricter banking supervision standards. The most typical representative is the International Convergence of Capital Measurement and Capital Standards (Basel Capital Accord for short) issued by the Basel Committee in 1988. The core content of Basel Capital Accord is to regulate that to late 1992, the capital adequacy ratio of every bank engaged in international financial business must reach $8 \%$. This accord requires all commercial banks to decrease the proportion of risk assets in the balance sheet in case of commercial banks bearing greater commercial banks. Under the influences of Basel Capital Accord, China, America, Japan, EU, and other countries or regions take actions to improve supervision standards. Under the rule that emphasizes on banks' capital adequacy rate, if a commercial bank has higher risk weight in its balance sheet, it has to hand in more reserves than commercial banks that have lower risks weights to avoid financial risks. It means more operational costs and less return. Therefore, banks that possess high-risk-weight loan assets can transfer their syndicated loans to banks or other investors that have low-risk-weight loan assets by transferable loan facilities or SPV mode, realizing decentralization of loan risks and regulation of law. These securitization modes offer an effective way for 
participated banks syndicated loans adjusting assets structures, enhancing capital strengths, realizing more flexible management of balance sheets. Meanwhile, because these modes can help to release capital adequacy pressures and improve financial system's safety, they are widely accepted by all participated banks.

\subsection{Inner requirement for decentralizing operational risks}

Securitization is the inner requirement for participated banks undertaking operational risks respectively and improving assets liquidity. As financial institutions, banks' operational principles are safety, liquidity, and profitability. Thereof, the safety is the most essential. In participating syndicated loans, banks usually face sorts of risks in credits, rates of interests, exchange rates, and inflation. The securitization of international syndicated loans offers a way for decentralizing these risks and carrying out the principle of safety in banks' operation.

In the mode of transferable loan facilities, participated banks transfer all or part of loans, as well as most risks, to other banks or institutional investors, releasing pressures caused by large and long-term syndicated loans. Especially, the leading bank usually undertakes greater credit risks for special borrowers, such as specific countries, currencies, or industries. By sales of loans, the leading bank can decentralize risks. Meanwhile, it is in accord with most countries' legal supervision requirements for forbidding loans to focus on certain country, currency, or industry.

In the SPV mode, the decentralization and transfer of participated banks' loan risks are better. This mode can convert relatively non-current assets into tradable securities in market, turning syndicated loans' potential risks in credits, rates of interests, inflation, and policies, into investors' market risks, decentralizing different risks to all investors in time by the secondary market. Besides, the SPV mode broadens the range of investors, what improves the liquidity of participated banks' loan assets, increasing new financial sources.

\subsection{The ultimate engine: improve rate of profits and competitiveness}

To win in the furious market competition and gain profits as much as possible are the greatest wishes of all participated banks of syndicated loans. In fact, considering the external pressures from avoiding banking supervision and the inner requirements for decentralizing operational risks, to improve rate of profits and competitiveness is the ultimate engine for securitization of international syndicated loans.

Profits-assets ratio is the standard that evaluates the profitability of a bank. If the leading bank sells syndicated loans by securitization, it can deduct the loan assets from its balance sheet. Meanwhile, the leading bank retains rights of getting parts of interests and charging for commissions. Under some circumstances, it even gains some interests margins. All these factors benefit the improvement of bank's profitability. Besides, just as what has discussed above, securitization enhances the liquidity of syndicated loans. Participated banks can take back some capitals before loans are terminated, and use them for other businesses. By expediting the circulation of credit capitals, operational scale of bank assets is larger and the rate of return on assets is improved, what will inevitably benefit the rise of bank's rate of profits. Moreover, as the realization of sales income, securitization of syndicated loans is free from handing in reserves. It effectively reduces costs of financing.

\section{References}

Davidson. (2006). Securitization: Structuring and Investment Analysis. Beijing: China Renmin University Press.

Guo, Hongjun. (2001). Researches on Law Issues in International Syndicated loans. Beijing: Law Press.

Huang, Song., Wei, Enqiu \& Liu, Yong. (2007). Theories and Cases for Assets Securitization. Beijing: China Development Press.

Moorad Choudhry. (2004). Structured Credit Products. John Wiley \& Sons.

Pan, Shujuan. (2003). International Credit ----- Theory, Practice, International Practice and Law. Beijing: China Financial Publishing House.

Zou, Xiaoyan. (2002). International Syndicated Loans. Beijing: China Citic Press. 


\title{
Power Congruence Approaches to Downward
}

\section{Influence in Malaysia Manufacturing Industry}

\author{
May-Chiun Lo (Corresponding author) \\ Universiti Malaysia Sarawak, Faculty of Economics and Business, 94300, Kota Saramarahan, \\ Sarawak, Malaysia
}

Tel: 60-82-582360Ｅ-mail: mclo@feb.unimas.my

Intan Osman

University Science Malaysia, School of Management, 11800 Penang, Malaysia

Tel: 60-4-653-3355 E-mail: intan@usm.my

We thank Mahfooz A. Ansari for his helpful comments.

\begin{abstract}
It has been proposed that issues of power and influence should be incorporated in the dyadic study of leadership. Building upon social exchange theory which explains how power is gained and lost in the process of influence between an agent and the target (Blau, 1964; Emerson, 1962), this paper hypothesized that the power congruence of supervisors and subordinates was anchored on 9 types of influence tactics. Three hundred and eighty-five pairs of Malaysian managers and executives working in manufacturing companies voluntarily participated in this study. The findings suggested that supervisors would use a combination of hard and soft tactics when their subordinates perceived them to have position or personal power. Implications of the findings, potential limitations of the study, and directions for future research were further discussed.
\end{abstract}

Keywords: Malaysia manufacturing industry, Power congruence, Downward influence tactics

\section{Introduction}

Social power relationship occurs naturally when people with different levels of potential power interact to accomplish organizational goals (Mossholder, Kemery, Bennett, \& Wesolowski, 1998). Theorists such as Barnard (1938), Blau (1964), Mechanic (1962), and Weick (1969) contended that supervisors' relationship with subordinates represented an important source of power to exert influence in their organizations. Blau's (1964) social exchange theory was built upon Gouldner's (1960) norm of reciprocity which stated that: “(i) people should help those who have helped them, and (ii) people should not injure those who have helped them" (Gouldner, 1960, p. 171). Past studies on leadership have not found conclusive evidence on Malaysian leadership style. For example, Gill (1998) suggested that Malaysian managers are found to be more direct, less delegate, and are more transactional. However, Govindan (2000) reported that Malaysian leaders lean more towards participative and consultative styles. This is in line with the assertion of Abdullah (1992) that the use of stronger tactics in Malaysian context is not likable as Malaysians generally are not in favor of overt display of anger and aggressive behavior.

Despite the enormous breadth of the literature on the relevance of power to organizational influence in general, and to an understanding of leadership in particular, research studies of power and influence are not well integrated. This is evidenced where the research on influence strategies that superiors use to translate power into actual influence is relatively recent (Ansari, 1990; Farrell \& Schroder, 1999; Hinkin \& Schriesheim, 1990; Somech \& Drach-Zahavy, 2002; Venkatesh, Kohli, \& Zaltman, 1995). In addition to that, no known researches have focused specifically on the factors that contribute to the interaction effects between the supervisors' self-perceptions of power and their subordinates' perceptions of them and vice versa, and their impact on supervisors' influence tactics. Even though the concept of fit has served as an important building block in several areas of research, there is still a lack of corresponding schemes by which fit has been tested (Venkatraman, 1989). Hence this study has two objectives in mind. First is to examine whether congruence between supervisors' perception of subordinates' power and subordinates' self-reported power predict the use of influence tactics and secondly, whether the congruence between supervisors' self-report power and subordinates' perception of supervisors' power predict the use of influence tactics. 


\section{Power and downward influence}

Extensive research is available in the organizational behavior literature investigating the process of interpersonal influence and social power. But the two constructs--power and influence seem to have been examined almost independently. A few researchers (e.g., Yang et al., 1998; Yang \& Cervero, 2001) have used the two terms--power and influence--interchangeably. For example, Mechnic (1962) considered power, influence, and control as synonymous. In the same vein, other researchers (e.g., Salancik \& Pfeffer, 1977; Tannenbaum, 1968) have defined power and influence as synonyms and used interchangeably, where the important element is control which can be exercised through formal authority.

Nonetheless, most of the researchers agree that power and influence are two distinct terms, where power refers to the potential influence, and influence as the actual use of power. It is reported that manager's effectiveness depends on his or her success in influencing others (Bass, 1990; Kotter, 1985). In other words, leadership is the ability of an individual to influence, motivate, and make others contribute towards the effectiveness and success of their organizations. Yukl and Van Fleet (1982) revealed that supervisory power is important not only for influencing subordinates, but can be used to influence peers, superiors, and also outsiders. That is, little research has been done to examine the relationship between bases of power and the use of downward influence tactics in organizations (Ansari, 1990; Hinkin \& Schriesheim, 1990). This is particularly true in the Malaysian context.

Kipnis (1976) contended that people who have a strong need for power and the ability to gain control of resources are likely to experience a desire to influence others. As a result, those being influenced will be gradually devalued, with the powerful individuals preferring to maintain social and psychological distance. The power and influence approach attempts to define leadership effectiveness in terms of the power as possessed by leaders, the types of power, and how power is exercised (Yukl, 2005). Similarly, leaders should employ different strategies in order to gain power through formal authority, reputation, and performance. It was found that power can be obtained through formal authority or informal coalitions with political influence (Pfeffer, 1992). Hence, this approach incorporates issues of change in the organizations and also accumulation and loss of power.

Kipnis, Schmidt, and Wilkinson (1980) crafted the original taxonomy of influence tactics and this was subsequently modified by Kipnis and Schmidt (1983) and their eventual development of a commercial version of their questionnaires known as the Profile of Organizational Influence Strategies (POIS) was developed. In the course of their research on intraorganizational influence tactics, Kipnis et al. initially have identified a large number of influence tactics, which they later factor analyzed, reducing the number of subscales into seven dimensions. The tactics that were identified are (i) reason, (ii) friendliness, (iii) coalition, (iv) bargaining, (v) assertiveness, (vi) higher authority, and (vii) sanctions. Beginning with the landmark work of Kipnis et al., other experts have also begun to examine the interpersonal influence processes in organizations (Ansari \& Kapoor, 1987; Erez \& Rim, 1982; Erez, Kim, \& Keider., 1986; Schriesheim \& Hinkin, 1990).

It was found that various factors such as organizational, personal, and situational factors have contributed to the success of influence style (Kipnis, Schmidt, Swaffin-Smith, \& Wilkinson, 1984). On a similar note, when influencing subordinates, supervisors were more likely to use assertiveness, friendliness, bargaining, and higher authority. Managers were found to vary their style of influence depending on the discrepancy in power between them and the target, how successfully they want to influence their subordinates, and also the number of reasons managers had for exercising influence. Another measure which is worth mentioning is the Influence Behavior Questionnaire (IBQ) designed by Yukl and Falbe (1990). The IBQ is a reconceptualization of Kipnis et al.'s (1980) earliest framework and the addition of two new tactics namely, inspirational appeals and consultation. Yukl and his associates (Falbe \& Yukl, 1992; Yukl, Kim, \& Falbe, 1996; Yukl \& Tracey, 1992) later developed the most comprehensive taxonomy of influence tactics, consisting of nine influence tactics (Cable \& Judge, 2003). The nine influence tactics are (i) pressure tactics, (ii) exchange tactics, (iii) coalition tactics, (iv) ingratiating tactics, (v) rational persuasion, (vi) inspirational appeals, (vii) consultation tactics, (viii) legitimating tactics, and lastly (ix) personal appeals. Even though Yukl's taxonomy was developed from Kipnis', it is claimed that the additional tactics included made the taxonomy more suitable for the use of managers. In fact, Yukl has further classified the outcomes of influence efforts into three qualitative groups known as commitment, compliance, and resistance. Kelman (1974) contended that this influence process relies upon the target's need for acceptance or esteem to gain compliance.

Further, other studies (Ansari, 1990; Bhal \& Ansari, 2000) have discovered another three new tactics known as showing expertise, personalized help, and instrumental dependency in Indian settings. In addition to that, some researchers have extended the influence tactics into 11 influence tactics that are relevant to managers (Yukl \& Seifert, 2002). According to their study, the four core tactics--rational persuasion, inspirational appeals, consultation, and collaboration are most likely to result in commitment by the target person, whereas other tactics such as exchange, pressure, or coalition were more likely to result in either compliance or resistance. 
Previous studies have examined the directional differences in influence behavior (Ansari, 1990; Bennebroek \& Boonstra, 1998; Bhal \& Ansari, 2000; Kipnis et al., 1980; Yukl \& Falbe, 1990; Yukl, Falbe, \& Youn., 1993; Yukl \& Tracey, 1992). Their findings have shown that the use of influence tactics is connected to the hierarchical relationship between the agent and target. The results of Burke (1986) and House, Filley, and Gujarati (1971) indicated that, downward power depended on the individual's upward power and lateral power where it could be seen as combining to influence an individual's total personal power. This implies that managers would adopt different influence tactics depending on whether they want to influence a subordinate, a colleague, or a supervisor. Kipnis and Schmidt (1985) introduced the idea of three basic intraorganizational influence dimensions known as hard, soft, and rational influence tactics. This classification of influence tactics has since been adopted by other researchers such as Deluga (1991), Falbe and Yukl (1992), and Thacker and Wayne (1995).

\section{Methodology}

\subsection{Sample}

With an aim to generalize on supervisors and subordinates in Malaysia, the population of the present study consists of supervisors and subordinates currently employed in large scale manufacturing companies in Malaysia. Malaysia is gradually becoming a major destination for foreign investment, particularly in the manufacturing sector. Since the 1980 's, Malaysia has started to diversify and transform its economy into a more industrialized one. This endeavor has been seeing continuing success, with manufacturing and high-tech industries now playing a significant role in shaping the economic expansion of the state. Currently, the manufacturing sector is considered as one of the cornerstone of Malaysia's economic diversification strategy. As the aim of this research is to study the relationship between supervisors' and subordinates' power, and their choice of influence tactics for influencing their subordinates, the unit of analysis is at individual level that is the individuals that make up the supervisor-subordinate dyads. 1,300 pairs of questionnaires were distributed to from executives working at 82 manufacturing companies that participated in this study, only 385 pairs were usable for analysis. 43 companies (53\%) from the industrial sector formed the majority of participating companies, followed by the consumer sector with 27 (32.5\%) companies, and the construction sector with $12(14.5 \%)$ companies. Of the sample, most of the companies were predominantly Malaysian companies, $52(63.4 \%)$. Others were American companies, 17 (20.7\%); Japanese companies, 6 (7.3\%); European companies, 2 (2.5\%); and others (consisting of Taiwanese, Korean, and Singaporean based companies), 5 (6.1\%).

\subsection{Measures}

Forty-four items arranged in random order in the questionnaires were used to measure the 9 influence tactics employed by supervisors in their attempts to influence their subordinates. Those items used as influence tactics were not gathered from one source, but were taken from different researches (Ansari, 1990; Ansari \& Kapoor, 1987; Bhal \& Ansari, 2000; Kipnis et al., 1980; Schriesheim \& Hinkin, 1990) and were grouped into three known as hard, soft, and rational tactics. Subjects were specifically cautioned not to make any judgment about the desirability or undesirability of the behaviors described and to merely report the frequency of attempts made by their supervisors to change their mind or opinion in the workplace. The subordinates were asked to describe on a 7-point Likert scale with the following anchors: never (1), almost never (2), seldom (3), sometimes (4), usually (5), almost always (6), always (7).

The five bases of power taxonomy as proposed by French and Raven, namely, reward, coercive, legitimate, referent, and expert power were used in this study as it still appears to be fairly representative and popular in application (Ansari, 1990; Frost \& Stahelski, 1988; Rahim, 1989; Rahim, Antonioni, Krumov, \& Ilieva., 2000). In addition, the items for another two power bases, namely information and connection, were adapted from the works by Ansari (1990) and Bhal and Ansari (2000). For the purpose of this study, the seven bases of power were further grouped under position and personal power. There were all together 35 items in the power bases section. Though these 35 items measured the same power dimensions, two versions had to be developed, one for the supervisors and one for the subordinates. Both versions had the same items but minor changes in wording were needed to make the questionnaire suitable for respondents in describing their own and their targets' power. Respondents were asked to rate their perception using the 7-point Likert scale with: $7=$ strongly agree, $6=$ agree, $5=$ slightly agree, $4=$ neutral, $3=$ slightly disagree, $2=$ disagree, and $1=$ strongly disagree, for all the 35 items. A higher score indicates greater bases of the supervisors' or subordinates' power.

\subsection{Analysis and results}

The reliability of the scales was assessed through Cronbach's coefficient alpha. The reliability coefficients and zero-order correlations among study variables are contained in Table 1.

Generally, the values indicating intercorrelations among the predictors variables were low, ranging from .13 to .43 . Only 17 out of 28 intercorrelation factors were statistically significant, thus indicating the independence of the scales used for measuring the predictors. In addition to that, a number of the predictor variables were noted to be significantly correlated to the criterion variables ranging from -.27 to .52 , which were considered as low intercorrelation values. 
In order to test the formulated hypotheses, a series of hierarchical multiple regression were conducted. The hierarchical regression equations consisted of three models. In the first model on each equation gender was entered as the control variable. It was necessary to control gender to ensure clearer, credible results as previous studies on the effect of gender the criterion variable had been inconsistent. The equation for the second model consists of the four perspectives (two each from both supervisors and subordinates) for the independent variables, namely position power and personal power. This is followed by the interaction terms of position and personal power from each perspective for simultaneous equations. Three separate hierarchical multiple regressions analyses were conducted for each of the dependent variables namely, hard, soft, and rational influence tactics. Results for the interaction effects are contained in Table 2.

The results have indicated that hard tactic will be used when subordinates' perception of personal power congruent with supervisors' perception of subordinates personal power $(\beta=1.06, p<.05)$. On the other hand, when supervisors self reported position power which interacted with subordinates' perception of supervisors' position power $(\beta=1.05, p$ $<.01$ ), soft tactics will be applied.

As illustrated in Figure 1, when supervisors perceived themselves as having low and high position power, and at the same time subordinates perceived the supervisors as having low to moderate power, then there is minimal impact on the use of soft tactics. In contrast, supervisors would apply more soft tactics to subordinates who perceived them as having high position power.

This indicates that supervisors who perceived themselves to have high position power would use soft influence tactics more frequently compared to supervisors who viewed themselves to have low or moderate position power.

In the cases where supervisors' perceptions were congruent with subordinates self-report that subordinates only possessed low to moderate personal power, supervisors use of hard tactics registered negligible changes. On the other hand, the use of hard tactics was more prominent when supervisors' perceived subordinates as possessing high personal power. The statistically significant interaction effect $(\beta=1.06, p<.05)$ are depicted in Figure 2.

Nevertheless, when subordinates' self-reported personal power reached above moderate levels, the use of hard influence tactics decreased drastically if supervisors' perceived their subordinates as having personal power regardless of whether it was low, moderate, or high. Thus, it can be concluded that if subordinates were perceived to hold high personal power, supervisors would apply hard tactics on them when at the same time; subordinates viewed themselves as possessing moderate and below personal power.

\section{Discussion and conclusions}

Contrary to expectation, soft tactics appeared to be the most commonly used tactics when supervisors' perceived themselves and were also perceived by subordinates to have position power. The rationale could be due to the fact that supervisors were aware that the attribution of success using the softer influence tactics such as personalized help and ingratiation could contribute to better interpersonal relations and help gain the support of members (Tandon, Ansari, \& Kapoor, 1991). Subordinates were often found to respect the hierarchy of social positions in effect in the organization and hence were more receptive to instructions, thus guaranteeing compliance (Chambon, 2005) without the need to use hard influence tactics. In addition, using the power-dependence theory, Sell, Lovaglia, Mannix, Samuelson, and Wilson (2004) explained that the more dependent an individual is on a social relationship, the less power that individual has.

As noted by Somech and Drach-Zahavy (2002), previous studies have shown that subordinates responded more favorably to personal power rather than positional power, as supervisors who used personal power were more likely to make the target feel useful and appreciated. On a similar note, Abdullah (1996) endorsed that Malaysian managers like to create a sense of "family atmosphere" among their employees as this will instill in them a sense of commitment to the organization.

Surprisingly, in the case of personal power, when the subordinates' self perception co-incided with the supervisors' perceptions of the subordinates', supervisors would resort to the usage of hard influence tactics. This could probably be due to the fact that supervisors were reluctant to admit or recognize the referent or expertise power bases of their subordinates, and in such situations those power cannot be translated into influence on the supervisors (Rodrigues \& Lloyd, 1998). As noted by Greene and Podsakoff (1981), when the leaders were under pressure to maintain high-productivity deadline, they would tend to disregard their subordinates' power and judged the targets as unworthy and hence use more hard tactics (Raven, 1993).

Rational appeal did not seem to be related to any power congruence variable. According to Yukl and Tracey (1992), studies found that rational persuasion and consultation are the most effective tactics for influencing peers. This is further supported by Brass and Burkhardt (1993) who stated that this influence tactic appeared to be "universal" and were unaffected by structural factors. Besides, others researchers such as Tepper, Brown, and Hunt (1998) indicated that subordinates regarded managers' use of rational influence tactics to be more objectionable only if it were used together with soft influence tactics. 


\section{Limitations and future research}

As with any research, this study has several limitations. This current study has relied primarily on samples drawn specifically from the workers in the manufacturing sectors. Besides, the data were collected from both the subordinates and their supervisors at a single point in time, hence the direction of causality cannot be determined. Clearly, a longitudinal approach would have placed researcher in a better position to draw causal conclusions. Therefore, only conclusions or discussions of the general relationships between the variables of interest could be drawn.

\section{Practical considerations}

The study has important implications for practicing managers. It is believed that by understanding their subordinates' power bases, supervisors when they become targets themselves can gain greater insights into the tactics used by their subordinates and thus avoid negative outcomes. In other words, supervisors would experience fewer conflicts and misunderstandings if they realized that some of the "confrontational" influence styles used by some subordinates are actually the results of power differences rather than personal hostility. It is believed that by sharing power with subordinates, it may be possible to expand the total amount of power available to the organization. More importantly, it allows management to control and accurately predict employees' behaviors and attitudes by using the appropriate influence tactic or combination tactics in tandem with the power bases for successful targeted outcomes such as compliance or commitment. This suggests that increasing a leader's awareness of how his or her self-perceptions compared to the subordinates' perceptions can lead to greater agreement.

\section{References}

Abdullah, A. (1992). Influence of ethnic values at the Malaysian workforce. In A. Abdullah (Ed.), Understanding the Malaysian workforce: Guidelines for managers (pp. 1-17). Kuala Lumpur: Malaysian Institute of Management.

Abdullah, A. (1996). Going glocal: Cultural dimensions in Malaysian management. Kuala Lumpur: Malaysian Institute of Management.

Ansari, M. A. (1990). Managing people at work: Leadership styles and influence strategies. Newbury Park, CA: Sage.

Ansari, M. A., \& Kapoor, A. (1987). Organizational context and upward influence tactics. Organizational Behavior and Human Decision Processes, 40, 39-49.

Barnard, C. I. (1938). The functions of the executive. Cambridge, MA: Harvard University Press.

Bass, B. M. (1990). Bass and Stogdill's handbook of leadership: Theory, research, and managerial applications. New York: Free Press.

Bennebroek, G. K. M., \& Boonstra, J. J. (1998). The use of influence tactics in constructive change process. European Journal of Work and Organizational Psychology, 7, 179-196.

Bhal, K. T., \& Ansari, M. A. (2000). Managing dyadic interactions in organizational leadership. New Delhi: Sage.

Blau, P. M. (1964). Exchange and power in social life. New York: Wiley.

Brass, D. J., \& Burkhardt, M. E. (1993). Potential power and power use: An investigation of structure and behavior. Academy of Management Journal, 36, 441-470.

Burke, W. (1986). Leadership as empowering others. In S. Srivastra and Associeates (Eds.), Executive power: How Executives influence people and organizations (pp. 51-77). San Francisco: Jossey-Bass.

Cable, D. M., \& Judge, T. A. (2003). Managers' upward influence tactic strategies: The role of manager personality and supervisor leadership style. Journal of Organizational Behavior, 24, 197-214.

Chambon, M. (2005). How to look modest in organization: Supervisors' perceptions of subordinates' account for success. Psychologie du Travail et des Organisation, 11, 151-164.

Deluga, R. J. (1991). The relationship of subordinate upward-influencing behavior, health care manager interpersonal stress, and performance. Journal of Applied Psychology, 21, 78-88.

Emerson, R. M. (1962). Power-dependence relations. American Sociological Review, 27, 31-41.

Erez, M., \& Rim, Y. (1982). The relationship between goals, influence tactics, and personal and organizational variables. Human Relations, 35, 871-878.

Erez, M., Rim, Y., \& Keider, I. (1986). The two sides of the tactics of influence: Agent vs. target. Journal of Occupational Psychology, 59, 25-39.

Falbe, C. M., \& Yukl, G. (1992). Consequences of managers using single influence tactics and combinations of tactics. The Academy of Management Journal, 33, 638-652. 
Farrell, M., \& Schroder, B. (1999). Power and influence in the buying center. European Journal of Marketing, 33, 1161-1170.

Frost, D. E., \& Stahelski, A. J. (1988). The systematic measurement of French and Raven's bases of social power in workgroups. Journal of Applied Social Psychology, 18, 375-389.

Gill, R. (1998). Cross-cultural comparison of the leadership styles and behavior of managers in the UK, USA and Southeast Asia. Asian Academy of Management Journal, 3, 19-32.

Gouldner, A. W. (1960). The norm of reciprocity: A preliminary statement. American Sociological Review, 25, 161-178.

Govindan, J .T. (2000). The Influence of Social Value Orientations and Demographic Factors on Leadership Preference among Malaysians. Unpublished MBA thesis. Penang: University Science Malaysia.

Greene, C. N., \& Podsakoff, P. M. (1981). Effects of withdrawal on a performance-contingent reward on supervisory influence and power. Academy of Management Journal, 24, 527-542.

Hinkin, T. R., \& Schriesheim, C. A. (1990). Relationships between subordinate perceptions of supervisor influence tactics and attributed bases of supervisory power. Human Relations, 43, 221-237.

House, R., Filley, A., \& Gujarati, D. (1971). Leadership style, hierarchical influence and the satisfaction of the subordinate role expectations. Journal of Applied Psychology, 55, 422-432.

Kelman, H. C. (1974). Further thoughts on the processes of compliance, identification, and internalization. In J. T. Tedeschi (Ed.), Perspectives on Social Power, (pp. 125-171). Chicago: Aldine.

Kipnis, D., \& Schmidt, S. M. (1983). An influence perspective on bargaining within organizations. In M. H. Bazerman, \& J. L. Roy (Eds.), Bargaining inside organizations (pp. 303-319). Beverley Hills, CA: Sage.

Kipnis, D., \& Schmidt, S. M. (1985). The language of persuasion. Psychology Today, 4, 40-46.

Kipnis, D., Schmidt, S. M., \& Wilkinson, I. (1980). Intraorganizational influence tactics: Explorations in getting one's way. Journal of Applied Psychology, 65, 440-452.

Kipnis, D., Schmidt, S. M., Swaffin-Smith, C., \& Wilkinson, I. (1984). Patterns of managerial influence: Shortgun manager, tactician, and bystanders. Organizational Dynamics, 12, 58-67.

Kotter, J. P. (1985). Power and influence. New York: The Free Press.

Mechanic, D. (1962). Sources of power of lower participants in complex organizations. Administrative Science Quarterly, 7, 349-364.

Mechanic, D. (1962). Sources of power of lower participants in complex organizations. Administrative Science Quarterly, 7, 349-364.

Mossholder, K. W., Kemery, E. R., Bennett, N., \& Wesolowski, M. A. (1998). Relationship between bases of power and work reactions: The mediational role of procedural justice. Journal of Management, 24, 533-552.

Pfeffer, J. (1992). Managing with power. Boston, MA: Harvard Business School Press.

Rahim, M. A. (1989). Relationships of leader power to compliance and satisfaction with supervision: Evidence form a national sample of managers. Journal of Management, 15, 545-576.

Rahim, M. A., Antonioni, D., Krumov, K., \& Ilieva, S. (2000). Power, conflict, and effectiveness. A cross-cultural study in the United States and Bulgaria. European Psychologist, 5, 28-33.

Raven, B. H. (1993). Bases of power: Origins and recent developments. Journal of Social Issues, 49, 227-251.

Rodrigues, A., \& Lloyd, K. L. (1998). Reexamining bases of power from an attributional perspective. Journal of Applied Social Psychology, 28, 973-997.

Salancik, G. R., \& Pfeffer, J. (1977). Who gets power and how they hold on to it: A strategic-contingency model of power. Organizational Dynamics, 5, 3-21.

Sell, J., Lovaglia, M. J., Mannix, E. A., Samuelson, C. D., \& Wilson, R. K. (2004). Investigating conflict, power, and status within and among groups. Small Group Research, 35, 44-72.

Somech, A., \& Drach-Zahavy, A. (2002). Relative power and influence strategies: The effects of agent/target organizational power on superiors' choices of influence strategies. Journal of Organizational Behavior, 23, 167-179.

Tandon, K., Ansari, M. A., \& Kapoor, A. (1991). Attributing upward influence attempts in organizations. The Journal of Psychology, 125, 59-63. 
Tannenbaum, A. S. (1968). Control in organizations. In A. Tannenbaum (Ed.), Control in organizations (pp. 3-30). New York: McGraw-Hill.

Tepper, B. J., Brown, S. J., \& Hunt, M. D. (1993). Strength of subordinates' upward influence tactics and gender congruency effects. Journal of Applied Psychology, 23, 1903-1919.

Thacker, R. A., \& Wayne, S. J. (1995). An examination of the relationship between upward influence tactics and assessments of promotability, Journal of Management, 21, 739-756.

Venkatesh, R., Kohli, A. K., \& Zaltman G. (1995). Influence strategies in buying centers. Journal of Marketing, 4, 71-82.

Venkatraman, N. (1989). The concept of fit in strategy research: Toward verbal and statistical correspondence. Academy of Management Review, 14, 423-444.

Weick, K. E. (1969). The social psychology of organizing. Readings, MA: Addison-Wesley.

Yang, B., \& Cervero, R. M. (2001). Power and influence styles in programme planning: Relationship with organizational political contexts. International Journal of Lifelong Education, 29, 289-296.

Yang, B., Cervero, R. M., Valentine, T., \& Benson, J. (1998). Development and validation of an instrument to measure adult educators' power and influence tactics in program planning practice. Adult Education Quarterly, 48, $227-255$.

Yukl, G. A. (2005). Leadership in organizations (6 ${ }^{\text {th }}$ ed.). Upper Saddle River, NJ: Prentice-Hall.

Yukl, G. A., Kim, H., \& Falbe, C. M. (1996). Antecedents of influence outcomes. Journal of Applied Psychology, 81, 309-17.

Yukl, G., \& Falbe, C. M. (1990). Influence tactics and objectives in upward, downward and lateral influence attempts. Journal of Applied Psychology, 75, 132-140.

Yukl, G., \& Seifert, C. (2002). Validation of the extended version of the Influence Behavior Questionnaire. Poster session presented at the annual meeting of the Society for Industrial and Organizational Psychology, Toronto, Ontario, Canada.

Yukl, G., \& Tracey, J. B. (1992). Consequences of influence tactics used with subordinate, peers, and the boss. Journal of Applied Psychology, 77, 522-535.

Yukl, G., \& Van Fleet, D. D. (1982). Cross-situational, multi-method research on military leader effectiveness. Organizational Behavior and Human Performance, 30, 87-108.

Yukl, G., Falbe, C. M., \& Youn, J. Y. (1993). Patterns of influence behavior for managers. Group \& Organization Management, 18, 5-28. 


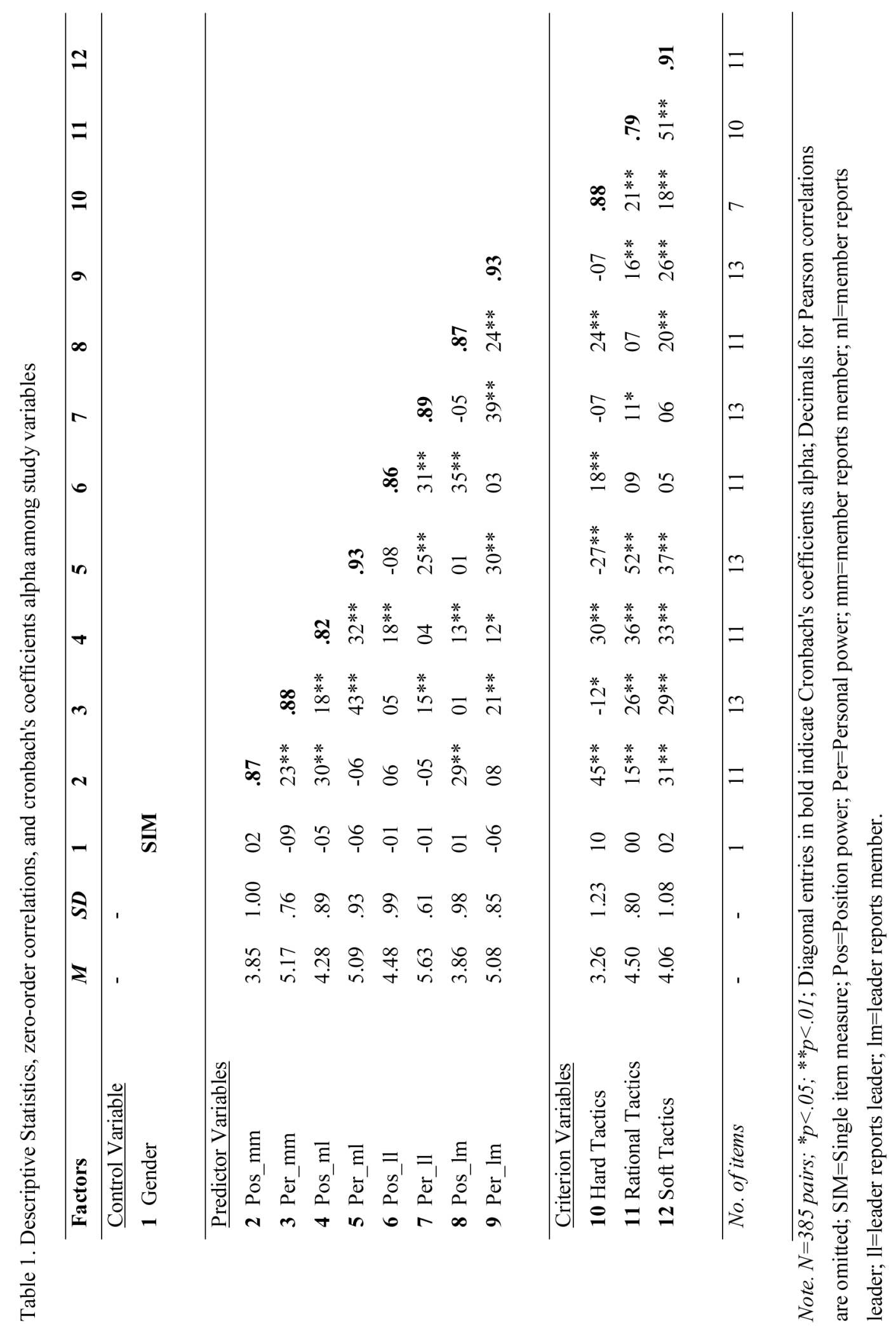




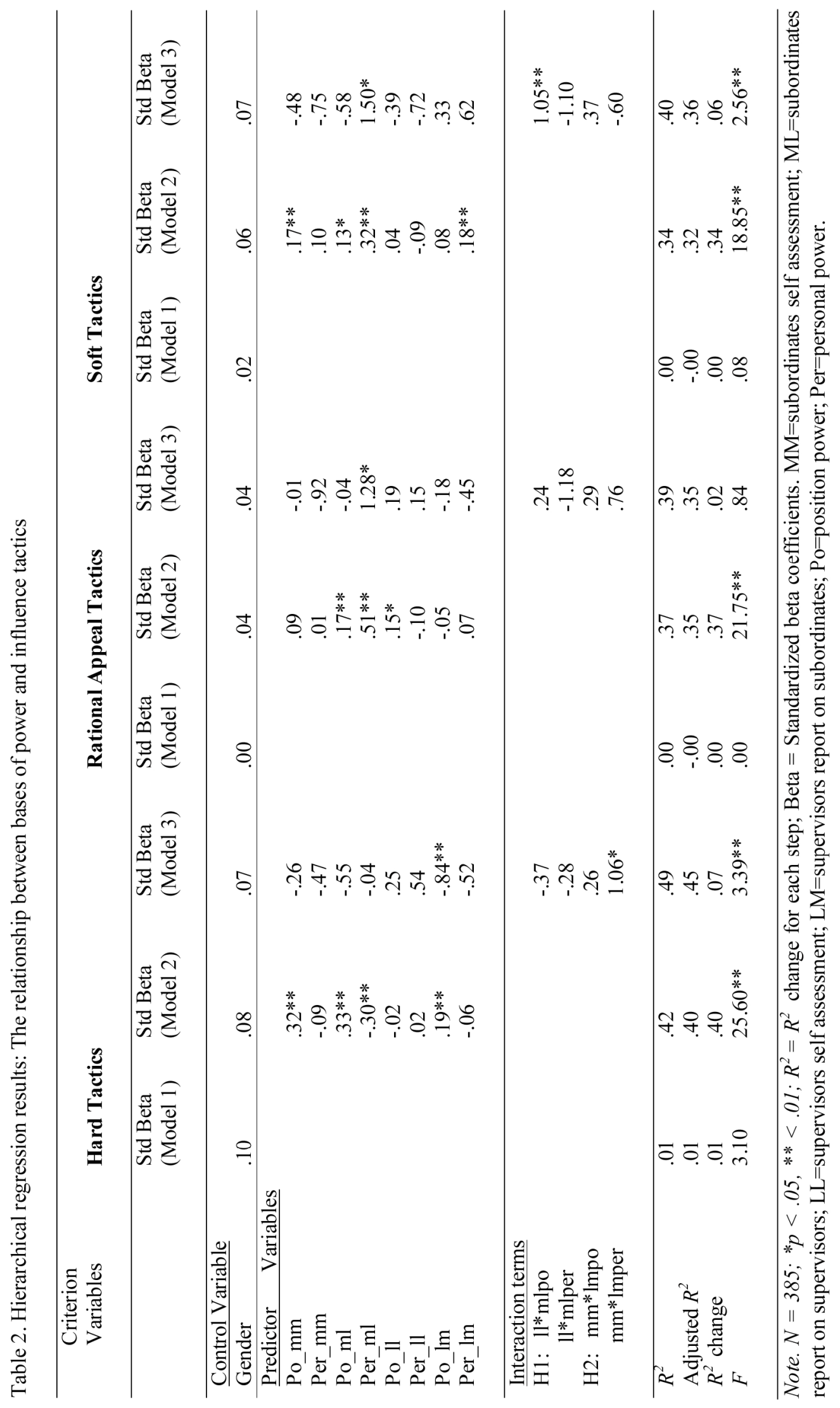




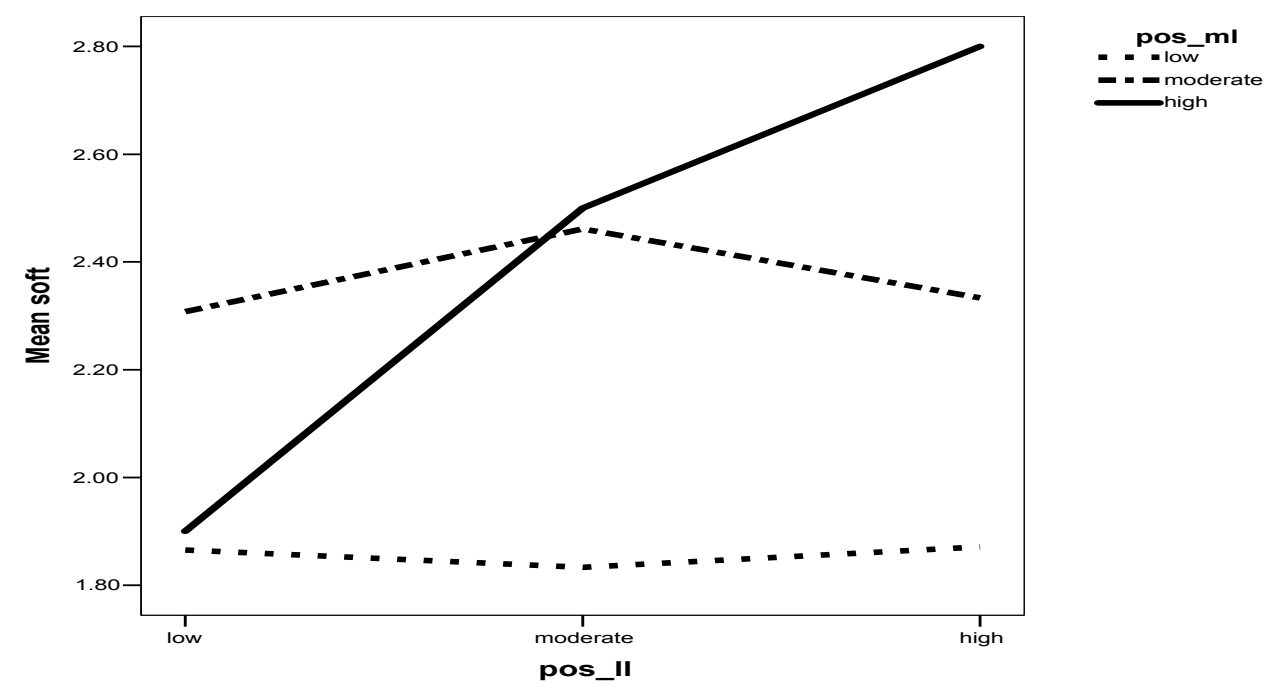

Figure 1. Interaction between supervisors' self-reported and subordinates' perception of supervisors' position power for soft influence tactics.

Note. Pos_ml=subordinates report on supervisors' position power; pos_ll=supervisors self assessment of position power.

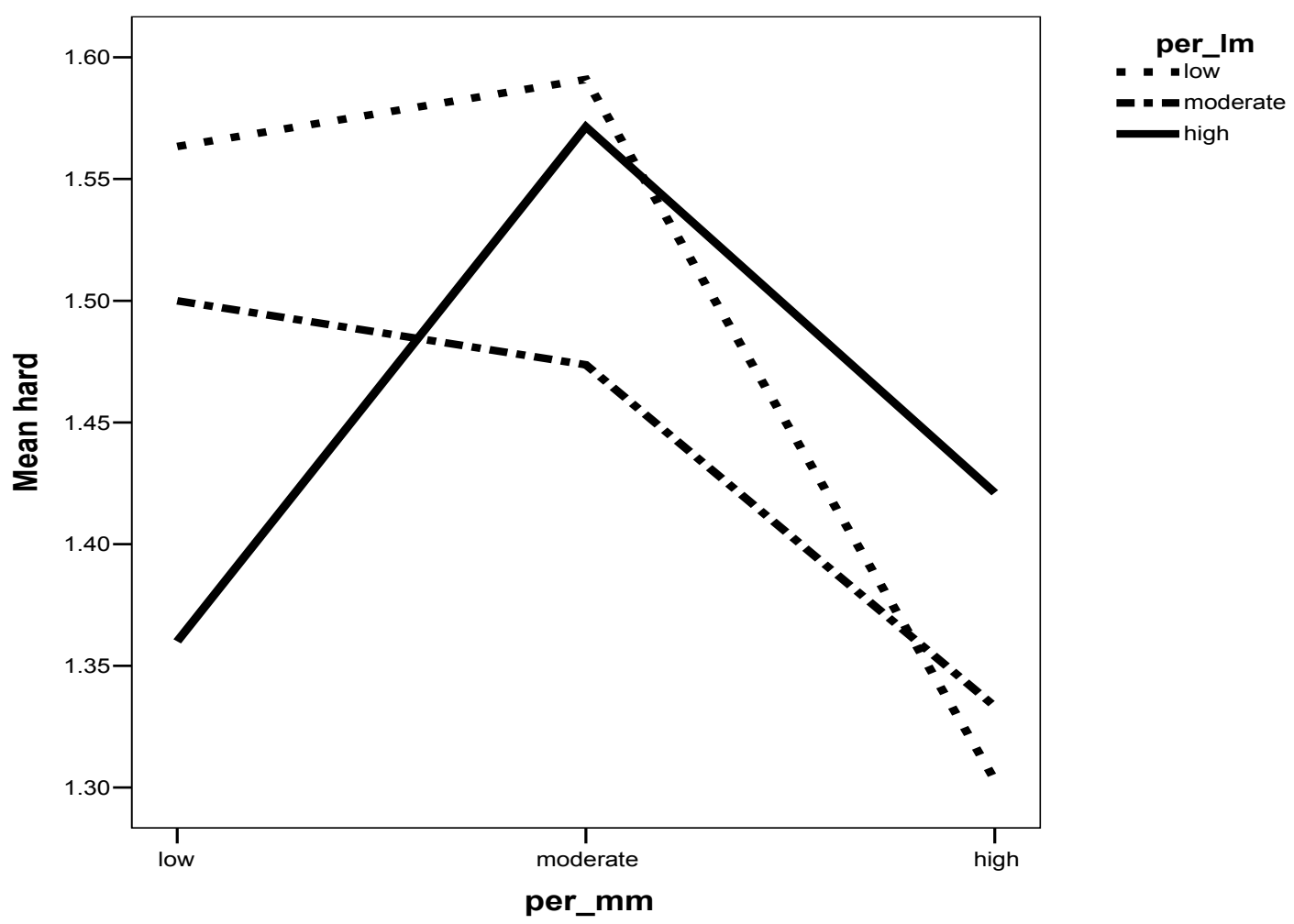

Figure 2. Interaction between subordinates' self-reported and supervisors' perception of subordinates' personal power on hard tactics.

Note. Per_lm=supervisors report on subordinates' personal power; per_mm=subordinates self assessment of personal power. 


\title{
Analysis of the Market Prospect of Folk Cultural
}

\section{Heritage Exhibition Center in Longji}

\author{
Jin Zhang \\ College of Tourism, Guilin University of Technology, Guilin 541004, China \\ E-mail:koiohjkl@qq.com
}

\begin{abstract}
This paper firstly clarifies the concept of cultural heritage and folk cultural heritage and introduces the situation of folk cultural heritage and the tourism development in Guangxi, and then analyses the environment of tourism market of cultural heritage as well as the development advantage of folk cultural heritage exhibition center in Longji, so as to forecast the market prospect of the exhibition center.
\end{abstract}

Keywords: Folk cultural heritage, Exhibition center, Market

\section{The definition of cultural heritage and folk cultural heritage}

Cultural heritage, which was produced and used in the past, kept up until now, and will be left behind to the future, is the common property of human. Cultural heritage includes tangible cultural heritage and intangible cultural heritage. Tangible cultural heritage is the cultural relic that has historical, artistic and scientific values, including ancient site, ancient tombs, ancient architecture, cave temple, stone carving, fresco, the unmovable historical sites and unique architecture in the modern time, the movable artistic work, literature, manuscript, books in the history, as well as the historic city (block, town) that integrated the architecture and environment well and has outstanding value. The intangible cultural heritage is the traditional cultural form that is intangible but has close relationship with people's daily life and is passed on generation after generation, including oral tradition, traditional artistic form, folk activities, etiquette, festival celebration, the traditional knowledge and practice about the nature and universe, the traditional handicraft skill, as well as the cultural space correlating with the traditional culture mentioned above.

Folk cultural heritage is the cultural heritage that is created and preserved by ethnic groups in the history. In broad sense, folk culture heritage has similar meaning with cultural heritage, because cultural heritage can not be created by social individual; in narrow sense, folk cultural heritage is the cultural heritage that is created and passed on by a special people in the process of history, which includes tangible folk cultural heritage and intangible folk cultural heritage. Folk cultural heritage contains the spiritual value, thinking method and imagination of the people and embodies the life force and creativity of Chinese people. Further more, folk cultural heritage embodies the intelligence of every people and is the treasure of whole mankind.

\section{General situation of folk cultural heritage in Guangxi and the status quo of tourism development}

\subsection{General situation of folk cultural heritage in Guangxi}

Guangxi is a place where multiple peoples live from time immemorial; various peoples exploited the treasured land in the southern China and created colorful folk culture.

The aboriginals in Guangxi are minorities from time immemorial. At the end of Qin and the beginning of Han, the distribution of various minorities in Guangxi exhibited plural pattern, The Cangwu people dwelled at the northeast of Guangxi, the Xiou people dwelled at the eastern and middle Guangxi, and the Luoyue people dwelled at the western Guangxi. After the unification of Lingnan Area by Qin Shi Huang, the Han Chinese from Inner China moved to Guangxi, and began to exploit Guangxi with the aboriginals. After the Han dynasty and until Tang and Song dynasty, the aboriginal minorities in Guangxi differentiated and integrated into Zhuang nationality, Dong nationality, Maonan nationality, Mulao nationality, Shui nationality, Yao nationality and Miao nationality, further more, Hui nationality began to move to Guangxi. At Ming and Qing dynasties, Yi nationality, Jing nationality and Gelao nationality moved to Guangxi. Meanwhile, the Han nationality moved to Guangxi continuously, and fused with part of the minorities. At Qing dynasty, the number of Han nationality in Guangxi is much larger than that of minorities, further more, the Han nationality mainly dwelled at the southeast of Guangxi and minorities mainly dwelled at the northwest of Guangxi. After the establishment of People's Republic of China, the state council formally admitted that the eleven minorities, including Zhuang nationality, Yao nationality, Miao nationality, Dong nationality, Maonan nationality, Mulao nationality, Yi nationality, Jing nationality, Hui nationality, Shui nationality and Gelao nationality, are minorities that lived in 
Guangxi for generations and they would develop and construct Guangxi with the Han nationality.

The Han nationality moved to Guangxi after the unification of Lingnan Area by Qin Shi Huang, and it brought more advanced material culture and spiritual culture from the Inner China, which greatly influenced the social development and culture of minorities in Guangxi. The minorities in Guangxi created unique folk culture during the long process of social development; they made great invention in literature and art, technological medicament, traditional physical training and so on. For example, the world famous Huashan fresco was firstly created by the ancestor of Zhuang nationality, Zhenwu Pavilion in Rong County, the artistic treasure of folk architecture, the Chengyang Wind and Rain Bridge in Sanjiang County, and the Mapang Drum-Tower were the products of the wisdom of Han nationality and Dong nationality and so on. Guangxi is the sea of song, the minorities created large number of folk songs and stories and colorful folk festival culture. In terms of folk medicine, there are lots of folk prescriptions in Zhuang nationality, Yao nationality, Miao nationality and Dong nationality. In addition, the minorities in Guangxi made great achievement in folk industrial arts, such as the world famous embroidery, brocade, wax printing, ceramic, and inscriptions.

In a word, the various nationalities in Guangxi influenced each other in the long term economic and cultural communication, and created colorful folk culture, and left behind numerous cultural heritages for the later generations.

\subsection{The status quo of tourism development of the folk cultural heritage}

The unique folk culture and Guilin landscape are the two main factors to attract tourists to travel in Guangxi. At present, there are some well developed and operated folk cultural heritage tourism regions, such as Longji terraced landscape in Longsheng County, but the status quo of tourism development in Guangxi doesn't commensurate with the abundant folk cultural heritage.

Lack of investment is one of the main problems in the development of folk cultural heritage in Guangxi. Guangxi is an underdeveloped province, which has weak economic strength. In most regions, the general investigation and scientific programming on cultural heritage can not be carried out, which lead to the low-level and single development of folk cultural heritage. In some regions, the blind development of cultural heritage exhibited the phenomenon of repeated construction.

Lack of capital makes numerous folk cultural heritages be in the state of underdevelopment. The present folk cultural tourism products are single and out of date, the infrastructure and supporting facilities for tourism are weak, inadequate, low-level, further more, the traffic and communication are not good, which can not meet the growing need of tourists.

In addition, the construction of public toilet, virescence, communication and sight spot, as well as the publicity and promotion need much money, so the situation is not going well as far as the tourism resource development and protection considered. Some precious tangible folk cultural heritages are still being destroyed, while some intangible folk cultural heritages gradually disappeared or are being vulgarized or commercialized by the inappropriate development behavior. The protection of folk cultural heritage is facing up with serious problems.

More over, the folk cultural heritage can not be developed at an all-round way because the lack of capital. The site spots of folk culture heritage are separated from each other, so it is difficult to realize "large scale effect".

\section{The folk cultural heritage exhibition center in Longji}

With the purpose of protecting the precious folk cultural heritage and displaying the unique folk culture in Guangxi, in May, 2007, local government of Longsheng County decided to establish a folk cultural heritage exhibition center at the entrance of Longji scenic spot to exhibit the folk culture of the eleven minorities in Guangxi. The exhibition center will spread the colorful and long standing folk culture to the tourists from all over the world in a live and direct form. The project of exhibition center had been approved, and the construction began at the end of 2007. The area of exhibition center was planned to be 45858 square meters, which will display the historical culture, architecture culture, costume culture, festival cultural, food culture and cultivation culture of eleven minorities with the manner of natural village.

In the following paragraphs, we will predict the market prospect of Longji folk cultural heritage exhibition center according to the background of tourism market of folk culture heritage, the market research result of folk culture tourism market in Longsheng and the advantage of Longji folk culture heritage exhibition center.

\section{Analysis of the tourism market environment of folk culture heritage}

\subsection{Analysis of the tourism market environment of culture heritage}

With the development of market economy and the rapid development of tourism, people are pursuing to experience different cultures. Fifteen years ago, cultural tourism was considered as a small and special market, but nowadays, cultural tourism has steadily become a popular tourism activity. World Tourism Organization predicts that cultural tourism accounts for $37 \%$ of the total tourism activity, and people's demand on cultural tourism increases $15 \%$ every year. Of the 0.65 billion international travel times, 0.24 billion belongs to cultural tourism, so cultural heritage tourism has become a special life style (Mckercher and Hilary, 2005). 
The spot check about the international tourists carried out by National Tourism Administration of China indicated the proportion of international tourists' choice about the tourism resources, as shown in table1.

It can be seen from table 1 that cultural relic and historic site, folk custom, culture and art are the main resources to attract international tourists to China. Tourists are more interested in the unique culture and custom of the eastern country with an ancient civilization than the landscape.

Heritage tourism is a newly developed tourism product in the international world, and it is developing at great speed (Garrod and Fyall, 2000). Heritage tourism has become the main tourism product in many places, for example, income from heritage tourism accounts for $28 \%$ of the total income of tourism in England (Markwell et al., 1997). Local government should accelerate the development of cultural tourism to promote the economic development if there are abundant cultural resources but little capital.

\subsection{Analysis on the market investigation of folk culture heritage tourism in Longji}

Experts from the Longsheng Tourism Programming Group, Academy of Tourism Programming and Design of Guilin University of Technology carried out three market investigations into the Longsheng folk culture heritage tourism from 2003 to 2007 . We analyzed the results as follows:

\subsubsection{Market investigation into the cultural heritage tourism in 2003}

To make a good general planning for the tourism development in Longsheng, the Tourism Programming Group carried out a spot check about the tourism market of Longsheng in April, 2003. The number of total sample was 1000, of which 800 were for domestic tourists and 200 were for international tourists. It was indicated that, the proportion of tourists who wanted to enjoy the natural landscape of Longsheng was $78.50 \%$, and the proportion of tourists who wanted to visit the folk village of Longsheng was $31.60 \%$, in which the Longji terraced landscape was the main attractive thing for the tourists. Investigation into the demand trend of tourists showed that tourists mainly wanted to go sightseeing in Longsheng, and the terrace product was the core of product system, being on vacation and folk custom tourism were supplements, but the vacation products were growing at great speed. Most tourists were interested in folk custom product in Longsheng, $51.90 \%$ thought that the product was attractive, $21.60 \%$ thought that the product was very attractive, and $23.40 \%$ thought that the product was ordinary. It can be seen that folk culture products are very attractive, they should be the second leading actor after the regulation of tourism product structure, and will be a breakthrough for the growth of tourism in Longsheng.

\subsubsection{Market investigation into the cultural heritage tourism in 2005}

Tourism development in Dazhaihongyao village was planned in 2005 subjecting to the guideline of Longsheng Tourism Bureau. Market investigation was carried out from $2^{\text {nd }}$ July to $9^{\text {th }} \mathrm{July}$, and the number of total sample was 70 . It was indicated that the proportion of tourists who wanted to enjoy the terrace sight, folk village, folk festival, and other tourism product was $63.64 \%, 18.18 \%, 14.14 \%$ and $4.04 \%$ respectively. The proportion of tourists who thought that the folk culture in Hongyao was very attractive, attractive, and ordinary was $32.35 \%, 26.47 \%, 41.18 \%$ respectively. The proportion of tourists who thought that the most attractive folk culture factor was Diaojiaolou, Hongyao feeling, folk dancing, folk activities, life scene and other was $27.18 \%, 34.95 \%, 9.71 \%, 5.83 \%, 16.50 \%$ and $5.83 \%$ respectively. The proportion of tourists who thought that the image of Dazhai was terrace culture, Hongyao feeling and the combination of terrace culture and Hongyao feeling was $20.00 \%, 7.69 \%$ and $72.31 \%$ respectively.

\subsubsection{Market investigation into the cultural heritage tourism in 2007}

Tourism development in the ancient Zhuang stockade village in Longji was planned in 2007 subjecting to the guideline of Longsheng Tourism Bureau. Market investigation was carried out from $3^{\text {rd }}$ Jan to $4^{\text {th }}$ Jan, and the number of total sample was 200. As for the authenticity of folk culture in ancient Zhuang stockade village, $15.43 \%$ tourists thought that the folk culture in ancient Zhuang stockade village was the same as they expected, $62.77 \%$ tourists thought that folk culture in ancient Zhuang stockade village was partly the same as they expected, 19.15\% tourists couldn't tell the authenticity of folk culture in ancient Zhuang stockade village, and 2.66\% tourists thought the folk culture in ancient Zhuang stockade village was completely different from what they expected. As for the favorite tourism product, the proportion of tourists who like the terrace landscape best was $51.05 \%$, the proportion of folk architecture, folk costume, folk craftwork, folk song and dance, Longji watery wine, special local product, Longji tea, folk food, and other was $18.92 \%, 6.31 \%, 4.80 \%, 4.50 \%, 3.60 \%, 2.70 \%, 2.40 \%, 2.40 \%, 3.30 \%$ respectively. The proportion of tourists whose purpose to travel in Longji was to enjoy the terrace landscape, experience folk custom, taste folk food, experience rural life, and other was $53.95 \%, 13.75 \%, 8.25 \%, 6.19 \%, 13.40 \%$, and $4.47 \%$ respectively. As far as the tourist's expectation on the tourism development, green ecological village and ecological museum were the main types, accounting for $21.54 \%$ and $18.85 \%$ respectively; the proportion of folk culture village was $18.46 \%$, so was the terrace landscape garden; some tourists thought that the ancient Zhuang stockade village should be kept as ancient village, accounting for $15.00 \%$; the proportion of vacation village and modern new village was $5.77 \%$ and $1.92 \%$ respectively. 
The investigation showed that the potential international tourists had the same characteristics in many aspects. Most tourists were well educated and they liked the local terrace landscape; they hoped that the ancient Zhuang stockade village should be kept as what they were and be developed as ecological museum; besides, all of them were uneasy about the environmental pollution and terrace destruction caused by tourism development.

The investigation results indicate that the colorful folk cultural heritages, which are becoming more and more attractive, are the main factors to attract tourists. The folk cultural heritages will introduce broad market for the folk cultural heritage exhibition center in Longji.

\section{The development advantage of Longji folk cultural heritage exhibition center}

Besides the advantageous market development trend, folk cultural heritage exhibition center in Longji has some other development advantages:

\subsection{The advantageous position}

The folk cultural heritage exhibition center in Longji is located at the southeast of Longsheng County; it is 13 kilometers away from the Longsheng County and 78 kilometers away from the Guilin City. The planning area, which is the entrance to the Longji scenic spot, is accessible because its typical great gate is at the side of 321 national highways.

\subsection{The advantageous tourism development background}

Tourism in Longsheng County is developing flourishingly in recent years. The number of tourists in the whole county was 840.8 thousand in 2007, of which 316 tourists paid a visit to Longji scenic spot (Table 2). There is no doubt that there will be enough tourists to pay a visit to the planning area. In addition, Longsheng County put forward the slogan of "constructing the county with tourism" in 1993, and took tourism as the supporting industries to develop the local economy. The advantageous background will provide strong support for the development of folk culture exhibition center in Longji.

\subsection{The rich folk culture background}

As an autonomous minority county, Longsheng County accumulated rich folk culture. The folk cultural heritage exhibition center has superior position, so it will definitely make the folk culture in Longsheng County be more and more colorful. Longsheng County was endowed with the title of "Cultural tourism county of China" in 2006, which further improved the fame of Longsheng as a tourism region and exhibited the advantage of folk culture in tourism development. The advantageous conditions in Longsheng will provide ample cultural nourishment for the folk cultural heritage exhibition center.

\section{Conclusion}

It can be concluded that the folk cultural heritage exhibition center has profound humanistic background and accords with the development trend of tourism market of folk cultural heritage. The advantageous conditions of "good climate, favorable geographical position, support of people" will help the folk cultural heritage exhibition center in Longji make great achievement in the cultural heritage tourism market.

\section{References}

Cheng, Jinneng. (2007). Heritage tourism. Tourism Education Press.

Garrod, B. Fyall, A. (2000). Managing Heritage Tourism. Annals of Tourism Research, 27 (3), 682-708.

Liu, Feng. (2001). Development strategy of tourism in western China. China Travel and Tourism Press.

Markwell, S. Bennett, M. and Ravenscroft, N. (1997). The changing market for heritage tourism: a case study of visits to historic houses in England. International Journal of Heritage Studies 3: 95-108.

McKercher Bob and Hilary du Cros. (2006). Cultural tourism:the partnership between tourism and cultural heritage management. Nankai University Press.

Peng, Decheng. (2003). Management model in tourism region. China Travel and Tourism Press.

Wei, Xiaoan and Wang, Jieping. (2005). Create the future cultural heritage. China Renmin University Press.

$\mathrm{Wu}$, Zhongjun, et al. (2003). General planning for the tourism development in Longsheng. Academy of Tourism Programming and Design of Guilin University of Technology.

$\mathrm{Wu}$, Zhongjun, et al. (2005). Tourism programming for Dazhaihongyao village in Longsheng autonomous county. Academy of Tourism Programming and Design of Guilin University of Technology.

$\mathrm{Wu}$, Zhongjun, et al. (2007). Constructive detailed planning for the tourism development in Longji ancient Zhuang stockade village. Academy of Tourism Programming and Design of Guilin University of Technology.

Xie, Chaowu. (2004). A research on the marketability of culture heritage resources based on tourism exploitation. Journal of Harbin University, (1), 114-117. 
Table 1. International tourists' choice about the Chinese tourism resources from 1996 to 2004

\begin{tabular}{|c|c|c|c|c|c|c|c|c|}
\hline Resourcelyear & 1996 & 1997 & 1998 & 2000 & 2001 & 2002 & 2004 & Average \\
\hline Landscape & 21.6 & 45.0 & 42.1 & 52.5 & 53.1 & 50.6 & 50.1 & 44.9 \\
\hline $\begin{array}{l}\text { Cultural relic } \\
\& \text { historic site }\end{array}$ & 18.8 & 36.1 & 40.0 & 44.0 & 45 & 45.5 & 43.2 & 38.9 \\
\hline Folk custom & 14.9 & 25.1 & 29.0 & 34.4 & 35.3 & 36.6 & 35.7 & 30.14 \\
\hline Culture \& art & 11.8 & 22.4 & 22.3 & 24.5 & 25.5 & 25.3 & 25.1 & 22.4 \\
\hline $\begin{array}{l}\text { Food and } \\
\text { cooking }\end{array}$ & 10.4 & 21.2 & 23.0 & 31.9 & 30.4 & 31.6 & 33.7 & 26 \\
\hline $\begin{array}{c}\text { Medical } \\
\text { treatment \& } \\
\text { health care }\end{array}$ & 2.6 & 5.5 & 6.1 & 9.7 & 12.6 & 11.9 & 10.5 & 8.41 \\
\hline $\begin{array}{c}\text { Tourism } \\
\text { shopping }\end{array}$ & 8.9 & 23.9 & 18.7 & 26.3 & 26.3 & 27.5 & 27.3 & 22.7 \\
\hline $\begin{array}{l}\text { Seaside \& } \\
\text { beach }\end{array}$ & 1.8 & 2.5 & 2.8 & 7.1 & 10.4 & 9.2 & 7.4 & 5.88 \\
\hline $\begin{array}{l}\text { Festival } \\
\text { activity }\end{array}$ & 1.7 & 2.3 & 2.8 & 9.4 & 11.4 & 10.2 & 8.8 & 6.65 \\
\hline
\end{tabular}

Table 2. The situation of tourism in Longji terrace landscape from 1996 to 2007

\begin{tabular}{ccc}
\hline Year & Tourist number (Ten thousand) & Income (Ten thousand Yuan) \\
\hline 1996 & 0.37 & 3.68 \\
1997 & 0.39 & 4.10 \\
1998 & 0.41 & 4.50 \\
1999 & 1.41 & 19.50 \\
2000 & 2.50 & 44.36 \\
2001 & 3.60 & 84.86 \\
2002 & 9.59 & 87.98 \\
2003 & 9.12 & 245.57 \\
2004 & 14.28 & 628.45 \\
2005 & 18.35 & 861 \\
2006 & 23.70 & 1034 \\
2007 & 31.60 & 1484 \\
\hline
\end{tabular}

Data resources: Longsheng Tourism Bureau/Guilin Longji Tourist Co. Ltd. 


\title{
Research on the Financing of Small and Medium Enterprises
}

\author{
Juan Zhao \\ Management Department, Guangzhou Trade and Industry Vocational and Technical College \\ Huadu 510850, China \\ E-mail: zhaojuan-8-15@163.com
}

\begin{abstract}
Small and medium enterprises' financing constraints are an important reason for its development in recent years, national policy and legal aspects are also efforts to promote the development of SMEs, the SME financing is still a lot of the biggest obstacles to entrepreneurs. In this paper, the status of financing small and medium enterprises start to analyze the reasons for its financing of the status, and guide financial institutions to be innovative financial products and improve financial services, a variety of financing at the same time, expand the financing channels for small and medium enterprises, can also build a multi-level credit Security system, security is difficult for SMEs to resolve outstanding issues.
\end{abstract}

Keywords: Small and medium enterprises, Financing

China's economic development in small and medium enterprises play an important role.There are more than 10million small and medium enterprises, which was the $99 \%$ of the total number of registered companies, the total industrial output value and profits were up $60 \%$ of the country and $40 \%$, provided About $75 \%$ of urban jobs, so how to properly resolve the problem of financing of small and medium enterprises is of great significance. Recently, the National Development and Reform Commission according to a survey: SME loans declined to be more than 56\%, a survey conducted by the National Bureau of Statistics also showed that nearly $4 \%$ of the working capital of private enterprises from some loan sharks, of which nearly $1 \%$ Of the companies working capital by more than $25 \%$ of the loan sharks of the financing. Financing the development of small and medium enterprises become one of the major problems. From a global point of view, financing is also constrained the development of SMEs in the primary bottleneck. As a result, analysis of the causes of the current situation and financing small and medium enterprises, small and medium enterprises to recall the basic practice of financing, financing for small and medium enterprises in the institutional, policy and operational obstacles to study hard to ease the financing of policy recommendations for promoting the healthy development of small and medium enterprises with very Important practical significance.

1. Difficulties of China's small and medium enterprises financing are caused by following main reasons.

In $2003,56 \%$ of China's GDP, $59 \%$ of sales in the community, $46 \%$ of revenue, $62 \%$ of exports and employment, $75 \%$ are from small and medium enterprises to create or provided. However,it is very disproportionate between SMEs' financial resources in its national economic and it's social development in the status of the role.

\subsection{Small and medium enterprises financing status}

1.1.1 The normal operation and necessary funds is insufficient.

China's system of financing of small and medium enterprises, venture capital funds is less obvious, there are also fewer funds invested in enterprises in total of 300 million. Specifically, small and medium enterprises, unlike large enterprises which can use issuing corporate bonds and stocks, and other means from the capital markets to raise funds; at the same time it is very difficult to borrow money from financial institutions for small and medium enterprises in order to retain profits, enterprises, equipment depreciation, and other internal capital accumulation is limited.

\subsubsection{Less access to credit support.}

According to statistics, China's 3,000,000 private bank loans supported by only 10\%. Township in 2003, private individuals, "three-capital" of corporate short-term loans accounted for all the short-term bank loans ratio was only 14.4 percent. According to the survey, in 2001 private investment which from bank loans was 20.1 percent in Zhejiang Province. Compared with large enterprises, the financial structure of SMEs is in much harsh conditions. Generally, SMEs have weak financial strength, low credit, when the financial institutions lending to SMEs, the mortgage on the property and guarantee is very strict, even to improve financing conditions, such as raising substantial interest rate, shorten the period of financing and so on. On the other hand, complicated credit procedures also affects the financing of SMEs. 


\subsubsection{Narrow channels of direct financing.}

Due to the high threshold of the stock market, the venture capital system, and it is difficult to raise funds through capital markets for small and medium enterprises. According to research of the People's Bank of China in August 2003 showed that 98.7 percent of SME' financing comes from bank loans, that means only 1.3 percent is direct financing.

\subsubsection{The lack of its own funds.}

China's non-public enterprises from scratch, from small to large and from weak to strong, enterprise development mainly depends on the accumulation of their own, with the source of financing, which greatly restricted the rapid development of business and grow in size and strength. According to the study of the International Finance Corporation, the owners of capital and retained earnings were within our private sources of funding accounted for $30 \%$ and $26 \%$, corporate bonds and external equity financing less than $1 \%$.

\subsection{The main causes of small and medium enterprises "financing".}

Small and medium enterprises have their own reasons in financing, but banks and other financial institutions as well as policies also have some problems, and many other reasons, as for their own reasons can be followed.

1.2.1 Small and medium enterprises usually operate in small-scale, with low ability to resist risks, industry competition, even more difficult to survive. From the safety of bank loans, more willing to choose loans for large and medium-sized enterprises. In mortgages, land, property, and other real estate as collateral are the form of loans or guarantees. Due to the small and medium enterprises in China for more than the current lease, in the form of contractual operation, without its own asset-backed, and those linked to collective or joint ventures, co-operation of private enterprises in the machinery and equipment and housing ownership, land use right of access on certain is the legal obstacles, which makes bank loans to SMEs more difficult to achieve.

1.2.2 Small-scale guarantee, decentralized risks and the lack of compensation, and corporate credit capacity is poor.

According to the survey, small and medium enterprises' loan ratio is as high as 23.8 percent, because of implementation of security, as much as 32.3 percent can not occur while the loan-to-resist, both the total refusal of the total loan rate is as high as 56.1 percent. However, the credit guarantee for small and medium enterprises development is also difficult to meet the majority of the SMEs need to enhance the ability of credit: the establishment of the government-funded credit guarantee agency usually only be the beginning of planning for the one-time financial support, lack of follow-up of a compensation mechanism; private security agencies' ownership by discrimination, can only be left holding the bag secured credit risk, and can not be shared with the collaboration mechanism for the formation of the bank. Due to security and to spread the risks of loss and share the compensation system has not yet taken shape, making security funds to enlarge the functions and the ability of credit guarantee agencies are subject to greater restrictions. In addition, credit guarantee and related laws and regulations behind the building of a certain extent, the impact of the credit guarantee agencies regulate development.

\subsubsection{Lower credit rating of SMEs also affected the enthusiasm of bank loans.}

Weak capacity to finance small and medium enterprises, information asymmetry, the impact on the enthusiasm of the banks. Weak basis for the management of small and medium enterprises, and a general lack of good corporate governance mechanism. Part of the financial management of small and medium enterprises need to be further regulate. As the small part of the financial reporting system behind, lack of transparency of information, lack of audit departments confirmed that the financial statements and good operating performance, an increase of the bank-to-business financial information to review the degree of difficulty, the banks face a greater risk. In addition, the complexity associated with the transaction, financial systems, a lower degree of transparency is not high degree of credit. SME loan is characterized by "less urgency, frequency," the bank credit for SMEs are often a result of asymmetric information, credit transactions and monitoring costs and high risks rather than loans. In 2003, China's major commercial banks to SMEs, the average non-performing loan rate of 32.1 persent, commercial banks than the average non-performing loan rate of 15.7 persent higher than that of poor quality loans have also affected the enthusiasm of bank loans. Such as Jiangsu, Zhejiang related to the survey, small and medium enterprises credit rating over 60 persent in the following. In recent years, corporate restructuring, a number of small and medium enterprises "Jinchantuoke" an attempt to evade the bank's debt occurred from time to time, making bank loans to SMEs with great care.

\section{The financing system also affects the small and medium enterprises finance.}

It's a long time for less credit of SMEs. China's policies and financing system based on state-owned enterprises, especially large state-owned enterprises, which was not for the SMEs in the service system, has become a constraint the crux of their development, specifically in the following areas. 


\subsection{The distribution of financial resources and distribution of small and medium enterprises does not match, and the} policy strength is not strong.

To guard against financial risks, the state-owned commercial banks are "big cities, large enterprises and projects," the strategy of large-scale grass-roots networks merge, the loan authority to make those small and medium enterprises and the supply of funds that match small and medium-sized financial institutions have a responsibility-free right, but not the power. At the same time, the government of the bank loans of small and medium enterprises to carry out incentive to be innovative, banking institutions in their own settings, product design, credit rating, credit management for small and medium enterprises find it hard to adapt to the specific needs of financial services. China has set up SME Technology Innovation Fund for small and medium enterprises and international market development funds, but each year only 10 billion meet the needs of small and medium enterprises development. From 1999-2004 in May, individual small business loans to national security only paid 1.8 billion, compared with the huge capital needs of small and medium enterprises which was only a drop in the bucket. China's other multi-level capital market has not yet taken shape, direct financing and indirect financing is of non-conforming. According to the data show that in 2003 the first two quarter of the stock market accounted for only 1.6 percent financing, equity financing in the first three quarters accounted for 2.2 percent. In direct financing and indirect financing structure of a lack of co-ordination under the premise of the main board stock market or tilt to large enterprises. In addition, the low threshold of the Growth Enterprise Market of the delay in opening, the local equity market have been banned, non-formal financing the lack of legal support for small and medium enterprises direct financing problems worse.

\subsection{Bank's inadequate incentives.}

Major banks enhance their risk management, credit to their non-performing loans caused by the acts of credit should be held responsible for life, and the economic benefits generated by lending its no incentive provisions, resulting in banks reluctant to lend.

\subsection{Social service agencies are not perfect.}

No unified national credit evaluation mechanism and supervision mechanism, the central budget has not yet secured funding clear, there is no comprehensive national security system, the lack of financing for small and medium enterprises to provide intermediary services, small and medium enterprises difficult to guarantee, mortgage difficult. Enterprises have to apply for a mortgage the property must apply for assessment of the property, registration, insurance, notary, and other complex procedures involved in a number of functional departments and to provide a wide range of relevant information, and mortgage registration and evaluation of high-cost, arbitrary. Due to the normal supply of funds and lack of blocking the channels, forcing a large number of small and medium enterprises to obtain the necessary funds have high exposure to interest rate risks on the ground floor of the capital market.

\section{Measures taken by small and medium enterprises for financing.}

To further enhance small and medium enterprises in China's economic and social development the states should take a series of measures in "financial difficulties" :

\subsection{Guide financial institutions, innovative financial products and improve financial services.}

In 1998, China's four major state-owned commercial banks have been formed by the Ministry of Finance, two small and medium enterprises to adjust lending rates, floating interest rates to encourage commercial banks to increase loans to small and medium enterprises, and encourage and guide a series of business Bank of strengthening and improving financial services for SMEs specific measures. For example, through the Central Bank refinancing and rediscount and to issue financial bonds in the form of small and medium enterprises in order to serve the small and medium-sized financial institutions to support; adequate working capital loans to small and medium enterprises delegation of authority is for approval; on the markets and economic returns, SME credit can be issued to simplify loan procedures and improve the credit system, expanding the proportion of credit, and so on. These incentives the mobilization of commercial bank loans to SMEs enthusiasm to a certain extent,. China Development Bank as a national policy banks, based on an active network of lending to small and medium enterprises, and the conditions of the credit guarantee institutions for SMEs is on a trial basis and secured. The joint-stock commercial banks are doing their best to achieve the financial philosophy of financial products and services innovation. Guangdong Development Bank decided lending 100billion yuan to non-public ownership enterprises and small and medium enterprises in three years, and this well-built "Private 100" special financial services program. In response to the "start" and "growth" and "development" phase of the three different financing needs of the eight packages designed to effectively address the difficult issues of corporate loans. According to the survey, urban commercial banks take more than $70 \%$ of credit funds into the various types of small and medium enterprises.

\subsection{Broaden the financing channels for small and medium enterprises.}

First, the establishment of scientific and technological innovation fund, through the discount interest loans,free financing, such as capital investment, science and technology to support the rapid development of small and medium 
enterprises. From 1999 to 2003, the state invested a total of 3.3 billion funds to support the 4946 national high-tech small and medium enterprises, vigorously promoted the development of small and medium enterprises and entrepreneurs. Second is the establishment of property rights in trading market. At present, China has established more than 200 different levels, different sizes of property rights trading market, Shanghai, Beijing, Tianjin and other cities of property rights trading market has been a considerable scale. 2003 Shanghai Property Rights Exchange's trading volume has exceeded 30,000million yuan, for all types of assets, restructuring small and medium enterprises, multi-property rights to provide a trading platform. Third, give full play to the pawn, lease financing for small and medium enterprises, and other characteristics of the role of the financial instrument. By the end of 2003, China's pawn line has been developed to more than 1,000, more than 60 million capital for SMEs through the pawn to facilitate financing; size of the lease financing have become increasingly polarized, 2003, only one in Zhejiang province, more than leasing business 7,000nillion yuan. Fourth, setting opening and direct financing channels. In May this year, the Shenzhen Stock Exchange launched the SME board, strong priority for the rapidly growing small and medium enterprises to provide a source of direct financing. According to statistics, there are now 34 completed public offering, with a total size of 83.4million shares, issued 822.1million yuan of the total amount of financing, the average size of 2,452 million shares issued, the average amount of 242 million financing, the listing of new shares on the first day or an average of $83 \%$. In line with a number of conditions for the growth of small and medium enterprises will be listed on financing opportunities.

\subsection{Building a multi-level credit guarantee system for SMEs to resolve outstanding security issues is difficult.}

Local governments at all levels support small and medium enterprises. Learning from developed countries, combined with the reality of our country to promote the SME credit guarantee system for the building work. Through years of practice and gradually explore with Chinese characteristics "One Body Two Wings four-story," the credit guarantee system for small and medium enterprises will be made. "Integration" means the main body model emphasis on "diversification of funding, market-oriented operation of enterprises, those blue-chip support"; "two wings" refers to the commercial and civil security guarantees as a necessary complement and mutual assistance; "four" refers to the central level, Province (cities, districts) level, city level, county (city) level. In recent years, issued a guarantee to the relevant laws, policies and tax incentives, and so on, has vigorously promoted the formation of the security industry and development. According to incomplete statistics, as of the end of in June 2003, the country has set up various types of SME credit guarantee agencies 966 , secured funds to raise a total of 28.70 million yuan; a total insured business of about 50,000 , the total amount secured a total of about 118 billion yuan, Insurance companies to add 11.8 billion sales, profits and taxes add 10.2 billion. To some extent alleviate the difficulties SMEs look for security problems.

\subsection{To promote small and medium enterprises credit system, enhance the capacity of small and medium enterprises} financing.

Credit needs to cultivate and standardize the credit market and improve the credit system and create a credit environment for SMEs to upgrade the overall quality and competitiveness, against credit risk, to increase its financing capacity, with urgent practical significance. On the one hand, establishing and improving the external business of small and medium enterprises credit information systems and credit evaluation system gradually. As for banks it is urgent to provide credit information business, and keeping promises in recognition of small and medium enterprises, establish a typical credit vigorously publicizing and promoting the advanced credit management mode and experience ; On the other hand, active in the enterprise credit system and the popularity of the work to strengthen the internal management of the contract, warning of marketing, business accounts collection, management and accounting investigations, and other former employees, business, management, detection, and other personnel to carry out credit and professional skills training, training credit analysis of the survey, evaluation and supervision of professionals. Through the establishment of business credit files, credit rating, business credit system, and improve their own financing capacity.

\section{References}

Shi, Qian. (2002). Corporate Finance of the problem. Southwestern University of Finance and Economics. (11).

$\mathrm{Hu}$ Chu. (2005). plans: to speed up measures to finance small and medium enterprises. Economy of the North. (5).

Pan, Xingjiang. (2005). SME financing knowledge. Socialist Hubei University.(5).

Liling Revolutionary Committee: to shape corporate culture and enhance the competitiveness of the private sector. Http://www.hnllmg.com 2006-2-27. 


\title{
Cost-Effectiveness Analysis for Arsenic Water Supply Project in Bangladesh
}

\author{
Nikhil Chandra Shil \\ Senior Lecturer \\ Department of Business Administration \\ East West University \\ 43, Mohakhali Commercial Area, Dhaka - 1212 \\ Bangladesh \\ E-mail: nikhilacc@yahoo.com
}

\begin{abstract}
Cost-effectiveness analysis $(C E A)$ is widely used to assess the investment criteria where cost-benefit analysis (CBA) is not economically feasible to apply. $C B A$ is generally used where there is a commercial motive whereas $C E A$ is used where service motive is prioritized. Thus, it is mainly applicable to evaluate social projects where the beneficiaries are scattered in any area or the society at large. The paper works as a background paper highlighting those issues with greater detail so that a stranger can use the tool confidently. The steps required for such application and the potential areas where $C E A$ will produce significant results are also highlighted here to limit the scope of the paper. The methodology used here is basically descriptive to keep it simple and easy to comprehend, with the practical insights of using such tool in a real life social project. The use of CEA is outlined here in a World Bank funded Arsenic Water Supply Project in Bangladesh.
\end{abstract}

Keywords: Cost-effectiveness analysis, Cost-benefit analysis, Arsenic Water Supply Project, Bangladesh

\section{Introduction}

Cost-effectiveness analysis refers to the consideration of decision alternatives in which both their costs and consequences are taken into account in a systematic way. It is a decision-oriented tool, in that it is designed to ascertain which means of attaining particular goals are most efficient. Consider two strategies intended to lengthen life in patients with heart diseases. One is simple and cheap (e. g., aspirin and $\beta$-blockers); the other is more complex, more expensive, and more effective (e. g., medication plus cardiac catheterization, angioplasty, stents, and bypass). Now, which strategy will be more effective? CEA will help to take decision in such situation.

In evaluating alternatives three different variants of analysis is available, viz. cost effectiveness analysis, cost utility analysis and cost benefit analysis. In $C E A$ the benefits are expressed in numeric but non-monetary terms, say, life years gained or symptom-free days whereas in cost-utility analysis they are expressed as quality-adjusted-life-years $(Q A L Y S)$ and in cost-benefit analysis in monetary terms. As with all economic evaluation techniques, the aim of $C E A$ is to maximize the level of benefits relative to resources available. The main metric is a ratio whose denominator represents project outcome in numerical but non-monetary unit, and numerator represents costs in monetary terms. The result can be interpreted as a unit cost, such as cost per kilometer or passenger, cost per child vaccinated or cost per laborer trained. Thus $C E A$ is used to assess the projects that have similar outcome but way of doing and other factors are different. The lower the unit cost, the more effective the project is.

CEA was developed in the 1950s by the United States Department of Defense as a device for adjudicating among the demands of the various branches of the armed services for increasingly costly weapons systems with different levels of performance and overlapping missions (Hitch and McKean, 1960). By 1960s it had become widely used as a tool for analyzing the efficiency of alternative government programs outside the military. It was first applied to health care in the mid-1960s and was introduced with enthusiasm to clinicians by Weinstein and Stasson in 1977: If these approaches were to become widely understood and accepted by the key decision makers in the health-care sector, including the physician, important health benefits or cost savings might be realized. CEA has also been used to determine which drugs will be reimbursed by public agencies in both Australia and the Canadian province of Ontario (Drummond et al., 1997; Sloan and Conover, 1995). 
The paper targets to explicate CEA with its basics and usability under budget constraints. And the discussion is mainly based on different secondary sources like research papers, published journal papers, books etc. Different interventions and ingredients with cost data is generated from a World Bank document titled "Project appraisal document for a proposed credit in the amount of SDR 24.2 million equivalents to the People's Republic of Bangladesh for an arsenic mitigation water supply project" upon permission. CEA is formulated mathematically at the very beginning followed by a discussion on the techniques of assessing the costs and benefits. Later on different interventions are introduced with the simulation of selective the most effective one under fund constraint. Finally, the paper concludes with an explanation of decision rule for selecting the candidates participated in the study and rationality behind it.

\section{Cost Effectiveness Analysis: Formulation and Derivation}

As an offshoot of $C B A, C E A$ is developed in economics to address resource allocation issues. Though $C B A$ is well grounded in welfare economics, $C E A$ is based on no such solid foundation. $C E A$ has become popular in cases where full-fledged $C B A$ is either too difficult to apply, or alternatively, where $C B A$ is judged inappropriate. Although $C E A$ is intuitive and easy to apply, it posses a number of methodological issues that are not always understood by practitioners (Hildred and Watkins, 1996). The discussion on the formulation of CEA can be started with the following basic equation:

$C E R=\frac{\text { Cost in monetary term }}{\text { Benefits in numeric but non }- \text { monetary term }} \ldots \ldots \ldots \ldots \ldots \ldots \ldots \ldots \ldots \ldots \ldots \ldots \ldots \ldots$ (eq. 1$)$

CER in equation 1 represents cost effectiveness ratio. Numerator represents total cost of the project in monetary terms throughout its life (t); and denominator represents benefits expressed in numerical but non-monetary term. Cost may be initial (investment) or recurring (running). Initial cost $(\cos t a t=0)$ requires no discounting but recurrent cost requires and for these two separate cost, we may use one single notation, e. g., Cost $t_{t}=\sum_{t=0}^{n} \frac{C_{t}}{(1+i)^{t}}$ where $i$ stands for a suitable discount rate. The denominator of the equation refers to the benefit from the project and presented in numerical but non-monetary terms. Let's suppose that the benefits are denoted by capital $\mathrm{n}(\mathrm{N})$ and to make it comparable with costs, let's again suppose that it will also be generated throughout the life and discounted by a suitable rate as used in case of costs. Thus the notion of the denominator will be, Benefit $t_{t}=\sum_{t=1}^{n} \frac{N_{t}}{(1+i)^{t}}$. Now, equation 1 can be extended with the notion of costs and benefits as given in equation 2 .

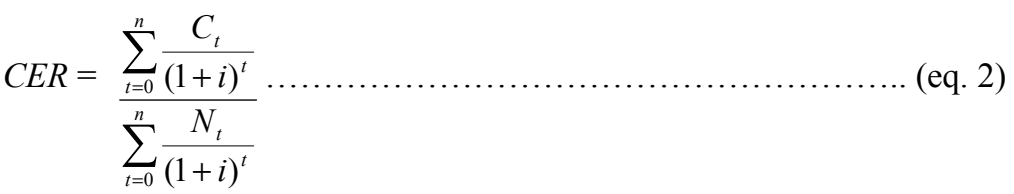

But, the basic formula of $C B A$ incorporates costs and benefits in a different way as presented below in equation 3 :

$N P V=\sum_{t=0}^{n} \frac{\left(B_{t}-C_{t}\right)}{(1+i)^{t}}$

Where, $N P V$ represents net present value, $B_{t}$ represents benefits in year $t$ and $C_{t}$ costs in year $t$ and $i$ is the discount rate.

Thus, the basic difference between these two equations is in terms of incorporation of benefits into consideration. As in $C B A$ both costs and benefits are expressed in monetary terms, they can be used to calculate the difference (net value) but in case of $C E A$ this is not possible and for that reason it is a ratio. In most of the projects that are headed towards the social welfare, or otherwise, the beneficiaries are scattered in the society in such a way that no monetary value can be put to quantify the benefits, $C E A$ is more applicable and accurate to use. For example, let's take the World Bank Project on Arsenic Mitigation Water Supply, where the beneficiaries are the targeted people living in the targeted area under the project. It's really difficult to quantify the benefits in monetary terms. But the outflow of fund is very much explicit even with the sources and that's why $C E A$ is very much effective to evaluate such a project. Table 1 calculates CER per person based on the project data using the equations derived earlier.

Insert Table 1

Here, the project sanctioning authority now may take decision on the basis of cost per person to evaluate the effectiveness of the project, or whether there are some other projects that will be more effective than the current one.

Many evaluations are confined to a relatively short time period of a year or less, and estimates of outcomes and costs are confined to that period. Yet, many evaluations occur over two or more years. When that is the case, outcomes and costs that occur in the future should be appropriately discounted to their "present value." Both $C B A$ and $C E A$ use 
discounting to express future costs and benefits in equivalent units of a base year. The purpose of this procedure is to reflect the desirability of receiving outcomes sooner (or, similarly, incurring costs later). To calculate present value, one uses the following general formula:

$$
P V=\sum_{t=0}^{n} \frac{O_{t}}{(1+r)^{t}}
$$

where $O_{t}$ is the outcome occurring at time $t$, and $r$ is a discount rate between 0 and 1 (the same formula applies to discounting costs). For example, the present value of a benefit of $\$ 100$ that is received immediately (at $t=0)$ is $\$ 100$. If the same amount is received one year hence, and the discount rate is $0.05(5 \%)$, the present value is $\$ 95.24(100 / 1.05)$; in two years, it is $\$ 90.70\left(100 / 1.05^{2}\right)$. Thus, outcomes occurring farther in the future are discounted more steeply. A discount rate larger than 0.05 would imply that future outcomes are to be discounted even more heavily. Intuitively, this implies that individuals evince an even stronger preference for outcomes that occur immediately.

There are two interrelated points in the discussion. What should the discount rate express? And should we discount benefits and costs in the $C E R$ at the same rate? To start with the first point, the reasons for discounting costs and benefits in $C B A$ or $C E A$ are inflation, risk, the opportunity cost of capital and social time preference. The first two points hold insignificant relevance with our area of discussion and hence, we can dismiss them entirely. In $C E A$, current cost is the best measure and we can use inflation corrected discount rate to check inflation. To control risk, there are a lot of ways available that are smarter and effective from discount rate like probability, sensitivity analysis, simulation etc. The opportunity cost of capital means the cost due to sacrificing the option to invest the fund in other alternatives. If that alternative has earned a rate of return of, say, $10 \%$, then it stands to reason that the project under consideration must have at least the same rate of return to be justified. If the project has a positive $N P V$ at this discount rate at this discount rate, it is apt to go for the project. Discounting in $C E A$ is recommended for exactly the same reason. Social time preference reflects the value the decision maker attaches to consumption benefits through time. If benefits are expressed in money terms, diminishing marginal utility of money makes that one-dollar of consumption for a rich person is worth less than one dollar for a poor person. To the extent that future generations are supposed to be better of materially, it is justified to discount the monetary values they assign to benefits. This argument can be used to discount benefits in $C B A$. If health benefits are expressed in physical terms, as is the case in $C E A$, the decision maker is likewise entitled to discount future benefits if he esteems that future patients have access to better health services than present patients, and that for this reason additional health treatments allocated to them are less desirable than those accruing to present patients. The argument is basically about equity. If future generations are better off, either financially or in terms of health services, there should be a preference for granting additional health benefits to the present generation. An appropriate discount rate expresses this. Social time preference discount rates can be estimated, as long as one is prepared to make a value judgment about intergenerational equity. Most calculations suggest that the social time preference discount rate is lower than the opportunity cost of capital discount rate.

Which of those two considerations, the opportunity cost of capital, or social time preference, is more relevant? There is no satisfactory answer to this, except to say that both must be addressed. The problem is that we have only one discount rate, and we cannot use it to express both at the same time. Satisfactory solutions have been worked out to deal with this problem. For instance, in UNIDO (1972) the discount rate expresses social time preference, and the opportunity cost of capital argument is taken into consideration by calculating a shadow price of investment. The alternative solution, proposed in Little and Mirrlees (1974), and taken over in Squire and van der Tak (1975), is to discount at the opportunity cost of capital and to use a shadow price for the value of consumption to take care of the social time preference dimension. Both approaches are equivalent, as discussed in Berlage and Renard (1985). Unfortunately those sophisticated but rigorous approaches to $C B A$ have not been popular in practice, and now a days both theoreticians and practitioners tend to stick to a single discount rate. This has severely hampered the debate about discounting in CEA. Viscusi (1995) for instance, fails to discuss these issues at all. Katz and Welch (1993) provide a more nuance analysis in which they acknowledge the issue raised here. But in the end they argue in favor of using a single discount rate. But this is far from evident. Health projects typically cause both a change in the time pattern of investment over time, and in the time pattern of health benefits.

In dealing with two contending discount rates, $C E A$ has an edge over $C B A$. Whereas $C B A$ cannot easily handle more than one discount rate, $C E A$ can do so without a problem, as physical benefits are in the denominator of the cost effectiveness ratio whereas costs are measured in the numerator. There is no reason why we would have to apply the same discount rate to both. We suggest replacing equation (2) with

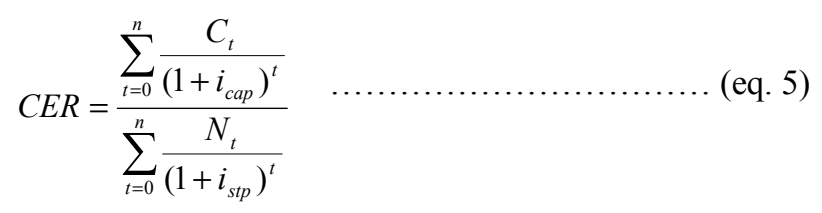


Where:

$\mathrm{i}_{\text {cap }}$ : discount rate expressing the opportunity cost of capital

$i_{\text {stp }}$ : discount rate expressing social time preference for consumption

The choice of discount rate is somewhat arbitrary, although a plausible range is between three and seven percent (Barnett, 1996). A recent set of national guidelines for economic evaluation of health care programs recommends a discount rate of three percent, although they also recommend the calculation of present values under a wider range of assumptions about the discount rate (Lipscomb et. al, 1996). The task force of experts organized by the U.S. Public Health Service $(P H S)$ has also recommended using a discount rate of $3 \%$ to reflect the lower economic value of an expense that is delayed and the higher value of a benefit that is recognized sooner (Gold et al., 1996). In part, the ambiguity stems from different conceptual approaches that can be used to arrive at a discount rate. Boardman et al. (1996) provide a general discussion. For a discussion of discounting that is applied specifically to non-pecuniary outcomes, see Drummond et al. (1997), Keeler \& Cretin (1983), Levin \& McEwan (2000) and Viscusi (1995).

\section{Measuring Cost-effectiveness}

The successful use of $C E A$ requires the estimation of costs and effectiveness accurately. This section is devoted to different criteria that are important for assessment of cost and effectiveness.

\subsection{Assessing cost}

Costs are seen differently from different points of view. In economics the notion of cost is based on the value that would be gained from using resources elsewhere - referred to as the opportunity cost. It is usual, in practice, to assume that the price paid reflects the opportunity cost and to adopt a pragmatic approach to costing and use market prices wherever possible. But this only rigorous cost study, that is based on the economic concept of opportunity cost, is now three decades old (Bartell, 1968). In CEA it is conventional to distinguish between the direct costs and the indirect costs associated with the intervention, together with what are termed intangibles. Intangibles may be difficult to quantify, still, sometimes they may have significant consequences on the interventions and should be included in the cost profile. A typical cost profile of the project under consideration is given in Table 2.

\section{Insert Table 2 here}

It is essential to specify exclusion and inclusion of specific costs categories in a $C E A$ to ensure that the findings are not subject to misinterpretation. Both $C B A$ and $C E A$ can be used from different points of view, ranging from the individual to group to society at large. When $C E A$ is used for healthcare as we are considering here, the later perspective is the appropriate one. Thus, we limit our attention to this case here. In this case, costs incurred by health sector are obvious candidates. In addition, future health costs in added years of life should also be counted here (Johannesson and Meltzer, 1998; Meltzer, 1997). Indeed, there is no reason to exclude any opportunity cost that emerges from a careful with-without analysis in case of $C B A$ and before-after analysis in case of $C E A$ (Figure 1). Non-medical costs; like patients' cost of transport to health centers, the value of time spent undergoing health treatment, the value of efforts given or hassle consumed to avail the facility of treatment; must also be counted. In fact, when the societal perspective comes, the net of costs should be as wide as possible as the total of societal costs from every respect should be considered. If we have no qualms with a broad definition of costs, and in fact argue in its favor, we must at the same time be attentive to the consequences of all inclusive cost measures for the interpretation of the cost-effectiveness ratio.

Insert Figure 1 here

Cost analysis is not always incorporated in decision-making. There are, however, some notable exceptions to this rule, many of these in health-care. In the United States, the state of Oregon attempted to use a wide-ranging cost-utility analysis to rank medical interventions and determine which would be available to Medicaid recipients (Eddy, 1991). Eventually, political considerations led to substantial modifications and the cost-utility approach "[was] ultimately abandoned in favor of a hybrid process in which cost was not a major factor in determining the final rankings" (Sloan and Conover, 1995). The World Bank used a series of cost analyses to formulate health sector lending priorities for developing countries (Jamison et al., 1993; World Bank Report, 1993).

Drummond et al. (1997) provides a more comprehensive quality checklist for cost analysis studies in health-care, covering both outcomes and costs. An important question is whether the cost analysis literature adheres to these minimal standards. The sheer quantity of cost analysis in health-care has led several authors to review costing methods. The results are sobering for research consumers. Among 77 cost effectiveness and cost-benefit studies that were reviewed, Udvarhelyi et al. (1992) found that $52 \%$ failed to properly discount costs, $47 \%$ failed to report cost-benefit or cost-effectiveness ratios, and $70 \%$ did not conduct a sensitivity analysis. In a review of 51 health cost-utility analyses, Gerard (1992) found that $69 \%$ included a comprehensive set of ingredients, $63 \%$ percent provided a clear description of methods used to cost ingredients, and $61 \%$ clearly described the costing data. Just $37 \%$ of studies conducted an extensive sensitivity analysis. Gerard concludes that about half the studies should be deemed "limited" in their execution. 
In cost analysis a simple technique is considered to ascertain the cost of an intervention in terms of the value of the resources that were used or lost by applying them in one way rather than in another. To do this, a straightforward approach called the "ingredients" method is used widely.

The ingredients method relies upon the notion that every intervention uses ingredients that have a value or cost (Levin, 1975, 1988, 1995; Levin \& McEwan, 2000). If specific ingredients can be identified and their costs can be ascertained, we can estimate the total costs of the intervention as well as the cost per unit of effectiveness. The ingredients method to cost estimation entails three distinct phases: (a) identification of ingredients; (b) determination of the value or cost of the ingredients and the overall costs of an intervention; and (c) an analysis of costs in an appropriate decision-oriented framework.

The first step is to ascertain which ingredients are required for an intervention (Levin, 1983). This entails the determination of what ingredients are required to create or replicate the interventions that are being evaluated, casting as wide a net as possible. It is obvious that even contributed or donated resources such as volunteers must be included as ingredients according to such an approach, for such resources will contribute to the outcome of the intervention, even if they are not included in budgetary expenditures.

There are three overriding considerations that should be recognized in identifying and specifying ingredients. First, the ingredients should be specified in sufficient detail that their value could be ascertained in the next stage of the analysis. Second, the categories into which ingredients are placed should be consistent, but there is no single approach to categorization that will be suitable in all cases. Finally, the degree of specificity and accuracy in listing ingredients should depend upon their overall contribution to the total cost of the intervention. It is important to obtain a familiarity with the intervention that is being subjected to cost analysis. Only by doing so can the evaluators identify the ingredients used by the intervention in sufficient detail (and, subsequently, attach values to those ingredients). Normally this familiarity can be gained in at least three ways: (1) through a review of program documents, (2) through discussions with individuals involved in the intervention, and (3) through direct observation of the interventions. If we consider the example of the World Bank Project on "Arsenic Mitigation Water Supply", we get the interventions, its ingredients with analysis of costs as given in Table 3.

Insert Table 3 here

\subsection{Assessing Effectiveness}

Before starting the cost analysis, it is necessary to know what the decision problem is, how to measure effectiveness, which alternatives are being considered and what their effects are. If a problem has arisen on the policy agenda that requires a response, a careful understanding of the problem is crucial to addressing its solution (Levin, 1983). Once the problem has been formulated, it will be necessary to consider how to assess the effectiveness of alternatives. For this purpose, clear dimensions and measures of effectiveness will be needed. Table 4 shows examples of effectiveness measures that respond to particular program objectives.

Insert Table 4 here

Given the problem and criteria for assessing the effectiveness of proposed solutions, it is necessary to formulate alternative programs or interventions. The search for such interventions should be as wide-ranging and creative as possible. This procedure sets the stage for the evaluation of effectiveness of the alternatives, a process that is akin to the standard use of evaluation methods (Rossi \& Freeman, 1985). Estimates of effectiveness can be derived from previous evaluations or from tailored evaluations for the present purpose.

It is important to emphasize that the evaluation of effectiveness is separable from the evaluation of costs. Most standard evaluation designs for assessing the effectiveness of an intervention are also suitable for incorporation into cost-effectiveness studies. This can be found in the standard evaluation literature (Rossi \& Freeman, 1985; Cook \& Campbell, 1979). The cost analysis is not typically found in the general evaluation literature and has been developed independently as a sub-specialization (Levin, 1983).

\section{Architecture of Using Cost Effectiveness Analysis}

The forgoing discussion concludes that identification of interventions in social project is very much important. A distinction must be made between those interventions that are completely independent $-i$. e., where the costs and effects of one intervention are not affected by other interventions - and those that are mutually exclusive - i. e., where implementing one intervention means that another cannot be implemented, or where the implementation of one intervention results in changes to the costs and effects of another.

\subsection{Independent interventions}

Using CEA with independent interventions requires that cost-effectiveness ratios (CERs) are calculated for each intervention and placed in rank order by using equation 4 below that is modified from equation 1 : 


$$
C E R=\frac{\text { Costs of Intervention }}{\text { Health Effects } \text { Produced (say, life }- \text { years gained })} \quad \ldots . . . . . . . . . . . . \text { (eq. 4) }
$$

For example, in table 5, there are three interventions for different patient groups, with the alternative for each of them of 'doing nothing'. According to $C E A$, intervention B should

Insert Table 5 here

be given priority over A since it has a lower $C E R$, but in order to decide which intervention to implement, the extent of resources available must be considered (table 6).

Insert Table 6 here

If a further intervention becomes available, it should be considered on the basis of its CER figure compared with table 4. Resources for the new intervention should be considered in the same manner as above.

\subsection{Mutually exclusive interventions}

In reality, the likelihood is that choices will have to be made between different treatment regimens for the same condition, different dosages or treatment versus prophylaxis - i. e., mutually exclusive interventions. In this situation, incremental cost-effectiveness ratios (ICERs) are used:

$$
I C E R=\frac{\text { Difference in } \cos t \text { s between int erventions }(I 1 \text { and I2) }}{\text { Difference in health effects between int erventions }(I 1 \text { and I2) }} \ldots \ldots . . . . \text { (eq. 5) }
$$

The alternative interventions are ranked according to their effectiveness - on the basis of securing maximum effect rather than considering cost - and ICERs are calculated as shown in Table 7.

Insert Table 7 here

The least effective intervention (I1) has the same average CER as its ICER, because it is compared with the alternative of 'doing nothing'. The negative ICER for I2 means that by adopting $\mathrm{I} 2$ rather than I1 there is an improvement in life years gained and a reduction in costs. The ICER for I3 works out to be 187.5 , which means that it costs $\$ 187.5$ to generate each additional life-year gained compared with I2. Alternatives that are more expensive and less effective are excluded. From table 7, we find that interventions I2 and I4 are followed by interventions I1 and I3 that are costly and therefore needed to be excluded. The table 8 is redrawn by excluding these two more expensive and less effective interventions.

\section{Insert Table 8 here}

Now the question of identification of 'dominated' alternative comes. Here, I4 is dominated by I2 since the former is more effective and costs less to produce an additional unit of effect (\$62.5 compared with \$85.71). The dominated alternative is then excluded and the ICERs are recalculated again in table 9.

Insert Table 9 here

Finally, interventions I2 and I5 are proved to be cost effective. In deciding between them, the size of the available budget must be brought to consider. If the available budget is $\$ 100000$, all patients should receive intervention I1, while, if the available budget is $\$ 190000$, all patients should receive the more effective intervention I5. However, if the budget is, say, $\$ 130000$, then, since the cost difference between I2 and I5 is $\$ 90000$ and the budget surplus is $\$ 30000$, it is possible to switch one-third of patients to I5 and still remain within budget.

\section{Conclusion}

CEA is used as a ranking tool where a lot of alternatives become candidates to a limited budget. Rather in some situation, decision based on solely monetary consideration is proved unethical and illogical. Let's consider the example as we have taken here. Whenever the question of sound health comes, the expenditure or willingness to pay depends on the amount of income. So, if we consider the societal perspective, we have to initiate such project that will be cost effective in the sense that most people will avail the benefit at a lower amount of cost. Thus, in most of the social projects, $C E A$ can be used as a ranking tool to decide which alternative(s) to be chosen. But much use of $C E A$ leads to use of $C B A$. Even when we are talking about budget, we are going for $C B A$ ultimately. $C B A$ is a commercial perspective to choose the alternatives. In $C B A$, no projects may be chosen due to their infeasibility on financial perspective. But, in this case also, $C E A$ ranks one alternative to be the best among other. Basically, as $C E A$ is an offshoot of $C B A$, a detailed $C E A$ ultimately leads to $C B A$. But, when the beneficiary becomes the society, we should go for $C E A$ that is ethical and logical as it ensures the effective use of resources for the benefit of overall society.

\section{References}

Barnett, W. S. (1996). Lives in the balance: Age-27 benefit-cost analysis of the High/Scope Perry Preschool Program. Ypsilanti, MI: High/Scope Press. 
Bartell, E. (1968). Costs and benefits of Catholic elementary and secondary schools. Notre Dame: Notre Dame Press.

Berlage, L. \& Renard, R. (1985). The Discount Rate in Cost-Benefit Analysis and the Choice of a Numeraire. Oxford Economic Papers, 691-699.

Boardman, A. E., Greenberg, D. H., Vining, A. R., \& Weimer, D. L. (1996). Cost-benefit analysis: Concepts and practice. Upper Saddle River, NJ: Prentice Hall.

Cook, T. D. \& Campbell, D. T. (1979). Quasi-Experimentation. Houghton Mifflin, Boston, Massachusetts.

Drummond, M. F., O'Brien, B., Stoddart, G. L. and Torrance, G. W. (1997). Methods for the economic evaluation of health care programs. Oxford: Oxford University Press.

Eddy, D. M. (1991). Oregon's methods: Did cost-effectiveness analysis fail? Journal of the American Medical Association, 266(15), 2135-2141.

Gerard, K. (1992). Cost-utility in practice: A policy maker's guide to the state of the art. Health Policy, 21, $249-279$.

Gold, M. R., Siegel, J. E., Russell, L. B., \& Weinstein, M.C. (1996). Cost-Effectiveness in Health and Medicine. New York: Oxford University Press, 285.

Hildred, W. and Watkins, L. (1996). The nearly Good, the Bad, and the Ugly in Cost-Effectiveness Analysis in Health Care. Journal of Economic Issues, 30(3).

Hitch, J. C. and McKean, N. R. (1960). The Economics of Defense in the Nuclear Age. Harvard University Press, Cambridge, Massachusetts.

Jamison, D. T., Mosley, W. H., Measham, A. R., and Bobadilla, J. L. (eds.) (1993). Disease control priorities in developing countries. Oxford: Oxford University Press.

Johannesson, M. and Meltzer, D. (1998). Some Reflections on Cost-Effectiveness Analysis. Health Economics, 7, 1-7.

Katz, D. A. \& Welch, H. G. (1993). Discounting in Cost-Effectiveness Analysis on Healthcare Programmes. PharmacoEconomics, 3(4), 276-285.

Keeler, E. B., \& Cretin, S. (1983). Discounting of life-saving and other non-monetary Effects. Management Science, 29, 300-306.

Levin, H. M. (1975). Cost-effectiveness in evaluation research, in M. Guttentag and E. Struening (eds.), Handbook of evaluation research, 2, Beverly Hills, CA: Sage Publications.

Levin, H. M. (1983). Cost-Effectiveness: A Primer. Beverly Hills, CA: Sage Publications.

Levin, H. M. (1988). Cost-effectiveness and educational policy. Educational Evaluation and Policy Analysis, 10(1), 51-69.

Levin, H. M. (1995). Cost-effectiveness analysis, in M. Carnoy (ed.), International encyclopedia of economics of education, Oxford: Pergamon, 381-386.

Levin, H. M. \& McEwan, P. J. (2000). Cost-effectiveness analysis: Methods and applications. Thousand Oaks, CA: Sage Publications.

Lipscomb, J., Weinstein, M. C. \& Torrance, G. W. (1996). Time preference, in M. R. Gold, L. B. Russell, J. E. Siegel, \& M. C. Weinstein (eds.), Cost-effectiveness in health and medicine, New York: Oxford University Press, 214-246.

Little, I. M. D. \& Mirrlees, J. A. (1974). Project Appraisal and Planning in Developing countries. Heinemann: London. Meltzer, D. (1997). Accounting for future costs in Medical Cost-Effectiveness Analysis. Journal of Health Economics, 16(1), 33-64.

Rossi, P. H. \& Freeman, H. E. (1985). Evaluation: A Systematic Approach. Beverly Hills, CA: Sage Publications.

Sloan, F. A. and Conover, C. J., 1995, The use of cost-effectiveness/cost-benefit analysis in actual decision making: Current status and prospects. In F. A. Sloan (ed.), Valuing health care: Costs, benefits, and effectiveness of pharmaceuticals and other medical technologies. Cambridge: Cambridge University Press.

Squire, L. \& van der Tak, H.G. (1975). Economic Analysis of Projects. Johns Hopkins University Press.

Udvarhelyi, I. S., Colditz, G. A., Rai, A., \& Epstein, A. M. (1992). Cost-effectiveness and cost-benefit analyses in the medical literature: Are the methods being used correctly? Annals of Internal Medicine, 116, 238-244.

UNIDO. (1972). Guidelines for Project Evaluation. New York: United Nations.

Viscusi, W. K. (1995). Discounting health effects for medical decisions, in F. A. Sloan (ed.), Valuing health care: Costs, benefits, and effectiveness of pharmaceuticals and other medical technologies, Cambridge: Cambridge University Press, 125-147.

World Bank. (1993). World development report 1993: Investing in health. New York: Oxford University Press. 
Table 1. Project Costs and Benefits

\begin{tabular}{|l|l|r|r|r|r|r|}
\hline \multicolumn{1}{|c|}{ Particulars } & Rules & $\mathbf{9 8 / 9 9}$ & $\mathbf{9 9 / 0 0}$ & $\mathbf{0 0 / 0 1}$ & $\mathbf{0 1 / 0 2}$ & \multicolumn{1}{|c|}{ Total } \\
\hline $\begin{array}{l}\text { 1. Project Costs (in million US\$, with } \\
\text { base year 1998): }\end{array}$ & & & & & & \\
\hline 1.1 Investment & & 8.3 & 10.9 & 17.3 & 4.9 & 41.4 \\
\hline 1.2 Recurrent & & 0.7 & 0.7 & 0.8 & 0.8 & 3.0 \\
\hline $\begin{array}{l}\text { 2. Total Present Value @ 12\% (the rate as } \\
\text { used in the project) }\end{array}$ & & $9.1+1.2$ & 11.6 & 18.1 & 5.7 & 44.4 \\
\hline 4. Project Benefits (in numbers) & 8.925 & 10.29 & 15.20 & 4.296 & 38.71 \\
\hline 5.Population served (average) & & & & & \\
\hline 6. Discounted @ 12\% & & & & & \\
\hline 7. CER (cost per person) & & & & & \\
\hline
\end{tabular}

Table 2.Cost Profile of the Project

\begin{tabular}{|l|l|l|}
\hline \multicolumn{1}{|l|}{ 1.0 Direct Costs: } \\
\hline & 1.1 Medical : & drugs, staff time, equipment \\
\hline & 1.2 Patient : & Transport, out-of-pocket expenses \\
\hline 2.0 Indirect Costs: Production losses, other uses of time \\
\hline 3.0 Intangibles: Pain, suffering, adverse effects \\
\hline
\end{tabular}


Table 3. Estimated Project Costs in million US\$

\begin{tabular}{|c|c|c|c|c|}
\hline \multirow{2}{*}{$\begin{array}{l}\text { Interventions/ } \\
\text { Alternative } \\
\text { Programs }\end{array}$} & \multirow{2}{*}{ Ingredients } & \multicolumn{3}{|c|}{ Cost Analysis } \\
\hline & & Local & Foreign & Total \\
\hline \multirow{10}{*}{$\begin{array}{l}\text { On - Site } \\
\text { Mitigation }\end{array}$} & 1. Provide emergency/temporary water supply. & & & \\
\hline & & 7.3 & 0.1 & 7.4 \\
\hline & 2. Participatory appraisal of subprojects & 1.7 & - & 1.7 \\
\hline & 3. Establish sustainable rural systems & & & \\
\hline & Community development & 5.2 & - & 5.2 \\
\hline & Design and construction & 6.5 & - & 6.5 \\
\hline & 4. Establish sustainable urban systems & & & \\
\hline & Institutional development & 0.6 & - & 0.6 \\
\hline & Design and construction & 4.3 & - & 4.3 \\
\hline & $\begin{array}{l}\text { 5. Provide limited health relief for arsenic } \\
\text {-affected patients }\end{array}$ & 0.2 & 0.2 & 0.4 \\
\hline \multicolumn{2}{|c|}{ Subtotal On-Site Mitigation } & 25.8 & 0.3 & 26.1 \\
\hline \multirow{5}{*}{$\begin{array}{l}\text { Understanding } \\
\text { of the Arsenic } \\
\text { Problem }\end{array}$} & $\begin{array}{l}\text { 1. Undertake well screening and community } \\
\text { understanding. }\end{array}$ & 2.5 & - & 2.5 \\
\hline & 2. Studies & & & \\
\hline & Causes and impacts & 0.2 & 0.2 & 0.4 \\
\hline & Social and economic approaches & 0.1 & 0.1 & 0.2 \\
\hline & Groundwater prospecting & 0.3 & 0.4 & 0.7 \\
\hline \multicolumn{2}{|c|}{ Subtotal Understanding of the Arsenic Problem } & 3.1 & 0.7 & 3.8 \\
\hline \multirow{7}{*}{$\begin{array}{l}\text { Institutional } \\
\text { Strengthening }\end{array}$} & 1. Support project management & 3.3 & 2.3 & 5.6 \\
\hline & $\begin{array}{l}\text { 2. Establish capacity for data collection, } \\
\text { management and dissemination }\end{array}$ & 2.4 & 1.6 & 4.0 \\
\hline & $\begin{array}{l}\text { 3. Establish capacity for technical and social } \\
\text { assessment of options }\end{array}$ & 0.4 & 0.4 & 0.8 \\
\hline & 4. Training of NGOs & - & 0.2 & 0.2 \\
\hline & $\begin{array}{l}\text { 5. Capacity building for central and local } \\
\text { government officials }\end{array}$ & 1.5 & 0.5 & 2.0 \\
\hline & 6. Strengthen policy and institutional reform & 0.5 & 0.4 & 0.9 \\
\hline & 7. Enhance community development & 0.5 & 0.5 & 1.0 \\
\hline \multicolumn{2}{|c|}{ Subtotal Institutional Strengthening } & 8.6 & 5.9 & 14.5 \\
\hline \multicolumn{2}{|l|}{ Total } & 37.5 & 6.9 & 44.4 \\
\hline
\end{tabular}


Table 4. Examples of Effectiveness Measures

\begin{tabular}{|c|c|}
\hline Program Objectives & Measure of Effectiveness \\
\hline Program completions & Number of beneficiaries receiving the benefits \\
\hline $\begin{array}{l}\text { Reduce morbidity and } \\
\text { mortality }\end{array}$ & Number of people suffering from arsenicosis \\
\hline Ensure sound health & Percentage changes in life years gained \\
\hline Ensure pure water supply & $\begin{array}{l}\text { Number of people availing the pure water as compared with the number } \\
\text { of people availed pure water before the project. }\end{array}$ \\
\hline Poverty alleviation & Cost saved by the people due to their less or no visit to the physician. \\
\hline Societal development & Changes in the life style of the targeted people. \\
\hline Education & $\begin{array}{l}\text { Number of people trained under the project to handle arsenic related } \\
\text { problem by themselves or with the help of others. }\end{array}$ \\
\hline Employment & Number of people got employed in the project. \\
\hline Economic Development & $\begin{array}{l}\text { Impact of the project on the Gross National Product (GNP), Inflation, } \\
\text { Productivity, Per Capita Income and other macro economic variables }\end{array}$ \\
\hline
\end{tabular}

Table 5. Cost-effectiveness of three independent interventions

\begin{tabular}{cccc}
\hline Interventions & $\begin{array}{c}\text { Cost }(\mathbf{\$}) \\
{[\mathbf{C}]}\end{array}$ & $\begin{array}{c}\text { Health Effect } \\
\text { (life-years gained) }[\mathbf{E}]\end{array}$ & $\begin{array}{c}\text { Cost-effectiveness ratio } \\
\text { (\$/life-years gained) [C/E] }\end{array}$ \\
\hline $\mathrm{B}$ & 300000 & 3800 & 78.95 \\
$\mathrm{~A}$ & 200000 & 2500 & 80.00 \\
$\mathrm{C}$ & 250000 & 2600 & 96.15 \\
\hline
\end{tabular}

Table 6. Budget-Interventions Trade-off

\begin{aligned} \hline Budgets available (\$) & Intervention(s) to be implemented \\ \hline$<\mathbf{3 0 0 0 0 0} &$ As much of intervention B as budget allows \\ $\mathbf{=} \mathbf{3 0 0 0 0 0} &$ All of intervention B \\ $\mathbf{3 0 0 0 0 0}-\mathbf{5 0 0 0 0 0} &$ All of intervention B and as much of A as budget allows \\ $=\mathbf{5 0 0 0 0 0} &$ All of interventions B and A \\ $\mathbf{5 0 0 0 0 0}-\mathbf{7 5 0 0 0 0} &$ All of interventions B and A and as much of C as budget allows \\ $=\mathbf{7 5 0 0 0 0} &$ All 3 interventions \end{aligned}


Table 7. Incremental cost effectiveness ratios

\begin{tabular}{cccccc}
\hline Intervention & $\begin{array}{c}\text { Costs }(\$) \\
{[\mathbf{C}]}\end{array}$ & $\begin{array}{c}\text { Effects (life-years } \\
\text { gained) }[\mathbf{E}]\end{array}$ & $\begin{array}{c}\text { Incremental } \\
\operatorname{cost}[\Delta \mathbf{C}]\end{array}$ & $\begin{array}{c}\text { Incremental } \\
\text { Effect }[\Delta \mathbf{E}]\end{array}$ & $\begin{array}{c}\text { ICER } \\
{[\Delta \mathbf{C} / \Delta \mathbf{E}]}\end{array}$ \\
\hline $\mathbf{I 1}$ & 150000 & 1500 & 150000 & 1500 & 100 \\
$\mathbf{I 2}$ & 100000 & 1600 & -50000 & 100 & -500 \\
$\mathbf{I 3}$ & 175000 & 2000 & 75000 & 400 & 187.5 \\
$\mathbf{I 4}$ & 160000 & 2300 & -15000 & 300 & -50 \\
$\mathbf{I 5}$ & 190000 & 2800 & 30000 & 500 & 60 \\
\hline
\end{tabular}

Table 8. Exclusion of more costly and less effective alternatives

\begin{tabular}{cccccc}
\hline Intervention & $\begin{array}{c}\text { Costs }(\$) \\
{[\mathbf{C}]}\end{array}$ & $\begin{array}{c}\text { Effects (life-years } \\
\text { gained)[E] }\end{array}$ & $\begin{array}{c}\text { Incremental } \\
\text { cost }[\Delta \mathbf{C}]\end{array}$ & $\begin{array}{c}\text { Incremental } \\
\text { Effect }[\Delta \mathbf{E}]\end{array}$ & $\begin{array}{c}\text { ICER } \\
{[\Delta \mathbf{C} / \Delta \mathbf{E}]}\end{array}$ \\
\hline $\mathbf{I 2}$ & 100000 & 1600 & 100000 & 1600 & 62.5 \\
$\mathbf{I 4}$ & 160000 & 2300 & 60000 & 700 & 85.71 \\
$\mathbf{I 5}$ & 190000 & 2800 & 30000 & 500 & 60 \\
\hline
\end{tabular}

Table 9. Exclusion of dominated alternatives

\begin{tabular}{cccccc}
\hline Intervention & $\begin{array}{c}\text { Costs }(\$) \\
{[\mathbf{C}]}\end{array}$ & $\begin{array}{c}\text { Effects (life-years } \\
\text { gained) }[\mathbf{E}]\end{array}$ & $\begin{array}{c}\text { Incremental } \\
\text { cost }[\Delta \mathbf{C}]\end{array}$ & $\begin{array}{c}\text { Incremental } \\
\text { Effect }[\Delta \mathbf{E}]\end{array}$ & $\begin{array}{c}\text { ICER } \\
{[\Delta \mathbf{C} / \Delta \mathbf{E}]}\end{array}$ \\
\hline I2 & 100000 & 1600 & 100000 & 1600 & 62.5 \\
I5 & 190000 & 2800 & 90000 & 1200 & 75 \\
\hline
\end{tabular}

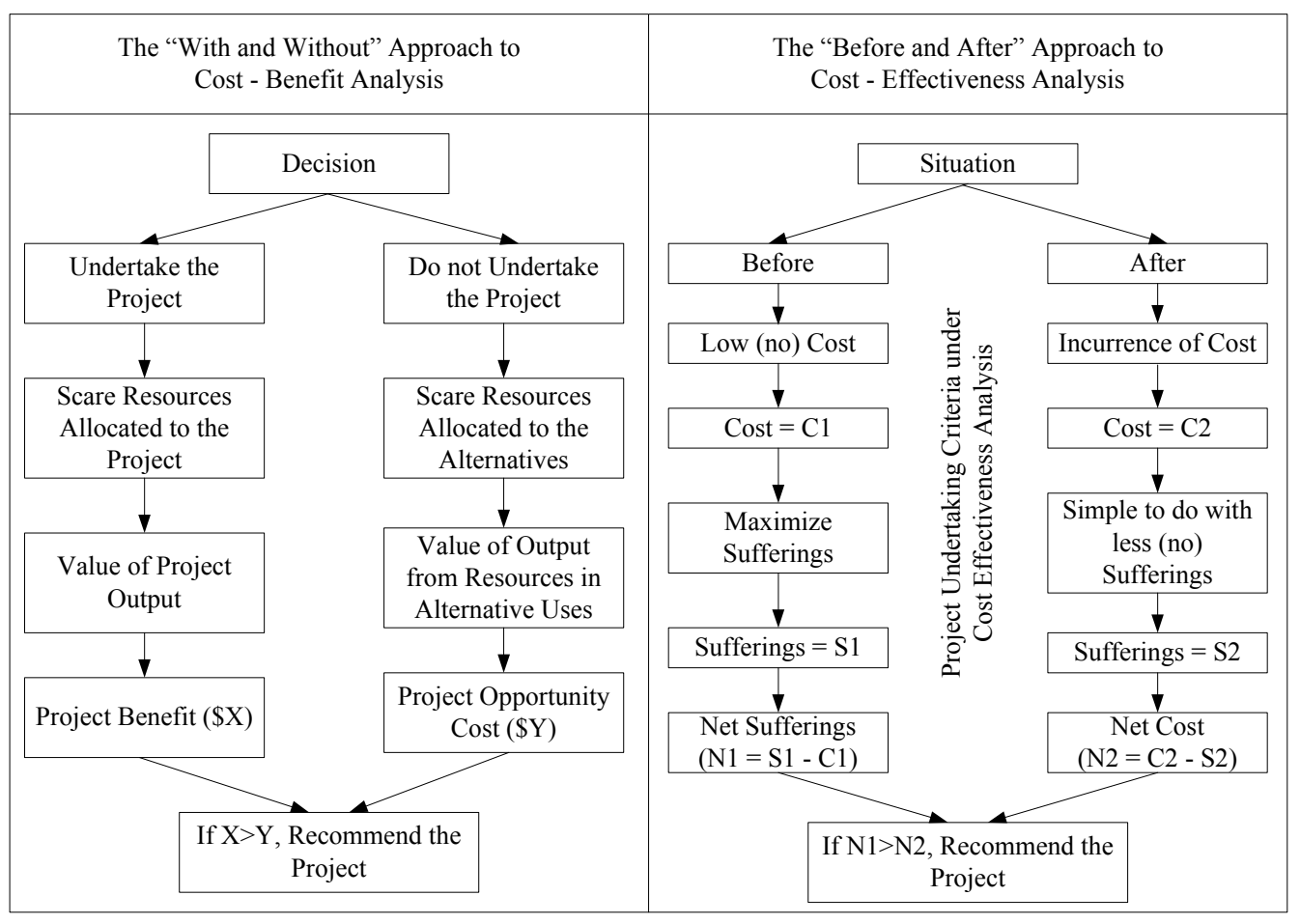

Figure 1: Decision Rule Comparison 


\section{Editorial Board}

Balakrishnan Parasuraman Universiti Malaysia Sabah, Malaysia

Dennis Yao Dzansi Central University of Technology, South Africa

Donald Henry Ah Pak Xi'an Jiaotong-Liverpool University, China

Hafizi Muhamad Ali Universiti Utara Malaysia, Malaysian

K. G. Viswanadhan NSS College of Engineering, India

Mahdi Salehi Zanjan University, Iran

Muhammad Madi Bin Abdullah Universiti Tenaga Nasional, Malaysia

Selcuk Burak Hasiloglu Pamukkale University, Turkey

Susan Sun Canadian Center of Science and Education, Canada

Ying Jin Qingdao Technological University, China 
A journal archived in Library and Archives Canada

A journal indexed in Canadiana (The National Bibliography)

A journal indexed in AMICUS

A journal archived in National Library of Australia

Ajournal indexed in APAIS (the Australian Public Affairs Information Service)

A leading journal in business management

\section{International Journal of Business and Management}

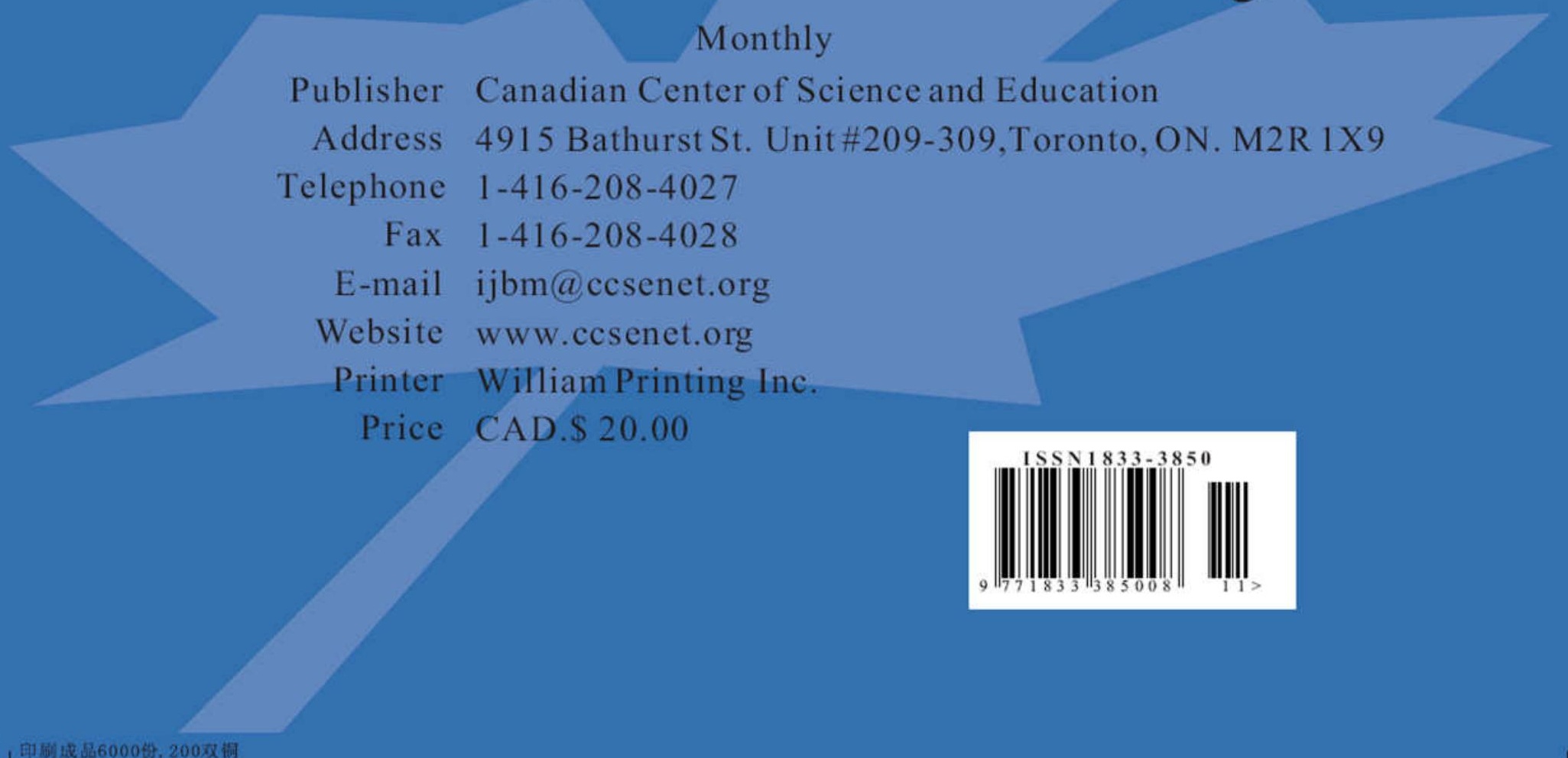

